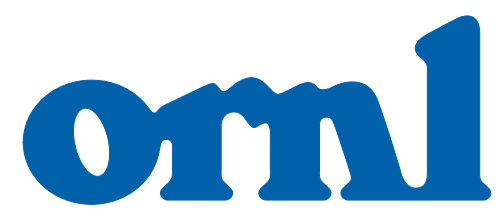

OAK RIDGE NATIONAL LABORATORY

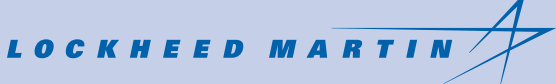

\section{Advanced Power Generation Systems for the 21st Century: Market Survey and Recommendations for a Design Philosophy}

J. B. Andriulli

A. E. Gates*

H. D. Haynes

L. B. Klett

S. N. Matthews*

E. A. Nawrocki ${ }^{\star}$

P. J. Otaduy

M. B. Scudiere

T. J. Theiss

J. F. Thomas

L. M. Tolbert

M. L. Yauss*

C. A. Voltz ${ }^{\star}$ 
This report has been reproduced from the best available copy.

Reports are available to the public from the following source.

National Technical Information Service

5285 Port Royal Road

Springfield, VA 22161

Telephone 703-605-6000 (1-800-553-6847)

TDD 703-487-4639

Fax 703-605-6900

E-mail orders@ntis.fedworld.gov

Web site http://www.ntis.gov/ordering.htm

Reports are available to U.S. Department of Energy (DOE) employees, DOE contractors, Energy Technology Data Exchange (ETDE) representatives, and International Nuclear Information System (INIS) representatives from the following source.

Office of Scientific and Technical Information

P.O. Box 62

Oak Ridge, TN 37831

Telephone 423-576-8401

Fax 423-576-5728

E-mail reports@adonis.osti.gov

Web site http://www.osti.gov/products/sources.html

Reports produced after January 1, 1996, are generally available via the DOE Information Bridge.

Web site http://www.doe.gov/bridge

This report was prepared as an account of work sponsored by an agency of the United States Government. Neither the United States Government nor any agency thereof, nor any of their employees, makes any warranty, express or implied, or assumes any legal liability or responsibility for the accuracy, completeness, or usefulness or any information, apparatus, product, or process disclosed, or represents that its use would not infringe privately owned rights. Reference herein to any specific commercial product, process, or service by trade name, trademark, manufacturer, or otherwise, does not necessarily constitute or imply its endorsement, recommendation, or favoring by the United States Government or any agency thereof. The views and opinions of authors expressed herein do not necessarily state or reflect those of the United States Government or any agency thereof. 
ORNL/TM-1999/213

Engineering Technology Division

\title{
ADVANCED POWER GENERATION SYSTEMS FOR THE 21st CENTURY: \\ MARKET SURVEY AND RECOMMENDATIONS FOR A DESIGN PHILOSOPHY
}

\author{
J. B. Andriulli \\ A. E. Gates* \\ H. D. Haynes \\ L. B. Klett \\ S. N. Matthews* \\ E. A. Nawrocki* \\ P. J. Otaduy \\ M. B. Scudiere \\ T. J. Theiss \\ J. F. Thomas \\ L. M. Tolbert \\ M. L. Yauss* \\ C. A. Voltz*
}

*Communications and Electronics Command-Research, Development, \& Engineering Center, Fort Belvoir, VA.

Manuscript completed: September 1999

Date published: November 1999

\author{
Prepared by \\ OAK RIDGE NATIONAL LABORATORY \\ Oak Ridge, TN 37831-8050 \\ managed by \\ LOCKHEED MARTIN ENERGY RESEARCH CORP. \\ for the \\ U.S. DEPARTMENT OF ENERGY \\ under contract DE-AC05-96OR22464
}




\section{CONTENTS}

LIST OF FIGURES

Part I-MARKET SURVEY(S) OF COMPONENTS

2. MARKET SURVEY OF STATE-OF-THE-ART PRIME MOVERS $\ldots \ldots \ldots \ldots \ldots \ldots \ldots \ldots . . \ldots \ldots \ldots$

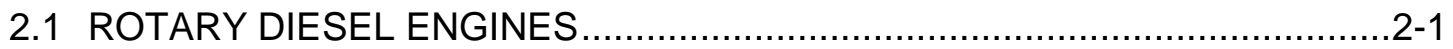

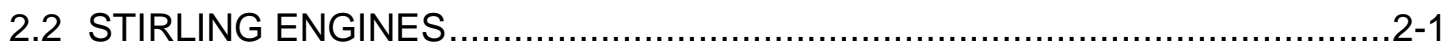

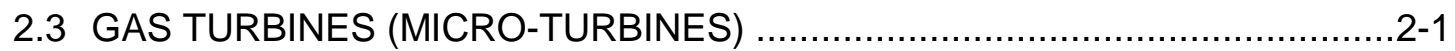

2.3.1 Hypothetical Turbine Model ........................................................ $2-1$

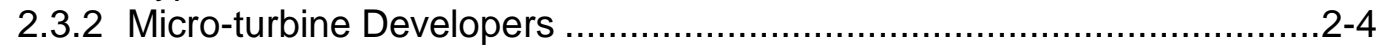

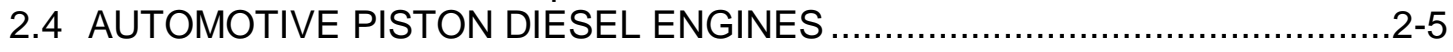

2.4.1 The Changing Automotive Diesel Market and Technology ....................2-5

2.4.2 Light-Duty Automotive Diesel Engines in the U.S. Market ....................2-6

2.4.3 U.S. Automotive Engines in Development ........................................2-6

2.4.4 Automotive Diesel Engine Technology Trends ..................................2-6

2.5 INDUSTRIAL PISTON DIESEL ENGINES .............................................

2.5.1 Environmental Regulations........................................................ $2-8$

2.5 .2 Technology Trends....................................................................... $2-9$

2.6 PISTON DIESEL ENGINE AVAILABILITY AND CHARACTERIZATION

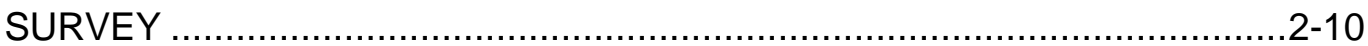

2.6.1 Engine Survey Results and Data Tables ....................................... $2-10$

2.6.2 Derating of Prime Movers .............................................................. $2-18$

2.6.3 Observed Trends .................................................................... $2-19$

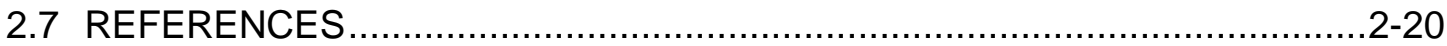

Appendix 2-A. DIESEL ENGINE GLOSSARY ................................................2-21

3. MARKET SURVEY OF STATE-OF-THE-ART ALTERNATORS/POWER

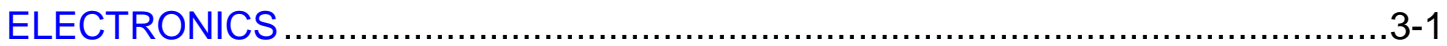

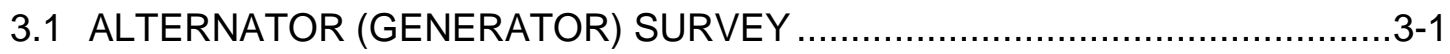

3.1.1 Induction Generator.................................................................

3.1.2 SR Generator ............................................................................

3.1.3 PM Brushless Generator ...........................................................

3.1.4 Alternator Market Survey Summary ..............................................

3.2 POWER ELECTRONICS SURVEY .................................................

3.2.1 Intelligent Power Modules ...................................................... $3-3$

3.2.2 Future Technology Directions .......................................................

3.2.3 Power Electronics Market Survey............................................... $3-7$

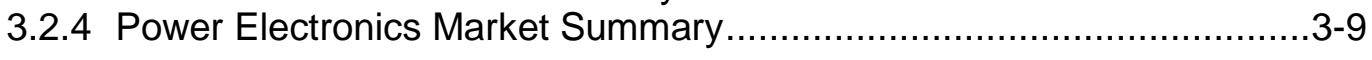


Appendix 3-A. ALTERNATOR DATA PROVIDED BY CECOM FOR MARKET SURVEY

Appendix 3-B. POWER ELECTRONICS DATA PROVIDED BY CECOM

FOR MARKET SURVEY

4. MARKET SURVEY OF STATE-OF-THE-ART DIGITAL CONTROL

AND D\&P SYSTEMS

4.1 SURVEY OF DIGITAL CONTROL SYSTEMS

4.2 SURVEY OF COMMERCIAL DEVICES FOR DIGITAL CONTROL

SYSTEMS....

4.2.1 Market Survey Results

4-4

4.2.2 Diesel Engine Diagnostic Systems

4-4

4.2.3 Other Diagnostic Systems....

4.2.4 Rugged Computers

4.2.5 Flat Panel Displays.....

4.3 SUMMARY OF DIGITAL CONTROL SYSTEMS (INCLUDING

D\&P) MARKET SURVEY

4.4 REFERENCE

Appendix 4-A. DIGITAL CONTROL SYSTEM DATA PROVIDED

BY CECOM FOR MARKET SURVEY...

Appendix 4-B. GEN-SET DATA PROVIDED BY CECOM FOR MARKET SURVEY

Appendix 4-C. DISPLAY DATA PROVIDED BY CECOM FOR MARKET SURVEY

\section{Part II-RECOMMENDATIONS FOR DESIGN PHILOSOPHY}

5. SUMMARY OF EXISTING GEN-SET DESIGN AND OPERATION ...................... $5-1$

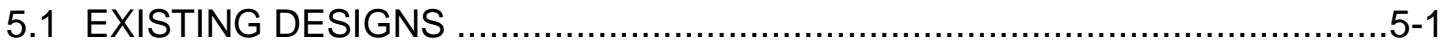

5.1.1 Industrial Diesel Engines .......................................................... $5-1$

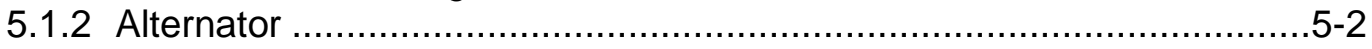

5.1.3 Control System.......................................................................

5.1.4 Current Gen-Set Frame and Housing Design .................................. 5-2

5.2 CURRENT SYSTEM PERFORMANCE ................................................

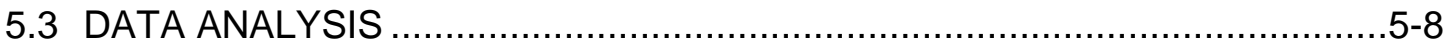

5.4 REFERENCES .................................................................................

Appendix 5-A. UTILIZATION AND DEMAND ENERGY ANALYSIS

OF EXISTING GEN-SET DATA ….......................................5-9

Appendix 5-B. MISSION WEIGHT ANALYSIS OF EXISTING GEN-SET DATA ......5-13

6. SYSTEM AND COMPONENT CONSIDERATIONS ......................................

6.1 PRIME MOVER DESIGN PHILOSOPHY .............................................6-1

6.1.1 Diesel vs Gas Turbine Weight Comparison (Weight vs Efficiency) ........6-1

6.1.2 Recommendations for Prime Mover ................................................6-4

6.2 VARIABLE-SPEED DIESEL ENGINE OPERATION...............................6-8

6.2.1 Variable-Speed Fuel Consumption Analysis ....................................6-8

6.2.2 Variable-Speed Advantages .................................................... 6-10

6.2.3 Variable-Speed Disadvantages ..................................................6-13

6.2.4 Recommendation for Fixed- vs Variable-Speed Engine Operation .......6-14

6.3 POTENTIAL FOR ENGINE WEIGHT AND VOLUME REDUCTION .............6-14

6.3.1 Potential Weight Reduction .................................................... 6-16

6.3.2 Potential Engine Volume Reduction ........................................6-17

6.4 ALTERNATOR DESIGN.................................................................

6.4.1 Reduction of Weight ............................................................ $6-18$ 
6.4.2 Reduction of Volume

6.4.3 Summary of Alternator Recommendations .....................................6-18

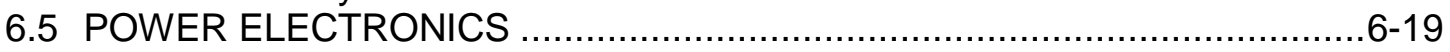

6.5.1 EMI Issues ...........................................................................

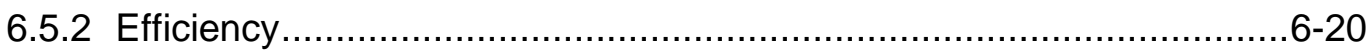

6.5.3 Cooling of the Power Electronics ...................................................6-21

6.5.4 Summary of Power Electronics Recommendations ..........................6-21

6.6 SIZING OF GEN-SET (MINIMUM AND MAXIMUM POWER RATINGS) .......6-21

6.7 SELECTION OF FAMILY SIZES ......................................................... Appendix 6-A. UNIVERSAL MISSION WEIGHT COMPARISON TOOL .................6-27

7. DIGITAL CONTROL SYSTEM ..................................................................

7.1 PURCHASE VS DEVELOPMENT OF CONTROL SYSTEM ........................

7.2 GEN-SET MODULAR CONSTRUCTION BLOCKS ....................................

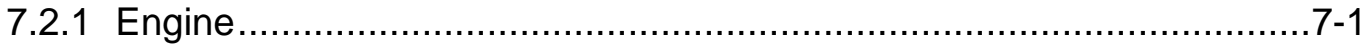

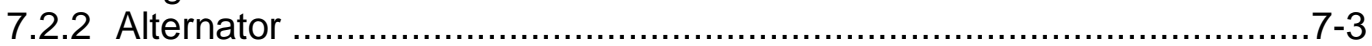

7.2.3 Power Electronics..................................................................

7.2.4 Onboard Computer (Global Controller) ..........................................

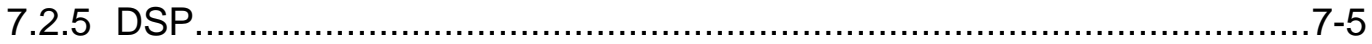

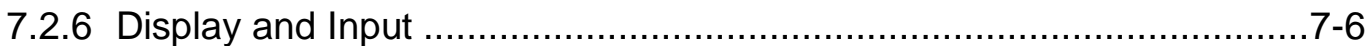

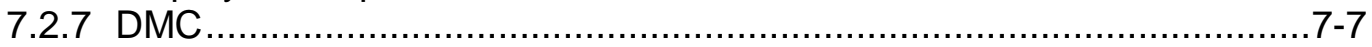

7.3 BACKUP PLAN FOR CONTROL SYSTEM ............................................

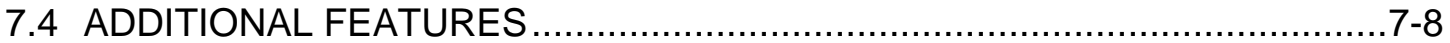

7.4.1 Fail Safe Options...........................................................................

7.4.2 Long Electrical Power Delivery Cables .............................................. $7-9$

7.4.3 Parallel Operation of Gen-sets ..................................................

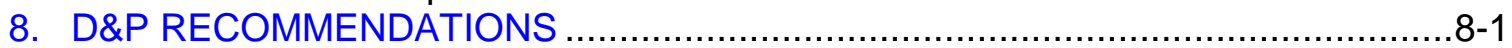

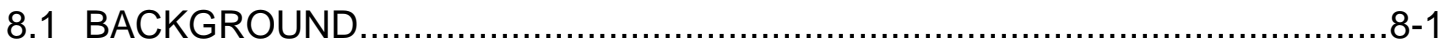

8.2 D\&P CAPABILITIES IN PURCHASE DESCRIPTION

FOR 100-/200-kW TQGs.......................................................................

8.2.1 Required Parameters ................................................................

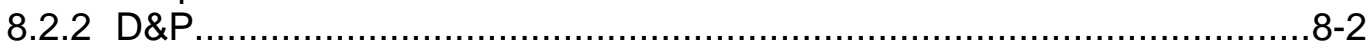

8.3 ANALYSIS OF GEN-SET MAINTENANCE RECORDS $\ldots \ldots \ldots \ldots \ldots \ldots \ldots \ldots \ldots .6$

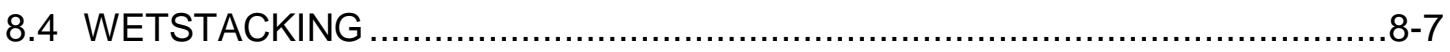

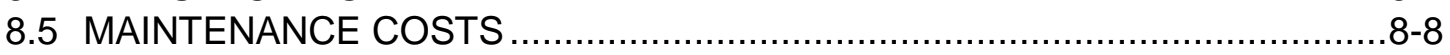

8.6 RECOMMENDATIONS FOR NEW GEN-SET D\&P ..............................

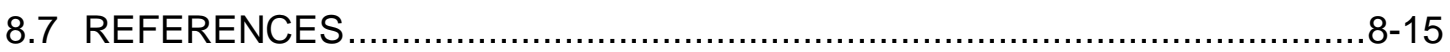

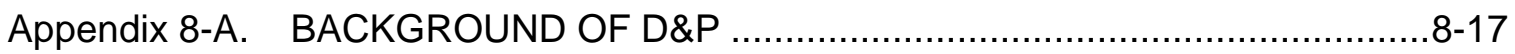

Appendix 8-B. REVIEW OF MAINTENANCE EVENTS FOR TQGs $\ldots \ldots \ldots \ldots \ldots \ldots \ldots . \ldots \ldots-27$

9. MATERIALS RECOMMENDATIONS ….....................................................

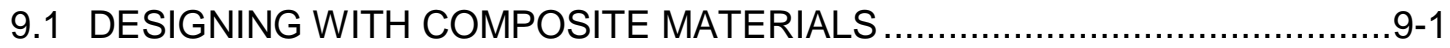

9.1.1 Fiber Reinforcements ...............................................................

9.1.2 Polymer Matrix Materials .......................................................... $9-3$

9.1.3 Manufacturing Process ........................................................... 9-3

9.1.4 Adhesive Bonding and Mechanical Fastening .................................9-4

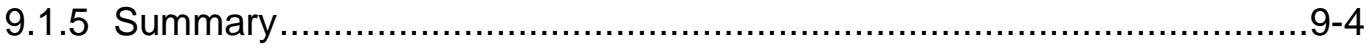

9.2 MATERIALS FOR THERMAL MANAGEMENT ....................................... 9

9.3 PREVIOUS ORNL WORK TO INCORPORATE COMPOSITE

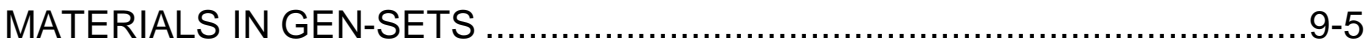

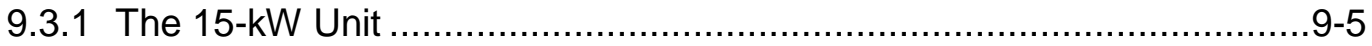

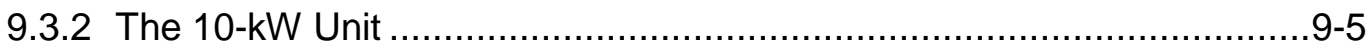

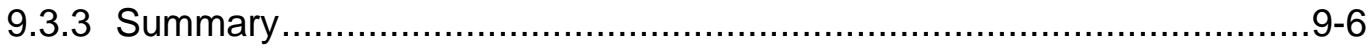


9.4 COMPOSITE TECHNOLOGY DEVELOPMENTS .................................

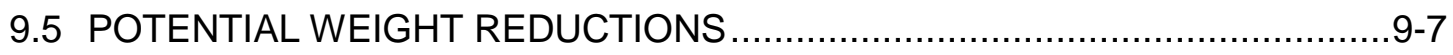

9.6 RECOMMENDATIONS FOR ADVANCED MATERIALS ...........................

9.7 ESTIMATED WEIGHT AND VOLUME FOR NEXT GENERATION

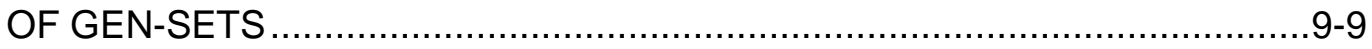

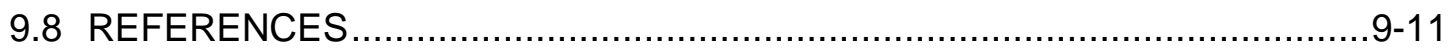

10. RECOMMENDATIONS FOR A DESIGN PHILOSOPHY .............................10-1

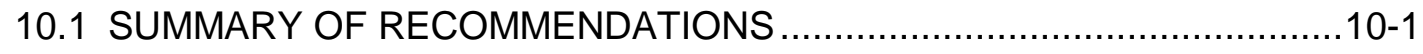

10.2 COMPARISON OF NEW GENERATORS WITH GOALS ........................10-3

10.2.1 Weight and Size ................................................................

10.2.2 Mission Duration ................................................................. 10-4

10.2.3 Efficiency ........................................................................ 10-4

10.2.4 Signature Suppression ........................................................ 10-5

10.2.5 Reliability, Availability, and Maintainability ..............................10-5

10.2 .6 Cost......................................................................................

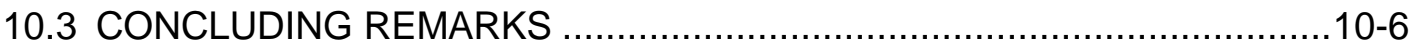




\section{LIST OF FIGURES}

$\begin{array}{ll}\text { Figure } & \text { Page }\end{array}$

$2.1 \quad$ Turboshaft engine with a recuperator............................................... 2-2

$2.2 \quad$ Grams of fuel per kilowatt-hour for $90 \%$ recuperator efficiency

at various turbine inlet temperatures

2.3 Grams of fuel per kilowatt-hour at $1600^{\circ} \mathrm{F}$ turbine temperature

at various recuperator efficiencies and appropriate

pressure losses

$2.4 \quad$ Grams of fuel per kilowatt-hour at $90 \%$ recuperator efficiency

at various compressor efficiencies

3.1

Two-switch version of the ART soft-switching inverter

Gen-set percent operating time at percent load capacity for average peacetime and projected wartime missions.

Monthly energy produced by the DOD 2- to $100-\mathrm{kW}$ inventory

of mobile electric generators during wartime and peacetime

missions

Peacetime monthly energy produced by the DOD 2- to $100-\mathrm{kW}$

inventory of mobile electric generators

5-A.1

DOD gen-set inventory by rated load capacity

Peacetime utilization for 5-, 10-, 15-, 30-, and 60-kW DOD

gen-sets with percent of operating time at percent load capacity

$5-B .1$

Weight for DOD TQG mobile electric generators, 5 to $60 \mathrm{~kW}$

Normalized weight for DOD TQG mobile electric generators, 5 to $60 \mathrm{~kW}$

5-B.3 Fuel consumption rate for DOD TQG mobile electric generators, 5 to $60 \mathrm{~kW}$

$5-B .4$

Thermal efficiency of DOD mobile electric generators, 5 to

$60 \mathrm{~kW}$

5-B.5 Mission weight for DOD mobile electric generators for 5-kW power

demand and different mission durations

5-B.6

Mission weight for DOD mobile electric generators for $10-\mathrm{kW}$

5-B.7 Mission weight for DOD mobile electric generators for 15-kW

power demand and different mission durations...

5-B.8 Mission weight for DOD mobile electric generators for 30-kW

power demand and different mission durations.

5-B.9 Mission weight for DOD mobile electric generators for 60-kW

power demand and different mission durations....

Fuel to gen-set weight ratio for an average TQG

Fuel to gen-set weight ratio for a light specific weight gen-set.

Mobile electric average peacetime mission weight

Mobile electric projected wartime mission weight

6.3

Diesel engine performance map

6.4 Fuel saved by variable-speed control as function of fixed-speed for peacetime average use profile (5- to 60-kW gen-sets)....

6.5 Fuel saved by variable-speed control as function of fixed-speed for projected wartime use profile.... 
6.6 Engine dry weight as a function of rated continuous power output for the TQG engines at $1800 \mathrm{rpm}$ and selected lightweight diesel engines at 1800 and $3000 \mathrm{rpm}$

6.7 Power electronics circuit for active rectifier and inverter for variable speed gen-set unit

6.8 5-kW inverter efficiency for various load factors

6.9 Estimated gen-set size ranges (minimum and maximum) as a function of engine dry weight for selected lightweight

diesel engines.

6-A.1 Mission weight break-even time comparing two gen-set designs for average peacetime mission

6-A.2 Mission weight break-even time comparing two gen-set designs for projected wartime mission for gen-sets $60 \mathrm{~kW}$ or less

6-A.3 Mission weight break-even time comparing two gen-set designs for projected wartime mission for gen-sets over $60 \mathrm{~kW}$....

6-A.4 Curves to estimate the difference in fuel consumption from two different gen-set efficiencies

7.1

8.1

Schematic of the control system

Block diagram of fuel system for $10-\mathrm{kW}$ TQG

Distribution of maintenance drivers for 10,358 gen-set maintenance activities at Fort Bragg and Fort Hood.

8.3 Illustration of how existing signals can be exploited for additional information useful in performing D\&P

Typical motor current signatures for a MOV

8-A.2

Device build by ORNL to demonstrate ESA

8-A.3 Frequency spectra of vibration (top plot), motor current (middle plot), and generator voltage (bottom plot) signals from the device illustrated in Fig. 8-A.1....

8-A.4 Degradation curves for two failure modes, $(A)$ and $(B)$ for a single piece of equipment under normal $(N)$ and extreme $(E)$ operating conditions. 


\section{LIST OF TABLES}

Table

Page

2.1 Characterization of selected commercial industrial diesel

engines.

2.2 Characterization of water-cooled, DI, high-speed automotive

diesel engines.

Characterization of water-cooled, DI, high-speed automotive

diesel engines in development

Comparison of material weights in alternator types .............................. $3-1$

3.1

3.2

Alternator power and efficiency comparisons

Current requirements for existing TQG sets.....

Available features from manufacturers of $1200-\mathrm{V}$ IGBT

modules

Temperature and voltage requirements for manufacturer's

IPMs

Weight of gen-set and frame for existing TQGs

Average demand power and operating time for the

DOD mobile electric generators

capacity for average peacetime and projected

wartime missions ....

Benefits and drawbacks of industrial diesel engine technology

advancements

Fuel saved due to variable-speed control relative to fixed-speed

control.

8.2 Approximate maintenance costs for Army TQGs

8.3 Comparison of three levels of incorporation of D\&P technologies

in new gen-sets

8.4 Parameters that should be included in a gen-set D\&P system .............. 8-12

9.1 Comparison of composite material properties with steel and aluminum ...................................................................... $9-1$

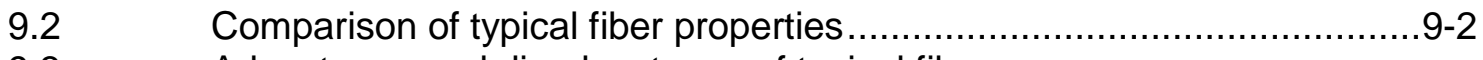

9.3 Advantages and disadvantages of typical fiber reinforcements.

9.4 Weight savings using composite materials in previous gen-sets. 
9.5 Breakdown of estimated gen-set weights for proposed

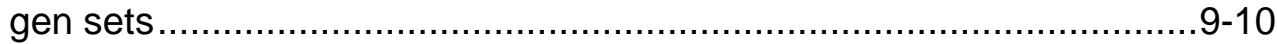

9.6 Size and weight estimates for proposed gen-sets compared with 400-Hz TQGs 


\section{ACRONYMS}

\begin{tabular}{|c|c|}
\hline AAN & Army After Next \\
\hline ac & alternating current \\
\hline AGET & Advanced Generator Evaluation Tool \\
\hline AIPM & automotive integrated power module \\
\hline AMMPS & Advanced Medium-Sized Mobile Power System \\
\hline AOAP & Army Oil Analysis Program \\
\hline ART & auxiliary resonant tank \\
\hline ASSTC & Advanced Surgical Suite for Trauma Casualties \\
\hline C3I & Command, Control, Communications, and Intelligence \\
\hline CECOM & U.S. Army Communications \& Electronics Command \\
\hline $\mathrm{CO}$ & carbon monoxide \\
\hline COTS & commercial off-the-shelf \\
\hline CSI & Computational Systems Incorporated \\
\hline CSS & Combat Service Support \\
\hline D\&P & diagnostics and prognostics \\
\hline dc & direct current \\
\hline DDC & Detroit Diesel Corporation \\
\hline DI & direct injection \\
\hline DMC & diagnostic and maintenance computer \\
\hline DOD & U.S. Department of Defense \\
\hline DOE & U.S. Department of Energy \\
\hline DSP & digital signal processor \\
\hline ECM & electronic control module \\
\hline EGR & exhaust gas recirculation \\
\hline EPA & U.S. Environmental Protection Agency \\
\hline EMI & electromagnetic interference \\
\hline ESA & electrical signature analysis \\
\hline $\begin{array}{l}\text { FARV } \\
\text { FPLA }\end{array}$ & $\begin{array}{l}\text { Future Armor Rearm Vehicle } \\
\text { field programmable logic array }\end{array}$ \\
\hline GAC & Giordano Automation Corporation \\
\hline gen-set & generator set \\
\hline GM & General Motors \\
\hline GUI & graphic user interface \\
\hline HEV & hybrid-electric vehicle \\
\hline HMMWV & high-mobility multipurpose wheeled vehicle \\
\hline IC & internal combustion \\
\hline ICAV & instantaneous crankshaft angular velocity \\
\hline IDG & integrated drive generator \\
\hline IDI & indirect injection \\
\hline IETM & Interactive Electronic Technical Manual \\
\hline IGBT & insulated gate bipolar transistor \\
\hline IPM & intelligent power module \\
\hline
\end{tabular}




\begin{tabular}{|c|c|}
\hline $\begin{array}{l}\text { MCSA } \\
\text { MEP } \\
\text { MOV } \\
\text { MTBUSE }\end{array}$ & $\begin{array}{l}\text { motor current signature analysis } \\
\text { mobile electric power } \\
\text { motor-operated valve } \\
\text { mean time between unscheduled events }\end{array}$ \\
\hline $\begin{array}{l}\text { NFPA } \\
\mathrm{NO}_{x}\end{array}$ & $\begin{array}{l}\text { National Fire Protection Association } \\
\text { oxides of nitrogen, usually including } \mathrm{NO}_{2} \text { and } \mathrm{NO}\end{array}$ \\
\hline $\begin{array}{l}\text { OD } \\
\text { ORNL }\end{array}$ & $\begin{array}{l}\text { outside diameter } \\
\text { Oak Ridge National Laboratory }\end{array}$ \\
\hline $\begin{array}{l}\text { PC } \\
\text { PD } \\
\text { PM } \\
\text { PM-MEP } \\
\text { PNGV } \\
\text { PWM }\end{array}$ & $\begin{array}{l}\text { personal computer } \\
\text { purchase description } \\
\text { permanent magnet } \\
\text { Program Manager for Mobile Electric Power } \\
\text { New Generation of Vehicles } \\
\text { pulse width modulation }\end{array}$ \\
\hline $\begin{array}{l}\text { RBM } \\
\text { RD\&E } \\
\text { RFI } \\
\text { RF } \\
\text { RMS } \\
\text { RPF }\end{array}$ & $\begin{array}{l}\text { reliability-based maintenance } \\
\text { research, development, and engineering } \\
\text { radio frequency interference } \\
\text { radio frequency } \\
\text { roof-mean-square } \\
\text { roller pass frequency }\end{array}$ \\
\hline $\begin{array}{l}\text { SOUM } \\
\text { SPCO } \\
\text { SMC } \\
\text { SPL } \\
\text { SR } \\
\text { SSTC }\end{array}$ & $\begin{array}{l}\text { Safety of Use Message } \\
\text { Silicon Power Corporation } \\
\text { sheet molding compound } \\
\text { sound pressure level } \\
\text { switched reluctance } \\
\text { Support Systems Technology Corporation }\end{array}$ \\
\hline $\begin{array}{l}\text { TOC } \\
\text { TQG }\end{array}$ & $\begin{array}{l}\text { Tactical Operating Center } \\
\text { tactical quiet generator }\end{array}$ \\
\hline $\begin{array}{l}\text { VI } \\
\text { VMM }\end{array}$ & $\begin{array}{l}\text { virtual instrumentation } \\
\text { VM Motori }\end{array}$ \\
\hline
\end{tabular}




\section{EXECUTIVE SUMMARY}

This report and underlying study are part of the Advanced Medium-Sized Mobile Power System (AMMPS) Program conducted by the U.S. Army Communications \& Electronics Command (CECOM) Research, Development, \& Engineering (RD\&E) Center under sponsorship of the Department of Defense Program Manager for Mobile Electric Power (PM-MEP). The work was performed by personnel at the Department of Energy's (DOE's) Oak Ridge National Laboratory (ORNL) in close cooperation with CECOM and PM-MEP personnel.

The need for reliable electrical power in the battlefield is a requirement that cuts across all services, all locations, and will extend into the foreseeable future. The AMMPS Program will be used to upgrade and enhance existing inventoried military assets to improve present capability and enhance military readiness and operations. These tactical power systems must be portable, lightweight systems that are electronically controlled, signature suppressed, and capable of starting and operating on DF-2/JP-8 fuels in extreme environmental conditions. This work is critical to ensure smooth transition of a system and/or components to the PM-MEP for application to future development and acquisition efforts, including upcoming Army procurements scheduled for FY 2008. The new standard family of 21 st century power systems will be compatible with Force XXI and Army After Next (AAN) military planning.

The purpose of this report is to document the results of our study, which can be used to enhance the performance of future military generator sets (gen-sets) in the medium power range. Specifically, this report has two primary thrusts:

- Survey and assess the state of the art in key component areas [i.e., engines, alternators, power electronics, digital control systems, and diagnostics and prognostics (D\&P) systems] to determine the status and viability of including these technologies in future gen-sets. The market survey considered products currently on the market and those expected within the next 2 to 3 years.

- Provide design philosophy recommendations for future gen-sets in the 5- to 60-kW power range, which would take advantage of the state-of-the-art components and meet operational objectives. The design philosophy provides guidance for selecting relevant commercial technologies, components, and systems for review for the next generation of gen-sets.

The approach in conducting this study for the next generation gen-sets has several elements. ORNL and CECOM personnel have had extensive interactions to gain an understanding of the military conditions under which the gen-sets have to function and their current design, operation, and functionality. Researchers with expertise in the component areas conducted the market surveys through informal discussions, trade shows, seminars, and the Internet to become even more familiar with the vendors and their products in these areas. The recommendations for a design philosophy were also based on input from multiple R\&D personnel with extensive expertise in hardware development using analytical tools, prior experiences, analysis of existing gen-set conditions, and equipment testing.

The primary finding of the market survey is that the commercial market is in a state of flux and is currently or will soon (within 2-3 years) be capable of providing the technology recommended here in a cost-effective manner. In most of the component 
areas of interest in gen-set design, new technologies are being introduced at a rapid rate. At the same time, more suppliers in these new technical areas are introducing products in the market with significant cost reductions expected in the next few years. Among (and even within) manufacturers, interchangeable digital control systems, which include diagnostics and prognostics (D\&P), for gen-sets are not available as commercial-off-the-shelf (COTS) components today and will not be in the near future because the control systems are specific to the gen-sets. However, the hardware components today that are necessary to fabricate the controls and diagnostics are COTS and capable of meeting the future requirements with the appropriate software.

The design philosophy summarizes existing gen-set design in the 5- to 60-kW range, identifies options for reducing the number of fielded families of gen-sets, evaluates the major components used in the gen-sets, addresses system effectiveness, and considers onboard D\&P and advanced materials. Viable options are evaluated in light of military goals and applicable technology and components. Recommendations that comprise a design philosophy for the next generation of gen-sets are listed below.

\section{Component and System Recommendations}

- Turbocharged, charge-cooled, automotive diesels, featuring advanced highpressure, electronically controlled fuel injection systems (common-rail or unit injection) and lightweight construction, are the recommended prime movers for gensets in the range of 15 to $60+\mathrm{kW}$ (Sect. 6.1.2).

- For a smaller gen-set with a peak rating below $15 \mathrm{~kW}$, it is recommended that naturally aspirated industrial diesel engines with a relatively high power-to-weight ratio (for that size range of engine) be utilized until the technology in the automotive diesels migrates to the smaller industrial diesel lines (Sect. 6.1.2).

- Gas turbines should be evaluated more closely and warrant consideration in niche areas where the need for lighter weight is substantially more important than fuel efficiency (e.g., short mission durations) (Sect. 6.1.2).

- Gen-set design should be based on variable-speed operation, and speeds of $3000 \mathrm{rpm}$ and above should be an initial design goal (Sect. 6.2.4).

- A three-phase alternator is recommended [either a permanent magnet (PM) alternator or a more conventional inductance alternator] so that integrated power electronics modules can be used to reduce the complexity, size, and cost of the power electronics system (Sect. 6.4.3).

- A high-flux PM alternator is the preferred alternator. The market survey indicates that mass production costs are not prohibitive (Sect. 6.4.3).

- During the design and prototyping phase, the main alternator should be evaluated for use as the engine starter by using a two-way buck-boost converter to charge the batteries and drive the starter. Justification for this would be the weight and volume savings from eliminating the engine starter motor and the alternator for charging the battery (Sect. 6.4.3).

- Using a variable-speed engine will require a system to convert the voltage generated to a selectable voltage and frequency. Power electronics are recommended to achieve this conversion because of their compact size and controllability. Designing 
a single gen-set unit able to generate power at 50,60 , and $400 \mathrm{~Hz}$ is recommended (Sect. 6.5.4).

- Intelligent Power Modules for the inverter and rectifier sections of the power electronics system should be used to maximize integration of the electronics, increase reliability, and improve maintainability (Sect. 6.5.4).

- The use of common components as much as possible in the power electronics systems for the different sizes of gen-sets should minimize the burden of parts logistics (Sect. 6.5.4).

- $\quad$ Future gen-sets should be sized with both a maximum and minimum power rating. The minimum rating would be determined during future testing but would be the lower bound of effective and reliable gen-set operation. The maximum power rating would be determined using the same qualification tests used today but at the highest power level for which the gen-set fully qualifies rather than at a predetermined arbitrary level (Sect. 6.6).

- Based on the engines available in the market survey, the number of future gen-set families recommended to cover the 5- to 60-kW range is three (Sect. 7).

- Based on projected market availability, the gen-set families should be sized at approximately $2-7 \mathrm{~kW}, 6-25 \mathrm{~kW}$, and $20-80 \mathrm{~kW}$. Final size ratings will be determined at the conclusion of the qualification testing (Sect. 6.7).

Digital Control System Recommendations

- Based on the market survey, it appears highly unlikely that a control system can be purchased separately from the gen-set. Therefore, we recommend that the control system be developed specifically to operate the future gen-sets (Sect. 7.1).

- The advantages tend to favor a PC-based global controller to run the control system. The final decision will be made during the prototyping phase of this program. The selection of the operating system will have to be made at a later date based on other system requirements chosen by the military (Sect. 7.2.4).

- We recommend the use of digital signal processors (DSPs) in the control system to govern the final current and voltage output (Sect. 7.2.5).

- The final recommendation for the display monitor will depend on further input from the military about what is needed in the field. Once requirements are determined, selection of the display format will be relatively easy (Sect. 7.2.6).

- A separate maintenance computer should be included to provide additional useful functions that are not deemed appropriate to be included onboard the gen-set itself (Sect. 7.2.7).

\section{D\&P System Recommendations}

- The D\&P system should be designed to include moderate to total incorporation of diagnosing and predicting impending failure. The "best" approach will be decided after the costs of these two approaches are determined through further development, testing, and application of D\&P methods and technologies (Sect. 8.6).

- Based on knowledge of parameters that are presently monitored on existing tactical quiet generators (TQGs), a review of available failure records, and discussions with 
CECOM, we recommend that several but not all available parameters be monitored for their importance in D\&P of new gen-sets. An initial listing of those parameters that should be included in the D\&P system is provided. The final list of monitored parameters will be determined during the prototyping of the new gen-sets (Sect. 8.6).

- A battle-short switch, similar to the current TQG design, should be provided on the new gen-set that disables the action of the safety (and unit protection) parameters listed in Sect. 8.6 (with exception of the short circuit and emergency stop function). It is further recommended that the indication (e.g., displays showing high current, high temperature, etc.) of all parameters still be available so that the user has the ability to monitor the condition of the gen-set, although the actions of its safety devices have been bypassed (Sect. 8.6).

- We recommend that several additional items be included in the D\&P system for the prototype and evaluated for effectiveness during prototype testing. The final resolution of exactly what is in the D\&P system will depend on the effectiveness of the system and additional requirements of the military (Sect. 8.6).

\section{Materials Recommendations}

- A hybrid design for the frame/enclosure using a combination of lower cost composites and aluminum appears to be a cost-effective means for reducing the gen-set weight beyond the savings due to lighter components. More costly designs can reduce the weight even further and should be considered during the design phase of the gen-set prototyping. The final frame/enclosure design will require additional input from the military and evaluation of the prototype (Sect. 9.5).

These recommendations, if implemented, should result in future power generation systems that are much more functional than today's gen-sets. The number of differing units necessary (both family sizes and frequency modes) to cover the medium power range would be decreased significantly, while the weight and volume of each unit would decrease markedly and improve the transportability of the power source. Improved fuel economy and overall performance would result from more effective use of the prime mover in the gen-set. The units would provide for more flexibility and control with improved reliability and more effective power management in the field.

The study includes an estimate of how the proposed gen-sets compare with existing TQGs in the key areas of weight and size; mission duration; efficiency; signature suppression; reliability, availability, and maintainability; and cost. The established metrics are ambitious but appear to be viable design targets for the proposed gen-sets.

While much has been learned during this study and we are optimistic about meeting the established targets, additional work remains before the exact design parameters can be established. We have assumed and we strongly concur with CECOM that the design and prototyping phase should proceed as soon as possible to avoid schedule delays. This phase should introduce most design recommendations and determine areas in which additional trade-offs and investigation are required. 


\title{
ADVANCED POWER GENERATION SYSTEMS FOR THE 21st CENTURY: MARKET SURVEY AND RECOMMENDATIONS FOR A DESIGN PHILOSOPHY
}

\author{
J. B. Andriulli \\ A. E. Gates \\ H. D. Haynes \\ L. B. Klett \\ S. N. Matthews
}

\author{
E. A. Nawrocki \\ P. J. Otaduy \\ M. B. Scudiere \\ T. J. Theiss
}

J. F. Thomas

L. M. Tolbert

M. L. Yauss

C. A. Voltz

\begin{abstract}
The purpose of this report is to document the results of a study designed to enhance the performance of future military generator sets (gen-sets) in the medium power range. The study includes a market survey of the state of the art in several key component areas and recommendations comprising a design philosophy for future military gen-sets. The market survey revealed that commercial market is in a state of flux, but it is currently or will soon be capable of providing the technologies recommended here in a cost-effective manner. The recommendations, if implemented, should result in future power generation systems that are much more functional than today's gen-sets. The number of differing units necessary (both family sizes and frequency modes) to cover the medium power range would be decreased significantly, while the weight and volume of each unit would decrease, improving the transportability of the power source. Improved fuel economy and overall performance would result from more effective utilization of the prime mover in the generator. The units would allow for more flexibility and control, improved reliability, and more effective power management in the field.
\end{abstract}

\section{INTRODUCTION}

This report and underlying work are part of the Advanced Medium-Sized Mobile Power System (AMMPS) Program conducted by the U.S. Army Communications \& Electronics Command (CECOM) Research Development \& Engineering (RD\&E) Center under sponsorship of the Department of Defense (DOD) Program Manager for Mobile Electric Power (PM-MEP). The work was performed by personnel at the Department of Energy's (DOE's) Oak Ridge National Laboratory (ORNL) in close cooperation with CECOM and PM-MEP personnel.

\subsection{BACKGROUND}

The need for reliable electrical power in the battlefield is a requirement that cuts across all services, all locations, and will extend into the foreseeable future. According to the PM-MEP Web site,

Electric power, provided primarily by mobile generators in the combat zone, is the lifeblood of the Armed Forces. For without it, all the technical wizardry of modern warfare-the Weapons' Systems, the Command, Control, 
Communications, and Intelligence (C3I) Systems, and Logistics Support Systems-are useless.

To that end, the Army's Advanced State of the Art Power Components Program was devised to advance and adapt state-of-the-art electromechanical power technologies. Because Army requirements are unique and cannot be satisfied with commercial generators, it is necessary for the military to clearly define the operational and performance parameters that are compatible with tactical field applications. The new standard family of 21 st century power systems will be compatible with Force XXI and Army After Next (AAN) military planning.

One objective of the AMMPS Program is to enhance electrical generation capabilities required for Combat Service Support (CSS) applications and the Tactical Operating Centers (TOCs), communication weapon systems, battery chargers, and sensors of the 21st century battlefield through the advancement/development of state-of-the-art power frequency electronic subsystems (i.e., gen-sets). The results of this endeavor will be used to upgrade and enhance existing inventoried military assets to improve current capability and enhance military readiness and operations. These tactical power systems must be portable, lightweight systems that are electronically controlled, signature suppressed, and capable of starting and operating on DF-2/JP-8 fuels in extreme environmental conditions. This work is critical to ensure smooth transition of a system and/or components to the PM-MEP for application to future development and acquisition efforts, including upcoming Army procurements scheduled for FY 2008.

\subsection{PURPOSE OF REPORT}

The purpose of this report is to document the results of our study, which can be used to enhance the performance of future military gen-sets in the medium power range. Specifically, this report has two primary thrusts:

- Survey and assess the state of the art in key component areas [i.e., engines, alternators, power electronics, digital control systems, and diagnostics and prognostics (D\&P) systems] to determine the status and viability of including these technologies in future gen-sets.

- Provide design philosophy recommendations for future gen-sets in the 5- to 60-kW power range, which would take advantage of the state of the art components and meet operational objectives.

The report is divided into to main portions: Part I is the Market Survey that includes Chaps. 2-4. Part II is the Recommendations for Design Philosophy that include Chaps. 5-10. Part I (Market Survey) includes as much detail as possible about the various components and their relative merits. Part II (Design Philosophy) includes all of the recommendations about the components and the gen-set system. Part II assumes that the reader has either read Part I or is very knowledgeable of the technologies being discussed.

\subsubsection{Market Survey}

The report includes a survey of the state of the art in the commercial market in the key component areas of engines, alternators/power electronics, digital control systems, and D\&P. The market survey seeks to locate components, which could be used in future gen-set designs, that are available in the commercial market today or would be ready for commercialization in the next 2 to 3 years. The survey provides information that is inherently short term, due to the rapid evolution of technologies and commercial embodiments of those technologies. The market survey is not intended to give a comprehensive listing of all components that might be used in 
future gen-sets but rather provide assurance that the technologies recommended for future units would be available from the commercial market in the appropriate time frame.

\subsubsection{Recommendations for Design Philosophy}

The design philosophy portion of this report provides guidance for selecting relevant commercial technologies, components, and systems for review for the next generation of gen-sets. The report summarizes existing gen-set design in the 5- to 60-kW range, identifies options for reducing the number of fielded families of gen-sets, considers onboard D\&P, and advanced materials, as well as manufacturability and affordability issues. The charter for the report is based on meeting both present and future gen-set operational requirements without eliminating or altering any of the existing requirements. In addition, the key issues of cost, size and weight, reliability, signature suppression, and availability are addressed. Because of the heavy emphasis on mobility, a great deal of attention will be given to weight and volume reductions. The report summarizes the advantages and disadvantages of the design philosophy and includes recommendations on future evaluations and/or design approaches. This report does not address the detailed design of future gen-sets but provides a roadmap of how the next generation gen-sets would be designed as an integrated system. The design philosophy provides information that has long-term applicability to gen-sets in the Force XXI and AAN time frame.

\subsection{APPROACH}

The approach to conducting the market survey and determining the recommendations for the design philosophy for the next generation gen-sets has been varied. Personnel with extensive expertise in the component areas conducted the market surveys. In addition to extensive interaction with CECOM personnel, these investigators conducted informal discussions, attended trade shows and seminars, and used the Internet to become even more familiar with the vendors and their products in these areas. CECOM personnel provided Oak Ridge market survey information for alternators, power electronics, control systems, displays, and gen-sets. The recommendations for a design philosophy were also made based on input from multiple R\&D personnel with extensive expertise in hardware development; they used analytical tools, prior experiences, analysis of existing gen-set conditions, and equipment testing to make the design

recommendations. Again, interactions with CECOM personnel were a fundamental part of understanding the military conditions under which the gen-sets have to function. 
1-4 


\section{MARKET SURVEY OF STATE-OF-THE-ART PRIME MOVERS}

This chapter addresses the prime mover or engine in future gen-sets. Four prime movers, all capable of burning diesel fuel, were considered: the rotary diesel, the Stirling engine, the piston diesel, and the gas turbine. As outlined in Sects. 2.1-2.3, only the gas turbine competes with the diesel engine as a viable alternative for gen-set application. Much attention is given to the new technical advances in the diesel engine because it is the dominate prime mover in gen-set applications in this size range.

\subsection{ROTARY DIESEL ENGINES}

Rotary diesel engines have been considered in the past, but there has been no commercial use of such devices. At least two companies (Patrick Power Products, Inc., and Wankel Rotary, $\mathrm{GmbH})^{1}$ are pursuing development of a rotary diesel engine for niche markets. Fuel consumption was reported to be relatively high $(350 \mathrm{~g} / \mathrm{kWh})$, but the engines are claimed to be very lightweight. ${ }^{1}$ Lack of information and commercial experience makes it difficult to evaluate this technology other than to say it is very unlikely to be widely available in the next few years based on the commercial market.

\subsection{STIRLING ENGINES}

The major advantage of the Stirling engine is that it can utilize an external heat source, such as relatively steady combustion, as opposed to high-speed intermittent combustion for internal combustion (IC) engines. This factor broadens fuel choice and can significantly lower exhaust emissions. The fuel economy for these engines is known to be lower compared to a diesel engine. ${ }^{2}$

Engines based on the Stirling cycle have been considered for a number of applications under DOE programs. Ambitious Stirling engine programs included development of automotive Stirling engines and Stirling-engine-driven heat pumps. ${ }^{3}$ Generally, these programs did not succeed, and the Stirling engine is not used in these applications today. The Stirling engine concept may be found suitable for some niche markets, but there is no evidence that such a device could match diesel engines in power-to-weight ratio, response, durability, and cost. No industrial support base exists for Stirling engines similar to that for diesel engines.

\subsection{GAS TURBINES (MICRO-TURBINES)}

Small gas turbine technology has advanced to the point of viable application in intermediate $(>25-\mathrm{kW})$ stationary and MEP systems. Micro-turbines are multifuel prime movers that are lighter and quieter than the diesel piston engines. Generally, turbines are less efficient but have lower emissions than the diesel engines. Also, at partial loads, gas turbine specific fuel consumption may tend to increase more than diesel engines. This tendency needs to be verified. The small gas turbine can surpass the reciprocating engine in terms of long life $(>40,000 \mathrm{~h})$ and low maintenance. Initial cost $(\$ / \mathrm{kW})$ is highly dependent on unit size. At this time, in the 30 - to $75-\mathrm{kW}$ range, turbines are likely to be more expensive than diesel piston engines. As the turbine market matures, the prices can be expected to be more competitive with the diesel engine.

\subsubsection{Hypothetical Turbine Model}

A turbo-shaft engine was modeled and analyzed to compare its performance (fuel consumption) to that of a reciprocating diesel engine. A diagram of a single-shaft, single-stage turbine engine 
with a recuperator is shown in Fig. 2.1. The recuperator increases the system efficiency by recovering exhaust heat and transferring it to the compressed air before the air enters the combustion chamber. The following are considered reasonable design parameters: a single-stage centrifugal air compressor with $80 \%$ efficiency, $1600^{\circ} \mathrm{F}$ turbine inlet temperature, $85 \%$ turbine efficiency, $5 \%$ recuperator pressure loss, and $90 \%$ recuperator efficiency. The $1600^{\circ} \mathrm{F}$ turbine inlet temperature is achievable with high-temperature metals without actively cooling the turbine blades, which keeps the design simple.

Figure 2.2 shows the micro-turbine fuel consumption vs compressor pressure ratio for various turbine inlet temperatures. For a $1600^{\circ} \mathrm{F}$ turbine inlet temperature and a compressor ratio between 3 and 4 , the micro-turbine fuel consumption could theoretically be about $250 \mathrm{~g} / \mathrm{kWh}$ (34\% efficiency for No. 2 diesel lower heating value of 18,200 Btu/lb). Modern reciprocating diesel engine fuel consumption can be as low as $190 \mathrm{~g} / \mathrm{kWh}$ (45\% efficiency) but usually falls in the $200-$ to $300-\mathrm{g} / \mathrm{kWh}$ (43 to $35 \%$ efficiency) range depending upon design and operating conditions. In practice, one should anticipate that turbines would be 5 to 15 percentage points less efficient than reciprocating diesels. From Fig. 2.2, the fuel consumption can be reduced by increasing turbine inlet temperature, but this requires use of more exotic materials and active cooling of the turbine blades and other components that complicates the design and increases weight and cost.

Figures 2.3 and 2.4 show micro-turbine fuel consumption vs compressor pressure ratio for different recuperator efficiencies and different compressor efficiencies, respectively. These curves are provided to show turbine performance sensitivity to various design parameters. Note in Fig. 2.3 that at a compressor pressure ratio of about 3 , the fuel consumption is double $(500 \mathrm{~g} / \mathrm{kWh})$ without the recuperator compared to using a $90 \%$ efficient recuperator. Figure 2.3 also shows that the maximum reduction in fuel consumption occurs when a $90 \%$ efficient recuperator is combined with a simple centrifugal compressor with a compression ratio of 3 or 4 .

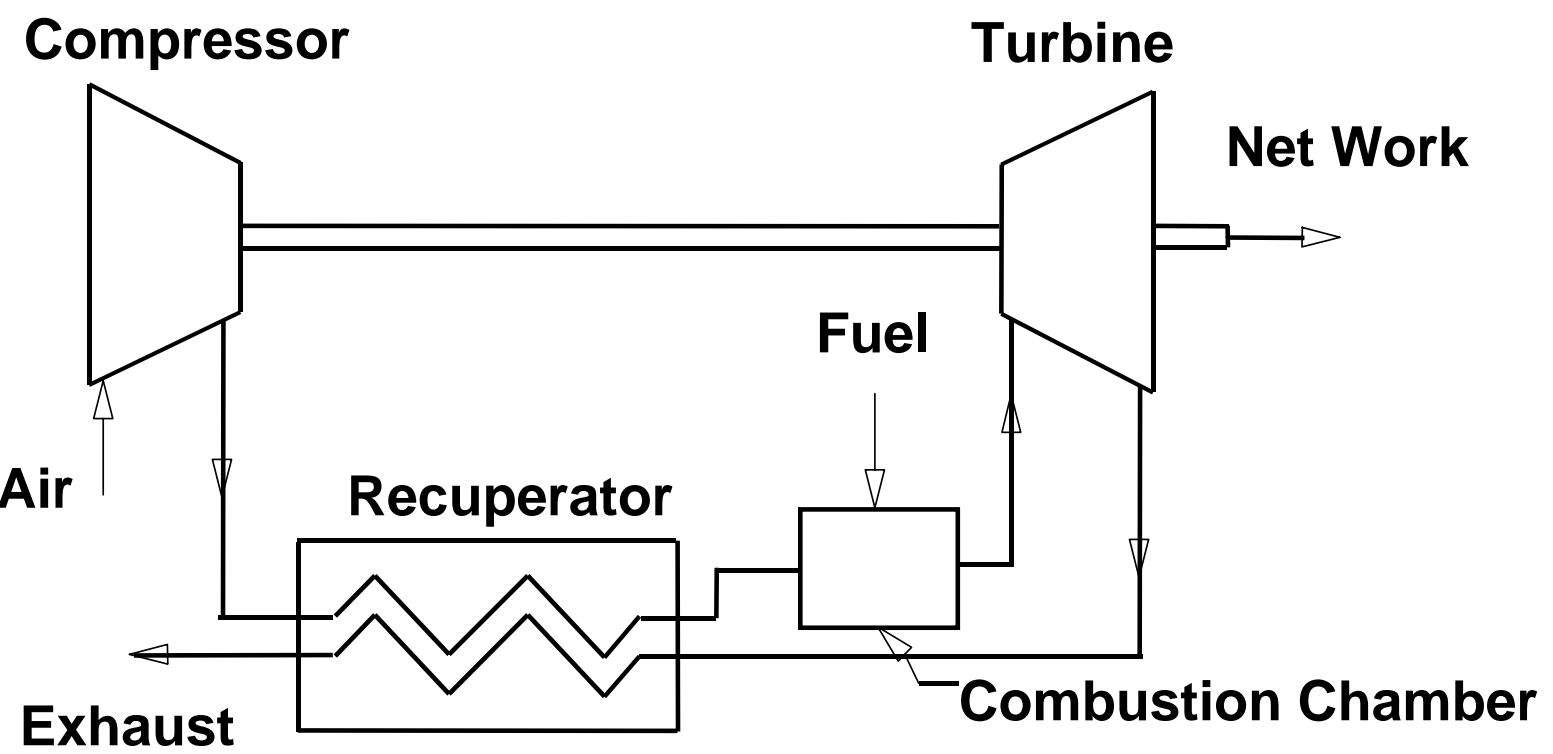

Fig. 2.1. Turboshaft engine with a recuperator. 
Recup.Press.Loss = 5\% Comp.Eff.=80\% Turb.Eff.=85\% Hv=18,200 Btu/lb

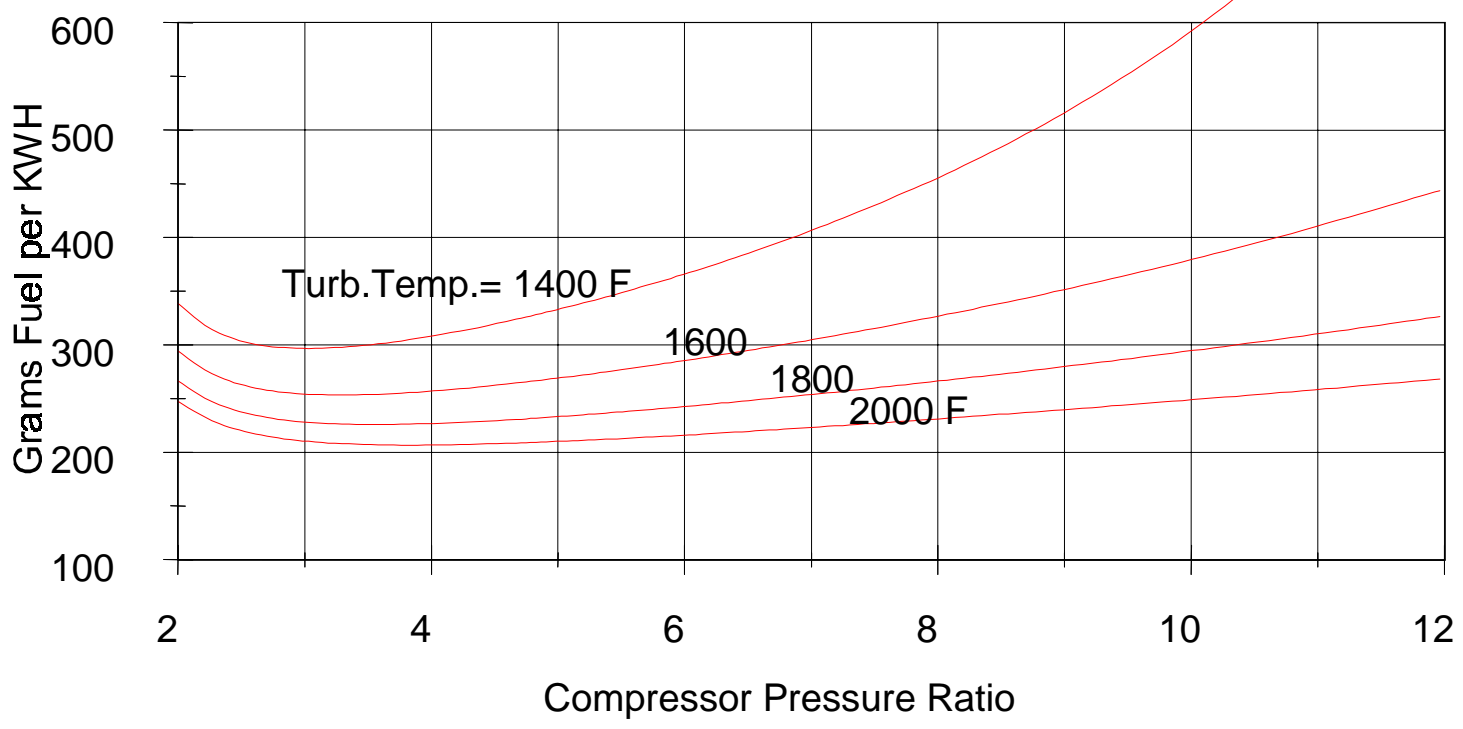

Fig. 2.2. Grams of fuel per kilowatt hour for $90 \%$ recuperator efficiency at various turbine inlet temperatures.

Comp.Eff. $=80 \% \quad$ Turb.Eff. $=85 \% \quad \mathrm{Hv}=18,200 \mathrm{Btu} / \mathrm{lb}$

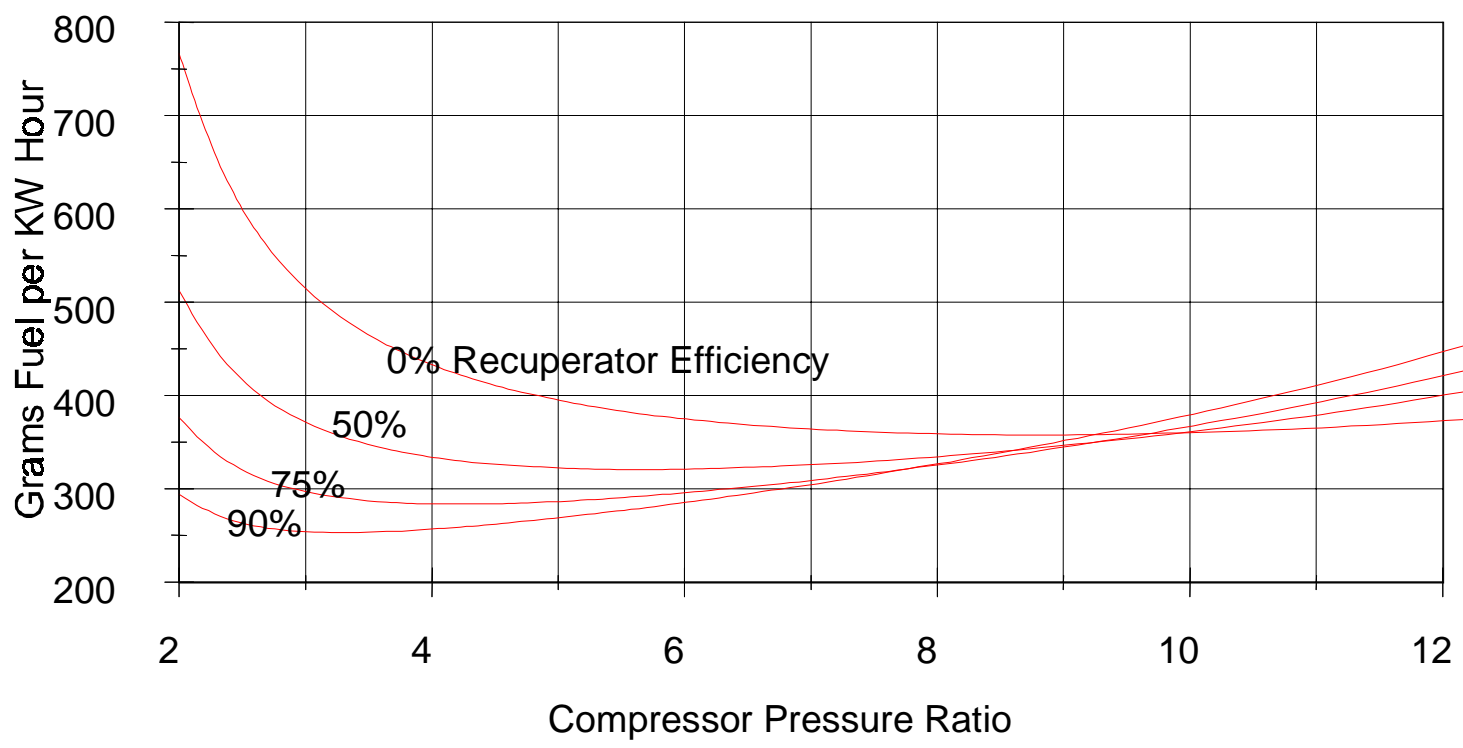

Fig. 2.3. Grams of fuel per kilowatt hour at $1600^{\circ} \mathrm{F}$ turbine temperature at various recuperator efficiencies and appropriate pressure losses. 
Turb.Temp. $=1600 \mathrm{~F}$ Recup.Press.Loss $=5 \% \quad$ Turb.Eff. $=85 \% \quad \mathrm{Hv}=18,200 \mathrm{Btu} / \mathrm{lb}$

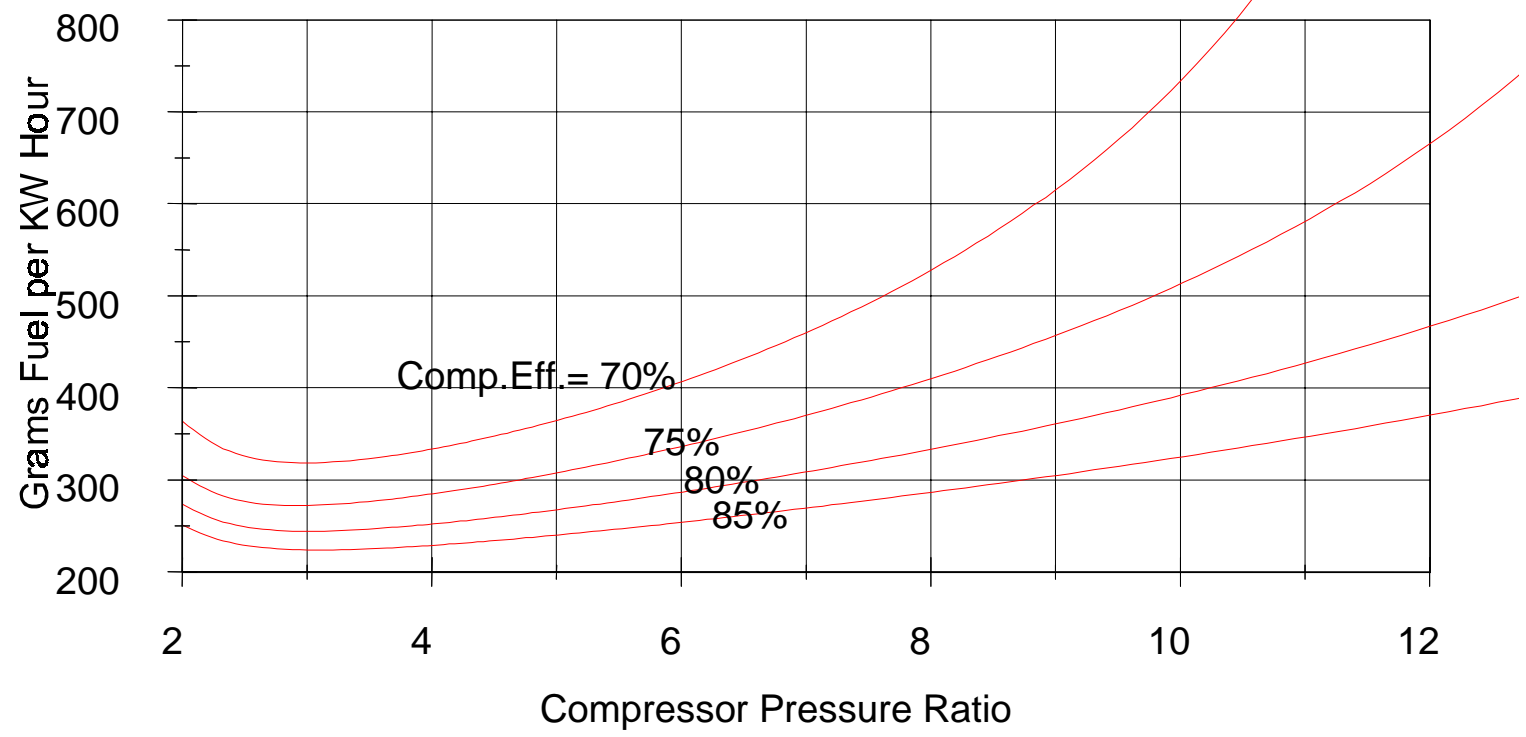

Fig. 2.4. Grams of fuel per kilowatt hour at $90 \%$ recuperator efficiency at various compressor efficiencies.

Recuperators have diminishing benefit at higher compression ratios because the compressed air temperature approaches the exhaust gas temperature and one can not make effective use of the exhaust heat to preheat the combustion air.

In summary, a simple lightweight single-shaft micro-turbine design would most likely have a turbine inlet temperature of about $1600^{\circ} \mathrm{F}$, a centrifugal compressor with compression ratio of about 3 or 4 , and a $90 \%$ efficient recuperator. More sophisticated designs are possible such as multiple shafts, higher temperatures, and intercooling, but they would be more complicated, heavier, and more costly. Micro-turbines do not scale well in performance in capacities below about $25 \mathrm{~kW}$. In addition, at partial load, gas turbine fuel consumption tends to increase more than that for a piston engine.

\subsubsection{Micro-Turbine Developers}

The following turbine developers are working on or have started to market gas turbine electric generators in the 28- to $200-\mathrm{kW}$ micro-turbine capacity range.

- AeroVironment

222 East Huntington Drive

Monrovia, CA 91016

- Allied Signal

Torrance, CA

75-kW TurboGenerator ${ }^{\mathrm{TM}}$
- Northern Research Engineering Co.

Woburn, MA

30-, 60-, 200-kW PowerWorks ${ }^{\mathrm{TM}}$

- Rolls-Royce Allison

P.O. Box 420

Indianapolis, IN 46206 
- Capstone Turbine Corp

Woodland Hills, CA

28-kW Capstone MicroTurbine ${ }^{\mathrm{TM}}$

- Elliot Energy Systems

Stuart, FL

45-, 80-, 200-kW Turbo Alternator ${ }^{\mathrm{TM}}$
- Sundstrand Aerospace

4400 Ruffin Road

P.O. Box 85757

San Diego, CA 92186-5757

- Williams International

2280 West Maple Road

Walled Lake, Ml 48390

\subsection{AUTOMOTIVE PISTON DIESEL ENGINES}

Diesel engines of interest to this study are often categorized as being either industrial/off-road engines or as automotive engines. Strictly speaking, these categories are not completely clear for certain engines, but they serve well for the vast majority of engines and designs. Because a great deal of diesel engine innovation and new technology application are currently emerging in the automotive diesel sector, the discussion of automotive diesel engines has been placed before the discussion of industrial diesels. This innovation appears to be quite relevant, resulting in engine changes that have attributes desirable for gen-sets that are smaller, lighter, more efficient and have lower acoustic, vibrational, and thermal output.

According to our investigations and the opinions of engine representatives, innovation in the automotive sector appears poised to cascade down to the industrial diesel market. This technology transfer from automotive engines to industrial engines has occurred in the past, but it is likely to occur at an accelerated pace in the future. Appendix 2.A includes a glossary for diesel engine terms for additional information.

\subsubsection{The Changing Automotive Diesel Market and Technology}

A great deal of diesel engine innovation and new technology application for the 60- to 250-hp output range is seen in automotive (light-duty vehicle) market applications-especially in markets where the allowable initial cost is relatively high. The automotive diesel engine market is currently responding to different market and regulatory forces than similarly sized industrial diesel engines. Note that light-duty (car and small truck) transportation diesel engines are usually operated at relatively high allowable rotational speeds $(3600-5000 \mathrm{rpm})$ for at least short time periods, often utilize sophisticated controls, are designed for high power-to-weight ratio, and employ turbochargers or superchargers (rarely used). Some of these engines are also relatively expensive, but this is moderated somewhat when they are produced and sold in very large quantities.

Transportation diesel engine technology is changing rapidly in both the United States and Europe due largely to a greater interest and competition in the automotive and light truck market $(60-250 \mathrm{hp})$ and due to increasingly stringent environmental regulations being applied to all sizes of diesel-powered vehicles. Such developments in the automotive diesel sector include a number of technological advances that are likely to be applied in the future to diesel engines used for industrial applications, including engines that power portable generators. Several of these advances appear to directly address desirable improvements in military generator technology, including lowering of size, weight, fuel consumption, noise, vibration, and thermal output.

The U.S. automotive and light truck market, as in decades past, is dominated by gasoline-fueled engines. In Europe and other places where the economics of passenger cars differ due to much 
more expensive petroleum-based fuel, diesel technology has captured a significant light-vehicle market share (variously reported to be 14-22\%). Much effort is being made by diesel manufacturers to advance technology and produce engines more suited to the light-vehicle market. Manufacturers are attempting to position themselves to hold and/or increase market share by lowering engine-out emissions, increasing fuel economy, and improving driveability and performance. Substantial improvements will be commercialized in diesel technology over the next several years. Although the North American market is potentially large, it is also evident that most new automotive diesel engines will target the European market and other regions outside of North America in the short term, continuing the trend of the past.

\subsubsection{Light-Duty Automotive Diesel Engines in the U.S. Market}

Only three light-duty diesel engines are Environmental Protection Agency (EPA)-certified for model year 1999 and actively marketed in the United States. General Motors (GM) offers a 6.5-L, indirect injection (IDI), V8 turbo diesel engine for the heaviest of the light-duty vehicles (i.e., Yukon and Tahoe). Passenger car, turbo, direct injection (DI) diesel engines being marketed are the Mercedes-Benz 3.0-L, 24-valve, in-line, 6-cylinder engine and the Volkswagen 1.9-L, 4-cylinder engine. Each of these engines uses exhaust gas recirculation (EGR) and an exhaust oxidation catalyst system to meet automotive diesel emission standards. According to published accounts, GM plans to phase out its IDI V8 diesel engine and replace it with a more advanced Isuzu/GM DI 6.6-L engine. A plant to produce such engines is expected to open in Ohio in 2000. The other two engines mentioned above will likely continue to be available and follow the pattern of being continuously updated as technology advances. Other well-known turbo diesel engines such as the Ford/Navistar 7.3-L, DI, V8 engine, and the Cummins 5.9-L, in-line 6-cylinder, DI engine are certified as heavy-duty engines and marketed for medium-duty vehicles (class 3 truck or higher).

\subsubsection{U.S. Automotive Engines in Development}

Advanced diesel engines are being developed for the largest vehicles in the U.S. light-duty market, including several being developed with assistance from DOE. These engines are generally sized at about 4-L displacement, with maximum power output near $200 \mathrm{hp}$ and are designed to satisfy the sport utility and pickup truck market. Detroit Diesel, Navistar, Cummins, and Caterpillar are currently developing such engines.

\subsubsection{Automotive Diesel Engine Technology Trends}

A wide variety of automotive diesel engines are available outside the United States. Notably, a large number of automotive turbocharged IDI and DI diesels are available in Europe where an especially high amount of innovation and competition is evident. The modernized automotive diesel engines are turbocharged and employ a high degree of electronic control. In this competitive world market, continuous effort has been made to increase the power and torque ratings for a given engine displacement and weight, to lower engine-out emissions, to boost fuel economy, and to reduce noise and vibration. The diesel engines available cover the entire light-duty size range with engines available from $60 \mathrm{hp}$ to more than $175 \mathrm{hp}$, and come in 3-, 4-, 5-, and 6 -cylinder configurations. The engine choices will continue to change, and new powerful V6 and V8 diesels are planned for the European luxury car market. It appears that the latest diesel engines are closing the gap when compared to gasoline engines in terms of power-to-weight ratio (a significant consumer-driven market force), while exceeding the gasoline engines in torque output capabilities. 
Fuel Injection Systems. There has been an obvious trend toward phasing out IDI systems in favor of DI fueling, with DI capturing nearly one-half of the current passenger car diesel market. Furthermore, a relatively large number of engines recently introduced, or planned for introduction in the next 2 years, employ high-pressure common-rail fuel injection with precision electronic control for fuel injector rate shaping. Rate shaping refers to careful control over the volume flow rate of fuel being injected (as a fine spray) into the cylinder, both as a function of time and engine crank angle. How the fuel flow rate is varied over the injection duration has a very large influence on fuel economy, power and torque capabilities, exhaust emissions, and combustion noise.

Although most major automotive diesel engine producers appear to be going to a common-rail system, this may not be the only path being taken in the advancement of sophisticated fuel injection. (Volkswagen is a notable exception to this trend by advancing high fuel pressure, electronically controlled unit-injector based systems.) Such a system can generate very high fuel pressures and may also be capable of improved rate shaping. High-pressure electronically controlled unit-injector fueling is used on much of the current generation of U.S. heavy-duty diesel engines (>350 hp). Volkswagen has scaled down unit injector technology for the much smaller displacement automotive engines. These new fueling systems rely heavily on intelligent electronic control. Attention is being given to the fuel injection, fuel spray, fluid mechanics, and rate shaping issues that control combustion.

Fuel economy, emissions, and power output. A chief purpose of recent advancements in highpressure $\mathrm{DI}$ systems is to lower engine-out $\mathrm{NO}_{\mathrm{x}}$ and particulate emissions. This is essential for the light-duty diesel market to remain competitive in Europe and to capture significant market share in North America. Fortunately, improvements in fuel efficiency are also a direct benefit. The improvements in controlling the injection and combustion process allow better control over the heat release rate. The engine can then make more power for the same amount of fuel, which boosts the fuel efficiency and power and torque output per unit swept volume (or per unit engine weight). This improved power and torque capability is seen as a major selling point for light-duty diesel vehicles.

Several other technology advances also have an effect on emissions, especially the air and EGR handling systems. Introduction of variable geometry and wastegated turbochargers provide better transient matching, which affects overall vehicle emissions in a favorable manner. Use of four valves per cylinder is being employed on some engines to reduce flow resistance and as a method to control airflow and swirl, which improves the mixing and combustion processes. The use of cooled EGR and intercooled turbochargers is also beneficial for controlling in-cylinder $\mathrm{NO}_{x}$ production. There is a significant power output improvement from adding intercooling to the turbocharging system.

Claims are being made that this newest generation of automotive diesel engines with sophisticated rate shaping combined with other advancements can drop fuel consumption up to $20 \%$ and boost low-speed torque by up to $50 \%$ and peak power by $25 \%$ over the previous generation diesels. Emission reductions of $60 \%$ for particulate matter, $50 \%$ for hydrocarbons, $40 \%$ for $\mathrm{CO}$, with no increase of $\mathrm{NO}_{x}$ are also claimed (by Peugeot). The actual achieved results for automotive engines will become evident as they enter the market in significant numbers.

Aluminum alloy use. The use of alloy engine heads is standard for most automotive diesel engines, but the engine crankcases of essentially all automotive diesel engines are made of gray cast iron. Aluminum alloy engine blocks (crankcases) are used widely for automotive 
gasoline engines, but the dynamic loads and stresses are significantly lower for gasoline engines compared to diesel engines. Volkswagen recently announced production in 1999 of an aluminum crankcase 1.4-L, 3-cylinder turbocharged automotive engine. Other all-aluminum (aluminum alloy head and crankcase) automotive diesel engines will likely be marketed in the future, and certain developmental prototypes have been built. An all-aluminum V6, four valves per cylinder, common-rail-fueled, engine prototype has been displayed by Isuzu. A few other allaluminum engines have been introduced for other purposes than normal automotive applications. These are discussed under industrial engines

Other benefits and innovations. A number of innovations have made the newest light-duty automotive diesel engines more attractive to the consumer. The advances in high-pressure electronically controlled DI have brought about very important benefits due to newly found abilities for fuel injection rate shaping. These include lower noise and vibration and significant increases in power and low-speed torque per unit engine displacement. Use of turbochargers with charge cooling, variable geometry, or wastegates or the use of dual turbochargers enhances performance significantly. At least one diesel car comes with a multistage tunedresonance intake manifold. A few engines feature four valves per cylinder to improve engine breathing. Low internal friction components and lower viscosity oils have been introduced on some new diesel automotive engines.

Efforts to control and perfect the combustion process will continue by advancing rate shaping, fuel/air mixing, EGR with cooling, and charge cooling (cooling the turbo-compressed intake air before introduction into the cylinder). Better control over the quantity, degree of cooling, and distribution is certain to continue EGR improvements. Both EGR cooling and charge cooling help lower peak combustion temperatures, which lowers $\mathrm{NO}_{\mathrm{x}}$ emissions.

\subsection{INDUSTRIAL PISTON DIESEL ENGINES}

Industrial diesel engines have traditionally been designed for low initial cost and maintenance cost, engine longevity and performance, and good fuel economy. Size and weight considerations are seldom major factors in the design philosophy, in contrast to the modern automotive diesel engines. Fuel economy has also been more of a consideration in Europe where fuel is three to four times the U.S. price.

The major shake-up occurring in the U.S. industrial diesel market is the phase-in of relatively stringent environmental regulations, enforced by the EPA. Environmental regulations are also being instituted in Europe and elsewhere. This has given a technological push to the market, and more sophisticated and costly engines are being introduced.

\subsubsection{Environmental Regulations}

A major change has taken place in the industrial diesel engine business because of the implementation of new EPA regulations for nonroad diesel engines. Regulated emissions include oxides of nitrogen, nonmethane hydrocarbons (in some cases total hydrocarbons including methane are regulated, but this is being phased out), carbon monoxide, and particulate matter. These current regulations become increasingly stringent over the time period (currently set for) 1996-2008, and vary by engine size and applications (a total of nine output range categories are recognized and three categories of use-variable speed, constant speed, and marine).

What is referred to as Tier 1 regulations already regulate all nonroad diesel engines rated from 19 to $560 \mathrm{~kW}$. In 2000, the $0-19 \mathrm{~kW}$ and those larger than 560-kW diesel engines will also fall 
under Tier 1 regulations. The allowed emissions vary with engine output rating. More stringent emission levels, referred to as Tier 2 and Tier 3, are slated to go into effect in a piecemeal fashion from 2001-2008.4,5

The engine manufacturer must certify each engine or engine family with the EPA in every model year. The manufacturer must test the engine (or have it tested) in a very specific manner and apply to EPA for certification. Engines do not necessarily need to be retested each year if no emission-related changes are made to the engine model. EPA plans to conduct confirmation testing.

Largely because of these new certification standards, a number of specific engine models are being or have been retired or modified. New engine models are being offered that are in compliance.

From discussions with nondomestic engine companies, it is apparent that certain engine models available in Europe are not being imported into the United States at this time because of the trouble and expense of certification with EPA. In some cases the engines are probably capable of meeting the U.S. certification requirements without any modification from current European version, but in other cases modification would be required to meet these environmental requirements. This is largely a business decision applied to engines for which the market outlook does not justify the certification expense.

\subsubsection{Technology Trends}

The major technology changes seen in the industrial engine market are driven by the latest EPA regulations. The most obvious trend is the widespread introduction of relatively high-pressure DI fueling systems, which are similar or identical to those that have been introduced in the automotive market.

Fueling and fueling control. In the past, IDI fueling systems were dominant, but they are rapidly being displaced by DI fueling. More stringent environmental regulations will increase the incentive to change from mechanically controlled fueling to electronically controlled fueling and to use increased fuel injection pressures. Current DI fueling systems for industrial engines are generally rotary-pump based systems. Although more costly, use of DI fueling with electronic fueling controls not only reduces emissions, but improves power, torque, and fuel economy. Higher noise levels are associated with DI fueling (compared with IDI), but sophisticated high-pressure DI systems can reduce combustion-associated noise considerably.

These rotary-pump fueling systems, which are seeing expanded application in the industrial engine market, should not be confused with the significantly more costly and sophisticated common-rail or unit injector based DI systems emerging in the automotive diesel market.

Aspiration. Many smaller industrial diesel engines are only offered as naturally aspirated units. The threshold for turbocharging to be an option appears to be at about 35-hp maximum power rating if the engine has three or more cylinders. Engines rated above $60 \mathrm{hp}$ generally are offered with turbocharging as an option.

Because the new EPA regulations require engines to lower $\mathrm{NO}_{\mathrm{x}}$ emissions, turbocharging with charge cooling (intercooling) may become more popular. Charge cooling can lower peak combustion temperatures and results in less $\mathrm{NO}_{x}$ formation during combustion. Turbocharging 
significantly boosts the power output of an engine with little added weight, and turbocharging with charge cooling boosts power still further.

Block and head material. Cast iron is the most common material for industrial diesel engine heads. Aluminum alloy is sometimes used for the engine head to reduce weight, but weight is often not a major concern for industrial engines.

Cast iron is used for virtually all industrial diesel engine blocks (crankcases), with a few notable exceptions. One small family of aluminum alloy block (crankcase) engines is currently being used for industrial applications in the United States and other markets. These are 2-cylinder (0.65-L and 0.85-L displacement), naturally aspirated, air-cooled, DI engines made by Ruggerini Motori (Italy). A water-cooled all-aluminum, 2-cylinder, IDI fueled, 0.75-L displacement engine by Yanmar became available in the United States in mid-1999 with the major use being lawn equipment (this engine was developed jointly with John Deere). This engine designed for mowing equipment (and similar uses) features a unique 80-degree $\mathrm{V}$ configuration and a vertical power shaft. An all-aluminum, 2-cylinder, IDI, naturally aspirated, 0.5-L displacement, watercooled engine is produced by Lombardini (Italy). One major use of this engine is to power city cars in France, which are very small, and low-speed cars that weigh less than $700 \mathrm{lb}$.

\subsection{PISTON DIESEL ENGINE AVAILABILITY AND CHARACTERIZATION SURVEY}

Basic data for a relatively large number of 10- to 140-hp engines and a small number of larger engines produced by more than 20 manufacturers were reviewed to survey the technology and to find observable trends. It is thought that the vast majority of applicable diesel engines with U.S. availability were examined. Emphasis was put on high power-to-weight ratio, so relatively heavy industrial engines were given only brief attention in the market survey. A number of high power-to-weight engines were examined that are currently only available outside the United States or that are still in the precommercial stage of development. It is believed such engines could be available for military gen-set use in the near future.

\subsubsection{Engine Survey Results and Data Tables}

The diesel market can be a confusing maze of manufacturers and engine types, which together fill the relatively large markets and smaller niche markets for diesel engines. Many companies are in the process of retiring entire engine lines and replacing them with updated engines and technology. This is mainly driven by the new EPA regulations for nonroad engines and similar legislation in Europe and other places. Please note that details concerning engine models and specific attributes may become outdated rather quickly. The information presented is not intended to examine every appropriate engine, and certain flaws in the information are unavoidable. Note that even the detailed information available from the manufacturers normally has disclaimers concerning the given specifications. The summary presented here focuses on engines in the power range suitable for $5-$ to $60-\mathrm{kW}$ gen-sets.

Data for selected diesel engines are summarized in Tables 2.1 to 2.3. Selected characteristics are summarized for industrial diesel engines in Table 2.1, most of which are readily available in the United States (unless noted otherwise). Most of industrial diesel engines available in the United States and in the size range of interest were considered; some engines with low powerto-weight ratio that were reviewed were not included in the table. Table 2.2 summarizes data for automotive diesel engines that either have current U.S. availability or were judged likely to be available in the next 2 years. Automotive diesel engines that are still in development or prototype stage are characterized in Table 2.3. 
Table 2.1. Characterization of selected commercial industrial diesel engines

\begin{tabular}{|c|c|c|c|c|c|c|c|c|c|c|c|c|c|}
\hline Engine Make & Model & Notes & $\begin{array}{c}\text { Fuel } \\
\text { injection }\end{array}$ & Aspiration & Cyl. & $\begin{array}{l}\text { Displ. } \\
\text { (L) }\end{array}$ & CR & $\begin{array}{c}\text { Continuous } \\
\text { Power } \\
\text { Output @ } \\
1800 \text { rpm } \\
\text { (kW/hp) }\end{array}$ & $\begin{array}{l}\text { Best } \\
\text { fuel } \\
\text { cons. } \\
\text { (g/kWh) }\end{array}$ & $\begin{array}{c}\text { Dry } \\
\text { weight } \\
\text { (lb/kg) }\end{array}$ & $\begin{array}{c}\text { Continuous } \\
\text { Power } \\
\text { Output } \\
\text { at rated } \\
\text { speed } \\
\text { hp@rpm }\end{array}$ & $\begin{array}{l}\text { Weight to } \\
\text { power } \\
\text { ratio } \\
\text { (lb/hp) } \\
\text { @rpm }\end{array}$ & Notes \\
\hline Lombardini & LDW502 & $\begin{array}{l}\text { all aluminum } \\
\text { water cooled }\end{array}$ & IDI & natural & 2 & 0.505 & & $\sim 4.9 / 6.5$ & & 119,54 & 11.0@3600 & 10.8@3600 & $\begin{array}{l}\text { Not available } \\
\text { in the United } \\
\text { States }\end{array}$ \\
\hline Lombardini & 602 FOCS & $\begin{array}{l}\text { aluminum head } \\
\text { water cooled }\end{array}$ & IDI & natural & 2 & 0.611 & & $5.4 / 7.3$ & 253 & 143,65 & 12.3@3600 & 11.6@3600 & \\
\hline Farymann & $43 \mathrm{~F}$ & air cooled & $\mathrm{DI}$ & natural & 1 & 0.708 & $19: 1$ & & 235 & 192,87 & 13.3@3000 & 14.4@3600 & \\
\hline Lombardini & LDW702 & $\begin{array}{l}\text { aluminum head } \\
\text { water cooled }\end{array}$ & IDI & natural & 2 & 0.686 & & & & 146,66 & 14.2@3600 & 10.3@3600 & $\begin{array}{l}\text { Not available } \\
\text { in the United } \\
\text { States }\end{array}$ \\
\hline Perkins & $103-07$ & water cooled & & natural & 3 & 0.676 & & & & 159,72 & $15.3 @ 3600$ & 10.4@3600 & \\
\hline $\begin{array}{l}\text { Duetz- } \\
\text { Ruggerini }\end{array}$ & MD 191 & $\begin{array}{l}\text { all aluminum } \\
\text { air cooled }\end{array}$ & $\mathrm{DI}$ & natural & 2 & 0.852 & $19: 1$ & $6.2 / 8.3$ & 230 & $117, / 53$ & $16.5 @ 3600$ & $7.1 @ 3600$ & \\
\hline Lombardini & 903 FOCS & $\begin{array}{l}\text { aluminum head } \\
\text { water cooled }\end{array}$ & IDI & natural & 3 & 0.916 & & $8.6 / 11.5$ & 272 & 187,85 & $18.4 @ 3600$ & $10.2 @ 3600$ & \\
\hline Yanmar & $2 \mathrm{~V} 78$ & $\begin{array}{l}\text { all aluminum } \\
\text { water cooled }\end{array}$ & $\mid \mathrm{IDI}$ & natural & 2 & 0.749 & $23: 1$ & $8.0 / 10.7$ & 240 & 115,56 & 17.2@3600 & $6.7 @ 3600$ & \\
\hline Lister-Petter & LPW2 & water cooled & $\mathrm{DI}$ & natural & 2 & 0.93 & $18.5: 1$ & $8.2 / 11.0$ & 230 & 247,112 & 18.8@3600 & 13.1@3600 & $\begin{array}{l}\text { used in } \\
5-\mathrm{kW} \text { TQG }\end{array}$ \\
\hline Lister-Petter & LPW3 & water cooled & $\mathrm{DI}$ & natural & 3 & 1.40 & $18.5: 1$ & $12.3 / 16.5$ & 230 & 330,150 & 28.2@3600 & 11.7@3600 & \\
\hline Lombardini & $1204 T$ & $\begin{array}{l}\text { aluminum head } \\
\text { water cooled }\end{array}$ & $\mid \overline{\mid D I}$ & turbo & 4 & 1.22 & & $15.3 / 20.5$ & 265 & 223,101 & 34.5@3600 & 6.5@3600 & \\
\hline Yanmar & 3TNE84T & water cooled & $\mathrm{DI}$ & turbo & 3 & 1.50 & & $16.5 / 22.1$ & 218 & 353,160 & 40.9@3600 & 8.6@3600 & \\
\hline Perkins & $104-22$ & water cooled & & natural & 4 & 2.216 & & & & 425,193 & 42.2@2800 & 10.1@3600 & \\
\hline Lister-Petter & LPW4 & water cooled & $\mathrm{DI}$ & natural & 4 & 1.86 & $18.5: 1$ & $16.4 / 22.0$ & 230 & 396,180 & 37.5@3600 & 10.6@3600 & $\begin{array}{l}\text { used in } \\
10-\mathrm{kW} \text { TQG }\end{array}$ \\
\hline Lister-Petter & LPWT4 & water cooled & $\mathrm{DI}$ & $\begin{array}{c}\text { turbo } \\
\text { wastegate }\end{array}$ & 4 & 1.86 & $18.5: 1$ & $23.8 / 31.9$ & 230 & 406,180 & $50.3 @ 3000$ & $8.1 @ 3000$ & \\
\hline
\end{tabular}


Table 2.1. (continued)

\begin{tabular}{|c|c|c|c|c|c|c|c|c|c|c|c|c|c|}
\hline Engine Make & Model & Notes & $\begin{array}{c}\text { Fuel } \\
\text { injec- } \\
\text { tion }\end{array}$ & $\begin{array}{l}\text { Aspir- } \\
\text { ation }\end{array}$ & Cyl. & $\begin{array}{l}\text { Displ. } \\
\text { (L) }\end{array}$ & CR & $\begin{array}{l}\text { Continuous } \\
\text { Power } \\
\text { Output @ } \\
1800 \text { rpm } \\
\text { (kW/hp) }\end{array}$ & $\begin{array}{c}\text { Best } \\
\text { fuel } \\
\text { cons. } \\
\text { (g/kWh) }\end{array}$ & $\begin{array}{c}\text { Dry } \\
\text { weight } \\
\text { (lb/kg) }\end{array}$ & $\begin{array}{l}\text { Continuous } \\
\text { Power } \\
\text { Output } \\
\text { at rated } \\
\text { speed } \\
\text { hp@rpm }\end{array}$ & $\begin{array}{l}\text { Weight to } \\
\text { power } \\
\text { ratio } \\
\text { (lb/hp) } \\
\text { @rpm }\end{array}$ & Notes \\
\hline Lombardini & $2004 T$ & $\begin{array}{c}\text { iron head } \\
\text { water cooled }\end{array}$ & IDI & turbo & 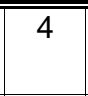 & 2.07 & & $20 / 26.9$ & & $430 / 195$ & $\mid 50.7 @ 3600$ & 8.5@3600 & \\
\hline Yanmar & 4TNE84T & water cooled & $\mathrm{DI}$ & turbo & 4 & 2.00 & & $24.3 / 32.6$ & 217 & $386 / 175$ & $54.7 @ 3600$ & $7.1 @ 3600$ & \\
\hline Isuzu & $\mathrm{C} 240$ & water cooled & IDI & natural & 4 & 2.37 & $20: 1$ & $23 / 31$ & 265 & $456 / 223$ & 45@3000 & $10.1 @ 3000$ & $\begin{array}{l}\text { used in } \\
15-k W \text { TQG }\end{array}$ \\
\hline Perkins & $704-30$ & water cooled & & natural & 4 & 3.00 & & & & $441 / 200$ & $55.9 @ 2600$ & 7.9@2600 & \\
\hline John Deere & 3029T & water cooled & $\mathrm{DI}$ & turbo & 3 & 2.9 & & $\sim 39 / 52$ & & $722 / 328$ & 71@2500 & 10.2@2500 & \\
\hline$\overline{\mathrm{DDC} / \mathrm{VM} \text { Motori }}$ & D704LTE & water cooled & $\mathrm{DI}$ & turbo & 4 & 2.8 & $17: 1$ & & & $578 / 262$ & 76@2600 & 7.6@2600 & \\
\hline Perkins & $\begin{array}{l}1004- \\
40 T W\end{array}$ & water cooled & & $\begin{array}{l}\text { cooled } \\
\text { turbo }\end{array}$ & 4 & 4 & & & & $628 / 285$ & 103@2500 & $6.1 @ 2500$ & \\
\hline DDC/VM Motori & D706LTE & water cooled & $\mathrm{DI}$ & turbo & 6 & 4.2 & $17: 1$ & & & $821 / 373$ & 111@2600 & 7.4@2600 & \\
\hline DDC/VM Motori & HR694HT & water cooled & $\mathrm{DI}$ & turbo & 6 & 4.2 & $17: 1$ & & & $727 / 330$ & 121@3200 & 6.0@2600 & \\
\hline Yanmar & 4TNE106T & water cooled & DI & turbo & 4 & 4.4 & & $65.5 / 87.8$ & & $675 / 306$ & 113@2500 & $6.0 @ 2500$ & \\
\hline John Deere & $4045 T$ & water cooled & $\mathrm{DI}$ & turbo & 4 & 4.5 & & $67 / 90$ & & $872 / 396$ & 103@2500 & 8.5@2500 & $\begin{array}{l}\text { used in } \\
30-k W \text { TQG }\end{array}$ \\
\hline John Deere & $4045 \mathrm{H}$ & water cooled & $\mathrm{DI}$ & $\begin{array}{l}\text { cooled } \\
\text { turbo }\end{array}$ & 4 & 4.5 & & $86 / 115$ & & $872 / 396$ & 126@2400 & 6.9@2400 & \\
\hline Wis-con/MWM & 4.10TCA & water cooled & $\begin{array}{c}\text { common } \\
\text { rail }\end{array}$ & $\begin{array}{c}\text { cooled } \\
\text { turbo }\end{array}$ & 4 & 4.3 & $16: 1$ & 129/173 & & $837 / 380$ & 149@2400 & $5.6 @ 3500$ & \\
\hline John Deere & $6068 \mathrm{~T}$ & water cooled & DI & turbo & 6 & 6.8 & & $101 / 135$ & & $1212 / 550$ & 153@2500 & 7.9@2500 & $\begin{array}{l}\text { used in } \\
60-k W \text { TQG }\end{array}$ \\
\hline John Deere & $6068 \mathrm{H}$ & water cooled & $\mathrm{DI}$ & $\begin{array}{c}\text { cooled } \\
\text { turbo }\end{array}$ & 6 & 6.8 & & $133 / 178$ & & $1250 / 567$ & 203@2400 & 6.2@2400 & \\
\hline
\end{tabular}


Table 2.2. Characterization of water-cooled, DI, high-speed automotive diesel engines

\begin{tabular}{|c|c|c|c|c|c|c|c|c|c|c|c|c|c|}
\hline Engine Make & Model & Notes & $\begin{array}{c}\text { Fuel } \\
\text { injec- } \\
\text { tion }\end{array}$ & $\begin{array}{l}\text { Aspir- } \\
\text { ation }\end{array}$ & Cyl. & $\begin{array}{l}\text { Displ. } \\
\text { (L) }\end{array}$ & CR & $\begin{array}{c}\text { Continuous } \\
\text { Power* } \\
\text { Output @ } \\
1800 \text { rpm } \\
\text { (kW/hp) }\end{array}$ & $\begin{array}{l}\text { Best } \\
\text { fuel } \\
\text { Con- } \\
\text { sump- } \\
\text { tion } \\
\text { (g/kWh) }\end{array}$ & $\begin{array}{c}\text { Dry } \\
\text { weight } \\
\text { (lb/kg) }\end{array}$ & $\begin{array}{l}\text { Continuous } \\
\text { Power* } \\
\text { Output at } \\
\text { rated } \\
\text { speed } \\
\text { hp@rpm }\end{array}$ & $\begin{array}{l}\text { Weight to } \\
\text { Power } \\
\text { ratio } \\
\text { (lb/hp) } \\
\text { @rpm }\end{array}$ & Notes \\
\hline Volkswagen & R3 & $\begin{array}{l}\text { aluminum } \\
\text { head } \\
\text { and } \\
\text { crankcase }\end{array}$ & $\begin{array}{l}\text { rotary } \\
\text { pump }\end{array}$ & $\begin{array}{l}\text { cooled } \\
\text { turbo }\end{array}$ & 3 & 1.42 & & $25 / 33$ & & $251 / 114$ & 63@4000 & $4.0 @ 4000$ & $\begin{array}{l}\text { U.S. availability } \\
\text { in } 2000\end{array}$ \\
\hline Volkswagen & AFD & $\begin{array}{l}\text { U.S. auto. } \\
\text { TDI }\end{array}$ & $\begin{array}{l}\text { rotary } \\
\text { pump }\end{array}$ & $\begin{array}{l}\text { cooled } \\
\text { turbo }\end{array}$ & 4 & 1.90 & 19.5:1 & $39 / 52$ & $\sim 200$ & $298 / 135$ & 93@4000 & $3.2 @ 4000$ & $\begin{array}{l}\text { sold in the } \\
\text { United States } \\
\text { as industrial } \\
\text { eng. }\end{array}$ \\
\hline Volkswagen & AJM or R4 & $\begin{array}{c}\text { sold in } \\
\text { European } \\
\text { cars }\end{array}$ & $\begin{array}{c}\text { unit } \\
\text { injection }\end{array}$ & $\begin{array}{l}\text { cooled } \\
\text { turbo }\end{array}$ & 4 & 1.90 & 18.0:1 & $46 / 61$ & & $310 / 141$ & 98@4000 & $3.0 @ 4000$ & $\begin{array}{l}\text { U.S. availability } \\
\text { in } 2000\end{array}$ \\
\hline Peugeot & DW10ATED & $\begin{array}{c}\text { sold in } \\
\text { European } \\
\text { cars }\end{array}$ & $\begin{array}{c}\text { common } \\
\text { rail }\end{array}$ & $\begin{array}{l}\text { cooled } \\
\text { turbo }\end{array}$ & 4 & 2.0 & & $41 / 55$ & 209 & $331 / 150$ & 98@4000 & $3.4 @ 4000$ & $\begin{array}{l}\text { limited sales } \\
\text { In the United } \\
\text { States }\end{array}$ \\
\hline Peugeot & DW12TED4 & 4 valves/cyl. & $\begin{array}{l}\text { common } \\
\text { rail }\end{array}$ & $\begin{array}{l}\text { cooled } \\
\text { turbo }\end{array}$ & 4 & 2.18 & & $54 / 73$ & & $401 / 182$ & 125@4000 & $3.2 @ 4000$ & $\begin{array}{l}\text { U.S. availability } \\
\text { in } 2000\end{array}$ \\
\hline Volkswagen & 5 cyl. TDI & $\begin{array}{l}5 \text { cyl. } \\
\text { TDI }\end{array}$ & $\begin{array}{l}\text { rotary } \\
\text { pump }\end{array}$ & $\begin{array}{l}\text { cooled } \\
\text { turbo }\end{array}$ & 5 & 2.4 & 19.5:1 & $44 / 58$ & $\sim 200$ & $365 / 166$ & 119@4000 & $3.1 @ 4000$ & $\begin{array}{l}\text { sold in the } \\
\text { United States } \\
\text { as industrial } \\
\text { eng. }\end{array}$ \\
\hline MWM & 4.07TCA & 3 valves/cyl. & $\begin{array}{c}\text { common } \\
\text { rail }\end{array}$ & $\begin{array}{l}\text { cooled } \\
\text { turbo }\end{array}$ & 4 & 2.8 & $19: 1$ & & & $470 / 213$ & 127@3500 & $3.7 @ 3500$ & $\begin{array}{l}\text { No current } \\
\text { U.S. availability }\end{array}$ \\
\hline MWM & 6.07TCA & 3 valves/cyl. & $\begin{array}{c}\text { common } \\
\text { rail }\end{array}$ & $\begin{array}{l}\text { cooled } \\
\text { turbo }\end{array}$ & 6 & 4.2 & $17.8: 1$ & & & $622 / 282$ & 190@3500 & 3.3@3500 & $\begin{array}{l}\text { No current } \\
\text { U.S. availability }\end{array}$ \\
\hline Cummins & 5.9-L ISB & 4 valves/cyl. & $\begin{array}{l}\text { rotary } \\
\text { pump }\end{array}$ & $\begin{array}{l}\text { cooled } \\
\text { turbo }\end{array}$ & 6 & 5.9 & & $100 / 134$ & & $900 / 408$ & 202@2700 & $4.5 @ 2700$ & available \\
\hline
\end{tabular}

${ }^{*}$ Continuous power rating was assumed to be $86 \%$ of SAE automotive power rating (ISO 1585) when only the automotive ratings were available. 
Table 2.3. Characterization of water-cooled, DI, high-speed, automotive diesel engines in development

\begin{tabular}{|c|c|c|c|c|c|c|c|c|c|c|c|c|c|}
\hline \multirow[b]{2}{*}{ Engine Make } & \multirow[b]{2}{*}{ model } & \multirow[b]{2}{*}{ notes } & \multirow[b]{2}{*}{$\begin{array}{c}\text { Fuel } \\
\text { injec- } \\
\text { tion }\end{array}$} & \multirow[b]{2}{*}{$\begin{array}{l}\text { Aspir- } \\
\text { ation }\end{array}$} & \multirow[b]{2}{*}{ Cyl. } & \multirow[b]{2}{*}{$\begin{array}{l}\text { Displ. } \\
\text { (L) }\end{array}$} & \multirow[b]{2}{*}{ CR } & \multicolumn{6}{|c|}{ Continuous } \\
\hline & & & & & & & & $\begin{array}{c}\text { Continuous } \\
\text { Power* }^{*} \\
\text { Output @ } \\
1800 \text { rpm } \\
\text { (kW/hp) }\end{array}$ & $\begin{array}{c}\text { Best } \\
\text { fuel } \\
\text { cons. } \\
\text { (g/kWh) }\end{array}$ & $\begin{array}{c}\text { Dry } \\
\text { weight } \\
\text { (lb/kg) }\end{array}$ & $\begin{array}{l}\text { Power* } \\
\text { Output } \\
\text { at rated } \\
\text { speed } \\
\text { hp@rpm }\end{array}$ & $\begin{array}{l}\text { Weight to } \\
\text { power } \\
\text { ratio } \\
\text { (lb/hp) } \\
\text { @rpm }\end{array}$ & Notes \\
\hline Peugeot & DV2TED & & $\begin{array}{c}\text { common } \\
\text { rail }\end{array}$ & $\begin{array}{c}\text { cooled } \\
\text { turbo }\end{array}$ & 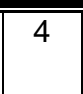 & 1.2 & & 25/33 & & $236 / 107$ & 50@4000 & 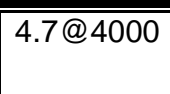 & in development \\
\hline Peugeot & DV4TD & & $\begin{array}{c}\text { common } \\
\text { rail }\end{array}$ & turbo & 4 & 1.4 & & $\sim 24 / 32$ & & $240 / 109$ & $58 @ 4000$ & $4.1 @ 4000$ & in development \\
\hline$\overline{\mathrm{DDC}}$ & & & $\begin{array}{c}\text { common } \\
\text { rail }\end{array}$ & $\begin{array}{c}\text { cooled } \\
\text { turbo }\end{array}$ & 3 & 1.4 & & & 208 & & 65 & & $\begin{array}{l}2000+ \\
\text { availability }\end{array}$ \\
\hline Peugeot & DV4TED4 & 4 valves/cyl. & $\begin{array}{c}\text { common } \\
\text { rail }\end{array}$ & $\begin{array}{c}\text { cooled } \\
\text { turbo }\end{array}$ & 4 & 1.4 & & $\sim 32 / 43$ & & $252 / 115$ & 76@4000 & 3.3@4000 & in development \\
\hline$\overline{\mathrm{DDC}}$ & & & $\begin{array}{c}\text { common } \\
\text { rail }\end{array}$ & $\begin{array}{l}\text { cooled } \\
\text { turbo }\end{array}$ & 4 & 1.9 & & & 205 & & 95 & & $\begin{array}{l}2000+ \\
\text { availability }\end{array}$ \\
\hline DDC (VMM) & 2.5L TD2 & & $\begin{array}{c}\text { common } \\
\text { rail }\end{array}$ & $\begin{array}{c}\text { cooled } \\
\text { turbo }\end{array}$ & 4 & 2.5 & & & 212 & & 115 & & $\begin{array}{l}1999 ? \\
\text { availability }\end{array}$ \\
\hline DDC & & & $\begin{array}{c}\text { common } \\
\text { rail }\end{array}$ & $\begin{array}{c}\text { cooled } \\
\text { turbo }\end{array}$ & 5 & 2.4 & & & 200 & & 121 & & $\begin{array}{l}1999 ? \\
\text { availability }\end{array}$ \\
\hline$\overline{\mathrm{DDC}}(\mathrm{VMM})$ & $2.5 \mathrm{~L}$ TD4 & & $\begin{array}{c}\text { common } \\
\text { rail }\end{array}$ & $\begin{array}{c}\text { cooled } \\
\text { turbo }\end{array}$ & 4 & 2.5 & & & 207 & & 132 & & $\begin{array}{l}1999 \\
\text { availability }\end{array}$ \\
\hline DDC (VMM) & $4.2 \mathrm{~L}$ TD2 & & $\begin{array}{c}\text { common } \\
\text { rail }\end{array}$ & $\begin{array}{c}\text { cooled } \\
\text { turbo }\end{array}$ & 6 & 4.2 & & & 210 & & 152 & & $\begin{array}{l}1999 ? \\
\text { availability }\end{array}$ \\
\hline DDC & Delta & $\begin{array}{l}\text { all cast iron } \\
4 \text { valves/cyl. }\end{array}$ & $\begin{array}{c}\text { common } \\
\text { rail }\end{array}$ & $\begin{array}{c}\text { cooled } \\
\text { turbo }\end{array}$ & V6 & 4.0 & 18.5:1 & $80 / 107$ & & $640 / 290$ & 202@4000 & 3.2@4000 & $\begin{array}{l}2000+ \\
\text { availability }\end{array}$ \\
\hline
\end{tabular}

${ }^{*}$ Continuous power rating was assumed to be $86 \%$ of SAE automotive power rating (ISO 1585) when only the automotive ratings were available. 
In all tables emphasis was put on power-to-weight ratio, with the inverse being quantified in the tables in terms of pounds per available horsepower. Values for power output are given in terms of continuous power rating or an approximation of this value. Engine weights listed are the manufacturers listed engine dry weight (i.e., usually the engine, starter, and alternator without exhaust, radiator or fluids). Because manufacturers' values for power output and dry weights may vary, these numbers should be treated with some caution.

A review included most major brands and models of diesel engines in the size range of interest and available in the United States. A short commentary by manufacturer or distributor is provided. The following diesel engines lines were considered:

\section{Caterpillar}

Caterpillar manufactures heavy-duty engines; it markets two DI engines in the size range of interest:

(1) model 3054, 4.0-L, in-line, 4-cylinder, continuous rating is 110 hp @ 2300 rpm for the intercooled turbocharged version. Dry weight $~ 600 \mathrm{lb}$.

(2) model 3054, 6.0-L, in-line, 6-cylinder, continuous rating is $162 \mathrm{hp} @ 2500 \mathrm{rpm}$ for the intercooled turbocharged version. Dry weight $~ 900 \mathrm{lb}$.

\section{Cummins Engine Co.}

Cummins mainly manufactures heavy-duty engines. In the power range of interest it markets the following two turbocharged engines.

(1) model B3.3: 3.3-L, in-line, 4-cylinder rated up to $85 \mathrm{hp} @ 2600 \mathrm{rpm}$. Dry weight is $553 \mathrm{lb}$.

(2) model B3.9: 3.9-L, in-line, 4-cylinder rated up to 130 hp @ 2500 rpm. Dry weight is about $700 \mathrm{lb}$.

\section{John Deere}

Deere Power Systems markets 3-, 4-, and 6-cylinder engines in the output range of 17 to $255 \mathrm{hp}$ of continuous power. The smaller engines offered (2.0-L and smaller) are Yanmar engines marketed by Deere. Deere engines currently power the 30- and 60-kW Tactical Quiet Generators (TQGs) (models 4045T and 6068T). Selected Deere engines (and Yanmar engines) are included in the accompanying database.

\section{Detroit Diesel, VMM}

Detroit Diesel Corporation (Penske) generally has produced diesel engines that are larger than would be useful for a 60-kW generator. Detroit Diesel acquired VM Motori (VMM) of Cento, Italy, which makes both automotive and industrial diesel engine. Some of the VMM engines families have been certified for industrial use in the United States (models 704L, 706L, and HR694) and are given in the database. An effort to produce a very competitive line of automotive diesel engines with common-rail fuel injection and cooled turbocharging is currently being publicized by Detroit Diesel. If the automotive-designed engines were to be marketed in the United States as industrial engines, they could be quite attractive for gen-sets larger than $20 \mathrm{~kW}$.

\section{Deutz}

Deutz Corporation Markets a wide variety of industrial diesel engines from 1 to 4, 6, 8, 10, and 12 cylinders and roughly 5 to $500 \mathrm{hp}$. Engine designs include water-, oil-, and air-cooled models. A few of the water-cooled, turbocharged-intercooled engines have power-to-weight ratios somewhat better than those found in the TQGs but still fairly typical of very rugged industrial diesels. 
Deutz also markets small 1- and 2-cylinder DI diesel engines made by Ruggerini Motori S.p.A. (Italy). The most interesting of these Ruggerini engines are the 2-cylinder MD151 and MD191 models featuring aluminum head and crankcase construction. These engines are very lightweight for small naturally aspirated diesels, and they are included in the database.

\section{Farymann}

Farymann Diesel USA (Whiting, NJ) markets engines by Farymann Diesel GMBH (Germany) in a power range up to about $55 \mathrm{hp}$. Engine lines include nine models of 1-cylinder engines and six models of 2-, 3-, and 4-cylinder diesel engines. Generally these engines are heavy, and only one engine is turbocharged. The multicylinder engines marketed by Farymann are the same as the "Alpha" series engines marketed by Lister-Petter.

\section{Hatz}

Hatz Diesel of America, Inc., markets 1- to 4-cylinder, air-cooled diesel engines up to about 80 -hp output. The power-to-weight ratio is typical for rugged industrial diesel engines.

\section{Isuzu}

American Isuzu Motors Inc. (Novi, MI) markets 14 water-cooled diesel engine models in the United States These engines come in 3-, 4-, and 6-cylinder configurations and vary in power rating from about 20-260 hp. The C240 model is currently used in the 15-kW TQG, and the other Isuzu engines are similar in power-to-weight ratio when compared to the other TQG engines.

\section{Kubota}

Kubota Engine America Corp. (Lincolnshire, IL) markets Kubota (Japan) water-cooled diesel engines in vertical and horizontal designs. These 1- to 5-cylinder engines span a 4- to 85-hp range. Turbocharging is an option on two vertical 4-cylinder engines. Power-to-weight ratio is typical to relatively low for the industry.

\section{Lister-Petter}

Lister-Petter Ltd. (Gloucestershire, UK) markets 22 models of 1- to 4-cylinder, water-cooled and air-cooled diesel engines in the 7- to 65-hp output range. Most of the engines are DI fueled, and only one model is turbocharged. The power-to-weight ratios of Lister-Petter engines are typical for industrial diesel engines in this size range. The engines used in the current TQGs and the 4-cylinder turbocharged engine are included in the database.

\section{Lombardini}

Lombardini F.I.M. S.p.A. (Italy) markets over 30 models of water- and air-cooled industrial diesel engines with continuous ratings up to about $60 \mathrm{hp}$. At least one of these engines is used in European "mini cars" (also called city cars), which are very small and low-speed cars that weigh less than $700 \mathrm{lb}$. A subset of these engines is sold in the United States by Lombardini USA, Inc., (Duluth GA) as industrial engines. Selected engines with favorable power-to-weight ratio are given in the database. Generally the lighter weight engines are water cooled with IDI fueling.

Mark IV Industries, Inc., which is an automotive components manufacturer, has recently acquired Lombardini to help Mark IV's position in the mini-car business. It has been publicly announced that Lombardini will upgrade its engines to common-rail type injection. The attractiveness in terms of weight and fuel economy of the engine line may improve in the next few years. 


\section{Mitsubishi}

Mitsubishi Engine North America, Inc. (Addison, IL) markets in-line 2-, 3-, 4-, and 6-cylinder water-cooled DI diesel engines that cover the entire power range of interest. The power-toweight ratio of these engines appears to be typical for industrial diesel engines.

\section{MWM}

MWM Motores Diesel Ltda. (Sao Paulo, Brazil) engines are sold by Wis-con. Please see the Wis-con description.

\section{Nissan}

Nissan currently only markets gasoline and gaseous-fueled engines in the United States Outside of the United States, Nissan markets a few models of in-line 4- and 6-cylinder water-cooled $\mathrm{DI}$ diesel engines in the power range of interest. The power-to-weight ratio of these engines appears to be typical for industrial diesel engines.

\section{Perkins}

Perkins Group Ltd. is owned by Caterpillar and produces several engine families in the power range of interest; the 100 Series, 700 Series, 900 Series, and 1000 Series. Although detailed information was not obtained from Perkins, the power-to-weight ratio and other specifications are similar to those engines currently used for the TQGs.

\section{Peugeot Citroen}

Peugeot Citroen Moteurs is the largest producer of passenger car diesel engines and has recently begun marketing common-rail diesel engines. New engine models are being introduced in Europe in 1999, and a second line of smaller displacement models (1.2-1.4 L) will be marketed in 2000 or 2001 . Some engine development is being performed in partnership with Ford.

Peugeot Citroen Engines (Little Falls, NJ) markets selected Peugeot Citroen Moteurs automotive diesel engines to U.S. companies that service and repair their own engines. No service support system is offered at this time for these engines. Currently one common-rail DI engine is offered as an industrial engines, and other models will likely become available in the near future. Cooled turbocharging is also offered. Selected engines are included in the engine database.

Robin (Fuji Heavy Industries Ltd.)

Robin engines are single-cylinder, DI, air-cooled diesels with peak power ratings up to $8.5 \mathrm{hp}$. They are unlikely to be useful for the $5-$ to $60-\mathrm{kW}$ gen-set range but could be considered for smaller gen-sets.

\section{Ruggerini}

Ruggerini Motori S.p.A. engines are marketed by Deutz. See description under the Deutz summary.

\section{Volkswagen Industrial Engines}

Volkswagen markets the highest power-to-weight engines in the United States for the power range of interest. Currently, these are the only true light-duty automotive engines sold as industrial engines. The current product line consists of variants of a 4- and a 5-cylinder engine. Turbocharging both with or without intercooling is an option. These engines are used in a variety of industrial applications, including gen-sets, and are used for several U.S. military applications. 
A 3-cylinder engine is scheduled to be added to the industrial engine line in the near future. Data on these engines are given in the database.

\section{VM Motori \\ VMM is owned by Detroit Diesel Corp.; please see the Detroit Diesel entry.}

\section{Wis-con}

Wis-con Total Power Corp (Memphis, TN) markets engines in the 20- to 215-hp range. Most of the engines are relatively heavy engines, but Wis-con markets MWM Motores Diesel Ltda. (Sao Paulo, Brazil) industrial diesel engines that have more attractive power-to-weight ratios (Continental 4.10 series and 6.10 series). If the MWM automotive diesel engines (known as the Sprint series or 4.07 series) were to be certified and marketed in the United States, they could be quite attractive. At this time they are not marketed in the United States, but selected Sprint engines are included in the database.

\section{Yanmar}

Yanmar Diesel America Corp. markets over 40 diesel engine models. Engines include 1-cylinder air-cooled diesels rated up to $10 \mathrm{hp}$ and 1- to 4-cylinder water cooled engines from about 13- to 113-hp maximum continuous rating. Two of the more interesting turbocharged engines show fairly high power-to-weight ratios for industrial engines not built as automotive engines. Also Yanmar is now marketing a 20-hp maximum output, aluminum head and crankcase, 2-cylinder, V-configuration, vertical shaft engine that is very unusual and very low weight for such an engine. These three interesting engines are included in the database.

\subsubsection{Derating of Prime Movers}

Engine power derating is a major design issue for military gen-sets. It is estimated that the engines used for the TQGs have been derated by a minimum of about $30 \%$. The major derating factors are engine power drop due to altitude and higher air temperatures, both of which affect air density and, in turn, the amount of air that will fill the combustion chamber each intake stroke. There is also derating due to the manufacturing variability in the engines, and some derating could occur because of very high humidity.

General derating factors from a number of diesel engine manufactures were considered and were found to be fairly consistent for naturally aspirated engines. Derating factors varied, but they were roughly quantified as a 3-5\% power loss per $1000 \mathrm{ft}$ above a standard altitude (usually sea level, but 325 and $800 \mathrm{ft}$ are also used) and 2.0 to $2.2 \%$ every $9^{\circ} \mathrm{F}$ above a standard temperature that is often $77^{\circ} \mathrm{F}$ (several use $68^{\circ} \mathrm{F}$ as the standard, one manufacturer used $88^{\circ} \mathrm{F}$ ). Derating for high humidity is seldom mentioned; but values of $6-10 \%$ for maximum derating are quoted by one engine manufacturer, Lister-Petter, and one gen-set manufacturer, Hawkpower Gen-sets. Derating charts supplied by Lombardini USA show $90 \%$ humidity can add up to $10 \%$ derating as temperatures approach 100 to $120^{\circ} \mathrm{F}$. These conditions, however, are very rare.

Use of a turbocharger reduces the amount of derating for altitude and temperature. A general rule of thumb for derating turbo diesels is not really possible because turbocharging technology and turbo-engine matching varies significantly. Turbocharging can also be with or without charge cooling, a wastegate, or variable inlet geometry. In general, turbocharging with charge cooling will limit derating due to altitude and temperature to about one-half or less of that required for naturally aspirated engines. Turbocharging with charge cooling may lower the necessary derating even further. 
A derating point of interest for TQG military gen-sets is $4000 \mathrm{ft}$ and $120^{\circ} \mathrm{F}$. Derating associated with this operating point is roughly $10 \%$ for a turbocharged intercooled industrial diesel engine and $23-30 \%$ for natural aspiration. The current derating specification used appears reasonable, but it should be recognized that the engine (and probably the gen-set) is capable of significantly more power output at lower temperatures and altitudes than is implied by the gen-set rating.

\subsubsection{Observed Trends}

A number of important trends can be seen from the survey results, and some are summarized in the following list:

1. Smaller engines_-engines less than about $35 \mathrm{hp}$-are generally less sophisticated and have lower power-to-weight ratios. One exception is use of aluminum alloy for the crankcase in a few smaller engines, which stand out in terms of power-to-weight among the small diesels.

2. Power density improves significantly by addition of turbocharging and more so for turbocharging with charge cooling (intercooling). Turbocharging is not available for engines with peak power ratings below $35 \mathrm{hp}$ (or below about $20 \mathrm{hp}$ at $1800 \mathrm{rpm}$ ). Turbochargers are offered for almost all diesels with ratings above about $60 \mathrm{hp}$ or displacements over $2.5-\mathrm{L}$.

3. Use of aluminum alloy heads is standard for many engines to lower weight modestly, but use of aluminum for the engine crankcase is only emerging.

4. The trend for industrial diesel fuel injection is for DI systems to replace IDI. Reported fuel economy is seen to be significantly better for DI when compared to IDI (as expected). Sophisticated high-pressure and electronically controlled fuel injection has many desirable effects on performance, but it is currently reserved for selected automotive diesel engines.

5. The most attractive engines, based on power-to-weight ratio, are the newer DI, turbocharged and charge-cooled, automotive diesel engines. These engines are in the power range above $35 \mathrm{hp}$ at $1800 \mathrm{rpm}$ or $60 \mathrm{hp}$ at rated conditions (usually $4000 \mathrm{rpm}$ or higher). Power-to-weight ratios of these automotive diesels appear to be roughly double that of standard turbocharged industrial diesel engines in the same power range, including those used for the 30- and 60-kW TQGs.

6. The highly appealing automotive-designed diesel engines have very limited availability, and this may continue for several years to come. It is reasonable to think that automotive diesels in power ratings from about 35-120 hp at $1800 \mathrm{rpm}$ and larger could be available in 35 years. This size range can also be roughly bounded by 1.2- to $4.0-\mathrm{L}$ displacement or 60 to 220 -hp maximum power rating.

7. High-pressure electronically controlled fuel injection using either a unit injection type system or a common-rail system increases engine appeal, particularly by significantly improving lower-speed power and torque, improving fuel economy, and possibly lowering higher-speed noise.

8. More sophisticated (higher pressure and electronic control) fueling systems are being employed on an increasing number of industrial diesel engines. This may "close the gap" slightly for the large power-to-weight ratio difference between most industrial diesel engines and the automotive-design diesels. Other performance measures, such as noise and emissions will improve incrementally as well. 


\subsection{REFERENCES}

1. Personal communication with S. Huter, Patrick Power Products, Inc., and G. Brooks, Wankel Rotary $\mathrm{GmbH}$.

2. G. Morrison, "Stirling Renewal," Mechanical Engineering, 121(5), 62-65, American Society of Mechanical Engineers, New York, May 1999.

3. Mechanical Technology Incorporated, Free-Piston Stirling Engine Heat-Activated Heat Pump: Phase Ilc Final Report, MTI90TR25, September 1990.

4. Federal Code of Regulations, 40 CFR Part 89, "Control of Emissions from New and In-use Nonroad Compression Ignition Engines."

5. Certification Guidance for Engines Regulated Under 40 CFR Part 86 On-Highway Heavy Duty Engines and 40 CFR Part 89 Nonroad Cl Engines, U.S. EPA, EPA 420-98-002, March 1999. 


\section{Appendix 2-A. DIESEL ENGINE GLOSSARY}

1. CO: Carbon monoxide is an EPA-regulated exhaust emission.

2. Common rail: Common-rail fuel injection technology utilizes a common rail or manifold containing high-pressure diesel fuel, which distributes the fuel to the injector for each cylinder via high-pressure delivery tubes. Electronic control is generally used to control injection timing and duration, fuel pressure during injection, rate of injection and may even allow multiple injections during a single power stroke. The high fuel pressures are produced by an engine-driven pump, which feeds the common fuel rail (manifold). Fuel pressures up to about 23,000 psi have been reported.

3. Continuous power rating: The net engine shaft power available to power a device (particularly a gen-set) under a constant speed operation scenario, and while retaining at least $10 \%$ power (or torque) in reserve to meet an intermittent load increase. Generally, a standard test is used to arrive at a power curve for continuous ratings (SAE J1349, ISO3046/a-ICXN).

4. DI, direct injection: Fuel is injected into the cylinder combustion chamber directly above the piston. Generally, the piston has a specially shaped "bowl" to form an optimized combustion chamber with favorable fluid flow. Greater demands are put on the injector system, which operates at relatively high pressure to form a very fine and properly distributed fuel spray. Engine fuel economy is superior to that achieved by IDI.

5. EGR, exhaust gas recirculation: In certain engines, exhaust gas is recirculated back to the air intake. The exhaust gas acts as a diluent, which slightly reduces oxygen concentration in the combustion zone and (more importantly) lowers peak combustion temperatures. Both effects can reduce formation of $\mathrm{NO}_{\mathrm{x}}$. Sometimes the EGR loop is also cooled to further lower peak combustion temperatures.

6. Heat release rate: As diesel fuel is sprayed into the combustion zone and is subsequently burned, chemical energy is changed to thermal energy (heat). This "release" of heat is the major cause of gas pressure rise in the cylinder, and this pressure is responsible for doing work by pushing the piston during the power-stroke. The instantaneous heat release rate is expressed in units of energy per time such as $\mathrm{J} / \mathrm{s}$. The heat release profile-which is the heat release rate as a function of time or crank angle position (and piston position) is very important to the operation of the engine. Good control over heat release rate can optimize or at least control engine power, torque, fuel economy, noise and emissions. Also see rate shaping.

7. IDI, indirect injection: Sometimes known as a prechamber system, diesel fuel is injected into an auxiliary bulb-shaped chamber that is connected to the main cylinder by a smallbore passage. Generally, a relatively low-pressure fuel injector is used (throttling-pintle nozzle type) to spray fuel into this prechamber. This system has been used historically to obtain "soft" combustion and reduce emissions. Lower levels of noise, engine stress-loads and particulate matter emission are all cited as advantages of this system along with low cost. Flow losses through the small-bore passage during compression and expansion and the larger heat transfer surface due to the prechamber lead to lower efficiency compared to direct injection systems. 
8. $\mathrm{NO}_{\mathbf{x}}$ : Oxides of nitrogen, usually including $\mathrm{NO}_{2}$ and $\mathrm{NO} . \mathrm{NO}_{\mathbf{x}}$ is an EPA regulated exhaust emission.

9. Particulate matter is a regulated exhaust emission for virtually all diesel engines-both road and off-road.

10. Rate shaping: This refers to precisely controlling the timing and rate of fuel being injected to control the diesel combustion process. Rate shaping can tailor the pressure and pressure rise rate during the power stroke to obtain the desired characteristics (and tradeoffs) which usually are low noise, optimized fuel economy, low emissions, and increased power and torque. Also, see heat release rate.

11. Turbocharger: The (exhaust) turbocharger is a turbine-compressor device, which pressurizes the intake air of an engine to increase the charge density. Increasing charge density allows more air to be inducted into the cylinder, which greatly increases the power and torque output capabilities of the engine. The exhaust turbocharger uses the engine exhaust as the compressor power source. Instead of simply discharging the exhaust, it is used to drive a small turbine, which is on a common shaft with the intake air turbocompressor.

12. Turbocharger intercooling: Because an exhaust turbocharger compresses the intake air, the air increases in density. In some cases, intercooling (cooling between the turbocompressor and the intake to the cylinder) or aftercooling (cooling after the compression step) is employed. Intercooling usually is done by routing the compressed air through a compact heat exchanger that is cooled by ambient air (which is blown by a fan for stationary engines). An alternative method is to use the liquid engine coolant (virtually always an ethylene-glycol water mixture or similar mixture).

There are at least two positive effects of intercooling. The power and torque rating can be higher for an engine due to the effect of higher air charge density compared to not intercooling. Also, the cooled air will keep peak combustion temperature somewhat lower, which reduces the formation of $\mathrm{NO}_{x}\left(\mathrm{NO}_{2}\right.$ and $\left.\mathrm{NO}\right)$ which is a regulated exhaust emission. Turbocharging can have a beneficial effect on fuel economy, but this is application and engine specific.

13. Turbocharger wastegate: A turbocharger must sometimes be limited in how much compressive work is done. This limitation may be due to the need to protect the engine or other devices, meet emission standards, or other concerns. A wastegate is essentially a pressure relief device that allow some exhaust to bypass the exhaust turbine (which powers the turbo-compressor) when a certain pressure is reached. The bypass exhaust is simply "dumped" to the exhaust system.

Using a wastegate can be useful if it is desired to use a turbocharger that compresses the air charge to relatively high pressures at lower speeds and loads. This boosts the lowerspeed performance of the engine. The wastegate will control the intake compression to within specified limits at high engine power output.

14. Unit injector: A unit injector is a type of combined injection nozzle and fuel pump used for high-pressure direct fuel injection. The unit injector is screwed into position through the engine cylinder head and is driven by the engine camshaft. Details vary with different unit 
injector designs, but a cam is used to put force on a plunger device, which creates the very high fuel pressures. Peak pressures of 20,000 to 35,000 psi are reported and allow very fine fuel sprays to be formed. No high-pressure fuel lines are needed for this type of system because the high pressure is created in the injector itself. The injection timing and amount are controlled by a high-speed solenoid valve, which in turn is normally controlled by a computer-chip based electronic control unit. Relatively sophisticated fuel injection control is possible using engine-map based control with input from the various engine and fuel sensors (such as fuel temperature), and rate shaping may be possible. The cost of unit injector systems can be relatively high.

15. Variable geometry turbocharger: Some turbochargers have movable intake guide vanes that can change air intake geometry to optimize response and efficiency. This ability is generally only employed on "high-end" diesel vehicles and may not be of much interest for gen-sets.

\section{REFERENCES}

Diesel Fuel Injection, 1st Edition, Robert Bosch $\mathrm{GmbH}$, distributed by SAE Society of Automotive Engineers, 1994.

Automotive Handbook, 3rd Edition, Robert Bosch GmbH, distributed by SAE Society of Automotive Engineers, 1993.

Mike Brezonick, "Lucas Varity New Common Rail System," pp. 30, 32 in Diesel Progress, North American Edition Diesel and \& Gas Turbine Publications, Brookfield, WI, October 1998. 
2-24 


\section{MARKET SURVEY FOR STATE-OF-THE-ART ALTERNATORS/POWER ELECTRONICS}

The purpose of this chapter is to present the results of the market surveys in the alternator (generator) and power electronics areas. The chapter includes a brief description of the technologies available on the market and results of the survey. The input from CECOM surveying the alternator and power electronics markets is included in Appendixes 3-A and 3-B, respectively.

\subsection{ALTERNATOR (GENERATOR) SURVEY}

The prime mover of the gen-set is directly coupled to an electric machine that acts as an alternating current (ac) generator. Possibilities for this alternator include an ac induction motor, a permanent magnet (PM) brushless motor, and a switched reluctance (SR) brushless motor.

Induction motors are by far the cheapest of the three because they are currently being produced in vast quantities (millions), annually. Tables 3.1 and 3.2 show a comparison of the three motor types using a standard 5-hp induction motor frame as the base case. The two other motors (SR and $\mathrm{PM}$ ) then assume construction of these motors using the same physical frame in terms of stator outside diameter (OD) and stack length. A PM generator using high-flux rare earth permanent magnets has a specific power approximately three times that of the induction motor and $33 \%$ higher than the SR generator.

\subsubsection{Induction Generator}

Induction machines are the most common and least expensive electrical machines being manufactured today. These are available in a variety of sizes from a multitude of manufacturing sources. However, these machines have the lowest specific power rating and lowest efficiency

Table 3.1. Comparison of material weights in alternator types

\begin{tabular}{|l|c|c|c|c|c|c|}
\hline \multicolumn{1}{|c|}{$\begin{array}{c}\text { Motor } \\
\text { type }\end{array}$} & $\begin{array}{c}\text { Stator } \\
\text { OD } \\
\text { (in.) }\end{array}$ & $\begin{array}{c}\text { Stack } \\
\text { length } \\
\text { (in.) }\end{array}$ & $\begin{array}{c}\text { Iron } \\
\text { weight } \\
\text { (lb) }\end{array}$ & $\begin{array}{c}\text { Copper } \\
\text { weight } \\
(\mathrm{lb})\end{array}$ & $\begin{array}{c}\text { PM or } \\
\text { aluminum } \\
\text { weight } \\
\text { (lb) }\end{array}$ & $\begin{array}{c}\text { Total } \\
\text { weight } \\
(\mathrm{lb})\end{array}$ \\
\hline ac induction & 7.6 & 5.0 & 33 & 15.4 & $2.8(\mathrm{Al})$ & 51.4 \\
\hline PM brushless & 7.6 & 5.0 & 40 & 12 & $2.2(\mathrm{PM})$ & 54.2 \\
\hline SR brushless & 7.6 & 5.0 & 34.8 & 10.5 & 0.0 & 45.3 \\
\hline
\end{tabular}

Table 3.2. Alternator power and efficiency comparisons

\begin{tabular}{|l|c|c|c|c|c|}
\hline $\begin{array}{c}\text { Motor } \\
\text { type }\end{array}$ & $\begin{array}{c}\text { Maximum } \\
\text { torque } \\
(\mathrm{N}-\mathrm{m})\end{array}$ & $\begin{array}{c}\text { Output } \\
\text { power } \\
(\mathrm{kW})\end{array}$ & $\begin{array}{c}\text { Specific } \\
\text { torque } \\
(\mathrm{N}-\mathrm{m} / \mathrm{kg})\end{array}$ & $\begin{array}{c}\text { Specific } \\
\text { power } \\
(\mathrm{kW} / \mathrm{kg})\end{array}$ & $\begin{array}{c}\text { Maximum } \\
\text { efficiency } \\
(\%)\end{array}$ \\
\hline ac induction & 19.8 & 3.73 & 0.85 & 0.16 & 90 \\
\hline PM brushless & 57.7 & 10.82 & 2.35 & 0.44 & 94 \\
\hline SR brushless & 36.6 & 6.71 & 1.78 & 0.33 & 92 \\
\hline
\end{tabular}


of the three machines being considered for use as the electric alternator in the gen-set. Reduction of weight or volume from the current design of the gen-sets is not likely if these machines are used. Three-phase full-bridge active rectifiers can be used with the machines, and "sensorless" control methods are available such that use of a speed encoder may not be necessary.

\subsubsection{SR Generator}

The SR generator is perhaps the most robust of the machines, and it can have four, six, or eight phases. Loss of one of the phases still allows the generator to function but at a reduced power and voltage level (fault tolerant operation). However, the multiple phases of the SR generator will require a nonconventional power electronics circuit because a three-phase full-bridge rectifier can no longer be used. SR motors also usually require position sensors (encoders) so that exact position of the rotor with respect to the stator can be known at all times. SR machines are produced in mass quantities for consumer appliances like washers and dryers, but these are generally fractional horsepower in size.

\subsubsection{PM Brushless Generator}

When built with high flux rare-earth PMs, these generators have the highest specific power rating of the three machines and also the highest efficiency. PM motors are mass-produced as servo motors with low-cost and low-flux ceramic magnets. Three-phase full bridge active rectifiers can be used with these machines with only a minor change in the control of the active devices. PM motors can be controlled with "sensorless" control, which means that only voltage and current measurements, which are usually measured anyway, can be used for control of the generator output. The largest costs in a PM generator are the rare earth magnets used in the rotor of the generator. However, if automobile manufacturers standardize on PM motors for their traction motor, the cost of these materials would quickly come down in price because of the mass production required.

PM generators can be built as either axial gap or radial gap machines. Axial gap machines generally take the form of a "pancake" design with a rotor that contains the PMs sandwiched between two stators that contain coils of wire, which would produce voltage and currents when the rotor is mechanically driven by a prime mover such as a diesel engine. The radial gap machine has magnets positioned around the circumference of a cylinder. Sometimes the cylinder is long and has a small diameter (rod-shaped), and sometimes the cylinder is short and has a large diameter. Magnet retention is usually easier with the axial gap design; however, lowpower radial gap PM motors can be designed to run at much higher speeds $(100,000 \mathrm{rpm})$ than axial gap motors.

Unique Mobility, Inc., sells PM machines and inverters to control them. The prices for these systems are high when you just buy one $(\$ 12,000$ to $\$ 25,000$ each). However, Unique Mobility has indicated that if 10,000 were purchased, the price for a complete generator and inverter system would be in the range of $\$ 800-\$ 1200$ each for sizes in the 30 - to $75-\mathrm{kW}$ range. This mass production price compares favorably with what DOD could afford on a diesel gen-set.

\subsubsection{Alternator Market Survey Summary}

In addition to the six companies-Baylor, Caterpillar, Leroy-Somer, MagneTek, Marathon, and Newage Ltd.- recommended by CECOM from its comprehensive market survey of alternator manufacturers (Appendix 3-A), the very compact PM machines with high power density built by Unique Mobility or Kaman Electromagnetics should also be evaluated. The greatest uncertainty with their machines would be if mass production of these machines would lower their price 
enough so that they could be incorporated into inexpensive but reliable future gen-set units. Projections by Unique Mobility have indicated that its PM motor and inverter systems would be price competitive when produced in large volumes. Should these PM machines be too expensive once a final design and/or prototype has been established, even when produced at higher volumes, more conventional generators could be used as a backup plan.

\section{PM Generator (Alternator) Contact Information:}

- Unique Mobility

425 Corporate Circle

Golden, CO 80401

Phone: (303) 278-2002

FAX: (303) 278-7007

www.uqm.com
- Kaman Electromagnetics

1332 Blue Hills Avenue

Bloomfield, CT 06002

Phone: (860) 243-7100

www.kaman.com

\subsection{POWER ELECTRONICS SURVEY}

Power electronics process and control the flow of electric energy by supplying voltages and/or currents in a form that best matches what is needed for user loads. In a gen-set, the power electronics change the power generated by the alternator into processed output power that has the voltage, current, frequency, and number of phases as required by the load.

If the gen-sets are to operate in a mode where the internal combustion (IC) engine runs at variable speed, an active three-phase bridge rectifier will be needed to convert the variable voltage, variable frequency power produced by the IC-driven generator to a controlled direct current (dc) link voltage. A three-phase full-bridge inverter is then required to convert the dc link voltage to a selectable voltage (120/208 V or $240 / 416 \mathrm{~V})$ and selectable frequency $(50,60$, or $400 \mathrm{~Hz})$.

\subsubsection{Intelligent Power Modules}

Three-phase bridge inverters are currently available in a single module, "six-pack," or as one phase of a three-phase inverter in a single module called a "dual." Some manufacturers also offer "intelligent power modules" (IPMs), which are three-phase full-bridge inverters using insulated gate bipolar transistors (IGBTs) as active switches and additionally integrate some or all of the following in a single module: gate driver circuitry, overtemperature protection, overcurrent protection, and overvoltage protection. Integration of these driver and protective functions into the module helps the power electronics designer concentrate more on application of these devices instead of having to custom design all of these functions. The user can connect digital TTL or CMOS integrated circuits directly to the IPM. IPMs also offer higher reliability because the single module contains fewer components and connections where a failure might occur. Troubleshooting and repairs would also be quicker with the IPM because a single module could be replaced instead of trying to track down the problem on one of several modules.

The maximum line-line voltage that the $15-$ to $60-\mathrm{kW}$ TQGs have to provide is $416 \mathrm{~V}$ ac. This corresponds to a dc link voltage of at least $590 \mathrm{~V}$ dc. Therefore, it will be necessary to use $1200-\mathrm{V}$ (or higher) IGBT modules for the active rectifier and inverter for units that produce $416 \mathrm{~V}$ ac. Table 3.3 is a list of the maximum continuous current ratings required for various existing TQGs based on providing current at a power factor of 0.8 .

IGBTs that have a current rating of $150 \mathrm{~A}$ likely will be sufficient for gen-set units $30 \mathrm{~kW}$ and smaller. A $60-\mathrm{kW}$ gen-set would require an IGBT rating of $300 \mathrm{~A}$. By using 1200-V, 150-A sixpack IPMs for all of the new gen-sets for sizes $30 \mathrm{~kW}$ and smaller, the power electronics and 
Table 3.3. Current requirements for existing TQG sets

\begin{tabular}{|c|c|}
\hline $\begin{array}{c}\text { Generator size } \\
(\mathrm{kW})\end{array}$ & $\begin{array}{c}\text { Maximum continuous rated } \\
\text { current }(\mathrm{A})\end{array}$ \\
\hline 5 & $52.1 @ 120 \mathrm{~V} 1 \phi$ \\
\hline 10 & $104.2 @ 120 \vee 1 \phi$ \\
\hline 15 & $52.0 @ 120 / 208 \vee 3 \phi$ \\
\hline 30 & $104.1 @ 120 / 208 \vee 3 \phi$ \\
\hline 60 & $208.2 @ 120 / 208 \vee 3 \phi$ \\
\hline
\end{tabular}

control circuitry between the different units would be a common module that would be interchangeable between the various units.

Table 3.4 is a list of companies that make 1200-V IGBT modules of sufficient current rating for use in gen-sets in the 5- to $60-\mathrm{kW}$ range, the features offered in their IPMs, and their maximum available continuous current ratings.

The continuous current ratings in Table 3.4 are for a junction temperature of $25^{\circ} \mathrm{C}$. For temperatures above $25^{\circ} \mathrm{C}$, these currents are derated according to manufacturer-provided curves, which are not linear. The modules are generally rated to conduct 65 to $75 \%$ of their rated current at a junction temperature of $100^{\circ} \mathrm{C}$. Generally, IGBT modules have a short time (1-ms) current rating equal to twice their continuous current rating.

From Table 3.4, both 1200-V, 150-A six-packs and 1200-V, 300-A duals are currently available. It is expected in the next 2-3 years that the available current ratings for both of these devices will increase by a factor of 2 . However, note that the $1200-\mathrm{V}, 150-\mathrm{A}$ six-packs already have the current and voltage rating required for gen-set units $30 \mathrm{~kW}$ and smaller.

Table 3.5 shows the storage and operating temperatures and the control and power supply voltages for existing IMPs. The minimum operating temperature for most of the modules is

Table 3.4. Available features from manufacturers of 1200-V IGBT modules

\begin{tabular}{|l|l|l|l|l|l|l|l|l|}
\hline Company & Package & $\begin{array}{c}\text { Maximum } \\
\text { current }\end{array}$ & $\begin{array}{c}\text { Sensors } \\
\text { available }\end{array}$ & $\begin{array}{c}\text { Integrate } \\
\text { isolated } \\
\text { driver }\end{array}$ & $\begin{array}{c}\text { Over- } \\
\text { temperature }\end{array}$ & $\begin{array}{c}\text { Over- } \\
\text { current }\end{array}$ & $\begin{array}{c}\text { dc Link } \\
\text { over- } \\
\text { voltage }\end{array}$ & $\begin{array}{c}\text { Control } \\
\text { power } \\
\text { under- } \\
\text { voltage }\end{array}$ \\
\hline Powerex & Dual & 300 & No & Yes & Yes & Yes & No & Yes \\
6-pack & 150 & no & Yes & Yes & Yes & no & yes \\
\hline IXYS & Dual & 330 & No & Yes & No & Yes & No & Yes \\
\hline Fuji & 6-pack & 150 & Yes & Yes & Yes & Yes & No & Yes \\
\hline Semikron & Dual & 400 & Yes & Yes & Yes & Yes & Yes & Yes \\
& 6-pack & 300 & Yes & Yes & Yes & Yes & Yes & Yes \\
\hline Toshiba & Dual & 300 & No & Yes & Yes & Yes & No & Yes \\
& 6-pack & 150 & No & Yes & Yes & Yes & No & Yes \\
\hline Hitachi & Dual & 300 & No & No & No & No & No & No \\
& 6-pack & 100 & No & No & No & No & No & No \\
\hline
\end{tabular}


Table 3.5. Temperature and voltage requirements for manufacturer's IPMs

\begin{tabular}{|l|c|c|c|c|c|c|}
\hline Company & Package & $\begin{array}{c}\text { Storage } \\
\text { temperature } \\
\left({ }^{\circ} \mathrm{C}\right)\end{array}$ & $\begin{array}{c}\text { Operating } \\
\text { temperature } \\
\left({ }^{\circ} \mathrm{C}\right)\end{array}$ & $\begin{array}{c}\text { Control } \\
\text { voltage } \\
(\mathrm{V})\end{array}$ & $\begin{array}{c}\text { Power } \\
\text { supply } \\
\text { voltage } \\
(\mathrm{V})\end{array}$ & $\begin{array}{c}\text { Meets current } \\
\text { requirements }\end{array}$ \\
\hline Powerex & IPM & $-40 \sim 125$ & $-20 \sim 100$ & 10 & 20 & Now \\
\hline IXYS & IPM & $-40 \sim 125$ & $-40 \sim 110$ & 15 & 15 & Now \\
\hline Fuji & IPM & $-40 \sim 125$ & $-20 \sim 100$ & 15 & 15 & Now \\
\hline Semikron & IPM & $-40 \sim 125$ & $-25 \sim 85$ & 20 & 20 & Now \\
\hline Toshiba & IPM & $-40 \sim 125$ & $-20 \sim 100$ & 20 & 20 & Now \\
\hline Omnirel & IPM & & $-55 \sim 120$ & & & Soon \\
\hline
\end{tabular}

$-20^{\circ} \mathrm{C}$. This is not sufficient for the requirement of operation at an ambient temperature of $-50^{\circ} \mathrm{C}$. One company that does package power electronic inverters for harsh environments is Omnirel. Its proprietary packaging of power modules is fully hermetic ceramic-to-metal seal modules that are rated for operation from -55 to $150^{\circ} \mathrm{C}$. These are currently available in up to $1200-\mathrm{V}, 200-\mathrm{A}$ modules. They are currently available as IPMs only in low current ratings of up to $30 \mathrm{~A}$, but higher current rated packages are expected to be available later this year.

\subsubsection{Future Technology Directions}

Soft-Switching Inverters

Soft-switching inverters are a class of inverters in which the main active devices switch at either zero voltage or zero current such that their switching loss is nearly zero. Benefits of this approach are improved output voltage waveform quality (less high-frequency ripple), lower electromagnetic interference (EMI) in the output waveform, and higher efficiency than hardswitching inverters. Soft-switching inverters, however, require additional passive components (capacitors, inductors) to set up a resonant tank and normally also require additional switches. This makes these circuits more complex with components that can fail. No soft-switching inverters are currently being mass-produced as variable-speed drives; however, a few small companies currently manufacture made-to-order soft-switching inverters. One new softswitching topology is the auxiliary resonant tank (ART) inverter. It is a modular topology in which the soft-switching part of the circuit could be an add-on module. This allows retrofit of existing hard-switched inverters, or in the case of a failure in the soft-switching circuitry, the converter can continue to operate in a hard-switched mode. The ART circuit is shown in Fig. 3.1.

Efficiency gains by using soft-switching inverters depend on the load factor (percentage of full load rating). At high load factors from 0.7 to 1.0 , the gain is usually 1 or 2 percentage points. At lower load factors, the gain can be between 3 to 5 percentage points because the switching losses dominate the losses in the inverter and soft switching almost eliminates these losses.

Soft-switching inverters, which do not require additional auxiliary switches to set up a resonant circuit and only require additional passive components, are also currently being investigated.

\section{Automotive Integrated Power Module}

Through its Partnership for a New Generation of Vehicles (PNGV) Program, DOE has spurred research for a hybrid-electric vehicle (HEV) and advances in power electronics and electric machinery. The main goals of the power electronics and motor program are to reduce volume, weight, and cost of the modules that would power electric vehicles. Significant leveraging of 


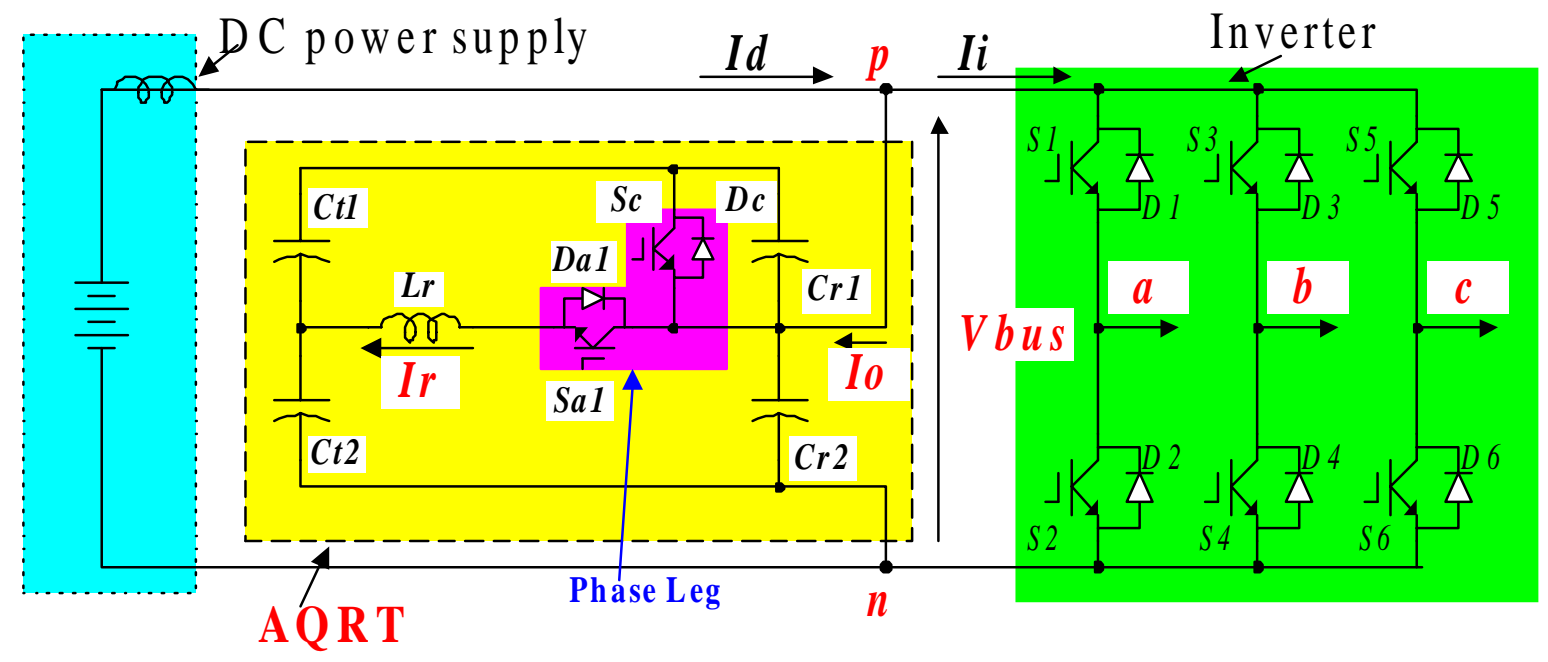

Fig. 3.1. Two-switch version of the ART soft-switching inverter.

technology developed as part of this program should be considered for the next generation of gen-set units.

The PNGV Program has just initiated a 3-year initiative funded at $\$ 20 \mathrm{M}$ for the development of a reliable, commercially viable automotive integrated power module (AIPM) for advanced HEVs. Much of the knowledge gained in developing an AIPM prototype for a HEV could also be directly applied to a gen-set. The two companies that likely will be working on this project are Satcon and Silicon Power Corporation (SPCO). A third company may also be awarded a portion of this contract. The companies have been tasked with developing a family of inverters for HEVs that standardizes and/or integrates several discrete components into one modular enclosure. The objectives of this project are as follows:

1. Develop a single integrated motor inverter package.

2. Combine the functions of commonly used power electronics into an integrated power block.

3. Improve automotive energy efficiency and component costs.

4. Achieve cost reduction through interchangeability and interoperability among several power level modules.

The single integrated package will contain as a minimum the following:

1. a power conversion stage from dc to three-phase ac at variable voltage and variable frequency;

2. heat sink;

3. gate drivers for power switches;

4. temperature sensor and protection;

5. laminated busbar with integrated passives for snubbing, filtering/EMI reduction, and resonant tank for soft switching; and

6. serial communication capability.

It is also desired (but not required in the contract) to integrate the following into the same package: 
1. power supply,

2. voltage and current sensors, and

3. DSP control system.

Hardware prototypes developed by the companies will be tested at ORNL. The family of inverters will be designed to operate at $450 \mathrm{~V}$ maximum and will be in current levels from 100 to $600 \mathrm{~A}$ in $100-\mathrm{A}$ steps. The required efficiency is greater than $90 \%$ from $5 \%$ to $100 \%$ of rated power. They will be required to operate for $6500 \mathrm{~h}$ at an ambient temperature from -40 to $65^{\circ} \mathrm{C}$ and be rated for storage at -50 to $125^{\circ} \mathrm{C}$. They should be capable of driving an ac induction motor or a PM brushless motor. A stringent set of test requirements for the prototype AIPM modules is currently being developed and will include the following tests:

1. Electrical testing

a. efficiency

b. input current ripple

c. output current ripple

d. output voltage ripple

e. input (I)/output $(\mathrm{O})$ isolation impedance

2. Noise-audible

3. ECM/EMI

4. Temperature/humidity

5. Altitude

6. Splash

7. Salt spray

8. Dust and sand

9. Vibration

10. Shock

11. Drop test

a. bench

b. transit

12. Life testing

The electrical testing will be repeated after this battery of tests to ensure that no degradation of the components has occurred. Many of the same tests conducted as a part of this program would be relevant to the power electronics for a military gen-set as well.

\subsubsection{Power Electronics Market Survey}

CECOM contacted 48 potential manufacturers of power electronics systems with a questionnaire and cover letter explaining the need for information on power electronics systems for genset units (Appendix 3-B). From the response to the questionnaire and data furnished by the manufacturers, two companies (i.e., Spectrum Research Corp. and Avionics) were identified that had the capabilities to build power electronic systems that would meet military requirements for 5- to $60-\mathrm{kW}$ gen-sets. Details of this market survey are found in a letter dated 21 May 1999, which is a part of Appendix 3-B.

On March 15-18, the 1999 IEEE Applied Power Electronics Conference and Exhibition was held in Dallas, Texas. Approximately 90 companies had booths in the exhibit hall. Catalogs and/or contact information were collected from about 20 companies that make products which incorporate power electronics and are of interest to a gen-set manufacturer. The companies included the following: 
1. International Rectifier

2. Harris Semiconductor

3. Semikron International

4. IXYS Semiconductor

5. Powerex Intelligent Power Modules

6. Coilcraft Magnetics

7. AVX Capacitors

8. TOKO Magnetics

9. LEM Measurement Components

10. Magnetics - Cores for Transformers and Inductors

11. Philips Magnetic Products

12. Eldre Busbar

13. Fuji Semiconductor

14. Omnirel

15. Seimens

16. Aavid Thermal Products

17. Cornel Dubilier Capacitors

18. Onan Power Electronics

19. Ohmite Resistors

20. Sanrex Semiconductors

Other sources of power electronics information have come from the trade magazine $P C I M-$ Power Conversion and Intelligent Motion, where many power electronics manufacturers advertise, and from company Internet Web sites.

Power Electronics Manufacturer Contact Information:

- Aerospace Avionics 100 MacArthur Memorial Highway

Bohemia, NY 11716

Phone: (516) 467-5500

Fax: (516) 467-5939

- Fuji Electric

Park 80 West Plaza II

Saddle Brook, NJ 0766

Phone : (201) 712-0555

Fax : (201) 368-8258

www.fujielectric.co.jp/eng/sg/scd/prod.html

- Hitachi America, Ltd.

Power and Industrial Division

660 White Plains Road

Tarrytown, NY 10591

Tel: (914) 631-0600

Fax: (914) 631-3672

www.hitachi.com
- Powerex, Inc. 200 Hills Street

Youngwood, PA 15697-1800

Phone: (724) 925-7272

Fax:

www.pwrx.com

- XYS Corporation

3540 Bassett Street

Santa Clara, CA 95054

Phone: (408) 982-0700

Fax: (408) 496-0670

www.ixys.com

- Omnirel

205 Crawford Street

Leominster, MA 01453

Phone: (978) 534-5776

Fax: (978) 537-4246

www.omnirel.com 
- Semikron International

P.O. Box 820251

D-90253 Nurnberg

Phone: +49 911-65 59-0

Fax: +49 911-65 59-2 62

www.semikron.com

- Spectrum Research

165 Jordan Road

Troy, NY 12180

Phone: (518) 283-7909

Fax: (518) 283-7813

www.generators.com
- Toshiba America Electronic Components

9775 Toledo Way

Irvine, CA 92618-1811

Phone: (800) 879-4963

http://www.toshiba.com/taec/nonflash/index

hpsemi.html

\subsubsection{Power Electronics Market Summary}

Five manufacturers-Fuji, Powerex, Toshiba, Semikron, and IXYS-have been identified that presently manufacture IGBT dual or six-pack IMPs with sufficient voltage and current ratings $(1200 \mathrm{~V}, 150 \mathrm{~A})$ for use as the main power electronics devices for a variable-speed gen-set. Additionally, a manufacturer (Omnirel) of special hermetic metal-to-ceramic seal packaging has been found that makes units to meet the harsh environmental specifications required of the gen-set. The individual components required for the power electronics in a variable-speed gen-set are presently being mass-produced, and two manufacturers have been identified that can integrate the components into a rugged, reliable module. These two companies also build power electronic systems that would satisfy military operational and performance requirements (Spectrum Research Corp. and Aerospace Avionics).

Although this is an emerging market area, the existing market is sufficient to provide technology desired for future gen-sets. Moreover, less expensive power electronics options will likely be available in the near future. 
3-10 


\title{
Appendix 3-A. ALTERNATOR DATA PROVIDED BY CECOM FOR MARKET SURVEY
}

\author{
COMMERCIAL QUESTIONNAIRE \\ ALTERNATORS FOR MILITARY GENERATOR SETS
}

\begin{abstract}
The subject of this questionnaire is to look at alternators that are available commercially for military generator sets in the $5 \mathrm{~kW}$ through $60 \mathrm{~kW}, 60 \mathrm{~Hz}$ range. The emphasis of this market survey is on obtaining sufficient data to identify and evaluate those state-of-theart alternators that can be applied to the next generation of Tactical Quiet Generators. Specifically, alternators that are currently available in the commercial market, and alternators soon to be available (marketed) in the next two to three years. Please answer the following questions to aid with the evaluation of your product (one questionnaire for each model and generator size). Please use continuation sheets if necessary.
\end{abstract}

1. Manufacturer and part or model number

a. Manufacturer:

b. Part or model no:

2. Design features

a. Alternator type:

b. Exciter type:

c. Alternator weight:

d. Alternator size $(\mathrm{L} \times \mathrm{W} \times \mathrm{H})$ :

e. Estimated minimum life expectancy:

f. Compliance with:

(1) NEMA: (4) CSA:

(2) IEEE: (5) NFPA:

(3) ANSI: (6) Other:

g. Electrical protection device (in the output circuit for human life safety):

h. Parallel operation:

i. Efficiency: 


\section{COMMERCIAL QUESTIONNAIRE \\ ALTERNATORS FOR MILITARY GENERATOR SETS \\ (continued)}

3. Ratings

a. Voltage connections, single- and three-phase:

(1) 120 volt:

(2) $120 / 240$ volt:

(3) 120/208 volt:

(4) Number of leads:

b. Rated speed:

c. Rated output power:

d. Power factor:

4. Mechanical features

a. Construction:

(1) Frame type/material:

(2) Drip-proof:

b. Ball bearings:

(1) Number:

(2) Type:

c. Direction of rotation:

d. Ventilation type:

e. Coupling: 


\section{COMMERCIAL QUESTIONNAIRE \\ ALTERNATORS FOR MILITARY GENERATOR SETS \\ (continued)}

\section{Operating conditions}

a. Insulation:
(1) Class F:
(2) Class H:

(3) Resistance, ambient temperature:

b. Operating altitude range:

c. Operating temperature range:

d. Humidity:

e. Overspeed:

f. Transportation and movement:

(1) Shock:

(2) Vibration:

6. Electrical features
a. Voltage regulator type:
b. Voltage regulation, no load to full load:
c. Frequency regulation, no load to full load:
d. Peak motor starting (kVA):
e. Sustained short-circuit current:
f. Radio frequency interference suppression:
g. Voltage recovery time after load application:
h. Voltage waveform deviation factor: 


\section{COMMERCIAL QUESTIONNAIRE \\ ALTERNATORS FOR MILITARY GENERATOR SETS \\ (continued)}

(1) Harmonic content:

(2) $2 / 3$ pitch windings:

i. Dielectric strength:

j. Winding resistance:

\section{Other special features/options}

a.

b.

8. Estimated cost c.

d.
Quantity

1
25
100
500
1,000

$\underline{\text { Cost (each) }}$

$\$$

$\$$

$\$$

$\$$

$\$$

9. Manufacturer Point of Contact

Name:

E-mail:
Telephone No.:

Fax: 


\section{List of Companies-Alternator Market Survey}

\begin{tabular}{|c|c|c|}
\hline Company & Address & Telephone/FAX Numbers \\
\hline Alturdyne & 8050 Armour, San Diego, CA 92111 & Tel: 619/565-2131 Fax: 619/279-4296 \\
\hline AMBAC International & $\begin{array}{l}103 \text { Myron St., West Springfield, MA } \\
01089\end{array}$ & Tel: 413/785-6600 Fax: 413/785-6664 \\
\hline Barber-Colman Company & $\begin{array}{l}1354 \text { Clifford Ave., P.O. Box 2940, Loves } \\
\text { Park, IL 61132-2940 }\end{array}$ & Tel: 815/637-3717 Fax: 815/877-0150 \\
\hline Basler Electric Company & Box 269, Rte 143, Highland, IL 62249 & Tel: 618/654-2341 Fax: 618/654-2351 \\
\hline Baylor Generator/Motor Group & $\begin{array}{l}500 \text { Industrial Rd., Sugar Land, TX 77478- } \\
2898\end{array}$ & Tel: 281/240-9444 Fax: 281/240-5074 \\
\hline C. E. Niehoff \& Company & 2021 Lee St., Evanston, IL 60202 & Tel: 847/866-1590 Fax: 847/492-1242 \\
\hline Caterpillar, Incorporated & $\begin{array}{l}\text { Galena Rd. at S.R. 29, P.O. Box 610, } \\
\text { Mossville, IL 61552-0610 }\end{array}$ & Tel: 800/447-4986 Fax: 309/578-7302 \\
\hline Cummins/Onan Corporation & $\begin{array}{l}140073^{\text {rd }} \text { Ave., N.E., Minneapolis, MN } \\
55432\end{array}$ & Tel: 612/574-5000 Fax: 612/574-8087 \\
\hline Elliott Energy Systems & 2901 S.E. Monroe St., Stuart, FL 34997 & Tel: 561/219-9449 Fax: 561/219-9448 \\
\hline Fisher Electric Technology & $\begin{array}{l}2870 \text { Scherer Dr., St. Petersburg, FL } \\
33716\end{array}$ & Tel: 727/572-9422 Fax: 727/572-8470 \\
\hline Generac Corporation & $\begin{array}{l}\text { Highway } 59 \text { \& Hillside Rd., P.O. Box 8, } \\
\text { Waukesha, WI } 53187\end{array}$ & Tel: 414/544-4811 Fax: 414/544-0770 \\
\hline Georator Corporation & $\begin{array}{l}9617 \text { Center St., Manassas, VA 20110- } \\
5521\end{array}$ & Tel: 703/368-2101 Fax: 703/368-1078 \\
\hline Governors America Corporation & 720 Silver St., Agawam, MA 01001-2907 & Tel: 413/786-5600 Fax: 413/786-5666 \\
\hline InterScience, Incorporated & 105 Jordan Rd., Troy, NY 12180 & Tel: $518 / 283-7500$ \\
\hline Kato Engineering Company & P.O. Box 8447, Mankato, MN 56002-8447 & Tel: 507/625-4011 Fax: 507/345-2798 \\
\hline $\begin{array}{l}\text { Leroy-Somer/USEM, Division of Emerson } \\
\text { Electric }\end{array}$ & $\begin{array}{l}8100 \text { W. Florissant Ave., Station 1996, St. } \\
\text { Louis, MO } 63136\end{array}$ & Tel: 314/553-1996 Fax: 314/553-3403 \\
\hline Louis Allis Company & $\begin{array}{l}427 \text { E. Stewart St., P.O. Drawer 2020, } \\
\text { Milwaukee, WI 53201-2020 }\end{array}$ & Tel: 414/481-6000 Fax: 414/481-8895 \\
\hline Magnetek Century Electric & $\begin{array}{l}669 \text { Natchez Trace Dr., Lexington, TN } \\
38351\end{array}$ & Tel: 901/968-4274 Fax: 901/968-8595 \\
\hline
\end{tabular}


List of Companies-Alternator Market Survey (continued)

\begin{tabular}{|c|c|c|}
\hline Company & Address & Telephone/FAX Numbers \\
\hline Marathon Electric Mfg. Corp. & $\begin{array}{l}100 \text { East Randolph St., P.O. Box 8003, } \\
\text { Wausau, WI 54402-8003 }\end{array}$ & Tel: 715/675-3311 Fax: 715/675-8026 \\
\hline Marvin Engineering Co., Inc. & $\begin{array}{l}260 \text { West Beach Ave., Inglewood, CA } \\
90302\end{array}$ & Tel: 310/674-5030 Fax: 310/673-9472 \\
\hline MCII/Kurz \& Root Companies & 1745 Hinton St., Dallas, TX 75235-5101 & Tel: 214/638-8080 Fax: 214/631-1277 \\
\hline MECC ALTE & $\begin{array}{l}815 \text { North Oakwood Rd., Unit 1, Lake } \\
\text { Zurich, IL } 60047\end{array}$ & Tel: 847/550-0530 Fax: 847/550-0528 \\
\hline Newage Limited & $\begin{array}{l}1 \text { Bacton Hill North, Suite 202, Frazer, PA } \\
19355\end{array}$ & Tel: 610/578-9233 Fax: 610/578-9244 \\
\hline O'Brien Energy Services Company & 920 Church St., Wilmington, DE 19899 & Tel: 302/658-7100 Fax: 302/654-2133 \\
\hline Spectrum Research Corporation & $\begin{array}{l}\text { Rensselaer Technology Park, } 165 \text { Jordan } \\
\text { Rd., Troy, NY 12180-8343 }\end{array}$ & Tel: 518/283-7660 Fax: 518/283-7813 \\
\hline Synchrotek & P.O. Box 4083, Appleton, WI 54915 & Tel: 920/739-7275 Fax: 920/739-7286 \\
\hline Synchro-Start Products, Incorporated & 6250 W. Howard St., Niles, IL 60714-3433 & Tel: 847/967-7730 Fax: 847/967-7832 \\
\hline T \& J Manufacturing, Incorporated & $\begin{array}{l}102 \text { W. 5th Ave., P.O. Box 200, Oshkosh, } \\
\text { WI 54902-0200 }\end{array}$ & Tel: 920/236-4200 Fax: 920/236-4219 \\
\hline Tradewinds Power Corporation & 5820 N. W. $84^{\text {th }}$ Ave., Miami, FL 33166 & Tel: 305/592-9745 Fax: 305/592-7461 \\
\hline Woodward Governor Company & P.O. Box 3800, Loveland, CO 80539-3800 & Tel: 970/663-3900 Fax: 970/962-7050 \\
\hline
\end{tabular}


Company Quick Reference-Alternator Market Survey

\begin{tabular}{|c|c|c|c|c|c|}
\hline \multirow[b]{2}{*}{ Company } & \multicolumn{2}{|c|}{ Reply } & \multicolumn{2}{|c|}{ Scratched } & \multirow{2}{*}{$\begin{array}{l}\text { Reason(s) } \\
\text { scratched } \\
\text { (footnote) }\end{array}$} \\
\hline & Yes & No & Yes & No & \\
\hline Alturdyne & $\mathrm{X}$ & & $\mathrm{X}$ & & 1 \\
\hline AMBAC International & $\mathrm{X}$ & & $\mathrm{X}$ & & 2 \\
\hline Barber-Colman Company & & $\mathrm{X}$ & $\mathrm{X}$ & & $2 \& 3$ \\
\hline Basler Electric Company & $\mathrm{X}$ & & $\mathrm{X}$ & & 4 \\
\hline Baylor Gen/Motor Group & $\mathrm{X}$ & & & $\mathrm{X}$ & $\mathrm{N} / \mathrm{A}$ \\
\hline C. E. Niehoff \& Company & $\mathrm{X}$ & & $\mathrm{X}$ & & 5 \\
\hline Caterpillar, Incorporated & $\mathrm{X}$ & & & $\mathrm{X}$ & $\mathrm{N} / \mathrm{A}$ \\
\hline Cummins/Onan Corporation & $\mathrm{X}$ & & $\mathrm{X}$ & & 6 \\
\hline Elliott Energy Systems & & $\mathrm{X}$ & $\mathrm{X}$ & & $1 \& 3$ \\
\hline Fisher Electric Technology & $\mathrm{X}$ & & $\mathrm{X}$ & & 7 \\
\hline Generac Corporation & & $X$ & $\mathrm{X}$ & & $1 \& 3$ \\
\hline Georator Corporation & $\mathrm{X}$ & & & $\mathrm{X}$ & $\mathrm{N} / \mathrm{A}$ \\
\hline Governors America Corporation & $\mathrm{X}$ & & $X$ & & 2 \\
\hline InterScience, Incorporated & $\mathrm{X}$ & & $\mathrm{X}$ & & 3 \\
\hline Kato Engineering Company & & $\mathrm{X}$ & $\mathrm{X}$ & & $1 \& 3$ \\
\hline Leroy-Somer/USEM & $\mathrm{X}$ & & & $\mathrm{X}$ & $\mathrm{N} / \mathrm{A}$ \\
\hline Louis Allis Company & & $\mathrm{X}$ & $\mathrm{X}$ & & 8 \\
\hline MagneTek Century Electric & $\mathrm{X}$ & & & $\mathrm{X}$ & $\mathrm{N} / \mathrm{A}$ \\
\hline Marathon Elec. Mfg. Corp. & $\mathrm{X}$ & & & $\mathrm{X}$ & $\mathrm{N} / \mathrm{A}$ \\
\hline Marvin Engrg. Co., Inc. & $\mathrm{X}$ & & & $X$ & $\mathrm{~N} / \mathrm{A}$ \\
\hline MCII/Kurz \& Root Companies & $\mathrm{X}$ & & $\mathrm{X}$ & & 3 \\
\hline MECC ALTE & $\mathrm{X}$ & & $\mathrm{X}$ & & 3 \\
\hline Newage Ltd. & $\mathrm{X}$ & & & $\mathrm{X}$ & $\mathrm{N} / \mathrm{A}$ \\
\hline O'Brien Energy Services Co. & & $\mathrm{X}$ & $\mathrm{X}$ & & $1 \& 3$ \\
\hline Spectrum Research Corp. & $\mathrm{X}$ & & & $\mathrm{X}$ & $\mathrm{N} / \mathrm{A}$ \\
\hline Synchrotek & & $\mathrm{X}$ & $\mathrm{X}$ & & 3 \\
\hline Synchro-Start Products, Inc. & $X$ & & $\mathrm{X}$ & & 4 \\
\hline T \& J Mfg., Inc. & $\mathrm{X}$ & & & $\mathrm{X}$ & $\mathrm{N} / \mathrm{A}$ \\
\hline Tradewinds Power Corporation & & $\mathrm{X}$ & $\mathrm{X}$ & & $1 \& 3$ \\
\hline Woodward Governor Company & $\mathrm{X}$ & & $\mathrm{X}$ & & 2 \\
\hline
\end{tabular}

1. Manufactures gen-sets.

2. Manufactures governors.

3. No reply/response to questionnaire and/or no data provided.

4. Manufactures electrical generator controls.

5. Manufactures only dc alternators at present time. Plans to also manufacture ac alternators.

6. "Sister" company is Newage Ltd., which manufactures alternators.

7. Manufactures custom electric motors and alternators.

8. Bankruptcy. Purchased by Baylor Company (Generator/Motor Group). 
February 17, 1999

Power Generation Branch

Subject: Alternators for Military Generator Sets, Size Range 5 kW - 60 kW

\author{
Alturdyne \\ 8050 Armour \\ San Diego CA 92111
}

Gentlemen:

The Department of Defense Project Manager for Mobile Electric Power (PM-MEP) has developed a new program to evaluate state-of-the-art power generation technologies for the development of the next generation of Tactical Quiet Generators (TQGs) in the $5 \mathrm{~kW}$ through $60 \mathrm{~kW}$ range. In this regard, this office has been tasked to conduct a market search to identify commercial sources of supply for the subject alternators. The emphasis of this market survey is on obtaining sufficient data to identify and evaluate those state-of-the-art alternators that are currently available and those soon to be available (marketed) in the next two to three years.

This office is interested in all of your alternator models, ranging in size from $5 \mathrm{~kW}$ to $60 \mathrm{~kW}$, as described above. Please complete the enclosed questionnaire (one questionnaire for each model and generator size) and return it to us by March 22, 1999. Please include any other data (catalog, brochure, photographs, engineering data sheets, test data) that is necessary to adequately define the subject items.

Should you require any additional information or wish to discuss the subject matter, do not hesitate to contact the undersigned. My telephone number is 703-704-3365; my office fax number is 703-704-3333; and my e-mail address is agates@belvoir.army.mil.

Sincerely,

Alvin E. Gates

Project Engineer 


\section{MEMORANDUM FOR AMSEL-RD-C2-AP-PG (Selma Matthews)}

SUBJECT: Addendum - Market Survey-Alternators for Military Generator Sets, 5-60 $\mathrm{kW}, 60 \mathrm{~Hz}$

1. Reference my Memorandum for Selma Matthews, 4 May 1999, Subject: Alternators for Military Generator Sets, $5-60 \mathrm{~kW}, 60 \mathrm{~Hz}$.

2. Since my Memorandum of 4 May, I have received some brochures and separate specification sheets from MagneTek covering their line of industrial alternators. Briefly, MagneTek is based in Lexington, TN with worldwide manufacturing capabilities/facilities and nearly 100 years of experience in manufacturing electrical power equipment. They are a multi-billion dollar FORTUNE 500 company. And according to MagneTek, they offer competitive pricing.

3. From the information contained in MagneTek's brochures, I developed a table of their alternator models and characteristics, just like the tables I enclosed with the 4 May Memorandum for the other alternator manufacturers that responded to our questionnaire. As you can see from the enclosed table, MagneTek offers a nice range of industrial alternators in the $5 \mathrm{~kW}$ to $60 \mathrm{~kW}$ electrical power range, with characteristics that, I think, look promising for our third generation of generator sets.

4. In my opinion, MagneTek looks like they would belong right up there with the top five manufacturers mentioned in the 4 May Memorandum. Without closely examining and evaluating these six companies and their products, it is hard to say that any one is superior to the other. From this limited Market Survey I would tend to rank all six, at this time, on an equal basis and work from there. In our future program efforts, I would definitely consider these six companies first. To give you an idea of what MagneTek's alternators look like, I've enclosed copies of the front pages of their brochures.

ALVIN E. GATES

Project Engineer

PM-MEP RDE Team 


\title{
MEMORANDUM FOR Mrs. Selma Matthews, IPT Leader for AMMPS
}

\author{
Subject: Market Survey for Power Electronics.
}

1. This Office has completed a formal Market Survey on Commercial Power Electronics Systems for application on 5-60 kW engine driven generator sets. Questionnaires requesting technical and cost information on state of the art power electronics packages, that are currently available and/or will be available in the next three years, were forwarded to 49 companies (attachment 1). Each company's product lines were reviewed to determine when the products were available and whether the available packages could operate in military environment and could provide the needed power output in the specified environments.

a. Of the 49 companies contacted, only seven (7) companies responded to the survey. Four companies; Exeltech Incorporated, Avionic Instruments, Inc., Capstone Turbine Corp., and Spectrum Research, manufacture power electronics packages. The other three companies do not manufacture power electronic systems.

b. The following is a generic description of the four main companies:

1) Exeltech Incorporated: Exeltech Inc. manufactures power electronics that are commercially available now for each power ranges $(5-60 \mathrm{~kW})$. They meet some of the army's power and environmental requirements. However, they do not provide the configuration and weight of the power electronic modules for each generator sets.

2) Avionics: Avionics is a premier manufacturer of high-density power conversion devices. They have power electronics that are available now for each power range $(5-60 \mathrm{~kW})$. Within two (2) years, Avionics will be upgrading their packages that will utilize current slope control modulation.

3) Capstone: Capstone currently sells power electronics systems for its $30 \mathrm{~kW}$ microturbine engine driven system. The company will have an electronics package for a $60 \mathrm{~kW}$ microturbine system available commercially in Oct 99.

4) Spectrum Research Corp.: Spectrum Research has a proof of concept power electronics package for an Army $5 \mathrm{~kW}$ power system that satisfies all Army operational and performance requirements. It will be formally demonstrated in FY99. The design is to be a scaleable platform for use in the $3-60 \mathrm{~kW}$ power systems. A commercialization plan is underway that will ensure the scaleable product will be available in the next two years.

c. Based on the technical information and plans for commercialization provided by the companies, this Office recommends Avionics and Spectrum Research be considered as potential contractors.

2. Point of Contact for above is the undersigned at 704-3372

Edmund A Nawrocki

Project Engineer

PM-MEP RD\&E Team 


\section{MEMORANDUM FOR AMSEL-RD-C2-AP-PG (Selma Matthews)}

SUBJECT: Market Survey - Alternators for Military Generator Sets, 5-60 kW, $60 \mathrm{~Hz}$

1. As part of the "Development of Advanced Medium Sized Mobile Power Systems (5-60 kW)", for use in the $2{ }^{\text {st }}$ Century Battlefield, this office conducted a Market Survey for the subject alternators. Presented in the following paragraphs is a summary of the results of the survey.

2. On 19 February 1999, this office mailed a cover letter and attached questionnaire (see enclosure 1) to twenty-eight potential manufacturers of alternators. This list of twentyeight companies was based almost entirely on information provided in EGSA's "1999 Buying Guide to Power Generation Components, Systems and Services". We looked at companies listed in the EGSA Buyer's Guide (Electrical Generating Systems Association) that manufacture generators/alternators, and not those that sell, rent, and/or provide service. Names and addresses of four of the companies (Fisher Electric, Marvin Engineering, Spectrum Research, and Synchrotek) were provided by Selma Matthews, and two companies (Georator and Louis Allis) were selected from the Thomas Register. Two other companies, again provided by Selma Matthews, were recently added to the list, InterScience and C. E. Niehoff, which brought the total number of companies canvassed to thirty (see enclosure 2).

3. As shown in enclosure 3, "Company Quick Reference - Alternator Market Survey", twenty of the thirty companies have been "scratched" or purged from the list. Four of the companies scratched manufacture governors, two manufacture electrical generator controls, and six companies manufacture generator sets. Cummins/Onan has a "sister" company on the list (Newage, Ltd.), Louis Allis unfortunately went bankrupt (but has been purchased by the Baylor Company), and Fisher Electric manufactures custom electrical motors and alternators. C. E. Niehoff currently manufactures only de alternators, and three companies, who apparently manufacture alternators and replied ${ }^{*}$ to the survey, were scratched because they did not provide any data. Synchrotek did not reply nor furnish any data. Of the twenty companies scratched, eight (including the bankrupt Louis Allis Co.) simply did not reply, even after attempts (fax and/or telephone calls) to get them to respond. Looking at the survey from another viewpoint, twenty-two companies $(73 \%)$ did reply and ten companies $(33 \%)$ furnished data.

*Reply is defined in this Memorandum as a company contacting me (via telephone or letter) and stating that they do/do not manufacture alternators, and if they do, they will be providing data. 
4. Enclosure 4, "Table of Alternator Models and Characteristics", presents the various models of alternators from nine alternator companies that responded to the questionnaire (and provided data), or more correctly to the cover letter. A tenth company (MagneTek) responded just recently, and a separate table for them is enclosed (enclosure 5). Along the left margin of the table is listed all of the design features, ratings, mechanical features, operating conditions, electrical features, and estimated costs, as presented in the questionnaire.

Only four of the companies that responded listed our any costs. However, three of those companies are cost prohibitive at this time, especially Spectrum Research Corporation. Spectrum's cost for building one of their alternators (plus inverter) is $\$ 75,000$ ! They are presently developing this alternator for CECOM under Contract Number DAAB07-98-C6023.

5. In our opinion, the top six manufacturers of alternators that would meet military requirements now and in the future (next 2-3 years) are Baylor, Caterpillar, Leroy-Somer, MagneTek, Marathon, and Newage Ltd. (listed alphabetically and not in order of merit or ranking). These companies provide numerous models in the $5-60 \mathrm{~kW}$ electrical power range (and beyond). They have been established, leading manufacturers of military-type and industrial alternators for many years, and provide alternator features and characteristics that would give military customers the best alternator value on the market today and in the coming years. Marathon alternators range from a cost per one of from $\$ 1,700.00$ to $\$ 3,750.00$ (6 $\mathrm{kW}$ to $60 \mathrm{~kW}$ power range). We expect that costs from Baylor, Caterpillar, Leroy-Somer, MagneTek, and Newage would be comparable. Before this office would look at other companies, we would certainly consider these six companies first. However, companies like Georator Corporation (located nearby in Manassas, VA) and Spectrum Research Corporation (Troy, NY) are worth looking into, resources permitting. Georator currently manufactures a $3 \mathrm{~kW}$ and a $5 \mathrm{~kW}$ unit but has plans to develop and manufacture, over the next two years, a range of alternators from $2 \mathrm{~kW}$ to 60 $\mathrm{kW}$ output. Likewise, Spectrum, who currently offers a $5 \mathrm{~kW}$ unit, plans to provide a range of alternators from $5 \mathrm{~kW}$ to $60 \mathrm{~kW}$, by utilizing a unique modular design of "stacking" individual units to create the various outputs. However, these companies simply do not have, at present, the "worldwide" status as the "top six", and their products are expensive.

6. With regard to the other alternator companies that provided data in response to our questionnaire, Marvin Engineering Co. apparently manufactures only a $15 \mathrm{~kW}$ alternator, at a cost per one of $\$ 10,000 . T \& \mathrm{~J}$ Manufacturing, Inc. provides a range of alternators from 5 to $20 \mathrm{~kW}$. T \& J's products appear promising and possibly should be further "looked into", resources permitting.

7. At the present time, C. E. Niehoff manufactures only dc alternators but plans to market ac alternators in the near future. They also look promising. Their dc alternators appear to be quality, more-than-adequate items that would "fit in" with military-type alternators for engine-generator sets. MCII/Kurz and Root Companies apparently is a major supplier of military-type and industrial ac generators. They contacted our office and planned to provide data. Unfortunately, they have not provided any data as of this date. Likewise, MECC ALTE planned to provide data but they have not done so. 
8. From this limited Market Survey, this office would tend to rank all six companies, at this time, on an equal basis. In our future program efforts, we would definitely consider these six companies and would plan to buy some units for future Government testing and evaluation.

\author{
ALVIN E. GATES \\ Project Engineer \\ PM-MEP RDE Team
}


TABLE OF ALTERNATOR MODELS AND CHARACTERISTICS

\begin{tabular}{|c|c|c|c|c|c|c|c|c|c|c|}
\hline Manufacturer & Baylor & Baylor & Caterpillar & Georator & Leroy-Somer & Marathon & Marvin & Newage & Spectrum & T \& J Mfg. \\
\hline Model No. & Eagle Series & Eagle Series & See attached & $38-132$ & See attached & See attached & $185-1002 / 1003$ & See attached & SRCPMG5000 & \\
\hline Alternator type & Rotating Arm. & Rotating Arm. & “ & PM, Brushless & " & " & PM, brushless & “ & Axial gap & Ext. v, 4 pole \\
\hline Exciter type & Brushless $^{1}$ & Brushless $^{1}$ & " & None & " & " & 24 Pole colbalt & " & PM & Brushless \\
\hline Weight (lbs.) & & & “ & 60 & “ & “ & $>80$ & " & 30 & \\
\hline Size (in.) & & & " & 7 L x 8 Dia. & " & " & $5 \mathrm{~L} \times 9.85$ Dia. & $"$ & 4.9 L x 12 Dia. & $11.5 \mathrm{D}, 6-24 \mathrm{~L}$ \\
\hline Life (min) & $>100,000 \mathrm{hrs}^{2}$ & $>100,000 \mathrm{hrs}^{2}$ & “ & $>15$ yrs. & “ & “ & 10,000 hrs. & “ & 10,000 & $>20,000$ \\
\hline NEMA & MG 1-22 & MG 1-22 & " & Yes & " & " & & " & Yes & Yes \\
\hline IEEE & Yes & Yes & " & Yes & " & " & & " & & Yes \\
\hline ANSI & Yes & Yes & " & Yes & " & " & & " & & \\
\hline CSA & & & " & Yes & " & " & & " & & Yes \\
\hline Other & Yes/ISO 9001 & Yes/ISO 9001 & " & & " & " & Mil 4624D & " & & \\
\hline Elec Protect & IP 22 & IP 22 & " & Optional & " & " & N/A & " & GFCI & GFCI/Isometer \\
\hline Par Operation & & & " & No (Possible) & " & " & No (Possible) & " & No (Possible) & Compatible \\
\hline Efficiency & & & " & $85 \%$ & " & “ & & " & 88 & $85-90$ \\
\hline $120 \mathrm{v}$ & Yes & Yes & " & Yes & " & " & Yes & " & Yes & Yes \\
\hline $120 / 240 \mathrm{v}$ & Yes & Yes & “ & Yes & " & " & Yes & " & Yes & Yes \\
\hline $120 / 208 \mathrm{v}$ & Yes/to $13,800^{3}$ & Yes/to $13,800^{3}$ & “ & Yes & " & " & Yes & " & Yes & Yes \\
\hline \# leads & & & “ & & " & “ & & “ & & 12 \\
\hline Speed (rpm) & 1200 & 1800 & " & 3600 & " & " & Up to 5,000 & " & $1800-3600$ & 1800 \\
\hline Power $(\mathrm{kW})$ & 20 to 5,000 & 38 to 4,500 & “ & $5^{5}$ & “ & " & 15 & $"$ & $5^{6}$ & $5-20$ \\
\hline Power Factor & 0.8 & 0.8 & “ & 1.0 & “ & “ & & " & $0.8-1.0$ & 0.8 \\
\hline Frame & Steel & Steel & " & Al housing & " & " & Aluminum & " & SS/Comp. & Steel \\
\hline Drip-proof & Yes & Yes & " & Optional & " & “ & Yes & " & Yes & Yes \\
\hline \# bearings & 1 or 2 & 1 or 2 & " & 1 or 2 & " & " & None & " & None & 1 \\
\hline Bearing type & Lubricated & Lubricated & " & Lubrication & " & " & N/A & " & N/A & 207 \\
\hline Rotation & & & " & Both & " & " & Both & " & Both & Both \\
\hline Ventilation & Mixed-flow & Mixed-flow & " & Internal fan & " & " & Ext. cooled & " & Integral fan & Internal fan \\
\hline Coupling & Available & Available & " & As required & " & " & Direct drive & " & Direct drive & SAE \\
\hline Insulation & Class F & $\mathrm{F}$ & " & F std, H opt & " & " & $\mathrm{H}$ & " & $\mathrm{F}$ & $\mathrm{F} \& \mathrm{H}$ (rotor) \\
\hline Ins resistance & Tested $^{4}$ & Tested $^{4}$ & $"$ & & " & " & & " & $>10$ megohms & \\
\hline Altitude range & & & " & $8000 \mathrm{ft} \min$ & " & " & To 10,000 & " & 6,000 & \\
\hline Temp. range & $40^{\circ} \mathrm{C}$ standard & $40^{\circ} \mathrm{C}$ standard & " & $-20^{\circ}$ to $55^{\circ} \mathrm{C}$ & " & " & $-20^{\circ}-125^{\circ} \mathrm{F}$ & " & $-25^{\circ}-125^{\circ} \mathrm{F}$ & At $40^{\circ} \mathrm{C}$ \\
\hline Humidity & Weatherproof & Weatherproof & " & $202 / 106$ & " & " & 100 & “ & 100 & 100 \\
\hline Overspeed & Rotor $125 \%$ & Rotor $125 \%$ & " & $4500 \mathrm{rpm}$ & “ & “ & 6,000 & " & 6,000 & $25 \%$ \\
\hline Shock & & & “ & $202 / 205$ & “ & “ & $27 \mathrm{G} / 18 \mathrm{~ms}$ & " & None & \\
\hline Vibration & 2 mils max. & 2 mils max. & " & $202 / 201$ & " & " & $810 / 514.3$ & " & None & \\
\hline V regulator & Static SCR & Static SCR & " & None & " & " & Omitted & " & PWM & Solid state \\
\hline V regulation & $+/-1 \%$ & $+/-1$ & " & Total 7.5 & " & " & " & " & 2 & 1 \\
\hline F regulation & & & " & Prime mover & " & " & " & " & $0.1 \%$ & 3 \\
\hline Peak motor & & & " & $>400 \%$ & " & " & " & " & $15 \mathrm{kVA}$ & $150 \%$ \\
\hline S-c current & Tested $^{4}$ & Tested $^{4}$ & “ & $>500 \%$ & “ & “ & “ & “ & $20 \mathrm{~A}$ & \\
\hline RFI & Filter & Filter & “ & 461 & “ & “ & “ & “ & Yes & Mil-Std-461 \\
\hline V recovery & & & " & $<500 \mathrm{~ms}$ & " & " & $"$ & $"$ & $1 \mathrm{~ms}$ & \\
\hline V dev factor & $5 \%$ max. & $5 \%$ max. & " & & " & " & " & " & & \\
\hline V harmonic & THC $5 \%$ max. & THC $5 \%$ max. & " & THD $<5 \%$ & " & " & " & " & & THD $6 \%$ \\
\hline $2 / 3$ pitch & Yes & Yes & "“ & N/A & " & “ & “ & " & & Yes \\
\hline Die strength & & & " & $>1500$ volts & " & " & $"$ & $"$ & $>3000 \mathrm{v}$ & \\
\hline Winding R & Tested $^{4}$ & Tested $^{4}$ & " & $0.10 \mathrm{ohms}$ & “ & “ & " & " & & \\
\hline Special feat. & & & " & & " & " & & " & Modular $^{6}$ & \\
\hline Cost per 1 & & & " & $\$ 9,720.00$ & " & "“ & 10,000 & " & $75,000.00$ & \\
\hline
\end{tabular}

1. PM excitation is available upon request.

2. Bearings sized for a minimum life of $>100,000 \mathrm{hrs}$.

4. All tests are in accordance with MIL-STD-705 \&/or IEEE Standard $115 \&$ exceed minimum test standards established by NEMA.

3. 3 phase for entire range; 1 phase up to $50 \mathrm{~kW}$.

5. Developing over next 2 yrs: $2,3,5,7.5,10,15,20,30,40,50, \& 60 \mathrm{~kW}$ alternators from $\$ 8,689$ - $\$ 24,584$ quantity of 1 .

6. Can be stacked to create a 10 or $15 \mathrm{~kW}$ alternator. Plans to develop a $20 \mathrm{~kW}$ alternator to produce $40 \mathrm{~kW}$ and $60 \mathrm{~kW}$ alternators. 
CATERPILLAR ALTERNATOR MODELS WITH CHARACTERISTICS

\begin{tabular}{|c|c|c|c|c|c|c|c|c|c|c|}
\hline Manufacturer & Caterpillar & Caterpillar & Caterpillar & Caterpillar & Caterpillar & Caterpillar & Caterpillar & Caterpillar & Caterpillar & Caterpillar \\
\hline Model No. & LA1014H & LA1012D & LA1012F & LL1014Q & LL1014S & LA1012N & LL2014B & LA1012P & LL2014D & LL2014H \\
\hline Alternator type & 4 Pole & 2 Pole & 2 Pole & 4 Pole & 4 Pole & 2 Pole & 4 Pole & 2 Pole & 4 Pole & 4 Pole \\
\hline Exciter type & Self excited & Self & Self & SE or AREP ${ }^{3}$ & SE or AREP $^{3}$ & Self & SE/PM/AREP 3 & Self & SE/PM/AREP ${ }^{3}$ & SE/PM/AREP 3 \\
\hline \multicolumn{11}{|l|}{ Weight (lbs.) } \\
\hline \multicolumn{11}{|l|}{ Size (in.) } \\
\hline \multicolumn{11}{|l|}{ Life (min) } \\
\hline NEMA & MG1-22 & MG1-22 & MG1-22 & MG1-22 & MG1-22 & MG1-22 & MG1-22 & MG1-22 & MG1-22 & MG1-22 \\
\hline \multicolumn{11}{|l|}{ IEEE } \\
\hline \multicolumn{11}{|l|}{ ANSI } \\
\hline \multicolumn{11}{|l|}{ CSA } \\
\hline Other & Yes & Yes & Yes & Yes & Yes & Yes & Yes & Yes & Yes & Yes \\
\hline Elec Protect & Enclosed IP22 & IP22 & IP22 & IP22 & IP22 & IP22 & IP23 & IP22 & IP23 & IP23 \\
\hline \multicolumn{11}{|l|}{ Par Operation } \\
\hline \multicolumn{11}{|l|}{ Efficiency } \\
\hline $120 \mathrm{v}$ & Yes & Yes & Yes & Yes & Yes & Yes & Yes & Yes & Yes & Yes \\
\hline $120 / 240 \mathrm{v}$ & Yes & Yes & Yes & Yes & Yes & Yes & Yes & Yes & Yes & Yes \\
\hline $120 / 208 \mathrm{v}$ & Yes & Yes & Yes & Yes & Yes & Yes & Yes & Yes & Yes & Yes \\
\hline \# leads & 12 & 12 & 12 & 12 & 12 & 12 & 12 & 12 & 12 & 12 \\
\hline Speed (rpm) & 1800 & 3600 & 3600 & 1800 & 1800 & 3600 & 1800 & 3600 & 1800 & 1800 \\
\hline Power (kW) & 14 & 18 & 20 & 25 & 30 & 32 & 40 & 40 & 50 & 60 \\
\hline Power Factor & 0.8 & 0.8 & 0.8 & 0.8 & 0.8 & 0.8 & 0.8 & 0.8 & 0.8 & 0.8 \\
\hline \multicolumn{11}{|l|}{ Frame } \\
\hline \multicolumn{11}{|l|}{ Drip-proof } \\
\hline \multirow{2}{*}{\multicolumn{11}{|c|}{$\begin{array}{l}\text { \# bearings } \\
\text { Bearing type }\end{array}$}} \\
\hline \multicolumn{6}{|l|}{ Bearing type } & & & & & \\
\hline \multirow{2}{*}{\multicolumn{11}{|c|}{$\begin{array}{l}\text { Rotation } \\
\text { Ventilation } \\
\end{array}$}} \\
\hline & & & & & & & & & & \\
\hline \multicolumn{11}{|l|}{ Coupling } \\
\hline Insulation & Class $\mathrm{H}$ & $\mathrm{H}$ & $\mathrm{H}$ & $\mathrm{H}$ & $\mathrm{H}$ & $\mathrm{H}$ & $\mathrm{H}$ & $\mathrm{H}$ & $\mathrm{H}$ & $\mathrm{H}$ \\
\hline \multicolumn{11}{|l|}{ Ins resistance } \\
\hline Altitude range & Up to $305 \mathrm{ft}$. & Up to 305 & Up to 305 & Up to 305 & Up to 305 & Up to 305 & Up to 305 & Up to 305 & Up to 305 & Up to 305 \\
\hline \multicolumn{11}{|l|}{ Temp. range } \\
\hline \multicolumn{11}{|l|}{ Humidity } \\
\hline Overspeed & $2250 \mathrm{rpm}$ & 4500 & 4500 & 2250 & 2250 & 4500 & 2250 & 4500 & 2250 & 2250 \\
\hline \multicolumn{11}{|l|}{ Shock } \\
\hline Vibration & & & & & & & & & & \\
\hline V regulator & AVR R230A & AVR R230A & AVR R230A & AVR R230A ${ }^{3}$ & AVR R230A ${ }^{3}$ & AVR R230A & AVR R230A 3 & AVR R230A & AVR R230A 3 & AVR R230A 3 \\
\hline V regulation & $1 \%$ & 1 & 1 & 1 & 1 & 1 & 1 & 1 & 1 & 1 \\
\hline F regulation & & & & & & & & & & \\
\hline Peak motor & Approx. $30 \%$ & Approx. 30 & Approx. 30 & Approx. 20 & Approx. 20-25 & Approx. 25-30 & Approx. 20-25 & Approx. 20-30 & Approx. 20-25 & Approx. 15-25 \\
\hline S-c current & Nil & Nil & Nil & $300 \%$ AREP & 300 w/AREP & Nil & $300 \mathrm{PM} / \mathrm{AREP}$ & Nil & $300 \mathrm{PM} / \mathrm{AREP}$ & $300 \mathrm{PM} / \mathrm{AREP}$ \\
\hline RFI & & & & & & & & & & \\
\hline $\mathrm{V}$ recovery & & & & & & & & & & \\
\hline $\mathrm{V}$ dev factor & & & & & & & & & & \\
\hline V harmonic & THD $<4 \%$ & $<4$ & $<4$ & $<4$ & $<4$ & $<4$ & $<4$ & $<4$ & $<4$ & $<4$ \\
\hline $2 / 3$ pitch & Yes & Yes & Yes & Yes & Yes & Yes & Yes & Yes & Yes & Yes \\
\hline Die strength & & & & & & & & & & \\
\hline Winding $\mathrm{R}^{1}$ & $1.32 \mathrm{ohms}$ & 1.52 & 1.2 & 0.416 & 0.381 & 0.448 & 0.310 & 0.324 & 0.255 & 0.167 \\
\hline Special feat. & & & & & & & & & & \\
\hline Cost per 1 & See footnote 2 & See footnote 2 & See footnote 2 & See footnote 2 & See footnote 2 & See footnote 2 & See footnote 2 & See footnote 2 & See footnote 2 & See footnote 2 \\
\hline
\end{tabular}

1. Stator LL at $20^{\circ} \mathrm{C}\left(68^{\circ} \mathrm{F}\right)$ Series Star Connected.

2. No individual prices; alternators are priced as packages with diesel or gas engines.

3. AREP = Auxiliary windings, Regulator, Excitation Principle. AREP or PM uses AVR R438 
LEROY-SOMER ALTERNATOR MODELS WITH CHARACTERISTICS

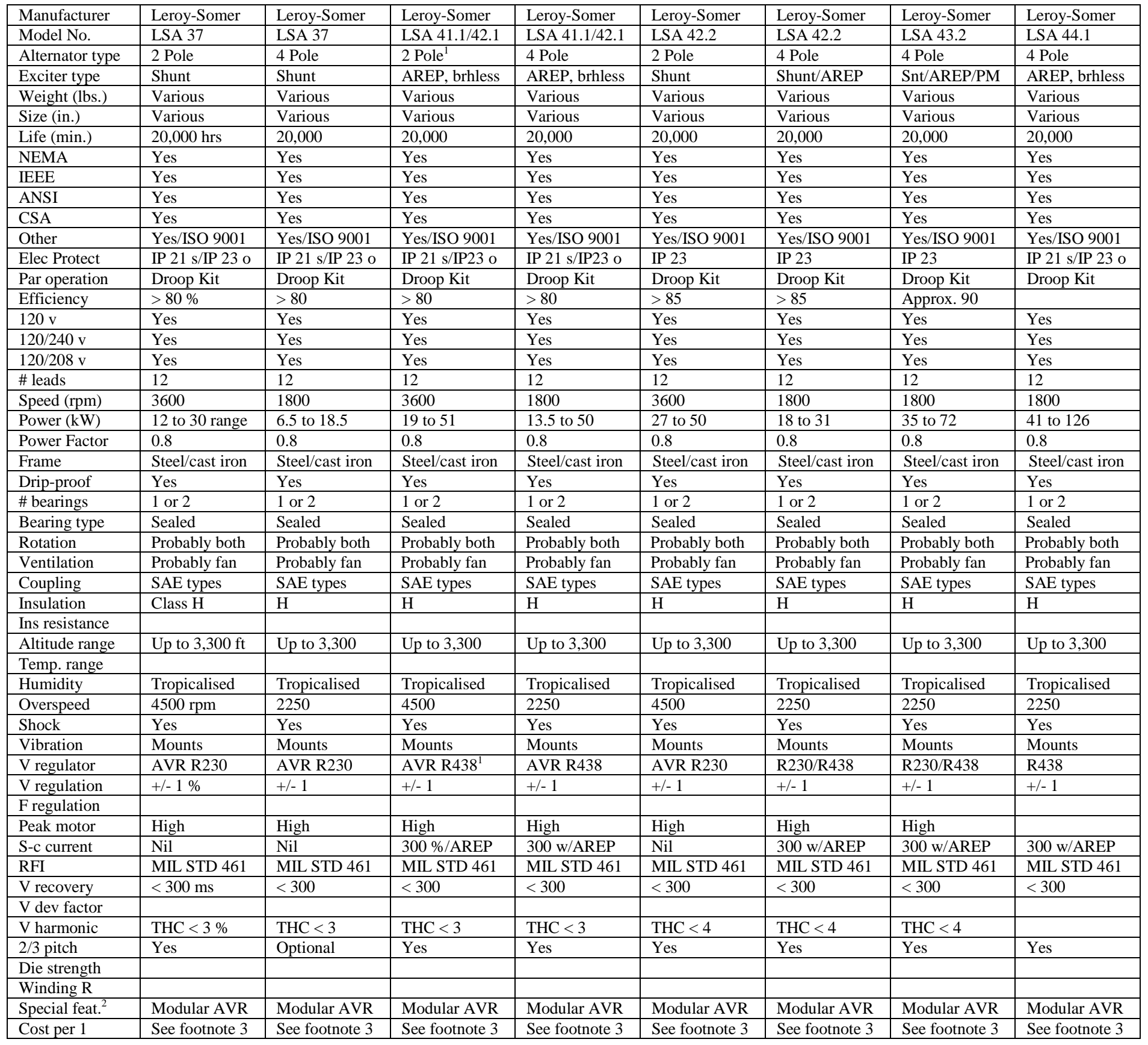

1. R230 regulation similar to the LSA 37 for 2-pole alternators.

2. LSA 41.1, 42.1, and 44.1 models supplied with LAM (Load Acceptance Module).

3. Prices not included with data supplied by Leroy-Somer but they can give pricing if interested in the product. 
MAGNETEK ALTERNATOR MODELS AND CHARACTERISTICS

\begin{tabular}{|c|c|c|c|c|c|c|c|c|c|c|}
\hline Manufacturer & MagneTek & MagneTek & MagneTek & MagneTek & MagneTek & MagneTek & MagneTek & MagneTek & MagneTek & MagneTek \\
\hline Model No. ${ }^{1}$ & MTG19 & MTG20 & MTG21 & MTG22 & MTG23 & MTG24 & MTG25 & MTG26 & MTG27 & MTG28 \\
\hline Alternator type & Brushless & Brushless & Brushless & Brushless & Brushless & Brushless & Brushless & Brushless & Brushless & Brushless \\
\hline Exciter type $^{2}$ & SE & $\mathrm{SE}$ & $\mathrm{SE}$ & $\mathrm{SE}$ & SE & SE & SE & SE & $\mathrm{SE}$ & SE \\
\hline Weight (lbs.) & 306 & 328 & 355 & 379 & 399 & 434 & 472 & 498 & 516 & 560 \\
\hline Size (in.) & See brochure & See brochure & See brochure & See brochure & See brochure & See brochure & See brochure & See brochure & See Brochure & See brochure \\
\hline Life (min.) ${ }^{3}$ & $40,000 \mathrm{hrs}$. & 40,000 & 40,000 & 40,000 & 40,000 & 40,000 & 40,000 & 40,000 & 40,000 & 40,000 \\
\hline NEMA & Yes & Yes & Yes & Yes & Yes & Yes & Yes & Yes & Yes & Yes \\
\hline IEEE & Yes & Yes & Yes & Yes & Yes & Yes & Yes & Yes & Yes & Yes \\
\hline ANSI & Probably & Probably & Probably & Probably & Probably & Probably & Probably & Probably & Probably & Probably \\
\hline CSA & Yes & Yes & Yes & Yes & Yes & Yes & Yes & Yes & Yes & Yes \\
\hline Other & ISO 9001 & ISO 9001 & ISO 9001 & ISO 9001 & ISO 9001 & ISO 9001 & ISO 9001 & ISO 9001 & ISO 9001 & ISO 9001 \\
\hline Elec Protect & IP21 s, IP22 o & IP21 s, IP22 o & IP21 s, IP22 o & IP21 s, IP22 o & IP21 s, IP22 o & IP21 s, IP22 o & IP21 s, IP22 o & IP21 s, IP22 o & IP21 s, IP22 o & IP21 s, IP22 o \\
\hline Par operation & Option & Option & Option & Option & Option & Option & Option & Option & Option & Option \\
\hline Efficiency & $80 \%$ (Class F) & $83(\mathrm{~F})$ & $83(\mathrm{~F})$ & $87(\mathrm{~F})$ & $88(\mathrm{~F})$ & $89(\mathrm{~F})$ & $90(\mathrm{~F})$ & $89(\mathrm{~F})$ & $91(\mathrm{~F})$ & $91(\mathrm{~F})$ \\
\hline $120 \mathrm{v}$ & Yes & Yes & Yes & Yes & Yes & Yes & Yes & Yes & Yes & Yes \\
\hline $120 / 240 \mathrm{v}$ & Yes & Yes & Yes & Yes & Yes & Yes & Yes & Yes & Yes & Yes \\
\hline $120 / 208 \mathrm{v}$ & Yes & Yes & Yes & Yes & Yes & Yes & Yes & Yes & Yes & Yes \\
\hline \# leads & 12 & 12 & 12 & 12 & 12 & 12 & 12 & 12 & 12 & 12 \\
\hline Speed (rpm) & 1800 & 1800 & 1800 & 1800 & 1800 & 1800 & 1800 & 1800 & 1800 & 1800 \\
\hline Power $(\mathrm{kW})$ & 12 & 17 & 26 & 32 & 35 & 45 & 50 & 57 & 60 & 65 \\
\hline Power Factor & 0.8 & 0.8 & 0.8 & 0.8 & 0.8 & 0.8 & 0.8 & 0.8 & 0.8 & 0.8 \\
\hline Frame & Steel & Steel & Steel & Steel & Steel & Steel & Steel & Steel & Steel & Steel \\
\hline Drip-proof & Option & Option & Option & Option & Option & Option & Option & Option & Option & Option \\
\hline \# bearings & 1 (sealed) & 1 (sealed) & 1 (sealed) & 1 (sealed) & 1 (sealed) & 1 (sealed) & 1 (sealed) & 1 (sealed) & 1 (sealed) & 1 (sealed) \\
\hline Bearing type & Prelubricated & Prelubricated & Prelubricated & Prelubricated & Prelubricated & Prelubricated & Prelubricated & Prelubricated & Prelubricated & Prelubricated \\
\hline \multicolumn{11}{|l|}{ Rotation } \\
\hline Ventilation & Fan & Fan & Fan & Fan & Fan & Fan & Fan & Fan & Fan & Fan \\
\hline Coupling & SAE/Disc & SAE/Disc & SAE/Disc & SAE/Disc & SAE/Disc & SAE/Disc & SAE/Disc & SAE/Disc & SAE/Disc & SAE/Disc \\
\hline Insulation & Class H & $\mathrm{H}$ & $\mathrm{H}$ & $\mathrm{H}$ & $\mathrm{H}$ & $\mathrm{H}$ & $\mathrm{H}$ & $\mathrm{H}$ & $\mathrm{H}$ & $\mathrm{H}$ \\
\hline \multicolumn{11}{|l|}{ Ins resistance } \\
\hline \multicolumn{11}{|l|}{ Altitude range } \\
\hline \multicolumn{11}{|l|}{ Temp. range } \\
\hline \multicolumn{11}{|l|}{ Humidity } \\
\hline Overspeed & $2250 \mathrm{rpm}$ & 2250 & 2250 & 2250 & 2250 & 2250 & 2250 & 2250 & 2250 & 2250 \\
\hline \multicolumn{11}{|l|}{ Shock } \\
\hline \multicolumn{11}{|l|}{ Vibration } \\
\hline V regulator & AVR MPR-5 & AVR MPR-5 & AVR MPR-5 & AVR MPR-5 & AVR MPR-5 & AVR MPR-5 & AVR MPR-5 & AVR MPR-5 & AVR MPR-5 & AVR MPR-5 \\
\hline V regulation & $1 \%$ & 1 & 1 & 1 & 1 & 1 & 1 & 1 & 1 & 1 \\
\hline \multicolumn{11}{|l|}{ F regulation } \\
\hline \multicolumn{11}{|l|}{ Peak motor } \\
\hline S-c current & Option & Option & Option & Option & Option & Option & Option & Option & Option & Option \\
\hline RFI & Option & Option & Option & Option & Option & Option & Option & Option & Option & Option \\
\hline \multicolumn{11}{|l|}{ V recovery } \\
\hline \multicolumn{11}{|l|}{$\mathrm{V}$ dev factor } \\
\hline \multicolumn{11}{|l|}{ V harmonic } \\
\hline $2 / 3$ pitch & Yes & Yes & Yes & Yes & Yes & Yes & Yes & Yes & Yes & Yes \\
\hline \multicolumn{11}{|l|}{ Die strength } \\
\hline Winding $\mathrm{R}^{4}$ & $1.0940 \mathrm{Ohms}$ & 0.7194 & 0.4651 & 0.2963 & 0.2396 & 0.1789 & 0.1598 & 0.1402 & 0.1151 & 0.0940 \\
\hline \multicolumn{11}{|l|}{ Special feat. } \\
\hline Cost per 1 & & & & & & & & & & \\
\hline
\end{tabular}

1. Century 2000 line of industrial alternators

4. Phase resistance

2. Optional filter or PM excitation

3. Sealed bearings with 40,000 hour B10 life 
MARATHON ALTERNATOR MODELS WITH CHARACTERISTICS

\begin{tabular}{|c|c|c|c|c|c|c|c|c|c|c|c|c|}
\hline Manufacturer & Marathon & Marathon & Marathon & Marathon & Marathon & Marathon & Marathon & Marathon & Marathon & Marathon & Marathon & Marathon \\
\hline Model \# & 281PSL1500 & 281PSL1501 & 281PSL1502 & 282PSL1503 & 282PSL1504 & 282PSL1505 & 283PSL1506 & 283PSL1507 & 284PSL1508 & 361PSL1600 & 361PSL1601 & 361PSL1602 \\
\hline Alternator type & Ext. v reg., BL & Ext. v reg., BL & Ext. v reg., BL & Ext. v reg., BL & Ext. v, BL & Ext. v, BL & Ext. v, BL & Ext. v, BL & Ext. v, BL & Ext. v, BL & Ext. v, BL & Ext. v, BL \\
\hline Exciter type & Rotating & Rotating & Rotating & Rotating & Rotating & Rotating & Rotating & Rotating & Rotating & Rotating & Rotating & Rotating \\
\hline Weight (lbs.) & 205 & 210 & 220 & 240 & 250 & 275 & 310 & 350 & 405 & 483 & 569 & 585 \\
\hline Size (in.) & $16 \times 14 \times 19$ & $16 \times 14 \times 19$ & $16 \times 14 \times 19$ & $18 \times 14 \times 19$ & $18 \times 14 \times 19$ & $18 \times 14 \times 19$ & $21 \times 14 \times 19$ & $21 \times 14 \times 19$ & $23 \times 14 \times 19$ & $26 \times 19 \times 28$ & $26 \times 19 \times 28$ & $26 \times 19 \times 28$ \\
\hline Life (min) & $40,000 \mathrm{hrs}$ & $40,000 \mathrm{hrs}$ & $40,000 \mathrm{hrs}$ & $40,000 \mathrm{hrs}$ & $40,000 \mathrm{hrs}$ & $40,000 \mathrm{hrs}$ & $40,000 \mathrm{hrs}$ & $40,000 \mathrm{hrs}$ & $40,000 \mathrm{hrs}$ & $40,000 \mathrm{hrs}$ & $40,000 \mathrm{hrs}$ & $40,000 \mathrm{hrs}$ \\
\hline NEMA & Yes & Yes & Yes & Yes & Yes & Yes & Yes & Yes & Yes & Yes & Yes & Yes \\
\hline IEEE & Yes & Yes & Yes & Yes & Yes & Yes & Yes & Yes & Yes & Yes & Yes & Yes \\
\hline ANSI & Yes & Yes & Yes & Yes & Yes & Yes & Yes & Yes & Yes & Yes & Yes & Yes \\
\hline CSA & Yes & Yes & Yes & Yes & Yes & Yes & Yes & Yes & Yes & Yes & Yes & Yes \\
\hline NFPA & Yes & Yes & Yes & Yes & Yes & Yes & Yes & Yes & Yes & Yes & Yes & Yes \\
\hline Other & ISO9000 & ISO9000 & ISO9000 & ISO9000 & ISO9000 & ISO9000 & ISO9000 & ISO9000 & ISO9000 & ISO9000 & ISO9000 & ISO9000 \\
\hline Elec Protect & Enclosed & Enclosed & Enclosed & Enclosed & Enclosed & Enclosed & Enclosed & Enclosed & Enclosed & Enclosed & Enclosed & Enclosed \\
\hline Parallel Operat & No & No & No & No & No & No & No & No & No & No & No & No \\
\hline Efficiency & $78 \%$ & 74 & 78 & 82 & 81 & 84 & 85 & 86 & 88 & 87 & 90 & 89 \\
\hline $120 \mathrm{v}$ & Yes & Yes & Yes & Yes & Yes & Yes & Yes & Yes & Yes & Yes & Yes & Yes \\
\hline $120 / 240 \mathrm{v}$ & Yes & Yes & Yes & Yes & Yes & Yes & Yes & Yes & Yes & Yes & Yes & Yes \\
\hline $120 / 280 \mathrm{v}$ & Yes & Yes & Yes & Yes & Yes & Yes & Yes & Yes & Yes & Yes & Yes & Yes \\
\hline \# leads & 12 & 12 & 12 & 12 & 12 & 12 & 12 & 12 & 12 & 12 & 12 & 12 \\
\hline Speed (rpm) & 1800 & 1800 & 1800 & 1800 & 1800 & 1800 & 1800 & 1800 & 1800 & 1800 & 1800 & 1800 \\
\hline Power (kW) & 6 & 8 & 10 & 12 & 15 & 20 & 25 & 30 & 35 & 40 & 50 & 60 \\
\hline Power Factor & 0.8 & 0.8 & 0.8 & 0.8 & 0.8 & 0.8 & 0.8 & 0.8 & 0.8 & 0.8 & 0.8 & 0.8 \\
\hline Frame & Rolled Steel & Rolled Steel & Rolled Steel & Rolled Steel & Rolled Steel & Rolled Steel & Rolled Steel & Rolled Steel & Rolled Steel & Rolled Steel & Rolled Steel & Rolled Steel \\
\hline Drip-proof & Yes & Yes & Yes & Yes & Yes & Yes & Yes & Yes & Yes & Yes & Yes & Yes \\
\hline \# bearings & 1 or 2 & 1 or 2 & 1 or 2 & 1 or 2 & 1 or 2 & 1 or 2 & 1 or 2 & 1 or 2 & 1 or 2 & 1 or 2 & 1 or 2 & 1 or 2 \\
\hline Bearing type & Sealed & Sealed & Sealed & Sealed & Sealed & Sealed & Sealed & Sealed & Sealed & Sealed & Sealed & Sealed \\
\hline Rotation & Both & Both & Both & Both & Both & Both & Both & Both & Both & Both & Both & Both \\
\hline Ventilation & Rotating fan & Rotating fan & Rotating fan & Rotating fan & Rotating fan & Rotating fan & Rotating fan & Rotating fan & Rotating fan & Rotating fan & Rotating fan & Rotating fan \\
\hline Coupling & Flexible & Flexible & Flexible & Flexible & Flexible & Flexible & Flexible & Flexible & Flexible & Flexible & Flexible & Flexible \\
\hline Insulation $\mathrm{H}$ & Yes & Yes & Yes & Yes & Yes & Yes & Yes & Yes & Yes & Yes & Yes & Yes \\
\hline Resistance & $>1.5$ megohm & $>1.5$ & $>1.5$ & $>1.5$ & $>1.5$ & $>1.5$ & $>1.5$ & $>1.5$ & $>1.5$ & $>1.5$ & $>1.5$ & $>1.5$ \\
\hline \multicolumn{13}{|l|}{ Altitude } \\
\hline \multicolumn{13}{|l|}{ Temp. range } \\
\hline \multicolumn{13}{|l|}{ Humidity } \\
\hline Overspeed rpm & 2250 & 2250 & 2250 & 2250 & 2250 & 2250 & 2250 & 2250 & 2250 & 2250 & 2250 & 2250 \\
\hline \multicolumn{13}{|l|}{ Shock } \\
\hline Vibration & 2 mils & 2 mils & 2 mils & 2 mils & 2 mils & 2 mils & 2 mils & 2 mils & 2 mils & 2 mils & 2 mils & 2 mils \\
\hline V reg type & SE350 & SE350 & SE350 & SE350 & SE350 & SE350 & SE350 & SE350 & SE350 & SE350 & SE350 & SE350 \\
\hline V regulation & $1 \%$ & 1 & 1 & 1 & 1 & 1 & 1 & 1 & 1 & 1 & 1 & 1 \\
\hline \multicolumn{13}{|l|}{ F regulation } \\
\hline Peak motor & $23 \%$ v dip & 30 & 32 & 24 & 25 & 24 & 19 & 18 & 20 & 22 & 18 & 16 \\
\hline \multicolumn{13}{|l|}{ S-c current } \\
\hline \multicolumn{13}{|l|}{ RFI } \\
\hline V recovery & 0.8 seconds & 0.8 & 0.9 & 0.7 & $<0.6$ & 0.6 & 0.6 & 0.5 & 0.7 & 0.5 & 0.3 & 0.4 \\
\hline $\mathrm{V} \mathrm{dev}$ factor & $6 \%$ & 6 & 6 & 6 & 6 & 6 & 6 & 6 & 6 & 6 & 6 & 6 \\
\hline V harmonic & THD 3\% & 3 & 3 & 3 & 3 & 3 & 3 & 3 & 3 & 3 & 3 & 3 \\
\hline \multicolumn{13}{|l|}{$2 / 3$ pitch } \\
\hline Die strength & 1500 volts & 1500 & 1500 & 1500 & 1500 & 1500 & 1500 & 1500 & 1500 & 1500 & 1500 & 1500 \\
\hline Winding R & $4.2 \mathrm{ohms}$ & 4.15 & 3.2 & 2.0 & 1.51 & 1.0 & 0.681 & 0.48 & 0.346 & 0.381 & 0.264 & 0.181 \\
\hline \multicolumn{13}{|l|}{ Special feat. } \\
\hline Cost per 1 & $\$ 1,700.00$ & $\$ 1,775.00$ & $\$ 1,850.00$ & $\$ 1,950.00$ & $\$ 2,050.00$ & $\$ 2,200.00$ & $\$ 2,450.00$ & $\$ 2,650.00$ & $\$ 2,900.00$ & $\$ 3,050.00$ & $\$ 3,300.00$ & $\$ 3,750.00$ \\
\hline
\end{tabular}


NEWAGE ALTERNATOR MODELS WITH CHARACTERISTICS

\begin{tabular}{|c|c|c|c|c|c|c|c|c|c|c|}
\hline Manufacturer & Newage & Newage & Newage & Newage & Newage & Newage & Newage & Newage & Newage & Newage \\
\hline Model No. & BCI 16 & BCI 16 & BCI 18 & BCI 18 & UCI 22 & UCDI 22 & BCI $16^{2}$ & BCI $18^{2}$ & $\mathrm{UCI} 22^{2}$ & UCDI $22^{2}$ \\
\hline Alternator type & 2 Pole, brls & 4 Pole, brls & 2 Pole, brls & 4 Pole, brls & 4 Pole, brls & 4 Pole, brls & 4 Pole, brls & 4 Pole, brls & 4 Pole, brls & 4 Pole, brls \\
\hline Exciter type & SE \& PM avail & SE \& PM avail & SE \& PM avail & SE \& PM avail & SE \& PM avail & SE \& PM avail & SE \& PM avail & SE \& PM avail & SE \& PM avail & SE \& PM avail \\
\hline \multicolumn{11}{|l|}{ Weight (lbs.) } \\
\hline \multicolumn{11}{|l|}{ Size (in.) } \\
\hline \multicolumn{11}{|l|}{ Life (min.) } \\
\hline \multicolumn{11}{|l|}{ NEMA } \\
\hline \multirow{2}{*}{\multicolumn{11}{|c|}{ IEEE }} \\
\hline & & & & & & & & & & ANSI \\
\hline \multicolumn{11}{|l|}{ CSA } \\
\hline Other & ISO9001 & ISO9001 & ISO9001 & ISO9001 & ISO9001 & ISO9001 & ISO9001 & ISO9001 & ISO9001 & ISO9001 \\
\hline Elec Protect & IP23 enclosure & IP23 & IP23 & IP23 & IP22 s, IP23 o & IP22 s, IP23 o & IP23 & IP23 & IP22 s, IP23 o & IP22 s, IP23 o \\
\hline \multicolumn{11}{|l|}{ Par operation } \\
\hline \multicolumn{11}{|l|}{ Efficiency } \\
\hline $120 \mathrm{v}$ & Yes & Yes & Yes & Yes & Yes & Yes & Yes & Yes & Yes & Yes \\
\hline $120 / 240 \mathrm{v}$ & Yes & Yes & Yes & Yes & Yes & Yes & Yes & Yes & Yes & Yes \\
\hline $120 / 208 \mathrm{v}$ & Yes & Yes & Yes & Yes & Yes & Yes & Yes & Yes & Yes & Yes \\
\hline \# leads & 12 & 12 & $12^{1}$ & $12^{1}$ & 12 & 12 & Windings spec & Windings spec & Windings spec & Windings spec \\
\hline Speed (rpm) & 3600 & 1800 & 3600 & 1800 & 1800 & 1800 & 1800 & 1800 & 1800 & 1800 \\
\hline Power $(\mathrm{kW})$ & 12-25 range & 8 -16 range & 28-37 range & 22-30 range & 42-83 range & 42-83 range & 6-14 range & 18-28 range & $30-70$ range & $30-70$ range \\
\hline Power Factor & 0.8 & 0.8 & 0.8 & 0.8 & 0.8 & 0.8 & 0.8 & 0.8 & 0.8 & 0.8 \\
\hline \multicolumn{11}{|l|}{ Frame } \\
\hline \multicolumn{11}{|l|}{ Drip-proof } \\
\hline \# bearings & 1 or 2 & 1 or 2 & 1 or 2 & 1 or 2 & 1 or 2 & 1 or 2 & 1 or 2 & 1 or 2 & 1 or 2 & 1 or 2 \\
\hline \multicolumn{11}{|l|}{ Bearing type } \\
\hline \multicolumn{11}{|l|}{ Rotation } \\
\hline \multicolumn{11}{|l|}{ Ventilation } \\
\hline Coupling & SAE & SAE & SAE & SAE & SAE & SAE & SAE & SAE & SAE & SAE \\
\hline Insulation & Class $\mathrm{H}$ & $\mathrm{H}$ & $\mathrm{H}$ & $\mathrm{H}$ & $\mathrm{H}$ & $\mathrm{H}$ & $\mathrm{H}$ & $\mathrm{H}$ & $\mathrm{H}$ & $\mathrm{H}$ \\
\hline \multicolumn{11}{|l|}{ Ins resistance } \\
\hline \multicolumn{11}{|l|}{ Altitude range } \\
\hline \multicolumn{11}{|l|}{ Temp. range } \\
\hline \multirow{2}{*}{\multicolumn{11}{|c|}{$\begin{array}{l}\text { Humidity } \\
\text { Overspeed }\end{array}$}} \\
\hline & & & & & & & & & & \\
\hline Shock & & & & & & & & & & \\
\hline Vibration & & & & & & & & & & \\
\hline V regulator & AVR & AVR & AVR & AVR & AVR & AVR & AVR & AVR & AVR & AVR \\
\hline V regulation ${ }^{3}$ & & & & & & & & & & \\
\hline F regulation & & & & & & & & & & \\
\hline Peak motor & & & & & & & $450 \%$ & 450 & 450 & 450 \\
\hline S-c current & & & See footnote 1 & See footnote 1 & & & & & & \\
\hline RFI & & & & & & & & & & \\
\hline V recovery & & & & & & & & & & \\
\hline V dev factor & & & & & & & & & & \\
\hline V harmonic & & & & & & & & & & \\
\hline $2 / 3$ pitch & & & & & & & & & & \\
\hline Die strength & & & & & & & & & & \\
\hline Winding R & & & & & & & & & & \\
\hline Special feat. & & & & & & & & & & \\
\hline Cost per 1 & & & & & & & & & & \\
\hline
\end{tabular}

1. Auxiliary wound version available for applications where sustained short circuit is required.

2. Transformer controlled machines.

3. Depends on type of AVR (from $1.5 \%$ standard (SE) to $0.5 \%$ (SE \& PM)). Also, a current transformer can be supplied with one of the SE AVRs (1.0 \%) for parallel operation. 
3-30 
Appendix 3-B. POWER ELECTRONICS DATA PROVIDED BY CECOM FOR MARKET SURVEY 
3-32 


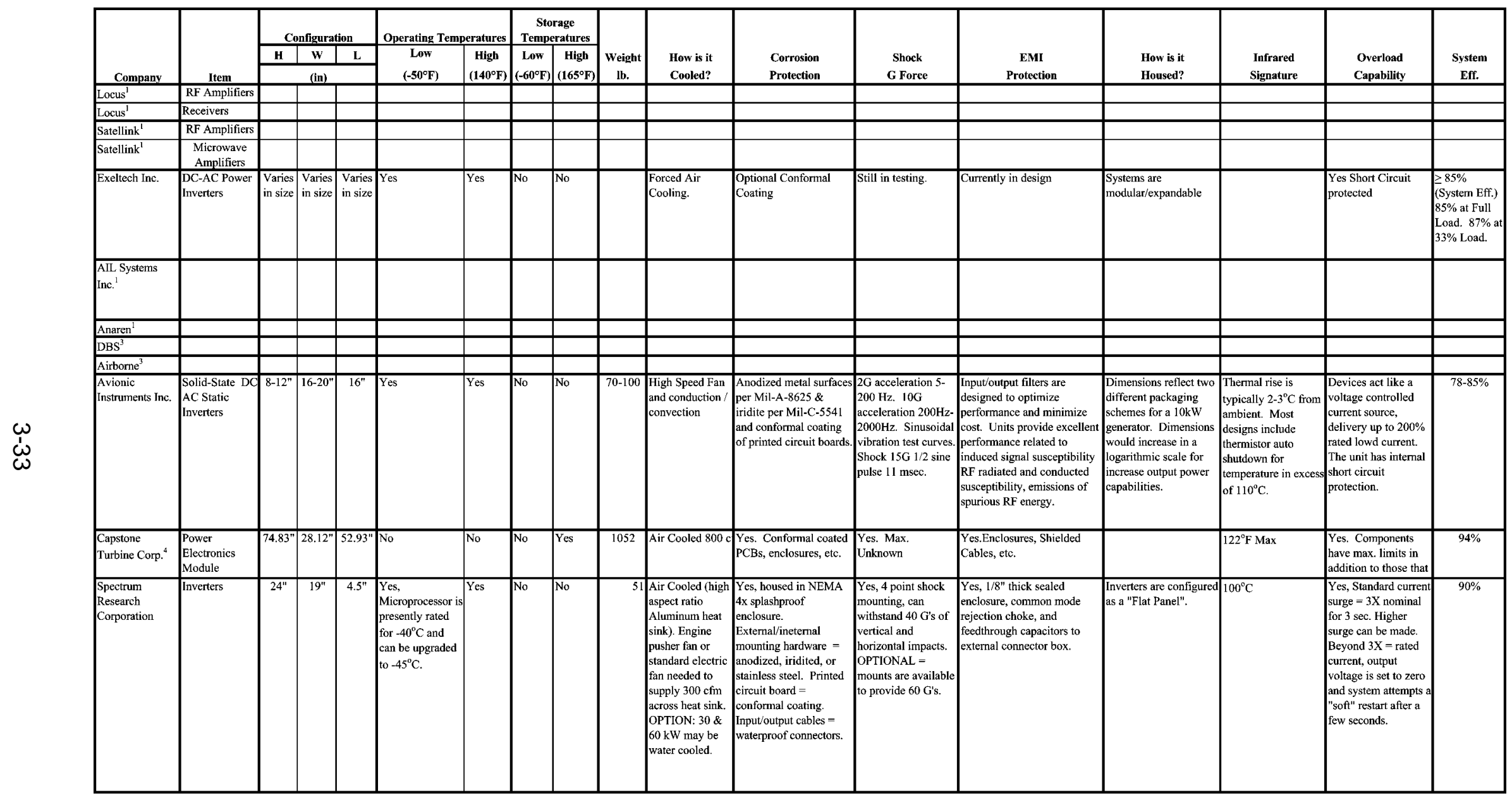

Note:

$1 \Rightarrow$ Does not make Power Electronics for Generators

$2 \rightarrow>$ Not in Business

$3 \rightarrow$ Just for a $30 \mathrm{~kW}$ system 


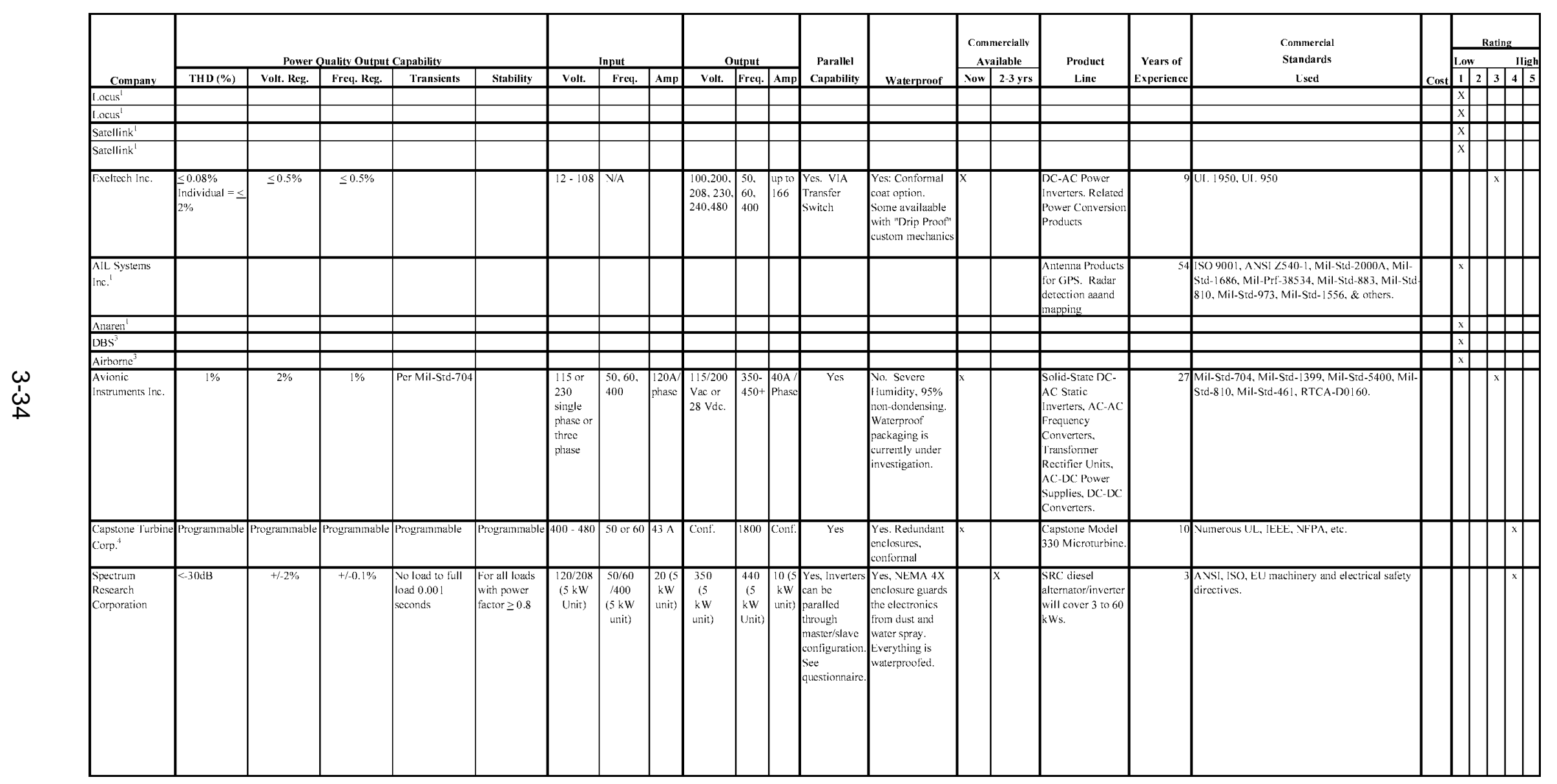




\begin{tabular}{|c|c|c|c|c|}
\hline Company & Address & Telephone FAX Numbers & Responded & Comments \\
\hline Governors America Corp. & $\begin{array}{l}720 \text { Silver Street } \\
\text { Agawam, Ma. } 01000\end{array}$ & $\begin{array}{l}413-786-5600[\mathrm{PH}] \\
413-786-5666[\mathrm{FAX}]\end{array}$ & No & \\
\hline Modular Devices Inc. & $\begin{array}{l}4115 \text { Spencer St. } \\
\text { Torrance, CA } 90503\end{array}$ & $\begin{array}{l}310-542-8561[\mathrm{PH}] \\
310-371-6331[\mathrm{FAX}]\end{array}$ & No & \\
\hline Unitron Inc. & \begin{tabular}{|l}
10925 Miller Rd \\
Dallas, Tx 75238 \\
\end{tabular} & $\begin{array}{l}\text { 214-340-8600 [PH] } \\
214-341-2099[\text { FAX] }\end{array}$ & No & \\
\hline $\begin{array}{l}\text { Wilmore Electronics } \\
\text { Compan Inc. }\end{array}$ & \begin{tabular}{|l} 
P.O. Box 1329 \\
Hillsborough, NC 27278
\end{tabular} & $\begin{array}{l}919-732-9351[\mathrm{PH}] \\
919-732-9359[\mathrm{FAX}]\end{array}$ & No & \\
\hline Exeltech Inc. & $\begin{array}{l}2225 \text { E. Loop } 820 \mathrm{~N} \\
\text { Fort Worth, Tx } 76118\end{array}$ & $\begin{array}{l}817-595-4969[\mathrm{PH}] \\
817-595-1290[\mathrm{FAX}]\end{array}$ & Yes & DC - AC Inverters \\
\hline Abbott Technologies Inc. & $\begin{array}{l}8203 \text { Vineland Ave } \\
\text { Sun Valley, CA } 91352\end{array}$ & \begin{tabular}{|l|}
$818-504-0644[\mathrm{PH}]$ \\
$818-768-0395[\mathrm{FAX}]$ \\
\end{tabular} & No & \\
\hline Abbott Electronics & $\begin{array}{l}2727 \text { La Cienga Blvd } \\
\text { Los Angeles, CA } 90034\end{array}$ & $\begin{array}{l}310-202-8820[\mathrm{PH}] \\
310-836-4926[\mathrm{FAX}]\end{array}$ & No & \\
\hline $\begin{array}{l}\text { Industrial Test Instrument } \\
\text { Instrument Company }\end{array}$ & $\begin{array}{l}21 \text { Yennicock Ave } \\
\text { Port Washington, NY } 11050\end{array}$ & $\begin{array}{l}516-883-1700[\mathrm{PH}] \\
516-883-7155[\text { FAX] } \\
\end{array}$ & No & \\
\hline Compact Power Company & $\begin{array}{l}17282 \text { Orange Dr. } \\
\text { Yorber Linda, CA } 92886 .\end{array}$ & $\begin{array}{l}714-996-5826[\mathrm{PH}] \\
714-996-5826[\mathrm{FAX}]\end{array}$ & No & \\
\hline California Instruments Corp. & $\begin{array}{l}9689 \text { Towne Centre Dr. } \\
\text { San Diego, CA } 92121\end{array}$ & $\begin{array}{l}619-677-9040[\mathrm{PH}] \\
619-677-0940[\mathrm{FAX}]\end{array}$ & No & \\
\hline Behlman Electronics Inc. & $\begin{array}{l}80 \text { Cabot Court } \\
\text { Hauppauge, NY } 11788\end{array}$ & \begin{tabular}{|l}
$516-435-0410[\mathrm{PH}]$ \\
$516-435-4341[\mathrm{FAX}]$
\end{tabular} & No & \\
\hline Avionic Instruments & $\begin{array}{l}1414 \text { Randolph Ave. } \\
\text { Avenel, NJ. 07001 }\end{array}$ & $\begin{array}{l}732-388-3500[\mathrm{PH}] \\
732-382-4996[\text { FAX }]\end{array}$ & No & \\
\hline Zeta & $\begin{array}{l}2811 \text { Orchard Parkway } \\
\text { San Jose, CA } 95134\end{array}$ & $\begin{array}{l}408-434-3600[\mathrm{PH}] \\
408-434-0205[\mathrm{FAX}]\end{array}$ & No & \\
\hline Transistor Devices Inc. & $\begin{array}{l}85 \text { Horsehill Rd } \\
\text { Cedar Knoll, NJ } 07927\end{array}$ & $\begin{array}{l}973-267-1900[\mathrm{PH}] \\
973-267-2047[\text { FAX] }\end{array}$ & No & \\
\hline TRAK Microwave Corp & $\begin{array}{l}4726 \text { Eisenhower Blvd } \\
\text { Dept E9 } \\
\text { Tampa, Fl 33634-6391 }\end{array}$ & $\begin{array}{l}813-884-1411[\mathrm{PH}] \\
813-886-2794[\text { FAX] }\end{array}$ & No & \\
\hline ST-Califomia Operations & $\begin{array}{l}975 \text { Benecia Ave } \\
\text { Sunnyvale, CA } 94086\end{array}$ & $\begin{array}{l}408-730-6300[\mathrm{PH}] \\
408-730-0254[\mathrm{FAX}]\end{array}$ & No & \\
\hline Satelink Inc. & $\begin{array}{l}3525 \text { Miller PK Dr } \\
\text { Garland, Tx } 75042\end{array}$ & $\begin{array}{l}972-487-1434[\mathrm{PH}] \\
972-487-1206[\mathrm{FAX}]\end{array}$ & Yes & Does Not Make Power Electronics \\
\hline RGB Spectrum & $\begin{array}{l}\text { 950 Marina Vlg Pkwy } \\
\text { Alameda, Ca 94501 }\end{array}$ & $\begin{array}{l}510-814-7026[\mathrm{FAX}] \\
510-814-7000[\mathrm{PH}]\end{array}$ & No & \\
\hline Reliance Electric Company & \begin{tabular}{|l}
25001 Tungsten Rd \\
Cleveland, $\mathrm{OH} 44117$
\end{tabular} & $216-266-7120[\mathrm{PH}]$ & No & \\
\hline Power Solutions Inc. & \begin{tabular}{|l|}
4699 N. Federal Hwy \\
Pompano Beach, FL 33064
\end{tabular} & $\begin{array}{l}954-943-4110[\mathrm{PH}] \\
954-943-6068[\mathrm{FAX}]\end{array}$ & No & \\
\hline Power Paragon & $\begin{array}{l}\text { P.O. Box } 66006 \\
\text { Anaheim, CA } 92816\end{array}$ & $\begin{array}{l}714-956-9200[\mathrm{PH}] \\
714-956-4016[\text { FAX }] \\
\end{array}$ & No & \\
\hline Power \& Data Technology Inc & $\begin{array}{l}\text { 81 Great Oaks Blvd } \\
\text { San Jose, CA 95119-1311 }\end{array}$ & $\begin{array}{l}408-629-3550[\mathrm{PH}] \\
408-628-5756[\mathrm{FAX}]\end{array}$ & No & \\
\hline Pacific Power Source Corp. & $\begin{array}{l}15122 \text { Bolsa Chica St. } \\
\text { Hungtington Beach, CA } 92649\end{array}$ & $\begin{array}{l}714-898-2691[\mathrm{PH}] \\
714-898-8076[\mathrm{FAX}]\end{array}$ & No & \\
\hline MITEQ Inc. & $\begin{array}{l}100 \text { Davids Rd } \\
\text { Hauppauge, NY } 11788\end{array}$ & \begin{tabular}{|l|}
$516-436-7400[\mathrm{PH}]$ \\
$516-436-7430[$ FAX] \\
\end{tabular} & No & \\
\hline Marine Electric Systems Inc. & $\begin{array}{l}\text { 2-E Bridewell Rd } \\
\text { Clifton, NJ } 07014\end{array}$ & $\begin{array}{l}973-471-6800[\mathrm{PH}] \\
973-471-2811[\text { FAX] }\end{array}$ & No & \\
\hline Magnum Micrwave Corp. & $\begin{array}{l}1990 \text { Concourse Dr. } \\
\text { San Jose, CA } 95131\end{array}$ & $\begin{array}{l}408-432-9898[\mathrm{PH}] \\
408-432-1551[\mathrm{FAX}]\end{array}$ & No & \\
\hline Locus & $\begin{array}{l}\text { P.O. Box 740 } \\
\text { State College, PA } 16804\end{array}$ & $\begin{array}{l}814-466-6275[\mathrm{PH}] \\
814-466-3341[\text { [FAX] }\end{array}$ & No & \\
\hline LNR Communications Inc. & $\begin{array}{l}70 \text { Suffolk Ct. } \\
\text { Hauppauge, NY } 11788\end{array}$ & \begin{tabular}{|l|}
$516-273-7111[\mathrm{PH}]$ \\
$516-761-5454[$ FAX]
\end{tabular} & No & \\
\hline
\end{tabular}




\begin{tabular}{|c|c|c|c|c|}
\hline Company & Address & Telephone/FAX Numbers & Responded & Comments \\
\hline Glenayre Western Multiplex & $\begin{array}{l}1196 \text { Borregas Ave } \\
\text { Sunnyvale, CA } 94089\end{array}$ & $\begin{array}{l}408-542-5200[\mathrm{PH}] \\
408-542-5300[\mathrm{FAX}]\end{array}$ & No & \\
\hline $\begin{array}{l}\text { Electro-Tech Inc. } \\
\text { Power Star Product Line }\end{array}$ & $\begin{array}{l}1313 \text { Newburgh Rd } \\
\text { Westland, MI } 48186\end{array}$ & $\begin{array}{l}313-729-0050[\mathrm{PH}] \\
313-729-0238[\mathrm{FAX}]\end{array}$ & No & \\
\hline Durmitor Inc. & $\begin{array}{l}23 \text { Crossley Ct. } \\
\text { King City, ON } \\
\text { L7B 1H4 Canada }\end{array}$ & $\begin{array}{l}905-833-3148[\mathrm{PH}] \\
905-833-2112[\mathrm{FAX}]\end{array}$ & No & \\
\hline DBS Microwave Inc. & $\begin{array}{l}4919 \text { Windplay Dr. Ste } 2 \\
\text { El Dorado Hills, CA } 95762\end{array}$ & $\begin{array}{l}916-939-7545[\mathrm{PH}] \\
916-939-7540[\mathrm{FAX}]\end{array}$ & No & Post Office did not deliver letter \\
\hline $\begin{array}{l}\text { Comtech Microwave } \\
\text { Products Corp. }\end{array}$ & $\begin{array}{l}105 \text { Baylis Rd. } \\
\text { Melville, NY } 11747\end{array}$ & $\begin{array}{l}516-777-8900[\mathrm{PH}] \\
516-777-8877[\mathrm{FAX}]\end{array}$ & No & \\
\hline Communications Solutions Inc. & $\begin{array}{l}7034 \text { Golden Ring Rd } \\
\text { Baltimore, MD } 21237\end{array}$ & $\begin{array}{l}410-574-4557[\mathrm{PH}] \\
410-574-4559[\mathrm{FAX}]\end{array}$ & No & \\
\hline $\begin{array}{l}\text { BEC Inc./Certified } \\
\text { Calibration Labs }\end{array}$ & $\begin{array}{l}812 \text { Chestnut Street } \\
\text { Perkasie, PA } 18944\end{array}$ & $\begin{array}{l}215-257-2900[\mathrm{PH}] \\
215-257-1975[\mathrm{FAX}] \\
\end{array}$ & No & \\
\hline Elgar Electronics Corp & $\begin{array}{l}9250 \text { Brown Deer Rd } \\
\text { San Diego, CA } 92121\end{array}$ & $\begin{array}{l}619-450-0085[\mathrm{PH}] \\
619-450-0267[\mathrm{FAX}]\end{array}$ & No & \\
\hline Anaren Microwave Inc & $\begin{array}{l}6635 \text { Kirkville Rd } \\
\text { E. Syracuse, NY } 13057\end{array}$ & $\begin{array}{l}315-432-8930[\mathrm{PH}] \\
315-432-9121[\mathrm{FAX}]\end{array}$ & Yes & Not a manufacturer of power electronics \\
\hline Airborne Power & $\begin{array}{l}\text { 2002 E. Watkins, Ste } 1 \\
\text { Phoenix, Az } 85034\end{array}$ & $\begin{array}{l}602-253-4663[\mathrm{PH}] \\
602-253-4773[\mathrm{FAX}]\end{array}$ & No & Post Office did not deliver letter \\
\hline Advance Power Design Inc. & $\begin{array}{l}\text { l7752 Skypark Cir } \# 240 \\
\text { Irvine, CA } 92714\end{array}$ & $\begin{array}{l}714-263-8605[\mathrm{PH}] \\
714-263-8607[\mathrm{FAX}]\end{array}$ & No & \\
\hline AIL Systems Inc. & $\begin{array}{l}455 \text { Commack Rd } \\
\text { Deer Park, NY } 11729\end{array}$ & $\begin{array}{l}516-595-3094[\mathrm{PH}] \\
516-595-3369[\mathrm{FAX}]\end{array}$ & Yes & Not a manufacturer of power electronics \\
\hline KGS Electronics Inc. & $\begin{array}{l}\text { 418a E. Live Oak Ave } \\
\text { Arcadia, CA } 91006\end{array}$ & $\begin{array}{l}626-574-1175[\mathrm{PH}] \\
626-574-0553[\mathrm{FAX}]\end{array}$ & No & \\
\hline Nova Electric & $\begin{array}{l}100 \text { School St. } \\
\text { Bergenfield, NJ } 07621\end{array}$ & $\begin{array}{l}201-385-0500[\mathrm{PH}] \\
201-385-0702[\mathrm{FAX}]\end{array}$ & No & \\
\hline Georator Corp & $\begin{array}{l}9617 \text { Center St } \\
\text { Manassas, VA } 20110\end{array}$ & $\begin{array}{l}703-368-2101[\mathrm{PH}] \\
703-368-1078[\mathrm{FAX}]\end{array}$ & No & \\
\hline Abacus Controls Inc. & $\begin{array}{l}80 \text { Readington } \mathrm{Rd} \\
\text { Somerville, NJ } 08876\end{array}$ & $\begin{array}{l}908-526-6010[\mathrm{PH}] \\
908-526-6866[\mathrm{FAX}]\end{array}$ & No & \\
\hline Spectrum Research Corp. & $\begin{array}{l}\text { Rensselaer Technology Park } \\
165 \text { Jordan Rd } \\
\text { Troy, NY } 12180 \\
\end{array}$ & $\begin{array}{l}518-283-7660[\mathrm{PH}] \\
518-283-7813[\mathrm{FAX}]\end{array}$ & Yes & \\
\hline Dewey Electronics Inc. & $\begin{array}{l}179 \text { Tinton Ave } \\
\text { Eatontown, NJ } 07724\end{array}$ & & No & \\
\hline Synchrotek & & & No & \\
\hline $\begin{array}{l}\text { Capstone Turbine } \\
\text { Corporation }\end{array}$ & $\begin{array}{l}6430 \text { Independence Ave } \\
\text { Woodland Hills, Ca. } 91367\end{array}$ & $\begin{array}{l}818-716-2929[\mathrm{PH}] \\
818-716-9910[\mathrm{FAX}]\end{array}$ & Yes & \\
\hline
\end{tabular}




\section{MARKET SURVEY OF STATE-OF-THE-ART DIGITAL CONTROL AND D\&P SYSTEMS}

The purpose of this chapter is to describe the results of the market survey on digital control systems including a D\&P system. Vendor-developed control systems and the components used to build a customized control system were considered.

\subsection{SURVEY OF DIGITAL CONTROL SYSTEMS}

Market survey data provided by CECOM (see Appendixes 4-A and 4-B) provided a fairly complete listing of the available controllers used by the various vendors. While an extensive array of controllers exists, there are none on the market today that are designed to be generic. They are all specifically designed to control the particular system of their application. Vendors are not inclined to make a product that the competition could use or provide the necessary intellectual property so that the controller could be purchased separate from the gen-set. Also, most gensets are not variable speed and do not require the power electronics to produce the desired output. The systems on the market today are primarily for operator interface, monitoring of the system, and limited diagnostics. They use standard imbedded computers or microcomputers. If variable-speed control is used, a very high speed digital signal processor (DSP) would be required to operate the inverter and produce the various frequencies and voltage levels from the gen-set. Current systems simply do not provide all the required capability for future gen-sets.

Commercial digital control systems also provide limited diagnostic capabilities that are inherently optimized for the specific vendor equipment they monitor and are thus not generically applicable. These systems usually provide simple signal level indicators that require interpretation by the operator. For example, low oil pressure and high engine temperature indicators are provided, but the root causes for these anomalous conditions are not determined and displayed by the system. While the majority of the "raw signal" information (from installed sensors) is thought to be available on the gen-set, the signal analysis required for problem/cause determination is typically not included. Likewise, the data acquisition and trending capabilities needed for failure prognostication are also missing.

This section contains information from the two controls manufacturers that supplied data to ORNL for this review and a matrix from CECOM detailing additional information from several gen-set manufacturers. The market survey of control systems is particularly useful for comparing the various features that are available.

\section{Kohler Power Systems}

The controller for the Kohler gen-set contains microcomputer-based logic with a ROM based control algorithm.

The Decision $3+, 16^{\mathrm{TM}}$ light controller has the following standard features:

- Analog gauges, $2 \%$ full-scale accuracy

- oil pressure

- water temperature

- battery voltage

- Analog meters

- ac current, $2 \%$ full-scale accuracy 
- ac voltage, $2 \%$ full-scale accuracy

- frequency meter, $0.5 \%$ full-scale accuracy

- Fault, and shutdown indicators

- emergency stop

- low fuel pressure or fuel level

- low coolant level

- overcrank

- overspeed

- low oil pressure

- prealarm, low oil pressure

- high engine temperature

- low water temperature

- prealarm, engine temperature

- high battery voltage

- low battery voltage

- battery charger fault

- overvoltage

The controllers are vibration isolated from the engine and can tolerate temperatures from -40 to $185^{\circ} \mathrm{F}$. They also meet the National Fire Protection Association (NFPA) requirements of NFPA-99 and NFPA 110, level 2.

Controllers have hardware and software filters to protect components from electrical noise.

\section{Onan Power Command ${ }^{\mathrm{TM}}$ Gen-Set Control}

The Power Command ${ }^{\mathrm{TM}}$ control is a microprocessor-based gen-set monitoring, metering, and control system. The control system has sophisticated servicing capabilities that allow system parameters to be interrogated, monitored, and adjusted with a laptop computer.

The front panel is covered with a membrane that is impervious to water spray, dust, and oil/exhaust residue. The control door is gasketed with a dual dust/moisture and RFI/EMI gasket to protect internal components. Operating temperature is between -40 and $15^{\circ} \mathrm{F}$, up to $95 \%$ relative humidity (noncondensing) and up to an altitude of $10,000 \mathrm{ft}$.

Basic gen-set operating parameters can be set by the operator after entering an access code. The adjustments are limited to prevent operator error and damage to connected equipment. The following parameters are adjustable:

- Voltage $\pm 5 \%$

- Frequency $\pm 5 \%$

- Time delay start (0-300 s)

- Time delay stop (0-600 s)

- Analog meters

- kilowatt meter

- ac voltmeter

- ac ammeter

- Digital meters

- gen-set output voltage (three-phase, line-to-line, or line-to-neutral) 
- power factor

- ac kilowatts

- ac kilowatt-hours

- alternator exciter duty and governor duty (\%)

- gen-set output frequency $(\mathrm{Hz})$

Alarm and status messages are displayed on a two-line 16 character-per-line, screen with reference to the operator's manual for further information.

- Engine warning and shutdown messages

- oil pressure sender (warning, indicates a sender or wiring failure)

- engine temperature sender (warning, indicates a sender or wiring failure)

- low oil pressure (warning)

- high coolant temperature (warning)

- low coolant temperature (warning)

- low coolant level (programmable shutdown or warning)

- low fuel level (warning)

- low battery voltage (warning)

- high battery voltage (warning)

- weak battery (warning)

- fail to crank (shutdown)

- overcrank (shutdown)

- overspeed (shutdown)

- magnetic pick-up failure (shutdown)

- emergency stop (shutdown)

AmpSentry Protection ${ }^{\mathrm{TM}}$ provides a comprehensive power monitoring and control system integral to the Power Command Control ${ }^{\mathrm{TM}}$ that guards the electrical integrity of the alternator and power system. This provides excellent matched protection for the alternator without danger of excessive tripping.

In comparison, it appears that Cummins Onan has much to offer in this area. It is the only single source manufacturer of engines, alternators, and gen-set controls in the world. This control unit has many more features that are not listed here and, excluding price comparisons, appears to be by far the best choice.

\subsection{SURVEY OF COMMERCIAL DEVICES FOR DIGITAL CONTROL SYSTEMS}

As previously described, a system providing the required digital control, and D\&P capabilities deemed to be necessary for future variable-speed gen-sets is not presently available commercially. This new system will need to be developed; however, the hardware devices utilized by the new system are commercially available now and for the foreseeable future.

The digital control system will be comprised of many devices, such as those included in Table 4.1. A market survey performed by ORNL confirmed the commercial existence and broad selection of many types of relevant devices, while a market survey performed by CECOM identified the variety of flat panel display units that are available (see Appendix 4-C). 
Table 4.1. Market survey areas (from project statement of work)

\begin{tabular}{|l|l|}
\hline \multicolumn{1}{|c|}{ Area } & \multicolumn{1}{c|}{ Examples } \\
\hline Microprocessors & Single board and single chip embedded micro-controllers. \\
\hline Sensors & $\begin{array}{l}\text { Oil pressure, air pressure, temperature (coolant, turbo- } \\
\text { charger, alternator, power electronics), engine speed, oil } \\
\text { viscosity, and any others needed for D\&P. }\end{array}$ \\
\hline Flat panel displays & $\begin{array}{l}\text { Field emitting displays (FEDs), liquid crystal displays } \\
\text { (LCDs), and vacuum florescent displays (VFDs). }\end{array}$ \\
\hline Instrumentation & $\begin{array}{l}\text { Gauges and meters, transducers and transmitters, power } \\
\text { conversion products, connectors, relays, user interface } \\
\text { panels (membrane panel), touch screens, toggle } \\
\text { switches, and all other components needed to interface } \\
\text { D\&P to a gen-set. }\end{array}$ \\
\hline Protective devices & $\begin{array}{l}\text { Ground fault interrupters (GFls), protective solid state } \\
\text { relays, permissive paralleling, power reversal, and other } \\
\text { methods and technologies that protect the gen-set from } \\
\text { damage and protect the user. }\end{array}$ \\
\hline Diagnostics & $\begin{array}{l}\text { Methods that are used to provide diagnostics (display, } \\
\text { monitor, and control the properties) of engine/generator } \\
\text { systems. }\end{array}$ \\
\hline Prognostics & $\begin{array}{l}\text { Approaches used to do prognostics on engine and gen- } \\
\text { erator items. }\end{array}$ \\
\hline
\end{tabular}

\subsubsection{Market Survey Results}

Using Table 4.1 as a guide, a general scoping effort was carried out to estimate the number of commercial sources of products that are related to gen-set digital control and D\&P. The "1999 Buyers Guide," published by Sensors Magazine was used as a reference because it provides a comprehensive directory of over 1100 suppliers of sensor-related technologies. From this reference, the numbers of commercial sources for products related to gen-set monitoring were determined and are presented in Table 4.2.

As shown in Table 4.2, the number of potential suppliers of relevant devices is very large and provides confidence that these devices are now and will be commercially available for the foreseeable future.

\subsubsection{Diesel Engine Diagnostic Systems}

Among the commercially available devices that were identified by the market survey include several diagnostic systems that have been specifically developed for application to diesel engines.

An example of one of these systems is the Engine Condition Monitor, developed by Advanced Engine Technology Ltd., for use by the Canadian Department of National Defense in its remotely located radar sites in northern Canada. This system is based on measurements of instantaneous crankshaft angular velocity (ICAV), a technology developed by the National Research Council of Canada. ICAV provides a nonintrusive method of evaluating the power contribution of each cylinder of a diesel engine. A variety of engine problems may be detected in this manner such as fuel rack adjustments, injector fouling, valve seating, and ring breakage. 
Table 4.2. Number of suppliers of selected products

\begin{tabular}{|l|c|}
\hline \multicolumn{1}{|c|}{ Product } & $\begin{array}{c}\text { Number of listed } \\
\text { suppliers }\end{array}$ \\
\hline Sensors & 144 \\
\hline Pressure & 298 \\
\hline Temperature & 66 \\
\hline Angular velocity & 24 \\
\hline Viscosity & 90 \\
\hline Electrical-frequency & 58 \\
\hline Electrical—power & 139 \\
\hline Electrical—voltage & 121 \\
\hline Electrical—current & 149 \\
\hline Flow-liquid & 193 \\
\hline Level—liquid & 119 \\
\hline Vibration/shock & 158 \\
\hline $\begin{array}{l}\text { Computer software for applying, designing, and } \\
\text { interfacing sensors }\end{array}$ & 84 \\
\hline Connectors & 126 \\
\hline Control systems & 279 \\
\hline Data acquisition software and hardware & 79 \\
\hline Leak detectors & 275 \\
\hline $\begin{array}{l}\text { Meters, gauges, displays, and other indicating } \\
\text { equipment }\end{array}$ & 75 \\
\hline Safety equipment and systems & \\
\hline
\end{tabular}

Source: "1999 Buyers Guide," Sensors Magazine.

The system has been designed to permit fully automated operation, with provisions for downloading diagnostic data from the system to a monitoring station for analysis.

In addition, increased interest in D\&P by the military and commercial sectors has resulted in the development of many systems for application to diesel engine vehicles. The core component of these systems is the electronic control module (ECM). The ECM typically collects and monitors several parameters such as engine revolutions per minute, crankshaft or camshaft position, atmospheric and oil pressures, coolant and intake air temperatures, and injector timing, using a variety of sensors. The ECM then adjusts engine operation to meet programmed objectives (e.g., increased efficiency and lower emissions) The ECM can also alert the user to problems and failures by means of lights, gauges, or other displays. Descriptions of several diesel vehicle diagnostics systems are described in an article ${ }^{1}$ that is available on the Internet at http://www.ccimagazine.com/0199f1.htm. Systems mentioned in the article are briefly described below, with the addition of other information obtained from the company Web sites. While these systems have been developed for specific rather than generic applications, their basic approach to engine monitoring, control, and diagnostics is of general interest and is thus included in this report.

- Mack Trucks, Inc.

World Headquarters, 2100 Mack Boulevard, P.O. Box M, Allentown, PA 18105-5000

Web Site: http://www.macktrucks.com/ 
Mack Trucks, Inc., has developed the $\mathrm{V}-\mathrm{MAC}^{\circledR}$ III system for use in their E-Tech ${ }^{\mathrm{TM}}$ engines. The V-MAC ${ }^{\circledR}$ III system includes separate ECMs for the vehicle (truck) and the engine. The engine ECM provides electronic fuel controls and electronic timing controls. Other programmable options include governor, low idle speed, high idle speed, torque limit option, "smart fan" option, engine brake control, and engine protection. This system also claims to provide a maintenance monitor and integrated diagnostics.

Engine malfunctions are logged into memory for retrieval by a personal computer (PC), handheld service tool, blink codes, or by an optional display called the "Co-pilot." The ECU is programmed at the dealer level by software called "Mack Data Programming" and "Product Software Programming." Additional software is available by use for technicians to diagnose and repair identified problems.

- $\quad$ Cummins Engine Company, Inc.

P.O. Box 3005, Columbus, IN 47202-3005

Web Site: http://www.cummins.com/

Cummins offers the Interact ${ }^{\mathrm{TM}}$ engine control system for several of its engines. The Interact $^{\mathrm{TM}}$ system provides fully integrated electronics that monitor and control engine and other vehicle parameters. The system claims to include advanced D\&P, with industrystandard means of uploading and downloading information.

Cummins Marine offers a new engine with integrated D\&P. This engine (the QSM11) features the Quantum System, a control system that provides an ECM, engine sensors, diagnostics, engine speed control and analog displays. A more advanced electronic package, called C Cruise, offers cruise control, alternate/custom low idle, engine synchronization for twin-engine applications, advanced, interactive digital (LCD) engine displays, and D\&P. Cummins claims that the ECM processes engine parameters every $20 \mathrm{~ms}$.

- Caterpillar Inc.

100 N. E. Adams, Peoria, IL 61629

Web Site: http://www.caterpillar.com/

Caterpillar offers an electronic system featuring an ECM that records engine parameters immediately before, during, and after a fault occurs. Caterpillar claims that the ECM provides advanced diagnostics and controls over 100 electronic functions. The same ECM is used on all Caterpillar electronic engines. An optional display gives information on particular engine operating conditions and can alert the user to fault codes as they happen. Caterpillar plans to market a new advanced diesel engine system (ADEM-III) this year. The new system will feature a 32-bit, 24-MHz processor, which can support up to 140 inputs and outputs.

In addition, Caterpillar advertises a tool for quickly determining battery condition and remaining life. The tool measures the battery's internal conductance and uses the measurements to identify bad cells. In addition, voltage and cranking power tests are done. Using this tool, Caterpillar claims to be able to diagnose battery problems before failure. Battery testing methods such as this should be further reviewed for possible incorporation onboard a gen-set. 
- Volvo Trucks North America, Inc.

P.O. Box 26115, Greensboro, NC 27402-6115

Web Site: http://www.volvo.com/

Volvo provides the Vectro II ECU that monitors engine parameters and makes adjustments as required to ensure that the engine operates properly under a variety of conditions. Engine parameters monitored by Vectro II include engine speed, crankshaft and camshaft position, coolant and intake air temperature, and boost pressure. Volvo plans to offer an information display this year that will eliminate the need to use a handheld reader to pull fault codes.

Volvo has also developed a PC-based diagnostic and repair service system called Impact ${ }^{\mathrm{TM}}$. Technicians enter symptoms of a problem into the Impact $^{\mathrm{TM}}$ system, and the system responds with an identification of the problem, and a list of the parts needed to repair the problem.

- Detroit Diesel Corporation

13400 Outer Drive, West, Detroit, Ml, 48239-4001

Web Site: $h$ ttp://www.detroitdiesel.com/

Since 1985, Detroit Diesel Corporation (DDC) claims to have produced over 425,000 electronically controlled engines. The first Detroit Diesel Electronic Controls (DDEC I) have now been followed by more advanced DDEC II, DDEC III, and now, DDEC IV. Like several other systems on the market, a technician can retrieve information from the system using a handheld reader or a computer. DDC's Diagnostic Link software contains a built-in service manual and is used to extract data and manage information from the DDEC system. "Case Based Reasoning" software is also available when troubleshooting help is needed. This software requires a brief description of the problem; then it displays additional questions to point the technician in the right direction. A display unit (ProDriver) is also available from DDC for monitoring and recording operating data, including of fault codes. Additional specific information on DDEC products may be found at $h$ ttp://www.valleydda.com/ddec.htm.

\subsubsection{Other Diagnostic Systems}

Examples of other products are provided in this section to illustrate the variety of systems that address equipment D\&P. Only a few commercially available systems are described here to show the diversity of approaches offered by the commercial systems.

- Support Systems Technology Corporation

P.O. Box 7945, Gaithersburg, MD 20898-7945

Web Site: $\underline{\text { http://www. sstctech.com/serv03.htm }}$

Support Systems Technology Corporation (SSTC) has developed a system for performing D\&P of nonelectronic equipment. The system provides original estimates of component design life that assume an expected operational environment. Sensor types and locations are then determined which will be required for the D\&P routines. Sensor signals, together with the remaining life equations developed by SSTC, are used to monitor equipment performance and the remaining life of individual components within the equipment. The remaining life equations are continually recalculated as operational and environmental conditions change. SSTC claims to provide information about existing and impending faults and isolates them to the appropriate replaceable assembly. Maintenance personnel are provided 
with recommended maintenance actions to be performed, such as necessary inspections and/or replacements or repairs to prevent equipment failures.

- Giordano Automation Corp.

21 White Deer Plaza, Sparta, NJ 07871

Web Site: http://www.premise.com/giordano/

Giordano Automation Corp. (GAC) markets several diagnostic software products that emphasize "model-based reasoning," rather than fault trees. One of its products, the "Diagnostician," identifies specific equipment faults by correlating test data to a diagnostic model of the equipment that is generated by another product called the "Diagnostic Profiler." GAC claims that the diagnostic capabilities provided by the Diagnostician are dynamic and not restricted to a predefined set of decision paths. Its capabilities may be accessed by other test software such as LabView ${ }^{\mathrm{TM}}$ and LabWindows ${ }^{\mathrm{TM}}$.

GAC has described its products in two presentations to CECOM (June 3, 1998). These presentations are available on the Internet:

http://edm.monmouth.army.mil/pubs/info sympo/diagnos1/sld001.htm, http://edm.monmouth.army.mil/pubs/info sympo/diagnos2/s/d001.htm.

- National Instruments Corporation

11500 N Mopac Expressway, Austin, TX 78759-3504

Web Site: http://www.natinst.com/

National Instruments develops and manufactures integrated software and hardware products that when combined with standard computers, are used to replace and/or communicate with traditional instrumentation and to monitor and control processes. Using its virtual instrumentation (VI) approach, standard instruments are replaced by user-defined instruments that possess the characteristics needed by specific applications. The software utilized to develop these VIs is LabView ${ }^{\top \mathrm{M}}$, a graphical programming development environment for data acquisition and control, data analysis, and data presentation. With LabView ${ }^{\mathrm{TM}}$, front panel user interfaces are quickly created. These interfaces can include numeric displays, meters, gauges, thermometers, tanks, LEDs, charts, graphs, and other objects. When the VI is complete, the front panel is used to control the instrument as well as display the desired information. System functionality is created by building a block diagram that is the program that runs the VI. Functional icons are selected and connected together with "wires." The icons are subprograms in themselves, and when wired together, they define the functionality of the VI. Very powerful VIs can be created that provide the data acquisition, analysis, trending, and displays needed by D\&P systems.

- $\quad$ SKF Condition Monitoring, Inc.

4141 Ruffin Road, San Diego, California 92123

Web Site: http://www.skfcm.com/

SKF Condition Monitoring, Inc., offers portable and on-line instrumentation, sensors, software, and accessories to support predictive maintenance programs. The SKF family of Microlog Data Collector/Analyzers and companion PRISM ${ }^{4} \mathrm{Pro}^{\mathrm{TM}}$ software are designed to work together to enable a user to solve condition monitoring problems. PRISM ${ }^{4} \mathrm{Pro}^{\mathrm{TM}}$ assesses machine condition, provides a diagnosis, and recommends corrective actions based on live and historical data. 
A variety of inputs are accepted including vibration data and process data (e.g., temperature, pressure, flow, load, voltage, and amperage). The system uses a rule base to identify problems and monitors many machinery types including fans, generators, pumps, reciprocating machinery, and other devices. Alert and alarm levels may be set to provide user feedback. The user has the ability to display any data set being analyzed by the system, including trend data.

- Computational Systems Incorporated

835 Innovation Drive, Knoxville, TN 37932

Web Site: http://www.compsys.com/home.nsf

Computational Systems Incorporated (CSI) provides products and services to enhance reliability-based maintenance (RBM) activities such as vibration analysis, oil analysis, infrared thermography, alignment, balance, motor diagnostics, and continuous monitoring. CSI offers lightweight, rugged signal analyzers that work together with its MasterTrend ${ }^{\mathrm{TM}}$ software for organization, comprehensive analysis, and problem diagnosis. Using MasterTrend ${ }^{\mathrm{TM}}$, maintenance technicians can detect, diagnose, confirm, and correct problems, as well as determine the root cause of problems.

\subsubsection{Rugged Computers}

To maximize onboard capabilities, consideration should be given toward the use of a dedicated computer for data monitoring, analysis, D\&P, and display functions. A computer running a $\mathrm{VI}$ software program can provide the capabilities needed for today and the ability to upgrade the system to meet tomorrow's needs. Recognizing that computing capability evolves at an extremely fast rate, it is important to select a computer system that may be easily upgraded. Equally important is the requirement for long-term support by the computer supplier/manufacturer. Ultimately, the D\&P computing capabilities should be integrated with the digital control system in a single sealed enclosure. Eighteen suppliers of rugged portable computers were identified through Internet searches and represent potential suppliers of a D\&P computer. Nine suppliers were identified from the Army Technology Web Site (http://www.armytechnology.com/, and nine were found elsewhere:

- Cyberchron Corporation

P.O. Box 160, Route 9, Cold Spring, NY 10516

Web Site: http://www.cyberchron.com/

- GETAC U.S.A

15273 Alton Parkway, Suite \#200, Irvine, CA 92618

Web Site: http://www.GetacUSA.com/

- MILPER Ltd.

58 Hama'avak St., P.O. Box 147, Givataim, Israel 53101

Web Site: http://www.milper.com/

- Miltope Corporation

500 Richardson Road South, Hope Hull, AL 36043

Web Site: http://www. miltope.com/ 
- Paravant Computer Systems, Inc.

1615A West NASA Boulevard, Melbourne, FL 32901

Web Site: http://www.paravant.com

- Promark Technology

10810 Guilford Road, Suite 101, Annapolis Junction, MD 20701

Web Site: http://www.promarktech.com/Promark/home.asp

- Rugged Portable Systems (RPS)

1740 E. Wilshire Ave., Santa Ana, CA 92705

Web Site: http://www.rpseagle.com/rps/rpsindex.htm

- Tadpole-RDI Computer Corporation

2300 Faraday Avenue, Carlsbad, CA 92008

Web Site: http://www.rdi.com/

- Thomson-CSF Services Industrie

105 Boulevard du Général Einsenhower, BP 1009, 31023 Toulouse Cedex, France

Web Site: http://www.tsi.thomson-csf.com (note: Web site is in French)

- SATLOC Inc.

15990 Greenway Hayden Loop, Scottsdale, AZ 85260

Web Site: http://www.satloc.com/

- Phoenix Group Inc.

123 Marcus Blvd., Hauppauge, NY 11788

Web Site: http://ivpgi.com/

- TransCOR Information Technologies

Five Market Square, 207 Hamilton Gateway Building, Amesbury, MA 01913-2440

Web Site: $\underline{\text { http://transcor-it.com/ }}$

- Laversab

10503 Rockley Road, \#103

Houston, TX 77099

Web Site: $\underline{\text { http://www.laversab.com/ }}$

- TerraDat UK Ltd.

P.O. Box 319, Cardiff, CF1 3UJ, U.K.

Web Site: http://www.geotechnology.co.uk/

- Fieldworks, Inc.

7631 Anagram Drive, Eden Prairie, MN 55344

Web Site: http://www.field-works.com/

- Itronix, Corp.

South 801 Stevens, Spokane, WA 99204

Web Site: http://www. itronix.com/ 
- Dolch Computer Systems, Inc.

3178 Laurelview Court, Fremont, CA 94538

Web Site: http://www.dolch.com/

- WPI Micro Processor Systems, Inc.

6405 Nineteen Mile Road, Sterling Heights, MI 48314

Web Site: http://www.mpsilink.com/

\subsubsection{Flat Panel Displays}

While many of the rugged computer manufacturers listed above use flat panel displays, seven additional suppliers of these displays were identified and are listed below. An additional detailed matrix of flat panel display specifications was created by CECOM and is included in this report as Appendix 4-C.

- General Digital Corporation

160 Chapel Road, Manchester, CT 06040

Web Site: http://www.gendig.com/hardware/products/hwprod.htm

- Motorola, Inc.

1303 E. Algonquin Rd. Schaumburg, IL 60196

Web Site: http://www.mot.com/flatpanel/

- BARCO Inc.

3240 Town Point Drive, 30144 Kennesaw, GA 30144

Web Site: http://www.barco.com/display/index.htm

- Computer Dynamics, Inc.

7640 Pelham Road, Greenville, SC 29615

Web Site: http://www.cdynamics.com/

- Litton Data Systems

Agoura Hills, CA

Web Site: http://www.littonsandiego.com/displays/rugged flat panel.html

- Aydin Displays

700 Dresher Road, Horsham, PA 19044

Web Site: $\underline{\text { http://www.aydin.com/displays/rugged-displays.html }}$

- Tactical Displays, Inc.

1720 E. Garry Ave., Suite 120, Santa Ana, CA 92705

Web Site: http://www.tacticaldisplays.com/

\subsection{SUMMARY OF DIGITAL CONTROL SYSTEMS (INCLUDING D\&P) MARKET SURVEY}

A market survey has been conducted to identify state-of-the-art technologies that are applicable to digital controls and D\&P for new MEP equipment. The survey considered the broad range of applicable methods and the numerous devices that would be needed for this application. 
A system providing the required digital control and D\&P capabilities deemed to be necessary for future variable-speed gen-sets is not presently available commercially. This new system will need to be developed; however, the hardware devices utilized by the new system are commercially available now and for the foreseeable future.

Perhaps the most important element that is presently missing from commercially available D\&P systems is the knowledge of how to relate gen-set specific "signatures" to the condition of components within the monitored equipment. This knowledge provides the foundation for advanced signature-analysis based D\&P methods and need to be obtained by testing gen-sets in both good and degraded condition. Test results will then be used to create algorithms for automated D\&P.

While the algorithms (software) have not yet been developed, the necessary system hardware components already exist on the commercial market. Several hundred suppliers of relevant products (including sensors, processors, and displays) have already been identified from the market survey.

The major conclusion from the market survey is that while the components necessary to construct a control system with D\&P capability in future gen-sets are available and reasonably affordable today, the control systems that are available today will not provide the required capability. The technology is largely electronics and should continue to progress rapidly in the next few years and allow not only more choices among the components but also lower prices for those components. Without a focused development effort, it is not anticipated that an acceptable COTS gen-set control system with D\&P will become available in the near future.

\subsection{REFERENCE}

1. N. Norville, "Diesel Diagnostics Update," Commercial Carrier Journal, January 1999. 
Appendix 4-A. DIGITAL CONTROL SYSTEM DATA PROVIDED BY CECOM FOR MARKET SURVEY 
4-14 


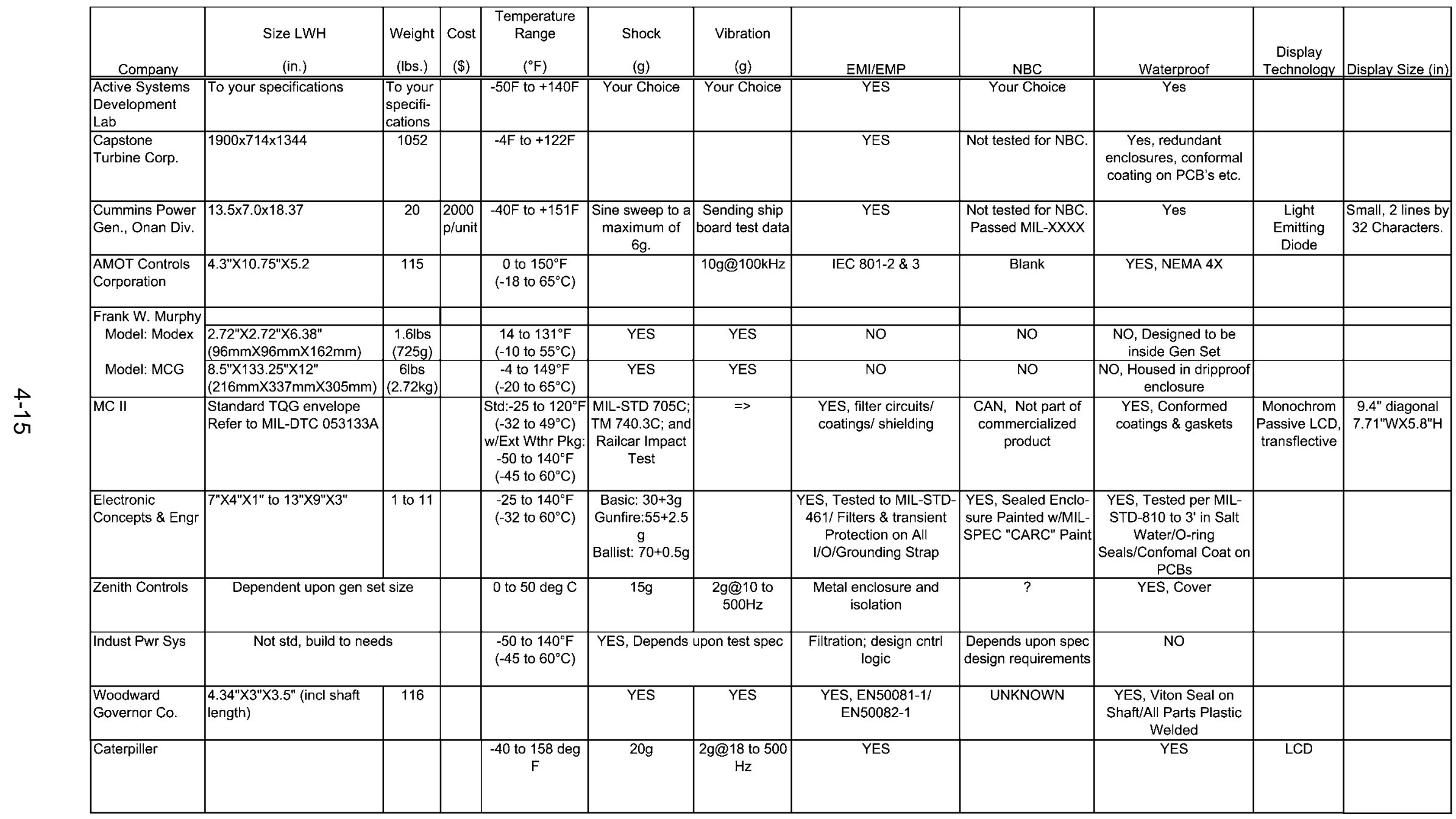




\begin{tabular}{|c|c|c|c|c|c|c|c|}
\hline \multirow[b]{2}{*}{ Company } & \multirow[b]{2}{*}{ User Interface } & \multirow[b]{2}{*}{ Digital Bus } & \multicolumn{2}{|c|}{ Parallel Utility } & \multirow{2}{*}{\begin{tabular}{|l|} 
Is the digital control system \\
Software Configurable for the \\
entire 5-60kW Range? If not \\
please specify the range.
\end{tabular}} & \multirow{2}{*}{$\begin{array}{l}\text { Have you ever sold Digital Control systems } \\
\text { to the US Army or other DoD agency? } \\
\text { Please specify. }\end{array}$} & \multirow[b]{2}{*}{ Corrosion Protection } \\
\hline & & & Utility & Generator & & & \\
\hline \begin{tabular}{|l|} 
Active Systems \\
Development Lab
\end{tabular} & Your Choice & Serial or Parallel & & YES & YES & NO & Yes, with conformal coating \\
\hline $\begin{array}{l}\text { Capstone Turbine } \\
\text { Corp. }\end{array}$ & Display or portable computer. & $\begin{array}{l}\text { RS-232 } \\
\text { RS-485 }\end{array}$ & & YES & No, up to $30 \mathrm{~kW}$ maximum. & & $\begin{array}{l}\text { Yes, conformal coating on PCB, } \\
\text { enclosures, etc. }\end{array}$ \\
\hline $\begin{array}{l}\text { Cummins Power } \\
\text { Gen., Onan Div. }\end{array}$ & Membrane Panel & EchelonLonWorks & $\begin{array}{c}\text { No, new } \\
\text { control } \\
\text { will. }\end{array}$ & YES & \begin{tabular}{|c|} 
Yes, control entire range by \\
adjusting software parameters
\end{tabular} & $\begin{array}{l}\text { Yes, Power Command control system to } \\
\text { the US Air Force for generator set control. }\end{array}$ & $\begin{array}{l}\text { Yes, by enclosures, coatings and } \\
\text { material selection. }\end{array}$ \\
\hline $\begin{array}{l}\text { AMOT Controls } \\
\text { Corporation }\end{array}$ & $\begin{array}{c}\text { 2X16 Character Display \& } 8 \\
\text { Keys }\end{array}$ & $\begin{array}{l}\text { MODBUS RTU } \\
\text { Protocol }\end{array}$ & & YES & YES & NO & Yes, NEMA 4X \\
\hline Frank W. Murphy & & & & & & YES, USCGS (ships) & \\
\hline Model: Modex & $\begin{array}{c}2 \text { lineX6 Charact LC Display; } \\
\text { Some w/remote access via }\end{array}$ & RS232 \& ASCII & & NO & YES & & \begin{tabular}{|l|}
$\begin{array}{l}\text { No, protection must come from } \\
\text { specified housing }\end{array}$ \\
\end{tabular} \\
\hline Model: MCG & $\begin{array}{l}2 \text { lineX6 Charact LC Display; } \\
\text { Some w/remote access via }\end{array}$ & $\begin{array}{l}\text { RS232 or RS485 \& } \\
\text { ASCII or MODBUS }\end{array}$ & & NO & YES & & $\begin{array}{l}\text { No, protection must come from } \\
\text { specified housing }\end{array}$ \\
\hline MC II & GUI, Flat Panel Display & RS232 and RS485 & & \begin{tabular}{|} 
YES, and \\
Auto Load \\
Sharing
\end{tabular} & YES & YES & $\begin{array}{l}\text { Yes, with Conformal Coatings \& } \\
\text { CARC Paint }\end{array}$ \\
\hline \begin{tabular}{|l} 
Electronic \\
Concepts \& Engr
\end{tabular} & $\begin{array}{l}\text { PC based Graphical User } \\
\text { Interface (GUI) }\end{array}$ & $\begin{array}{c}\text { Vectronics, RS-422, } \\
\text { RS-232 }\end{array}$ & & NO & YES & YES, MICOM \& DARPA & $\begin{array}{l}\text { Yes, Sealed Enclosure/ Exterior } \\
\text { Chemically Conversion } \\
\text { Coated/Primered \& Painted w/CARC } \\
\text { Paint to withstand NBC Decon }\end{array}$ \\
\hline Zenith Controls & Color touch screen & $\begin{array}{l}\text { RS } 845 \& \text { TCP/IP } \\
\text { (EFVIERNET) }\end{array}$ & & YES & YES & $\begin{array}{l}\text { YES, Engine generator paralleling } \\
\text { switchgear for Army, AF and Navy }\end{array}$ & Conformal coating on PCB \\
\hline Indust Pwr Sys & per spec design & $\begin{array}{c}\text { Depends upon } \\
\text { protocol requested }\end{array}$ & & YES & YES & $\begin{array}{c}\text { Yes, NavyT'AGOS } 23 \text { class vessel marine } \\
\text { switchboard }\end{array}$ & $\begin{array}{l}\text { NEMA 3R Stainless steel or } \\
\text { Fiberglass }\end{array}$ \\
\hline $\begin{array}{l}\text { Woodward } \\
\text { Governor Co. }\end{array}$ & Laptop Computer & $\begin{array}{l}\text { N/A, Can be added } \\
\text { for price }\end{array}$ & & YES & YES & $\begin{array}{l}\text { YES, Navy Aux GEN Set Ctrls/Gas Turbine } \\
\text { Cntrl Panel/Liq Fuel TMSS Monitor }\end{array}$ & YES, Plastic Housing \& Plated Shaft \\
\hline Caterpiller & Membrane panel & $\begin{array}{l}\text { Now RS } 232 \text { New: } \\
\text { MODBUS }\end{array}$ & $\begin{array}{l}\text { No new } \\
\text { control } \\
\text { will }\end{array}$ & $\begin{array}{c}\text { No new } \\
\text { control will }\end{array}$ & YES & YES, US Army, Air Force and Marines & $\begin{array}{l}\text { Impervious to salt spray, fuel, oil, oil } \\
\text { additives, coolant, spray cleaners, } \\
\text { chlorinated solvents, hydrogen } \\
\text { sulfide, methane gas and dust }\end{array}$ \\
\hline
\end{tabular}




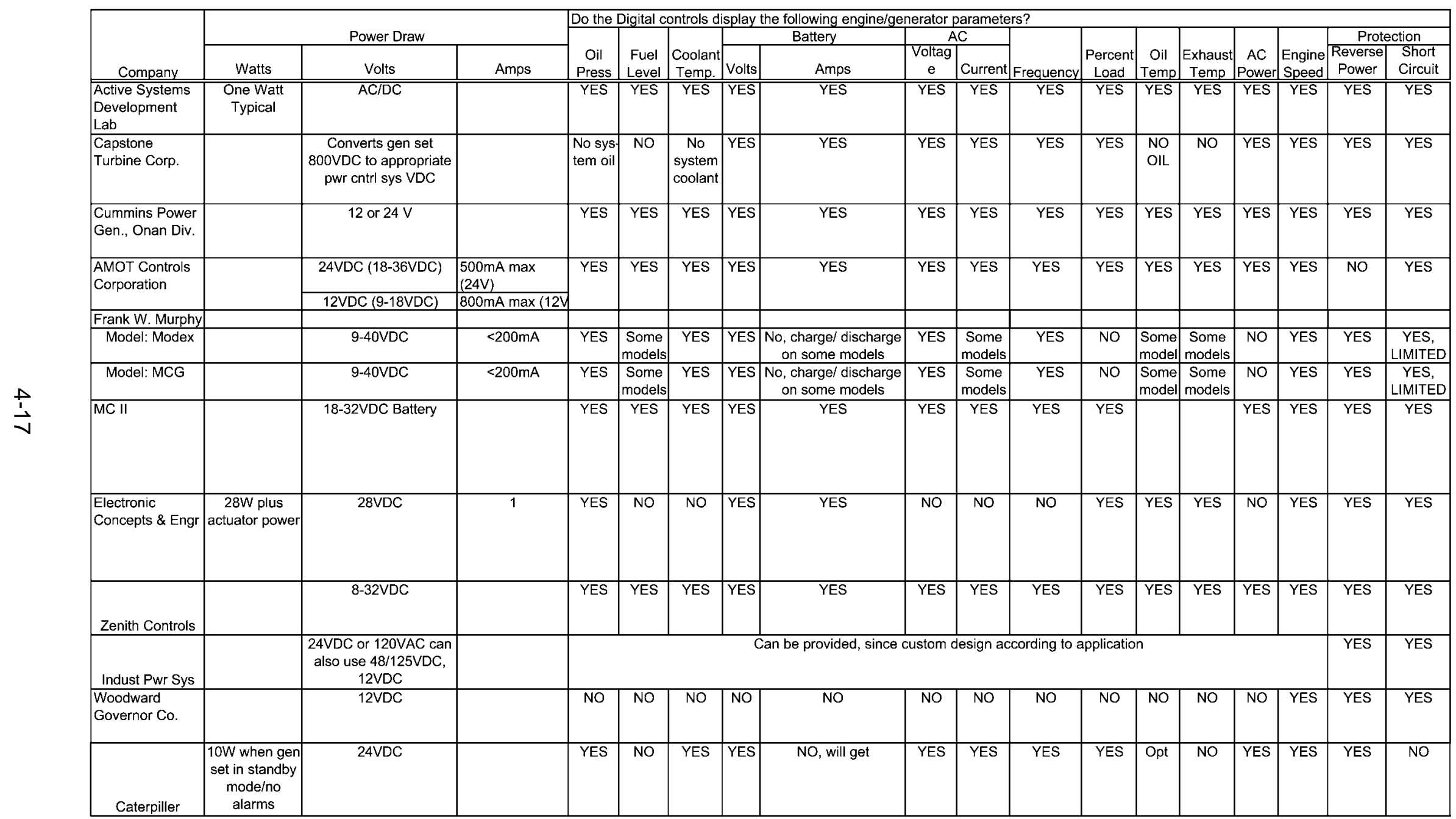




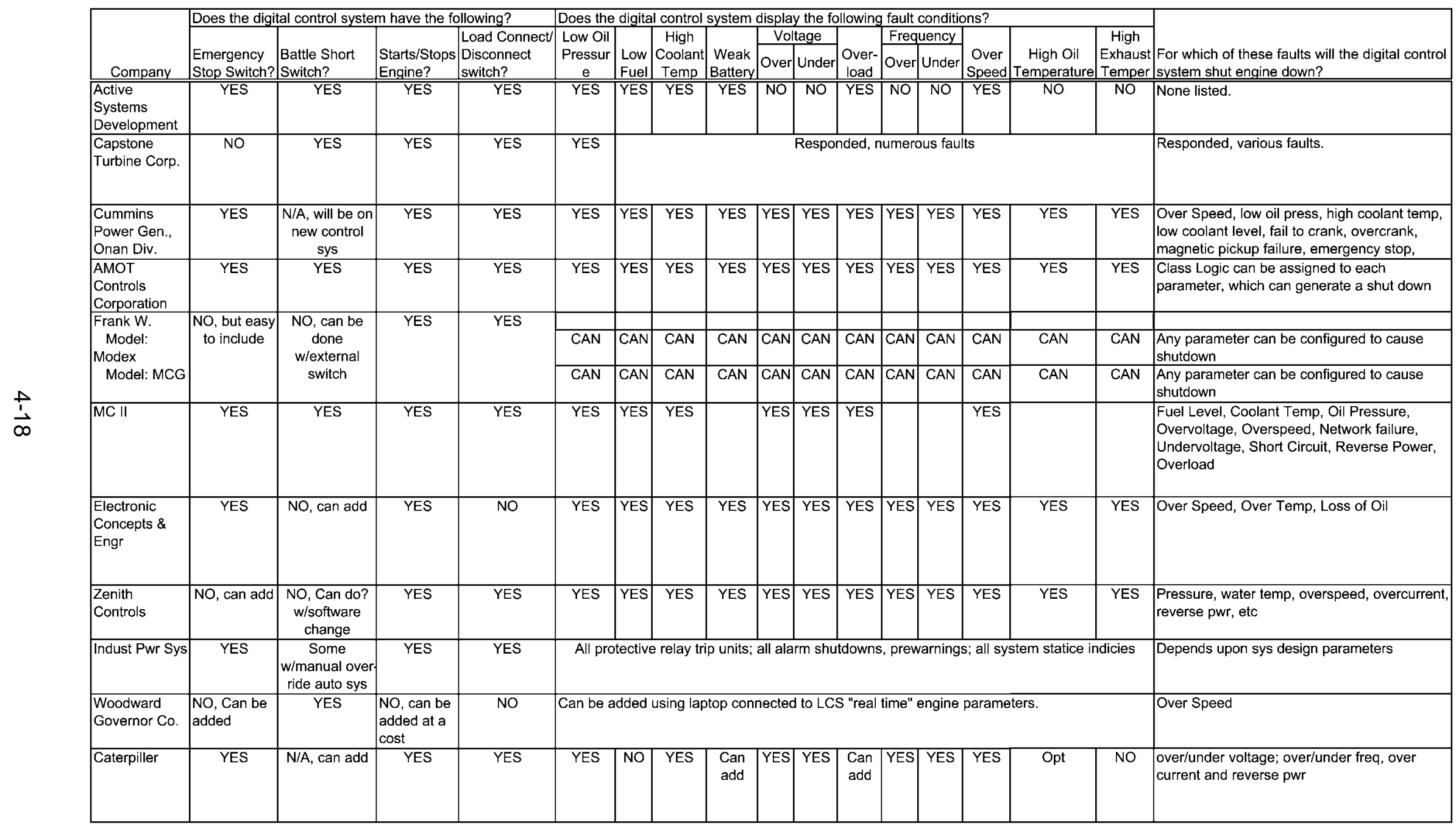




\begin{tabular}{|c|c|c|}
\hline Company & $\begin{array}{l}\text { How will the digital control system warn the user } \\
\text { when these faults occur? }\end{array}$ & Specify prognostic capabilities of your digital control system. \\
\hline $\begin{array}{l}\text { Active Systems } \\
\text { Development Lab }\end{array}$ & Answered YES & Answered, I can design to any parameters. \\
\hline $\begin{array}{l}\text { Capstone Turbine } \\
\text { Corp. }\end{array}$ & Responded, various faults. & \\
\hline $\begin{array}{l}\text { Cummins Power } \\
\text { Gen., Onan Div. }\end{array}$ & $\begin{array}{l}\text { Alarms proceed shutdown functions through } \\
\text { panel display, remote Annunciator(audible and } \\
\text { visual) or remotely through a computer. }\end{array}$ & $\begin{array}{l}\text { New system will eliminate need for any oil changes. Old oil is burned with diesel and } \\
\text { new oil is replenished in an oil reservoir/New System/KW versus fuel consumption } \\
\text { monitoring to determine when maint is needed }\end{array}$ \\
\hline $\begin{array}{l}\text { AMOT Controls } \\
\text { Corporation }\end{array}$ & By alarms & $\begin{array}{l}\text { Sensors to measure oil viscosity, engine belt tension, air \& fuel filter replacement need } \\
\text { to be specified by user. }\end{array}$ \\
\hline Frank W. Murphy & & \\
\hline Model: Modex & Alarm \& Blinking Display & Can add sensors to measure oil viscosity/engine belt tension/air \& fuel filter cleanliness \\
\hline Model: MCG & Alarm: light/horn w/various colors \& loudnesses & $\begin{array}{l}\text { Uses "hours of operation timers that are programmed to alert to service needs. Can } \\
\text { add sensors to measure oil viscosity/engine belt tension/air \& fuel filter cleanliness }\end{array}$ \\
\hline MC II & LEDS & System Status, Control PowerStatus, Oil Viscosity, Replace Air/Fuel Filter Notice \\
\hline $\begin{array}{l}\text { Electronic } \\
\text { Concepts \& Engr }\end{array}$ & $\begin{array}{l}\text { Via a Vectronics Interface \& PC Based } \\
\text { Graphical User Interface }\end{array}$ & $\begin{array}{l}\text { Measures Air \& Fuel Filter Cleanliness to determine when to Replace. Can include } \\
\text { Time at Temperature (EGT) \& Time at Speed }\end{array}$ \\
\hline Zenith Controls & Audible \& visual alarm and date stamp & None \\
\hline Indust Pwr Sys & Light and sound/PC interface alarms screen & None, comes with engine/gen set \\
\hline $\begin{array}{l}\text { Woodward } \\
\text { Governor Co. }\end{array}$ & NO & Adjusts for engine wear to maintain isoc speed ctrl. \\
\hline Caterpiller & Indicator lights; will get pager & $\begin{array}{l}\text { Getting: Battery check; alternator health, injector performance, oil/air/fuel filter checks, } \\
\text { battery accepting charge }\end{array}$ \\
\hline
\end{tabular}




\begin{tabular}{|c|c|c|c|c|c|c|c|c|c|c|c|}
\hline Company & $\begin{array}{l}\text { Size LWH } \\
\text { (in.) }\end{array}$ & $\begin{array}{l}\text { Weight } \\
\text { (lbs.) }\end{array}$ & $\begin{array}{c}\text { Cost } \\
(\$)\end{array}$ & $\begin{array}{c}\text { Temperature } \\
\text { Range } \\
\left({ }^{\circ} \mathrm{F}\right)\end{array}$ & Shock & Vibration & EMI/EMP & NBC & Waterproof & $\begin{array}{c}\text { Display } \\
\text { Technology }\end{array}$ & Display Size (in) \\
\hline $\begin{array}{l}\text { Marvin Land } \\
\text { Systems }\end{array}$ & 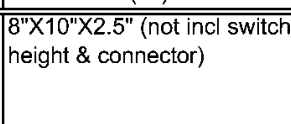 & 5.2 & & $=-50$ to $140^{\circ} \mathrm{F}$ & $\begin{array}{l}27 g @ \\
18 \mathrm{mS}\end{array}$ & YES & $\begin{array}{l}\text { YES, Ni plated AI Alloy } \\
\text { housing/shielded cables } / \\
\text { twisted pairs \& various } \\
\text { connectors }\end{array}$ & $\begin{array}{l}\text { NO, but can be } \\
\text { CARC painted }\end{array}$ & $\begin{array}{l}\text { YES, conformed } \\
\text { coatings }\end{array}$ & & \\
\hline Marvin Engr Co & $\begin{array}{l}\text { 8"X10"X2.5", not incl switch } \\
\text { \&connector }\end{array}$ & $5.2 \mathrm{lbs}$ & & $\begin{array}{l}-50 \text { to } 140^{\circ} \mathrm{F} \\
\left(-45 \text { to } 60^{\circ} \mathrm{C}\right)\end{array}$ & $\begin{array}{l}27 \mathrm{~g} @ \\
18 \mathrm{mS}\end{array}$ & $\Rightarrow$ & $\begin{array}{l}\text { YES, Ni plated Al Alloy } \\
\text { housing/ shielded cables } \\
\text { twisted pairs \& various } \\
\text { connectors }\end{array}$ & $\begin{array}{c}\text { Can be CARC } \\
\text { painted }\end{array}$ & $\begin{array}{c}\text { Sealed box, switches \& } \\
\text { indicators. Circuit } \\
\text { boards confrormal } \\
\text { coated } \\
\end{array}$ & & \\
\hline Kohler & $12 " X 18^{\prime \prime} \times 11 "$ & 25 & & -40 to $70 \operatorname{deg} C$ & $20 \mathrm{~g}$ & $\begin{array}{c}5-10 \mathrm{~Hz} 0.2^{\mathrm{n}} \\
\text { Displacement } \\
10-200 \mathrm{~Hz} 2 \mathrm{~g} \\
\text { all planes }\end{array}$ & $\begin{array}{l}\begin{array}{c}\text { Design to meet } \\
\text { requirements }\end{array} \\
\end{array}$ & can add coating & $\begin{array}{c}\text { No, conformal coatings \& } \\
\text { packaging }\end{array}$ & $\begin{array}{c}2 \text { line } \\
\text { vacuum } \\
\text { fluorescent } \\
\text { display }\end{array}$ & \\
\hline Electronic Design & $12 " X 24 " X 36 "$ & 60 & & $\begin{array}{l}-50 \text { to } 140^{\circ} \mathrm{F} \\
\left(-45 \text { to } 60^{\circ} \mathrm{C}\right)\end{array}$ & MIL-S-901 & MIL-STD-167 & \begin{tabular}{|c} 
EMI Gaskets around doors \\
$\&$ removable panels $/$ EMI \\
electrical filters
\end{tabular} & $\begin{array}{l}\text { Sealed Stainless } \\
\text { Steel Enclosure }\end{array}$ & Sealed enclosure & & \\
\hline Basler Electric & $7.75 \times 11.25 \times 1.95$ & 1.95 & & $-40 \mathrm{~F}$ to $+158 \mathrm{~F}$ & $15 \mathrm{~g}$ & $\begin{array}{c}2 \mathrm{~g} \text { from } \\
10-50 \mathrm{~Hz}\end{array}$ & YES & Not tested for NBC. & $\begin{array}{c}\text { Yes,contains sealed face } \\
\text { plate \& enclosure }\end{array}$ & Liquid Crystal & \\
\hline \begin{tabular}{|l|} 
Hurckman \\
Mechanical \\
Industries for CSI
\end{tabular} & custom, user specified & & & $\begin{array}{l}-50 \text { to } 140^{\circ} \mathrm{F} \\
\left(-45 \text { to } 60^{\circ} \mathrm{C}\right) \\
\text { (designed for } \\
\text { living areas) }\end{array}$ & \multicolumn{2}{|c|}{ YES,?g } & $\begin{array}{l}\text { ISO, IEEE standards for } \\
\text { UL 294, } 816\end{array}$ & & NO & & \\
\hline $\begin{array}{l}\text { Allied Marine } \\
\text { Services Inc. }\end{array}$ & $35 \mathrm{mmX} 144 \mathrm{~mm} \times 144 \mathrm{~mm}$ & $0.5 \mathrm{~kg}$ & & $\begin{array}{l}-10 \text { to } 70^{\circ} \mathrm{C} \\
-40 \text { to } 70^{\circ} \mathrm{C}\end{array}$ & $\begin{array}{c}\begin{array}{c}\text { Marine Type } \\
\text { Approval Soc } \\
\text { req }\end{array} \\
\end{array}$ & \begin{tabular}{|c|}
$\begin{array}{c}\text { Marine Type } \\
\text { Approval Soc } \\
\text { req }\end{array}$ \\
\end{tabular} & \begin{tabular}{|c|} 
EMC according to \\
EN50081-182, EN50082- \\
182
\end{tabular} & & Splash proof on front & & \\
\hline \begin{tabular}{|l|} 
Robicon \\
Grasslin Controls
\end{tabular} & \multicolumn{11}{|c|}{\begin{tabular}{|l|l|} 
Do not manufacture digital control systems with diagnostic \& prognostic capabilities. \\
Do not manufacture any digital controls for geerator sets.
\end{tabular}} \\
\hline \begin{tabular}{|l} 
GE Industrial Sys \\
Mallory \\
\end{tabular} & \multicolumn{11}{|c|}{$\begin{array}{l}\text { Not in Digital Control Systems for Small Generators. Their generator controls are for utility companies, and too large for Army applications. } \\
\text { No longer into Digital Control Systems } \\
\text { Thens }\end{array}$} \\
\hline \begin{tabular}{|l} 
Bailey Controls \\
Micon-Powell
\end{tabular} & \multicolumn{11}{|c|}{ 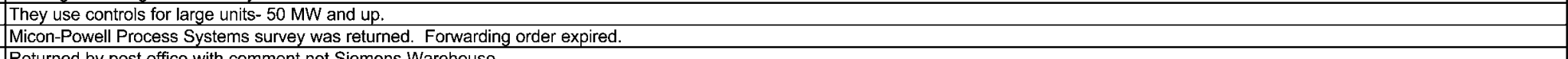 } \\
\hline \begin{tabular}{|l|} 
Controls Inc \\
\end{tabular} & \multicolumn{11}{|c|}{$\begin{array}{l}\text { Returned by post office with comment not Siemens Warehouse. } \\
\text { Private label of Kohler Co }\end{array}$} \\
\hline
\end{tabular}

"always "Selectable 


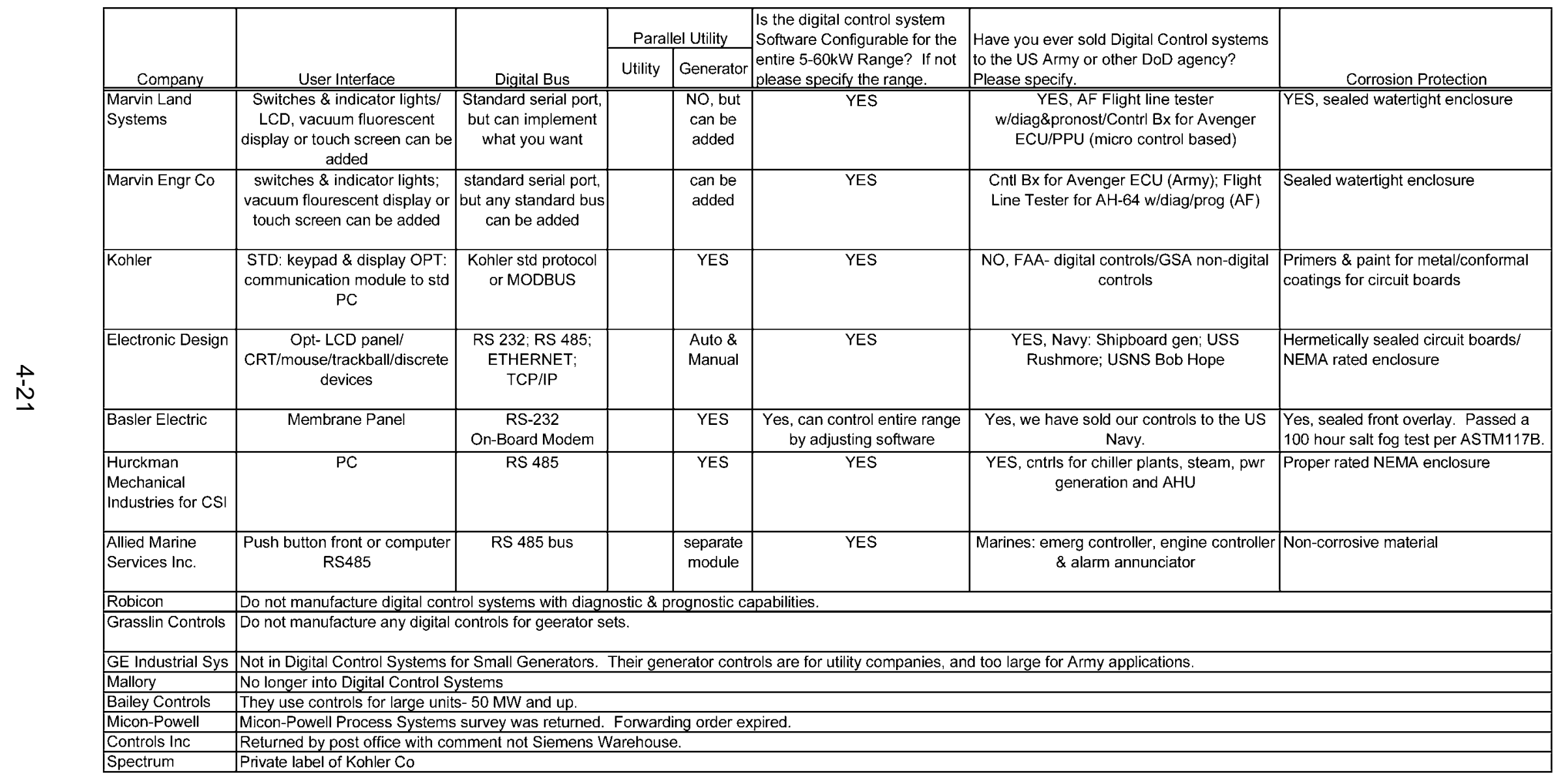




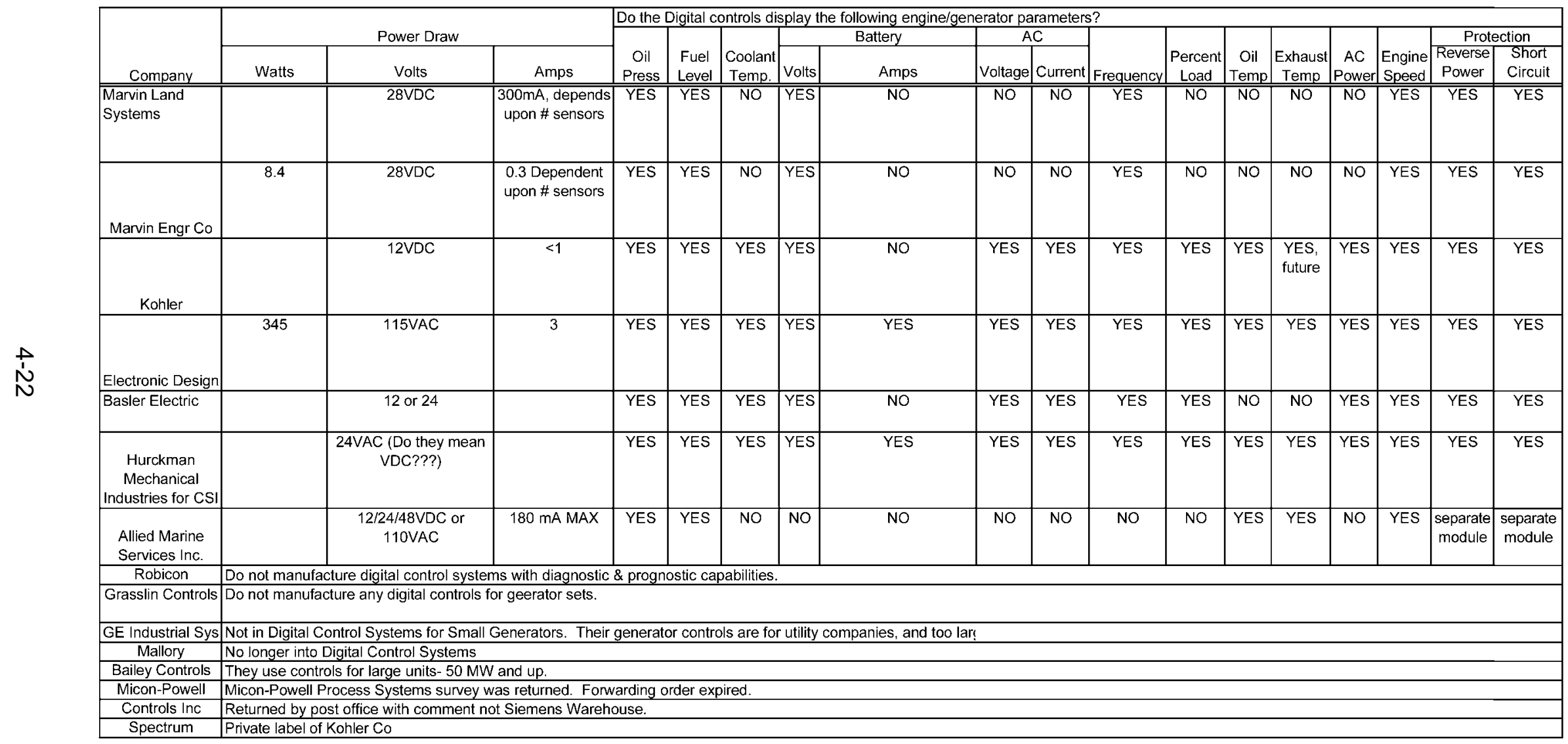




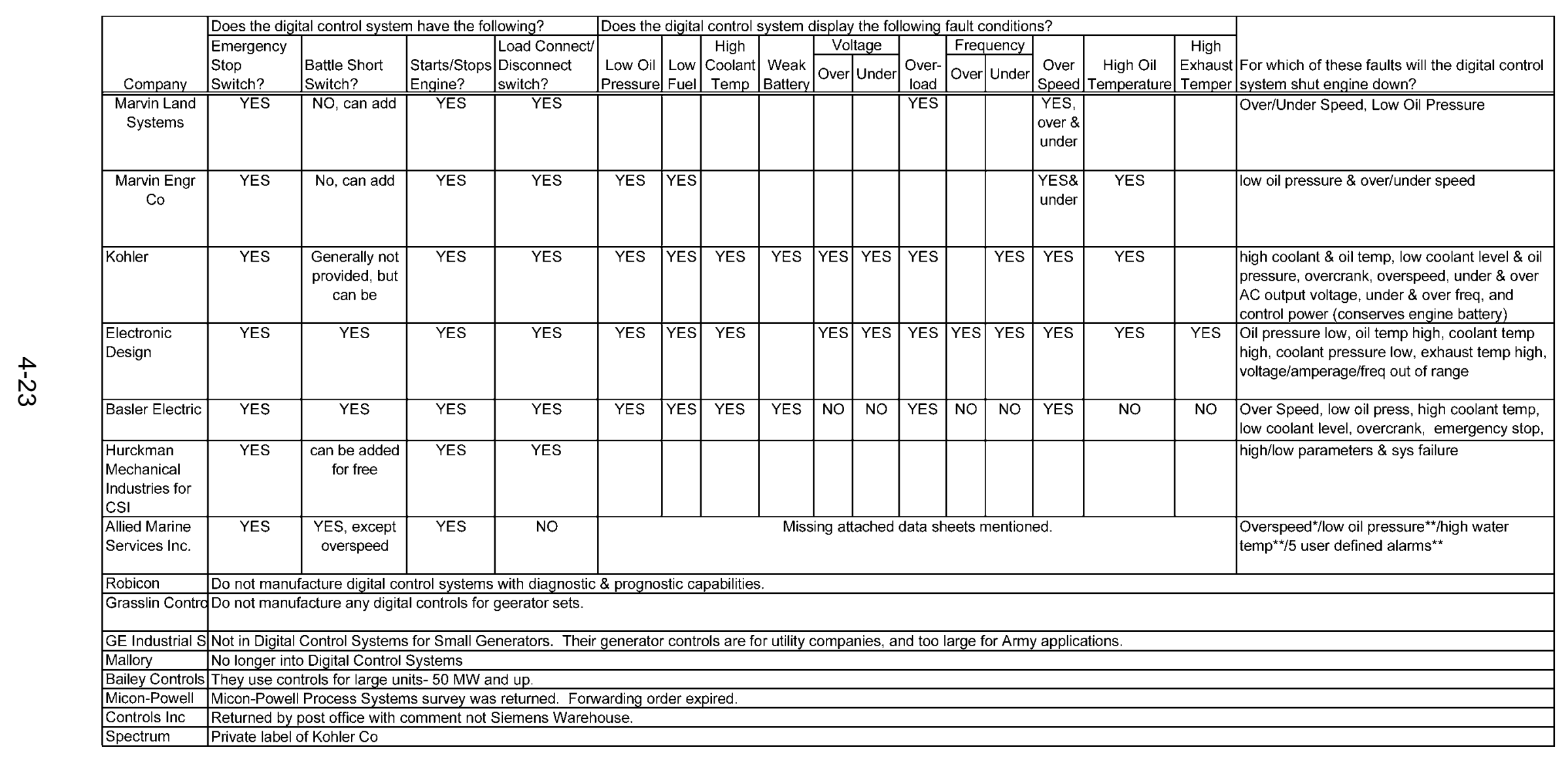




\begin{tabular}{|c|c|c|}
\hline Company & $\begin{array}{l}\text { How will the digital control system warn the user } \\
\text { when these faults occur? }\end{array}$ & Specify prognostic capabilities of your digital control system. \\
\hline $\begin{array}{l}\text { Marvin Land } \\
\text { Systems }\end{array}$ & \begin{tabular}{|l||} 
Indicator Lights \& Buzzers \\
\end{tabular} & Digital/analog sensors can be added to permit diag/prognost \\
\hline Marvin Engr Co & Indicator lights \& buzzers & \\
\hline Kohler & Light/digital display \& horn & $\begin{array}{l}\text { Fuel rate, ambient temp, rated engine pw, fuel usage, weak battery, and in future air \& } \\
\text { fuel filter cleanliness }\end{array}$ \\
\hline Electronic Design & Flashing indicator; alarm; flashing CRT icon & $\begin{array}{l}\text { oil viscosity, engine belt tension; air\&fuel filter cleanliness; cylinder exhaust temp } \\
\text { deviation excessive }\end{array}$ \\
\hline Basler Electric & $\begin{array}{l}\text { Audible and visual alarms and also dial out to a } \\
\text { pager via a modem and to a portable computer. }\end{array}$ & Currently developing prognostic capabilities that will be available in one year. \\
\hline $\begin{array}{l}\text { Hurckman } \\
\text { Mechanical } \\
\text { Industries for CSI }\end{array}$ & page using digital paper, call or at PC & $\begin{array}{l}\text { oil viscosity, engine belt tension and air\&fuel filter clean; all done using 3rd party } \\
\text { interfacesor field devices }\end{array}$ \\
\hline $\begin{array}{l}\text { Allied Marine } \\
\text { Services Inc. }\end{array}$ & Flashing LEDs and Siren relay & $\begin{array}{l}\text { oil viscosity, engine belt tension and ai\&fuel filter clean can be added as external alarm } \\
\text { outputs }\end{array}$ \\
\hline Robicon & \multicolumn{2}{|c|}{ Do not manufacture digital control systems with diagnostic \& prognostic capabilities. } \\
\hline Grasslin Controls & \multicolumn{2}{|c|}{ Do not manufacture any digital controls for geerator sets. } \\
\hline GE Industrial Sys & \multirow{2}{*}{\multicolumn{2}{|c|}{$\begin{array}{l}\text { Not in Digital Control Systems for Small Generators. Their generator controls are for utility companies, and too large for Army applications. } \\
\text { No longer into Digital Control Systems }\end{array}$}} \\
\hline Mallory & & \\
\hline Bailey Controls & \multicolumn{2}{|c|}{ They use controls for large units- $50 \mathrm{MW}$ and up. } \\
\hline Micon-Powell & \multicolumn{2}{|c|}{ Micon-Powell Process Systems survey was returned. Forwarding order expired. } \\
\hline Controls Inc & \multirow{2}{*}{\multicolumn{2}{|c|}{\begin{tabular}{|l} 
Returned by post office with comment not Siemens Warehouse. \\
Private label of Kohler Co \\
\end{tabular}}} \\
\hline Spectrum & & \\
\hline
\end{tabular}




\section{Appendix 4-B. GEN-SET DATA PROVIDED BY CECOM FOR MARKET SURVEY}


4-26 


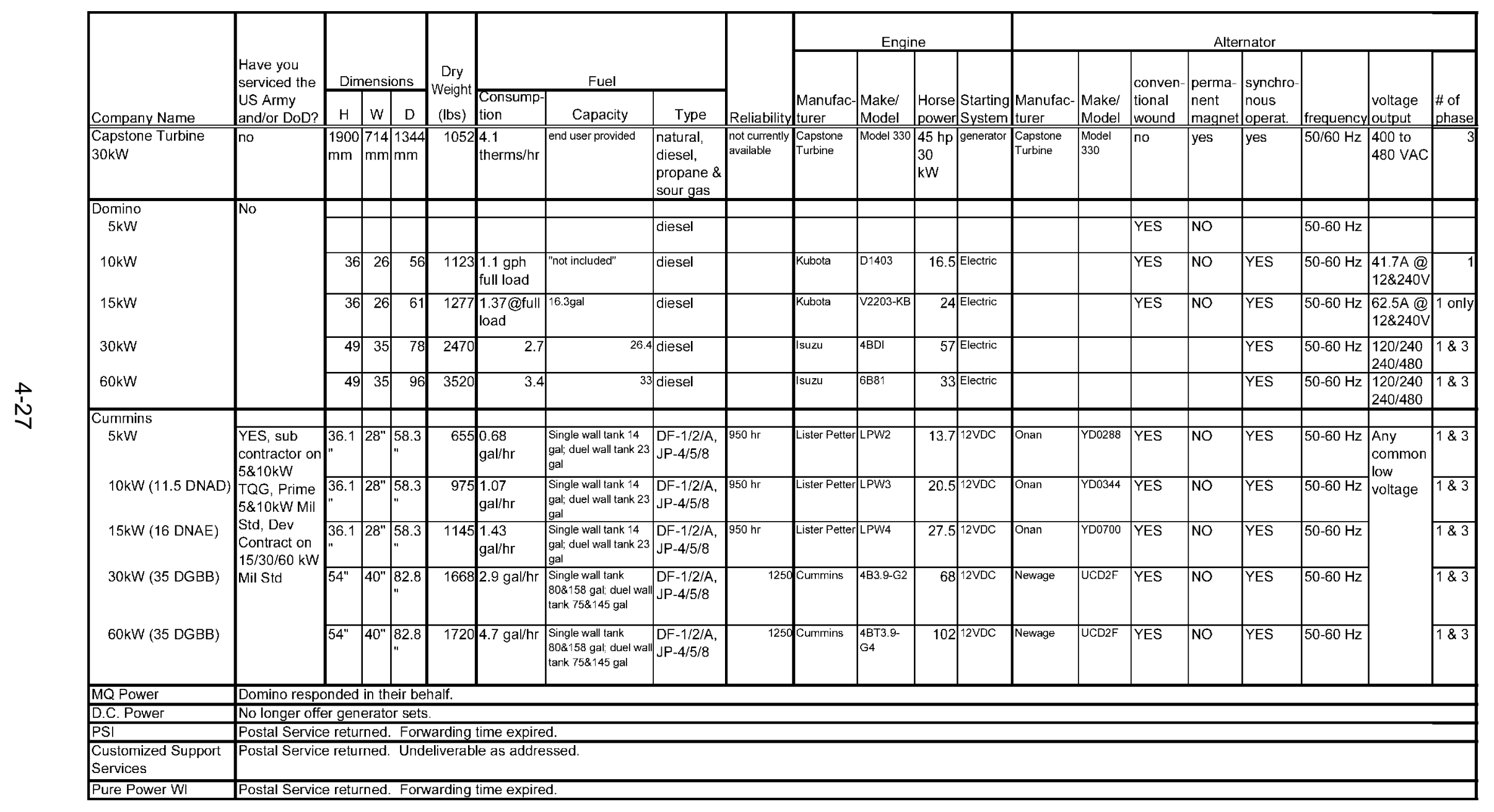




\begin{tabular}{|c|c|c|c|c|c|c|c|c|c|c|c|c|c|c|c|c|c|c|c|c|c|c|c|}
\hline \multirow{4}{*}{$\begin{array}{l}\text { Company Name } \\
\text { Capstone Turbine } \\
30 \mathrm{~kW}\end{array}$} & \multirow{2}{*}{\multicolumn{5}{|c|}{ Power Electronics }} & \multicolumn{18}{|c|}{ Controls } \\
\hline & & & & & & \multicolumn{3}{|c|}{ Instrumentation } & \multicolumn{4}{|c|}{ Engine } & \multicolumn{3}{|c|}{ Alternator } & \multicolumn{7}{|c|}{ Protective Device } & \multirow[b]{2}{*}{$\begin{array}{l}\text { Remote } \\
\text { operation } \\
\text { capability }\end{array}$} \\
\hline & \multirow{2}{*}{\begin{tabular}{|l} 
Power \\
Elec- \\
tronics
\end{tabular}} & \multirow{2}{*}{$\begin{array}{l}\text { variable } \\
\text { speed }\end{array}$} & \multirow{2}{*}{$\begin{array}{l}\text { constant } \\
\text { voltage } \\
\text { fequency } \\
\text { yes } \\
\text { adjustable }\end{array}$} & \multirow{2}{*}{ 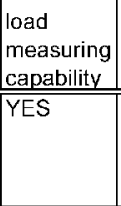 } & \multirow{2}{*}{$\frac{\begin{array}{l}\text { Engine } \\
\text { speed } \\
\text { gover- } \\
\text { ning }\end{array}}{\text { YES }}$} & \multirow{2}{*}{\begin{tabular}{|l|}
$\mid$ \\
Analog \\
yes (A \\
to $D)$
\end{tabular}} & \multirow{2}{*}{\begin{tabular}{|l|} 
Digital \\
yes
\end{tabular}} & \multirow{2}{*}{\begin{tabular}{|l|} 
software \\
yes
\end{tabular}} & \multirow{2}{*}{\begin{tabular}{|c|c} 
Oil \\
pressure \\
$\begin{array}{l}N / A \text { air } \\
\text { bearing }\end{array}$
\end{tabular}} & \multirow{2}{*}{\begin{tabular}{|l|} 
Coolant \\
$\begin{array}{l}\mathrm{N} / \mathrm{A} \text { air } \\
\text { cooled }\end{array}$ \\
\end{tabular}} & \multirow{2}{*}{\begin{tabular}{|l|} 
Fuel \\
yes
\end{tabular}} & \multirow{2}{*}{\begin{tabular}{|l} 
Battery \\
Voltage
\end{tabular}} & \multirow{2}{*}{\begin{tabular}{|c|}
$\begin{array}{c}\text { voltage } \\
\text { meter }\end{array}$ \\
yes
\end{tabular}} & \multirow{2}{*}{$\begin{array}{l}\text { current } \\
\text { meter } \\
\text { yes }\end{array}$} & \multirow{2}{*}{\begin{tabular}{|l|} 
power \\
meter \\
yes
\end{tabular}} & \multirow{2}{*}{\begin{tabular}{|l|l}
$\begin{array}{l}\text { oil } \\
\text { pressure }\end{array}$ & t \\
N/A & 1
\end{tabular}} & \multirow{2}{*}{\begin{tabular}{l|} 
coolant \\
temp
\end{tabular}} & \multirow{2}{*}{ fuel } & \multirow{2}{*}{\begin{tabular}{|l|} 
battery \\
voltage \\
yes
\end{tabular}} & $\begin{array}{l}\text { over } \\
\text { speed }\end{array}$ & \begin{tabular}{|l|} 
over \\
volt \\
age
\end{tabular} & other & \\
\hline & & & & & & & & & & & & & & & & & & & & yes & yes & $\begin{array}{l}\text { O/U } \\
\text { voltage\&freq } \\
\text { uency, over } \\
\text { current, }\end{array}$ & yes \\
\hline Domino & & & & & & & & & & & & & & & & & & & & & & & \\
\hline $5 \mathrm{~kW}$ & NO & NO & YES & NO & YES & YES & NO & NO & |NO & NO & NO & NO & YES & NO & NO & & & & & & & & \\
\hline $10 \mathrm{~kW}$ & NO & NO & $\begin{array}{l}120 / 240 \\
60 \mathrm{~Hz}\end{array}$ & NO & YES & YES & optional | & NO & YES & YES & \begin{tabular}{|l|} 
NO, \\
optional
\end{tabular} & $\begin{array}{l}\text { NO } \\
\text { optional }\end{array}$ & YES & YES & & YES & YES & optiona| & & & & & YES \\
\hline $15 \mathrm{~kW}$ & & YES & YES & & YES & YES & optional & & YES & YES & YES & NO & YES & NO & NO & YES & YES & optional & NO & YES & YES & & YES \\
\hline $30 \mathrm{~kW}$ & & & YES & & YES & YES & optional & & YES & YES & YES & NO & YES & NO & NO & YES & YES & optional| & NO & YES & YES & & YES \\
\hline $60 \mathrm{~kW}$ & & YES & YES & NO & YES & YES & optional & & YES & YES & YES & No & YES & NO & NO & YES & YES & optional & NO & YES & YES & & YES \\
\hline Cummins & & & & & & & & & & & & & & & & & & & & & & & \\
\hline $5 \mathrm{~kW}$ & NO & NO & YES & YES & YES & YES & NO & \begin{tabular}{|l|} 
Commun \\
ication \\
software
\end{tabular} & YES & YES & $\begin{array}{l}\begin{array}{l}\text { YES, low } \\
\text { fuel } \\
\text { warning }\end{array} \\
\text { wanin }\end{array}$ & YES & YES & YES & NO & YES & YES & YES & YES & YES & NO & \begin{tabular}{|l|} 
Running \\
time \\
meter/voltag
\end{tabular} & YES \\
\hline $10 \mathrm{~kW}(11.5 \mathrm{DNAD})$ & NO & NO & YES & YES & YES & YES & NO & avail & YES & YES & $\begin{array}{l}\text { avail } \\
\text { wropt } \\
\text { tank }\end{array}$ & YES & YES & YES & NO & YES & YES & YES & YES & YES & NO & $\begin{array}{l}\text { e adjust } \\
\text { rheostat/run/ }\end{array}$ & YES \\
\hline $15 \mathrm{~kW}(16 \mathrm{DNAE})$ & NO & NO & YES & YES & YES & YES & NO & & YES & YES & & YES & YES & YES & NO & YES & YES & YES & YES & YES & NO & $\begin{array}{l}\text { switch offf } \\
\text { pre-alarm } \\
\text { low oil }\end{array}$ & YES \\
\hline $30 \mathrm{~kW}$ (35 DGBB) & NO & NO & YES & YES & YES & YES & 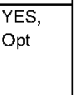 & & YES & YES & & YES & YES & YES & NO & YES & YES & YES & YES & YES & & $\begin{array}{l}\text { pressure/low } \\
\text { coolant temp } \\
\text { and }\end{array}$ & YES \\
\hline $60 \mathrm{~kW}(35 \mathrm{DGBB})$ & NO & NO & YES & YES & YES & YES & $\begin{array}{l}\text { YES, } \\
\text { Opt }\end{array}$ & & YES & YES & & YES & YES & YES & NO & YES & YES & YES & YES & YES & YES & $\begin{array}{l}\text { overcrank } \\
\text { lights }\end{array}$ & YES \\
\hline MQ Power & Domine & respond & ded in their & behalf. & & & & & & & & & & & & & & & & & & & \\
\hline D.C. Power & No lons & ger offer $\mathrm{g}$ & generator se & iets. & & & & & & & & & & & & & & & & & & & \\
\hline PSI & Postal & Service re & eturned. $\mathrm{Fc}$ & orwarding ti & Ime expi & & & & & & & & & & & & & & & & & & \\
\hline $\begin{array}{l}\text { Customized Support } \\
\text { Services }\end{array}$ & Postal & Service re & eturned. 1 & indeliverable & as add & ressed. & & & & & & & & & & & & & & & & & \\
\hline Pure Power W/ & & Service & eturned. & & & & & & & & & & & & & & & & & & & & \\
\hline
\end{tabular}




\begin{tabular}{|c|c|c|c|c|c|c|c|c|c|c|c|c|c|c|c|c|c|c|c|}
\hline \multirow{3}{*}{$\begin{array}{l} \\
\text { Company Name } \\
\text { Capstone Turbine } \\
30 \mathrm{~kW}\end{array}$} & \multicolumn{6}{|c|}{ Environmental } & \multicolumn{3}{|c|}{ EMI } & \multicolumn{2}{|c|}{ Noise (DbA) } & \multicolumn{3}{|c|}{ Human Factors } & \multicolumn{5}{|c|}{ Composites } \\
\hline & $\begin{array}{l}\text { Operational } \\
-250^{\circ} \\
120^{\circ} \mathrm{F} \\
\end{array}$ & 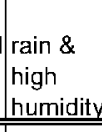 & $\begin{array}{l}\text { cold } \\
\text { storage } \\
\text { (-660 } \mathrm{F} \\
\end{array}$ & $\begin{array}{l}\text { power@ } \\
\text { 5000ft } \\
\end{array}$ & $\begin{array}{l}\text { power@ } \\
\text { 8000ft }\end{array}$ & $\begin{array}{l}\text { power@ } \\
10,000 \mathrm{ft} \\
\end{array}$ & Protection & $\begin{array}{l}\text { Comply wt } \\
\text { MLL-STD- } \\
\text { 4661C } \\
\end{array}$ & $\begin{array}{l}\text { Commercial } \\
\text { Standards } \\
\end{array}$ & \multirow{2}{*}{\multicolumn{2}{|c|}{\begin{tabular}{|l|l|}
$0.7 \mathrm{~m}$ & $7 \mathrm{~m}$ \\
from & from \\
operator & operator \\
station & station \\
\end{tabular}}} & \multicolumn{3}{|c|}{$\begin{array}{l}\text { MIL-STD- } \\
1472\end{array} \mid \begin{array}{l}\text { SAE } \\
\text { Standar }\end{array}$} & $\begin{array}{ll}\text { Skid } \\
\text { Base }\end{array}$ & \multicolumn{2}{|c|}{ Housinal Enaine } & \multicolumn{2}{|c|}{ Alternator Other } \\
\hline & optional & yes & no & $24.9 \mathrm{~kW}$ & $22.3 \mathrm{~kW}$ & $20.7 \mathrm{~kW}$ & yes & unknown & blank & & & & unknown & & & & & & \\
\hline \multirow{2}{*}{$\begin{array}{c}\text { Domino } \\
5 \mathrm{~kW}\end{array}$} & & & & \multirow{2}{*}{\multicolumn{2}{|c|}{$3.5 \%$ for ea $1000 \mathrm{ft}$}} & \multirow{6}{*}{$35 \%$} & & & & & & & & & & & & & \\
\hline & YES & YES & YES & & & & YES & NO & YES & & & & YES & YES & NO & NO & YES & NO & \\
\hline $10 \mathrm{~kW}$ & YES & YES & YES & & & & YES & NO & & & 65 & & & & NO & NO & YES & NO & \\
\hline $15 \mathrm{~kW}$ & YES & YES & YES & & & & YES & NO & YES & & 62 & & & & YES & YES & YES & YES & \\
\hline \multirow{2}{*}{$\begin{array}{l}30 \mathrm{~kW} \\
60 \mathrm{~kW}\end{array}$} & & & YES & & & & & & & & 64 & & & & YES & YES & YES & YES & \\
\hline & YES & YES & & & & & & & & & 66 & & & & YES & YES & YES & YES & \\
\hline \multirow{2}{*}{$\begin{array}{c}\text { Cummins } \\
5 \mathrm{~kW}\end{array}$} & & & & & & & & & & & & & & & & & & & \\
\hline & YES & YES & YES & $6.32 \mathrm{~kW}$ & $5.53 \mathrm{~kW}$ & $5.0 \mathrm{~kW}$ & NO & NO & YES & $06.1-87.0$ & $76.1-67.0$ & No & YES & YES & NO & NO & NO & NO & NO \\
\hline $10 \mathrm{~kW}(11.5 \mathrm{DNAD})$ & YES & YES & YES & $9.69 \mathrm{~kW}$ & $8.48 \mathrm{~kW}$ & $7.68 \mathrm{~kW}$ & NO & NO & YES & $98.51-85.4$ & $78.5-65.4$ & No & YES & YES & NO & NO & NO & NO & NO \\
\hline 15kW (16 DNAE) & YES & YES & YES & $13.48 \mathrm{~kW}$ & $11.8 \mathrm{~kW}$ & $10.68 \mathrm{~kW}$ & NO & NO & YES & $101.2-87.5$ & $\sqrt{812-67.5}$ & NO & YES & YES & NO & NO & NO & NO & NO \\
\hline $30 \mathrm{~kW}$ (35 DGBB) & YES & YES & YES & $34.25 \mathrm{~kW}$ & $31.1 \mathrm{~kW}$ & $28.99 \mathrm{~kW}$ & YES & YES & YES & $100.3-83$ & $80.3-63.0$ & No & YES & YES & NO & NO & NO & NO & NO \\
\hline $60 \mathrm{~kW}$ (35 DGBB) & YES & YES & YES & $60.0 \mathrm{~kW}$ & $53.4 \mathrm{~kW}$ & $48.6 \mathrm{~kW}$ & YES & YES & YES & $100.3-86.9$ & $83.2-66.9$ & No & YES & YES & NO & NO & NO & NO & NO \\
\hline \multirow{2}{*}{\multicolumn{20}{|c|}{\begin{tabular}{|l|l|} 
Domino responded in their behalf. \\
No longer offer generator sets
\end{tabular}}} \\
\hline & & & & & & & & & & & & & & & & & & & \\
\hline & \multicolumn{19}{|c|}{\begin{tabular}{|l} 
No longer offer generator sets. \\
Postal Service returned. Forwarding time expired.
\end{tabular}} \\
\hline $\begin{array}{l}\text { Customized Support } \\
\text { Services } \\
\end{array}$ & \multicolumn{19}{|c|}{ Postal Service returned. Undeliverable as addressed. } \\
\hline Pure Power WI & \multicolumn{19}{|c|}{ Postal Service returned. Forwarding time expired. } \\
\hline
\end{tabular}




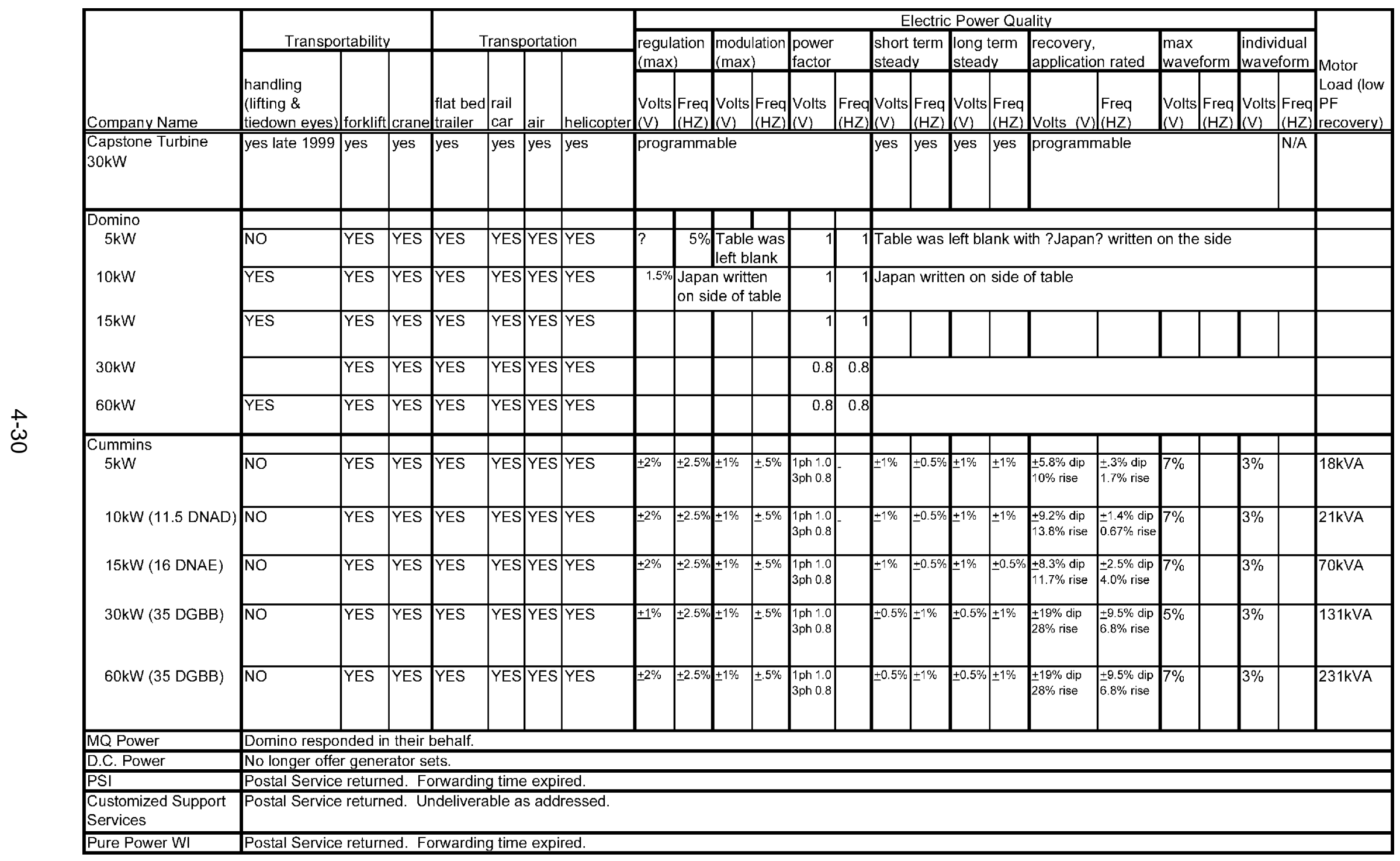


Appendix 4-C. DISPLAY DATA PROVIDED BY CECOM FOR MARKET SURVEY 
4-32 


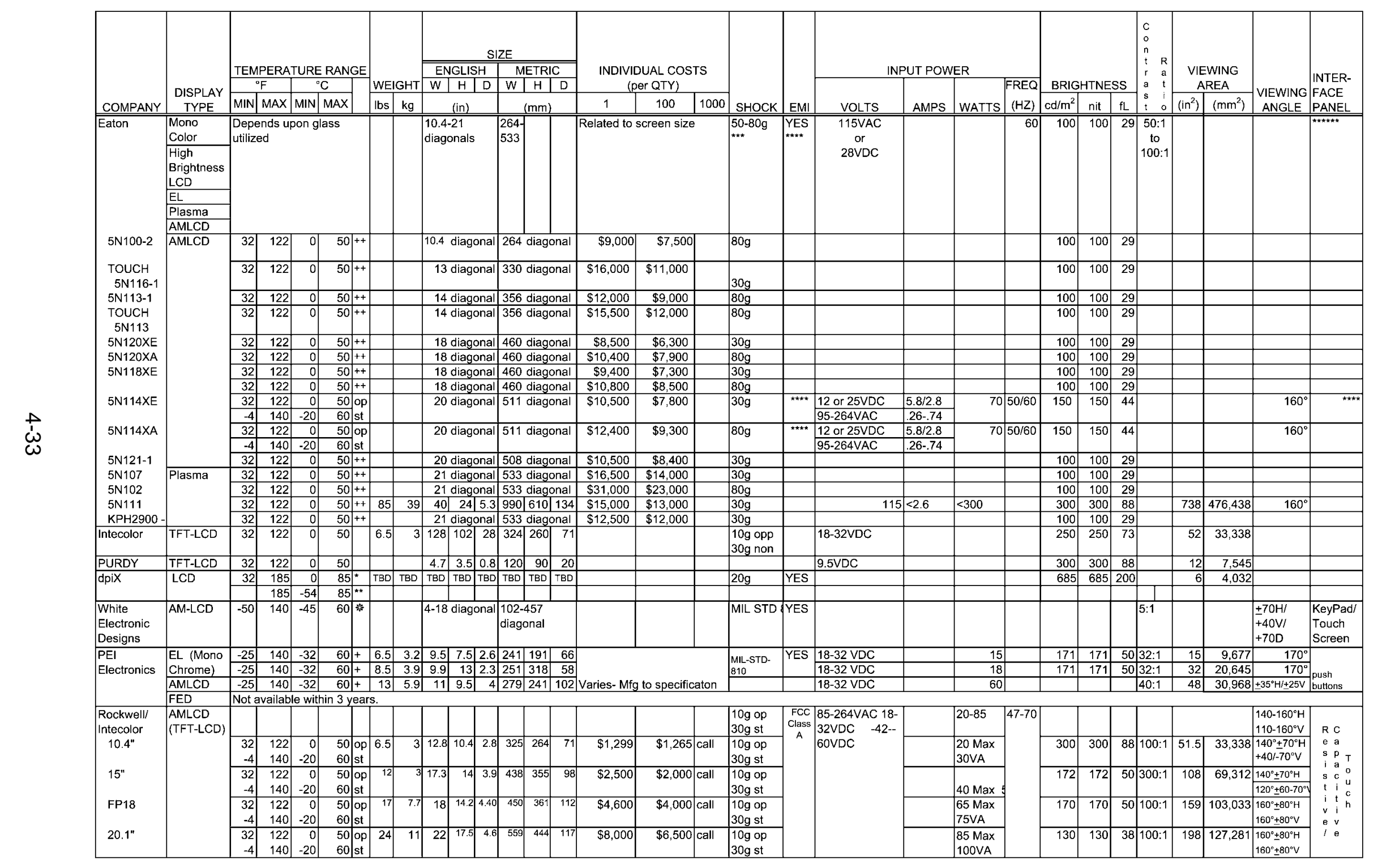




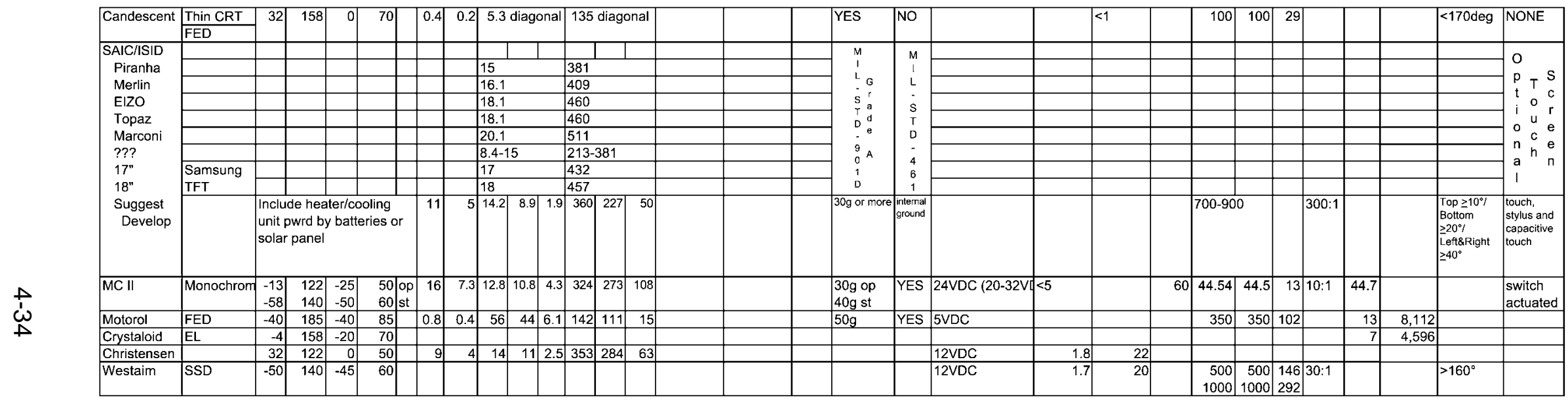

+ Exact temp not given, just answered question that it could operate at these temps. It won't degrade at $-55^{\circ} \mathrm{F}$, but may at $-65^{\circ} \mathrm{F}$ (but won't experience damage)

++ COTS \& Ruggedized $0-50^{\circ} \mathrm{C}$ Military -20 to $85^{\circ} \mathrm{C}$

* W/Heaters

* w/o Thermal Control

*** 50-80Gs full sine wave $11 \mathrm{mS} X Y \mathrm{Z}$ axis multiple blow/MIL-STD-810E/MLL-STD-90

***** FCC Rules, Part 15/MIL-STD-461D

$* * * * *$ Analog RGB; RS343; Separate, compsite or sync on green, mult resolution capability

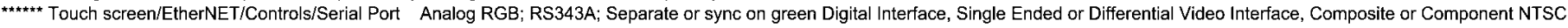
op- operating

st- storage 


\section{SUMMARY OF EXISTING GEN-SET DESIGN AND OPERATION}

The purpose of this chapter is to summarize the existing gen-set design and analyze its usage in the field. Full understanding of the design and usage of today's gen-sets is important for making valid recommendations for future generators.

\subsection{EXISTING DESIGNS}

Current gen-sets are designed to be extremely rugged, cost-effective sources of power that are capable of surviving the extreme conditions associated with military operations. The latest design, the tactical quiet generator (TQG), was designed to be quieter than its predecessor, the MIL-STD design, while maintaining the necessary ruggedness. Existing TQGs are significantly heavier than their industrial counterparts, in large measure to meet the stringent ruggedness requirements of the military, but also to provide capabilities and features that are not available on industrial units.

The following sections outline the major components and operation of existing TQGs.

\subsubsection{Industrial Diesel Engines}

Market forces have been the major driver of industrial diesel engine technology being commonly applied to power gen-sets. These engines are generally designed and manufactured to be very rugged, low maintenance, fuel efficient and inexpensive. The overwhelming number of commercial U.S. gen-sets produce $60-\mathrm{Hz}$ ac. In the United States, diesel engines are usually chosen to power generators on the basis of their performance near $1800 \mathrm{rpm}$, which is the speed most portable generators employ. Exceptions to this are the relatively few gen-sets that employ engine speeds of $3600 \mathrm{rpm}$, and the very small number of gen-sets that have been built where engine speed is independent of the ac output frequency.

The current diesel engine technology commonly used in gen-set applications is usually categorized as industrial as opposed to automotive technology. For industrial diesel engines, size and weight are seldom major factors in the design philosophy; the focus is generally on initial cost, fuel economy, maintenance cost, engine life, and performance. A list of common attributes of past and currently available industrial diesel engines follows:

\section{Aspiration}

Virtually all engines are naturally aspirated for rated outputs below $35 \mathrm{hp}$ or for swept volumes (engine displacement) below about 1.2 L. turbochargers are sometimes offered on engines with 1.2- to 3.0-L displacements and are routinely offered for engines with swept volume of $3.0 \mathrm{~L}$ or larger (power levels above $60 \mathrm{hp}$ ). For the larger engines and latest models, turbocharging may include charge cooling, which is sometimes referred to as intercooling or aftercooling. Charge cooling is often accomplished by an ambient air to turbo-compressed air heat exchanger or alternatively by using engine coolant to cool the compressed charge. Turbocharging will usually increase the rated power and torque output of a given engine by $25-35 \%$ or more at all useful engine speeds.

\section{Fueling}

What is known as IDI has commonly been the injection method of choice in the recent past, but now DI is used for many newer gen-set engines. Injection is normally mechanically controlled rather than electronically controlled. Electronic control is used for transportation engines and is significantly more costly. 
Although fueling is often categorized as IDI or DI, there is a lot of variation in technology and performance within these categories. There is an obvious trend to phase out IDI in favor of DI, and in the future the trend will likely be to use increasingly higher fuel pressures and control sophistication for DI. Useful discussions and information concerning fuel injection can be found in Chap. 2 (Automotive Diesel Engine Technology Trends) and Appendix 2-A (Diesel Engine Glossary).

\section{Block and head material}

Cast iron is used for virtually all diesel engine blocks (crankcases). Cast iron is also the most common material for the engine head. Aluminum alloys are sometimes used for the engine head material to reduce weight, but weight is usually not a major concern for industrial engines.

\subsubsection{Alternator}

Existing TQG sets have a diesel combustion engine that is governed to run at a fixed speed such that the directly coupled alternator (generator) driven by the engine produces a fixed frequency output of either 50 to $60 \mathrm{~Hz}$ (Mode I and III units) or $400 \mathrm{~Hz}$ (Mode II units). No power electronics are needed for synthesis of the output voltage waveform. Brushless synchronous machines are currently used to convert the mechanical power of their rotating shaft into threephase electrical voltage at a preset frequency.

\subsubsection{Control System}

Use of inexpensive, mechanical controls with dial gauges dominates. Speed is generally governed to $1800 \mathrm{rpm}$ for $60-\mathrm{Hz}$ ac power or $1500 \mathrm{rpm}$ for $50-\mathrm{Hz}$ ac power. Some gen-sets use other constant speeds, such as 3600 and 3000. A diagnostics connection is available on the control panel, but little information was available about the data provided through this connection.

\subsubsection{Current Gen-Set Frame and Housing Design}

The existing TQG gen-sets consist of a metal housing and frame structure. The 5- and 10-kW units utilize mostly aluminum components, while the 15-kW and larger units employ mainly steel. The estimated weights of the frame and housing along with the total gen-set weight for each unit and the contribution of the frame and housing to the total weight are listed in Table 5.1.

One of the main reasons for the large increase in weight of the gen-set going from the 10-kW unit to the $15-\mathrm{kW}$ unit is the shift from aluminum to steel for the enclosure and frame.

Table 5.1. Weight of gen-set and frame for existing TQGs

\begin{tabular}{|c|c|c|c|}
\hline Unit & $\begin{array}{c}\text { Estimated frame and } \\
\text { housing weight } \\
(\mathrm{lb})\end{array}$ & $\begin{array}{c}\text { Total gen-set } \\
\text { weight } \\
(\mathrm{lb})\end{array}$ & $\begin{array}{c}\text { Contribution of frame and } \\
\text { housing to total weight } \\
(\%)\end{array}$ \\
\hline $5 \mathrm{~kW}$ & 408 & 888 & 46 \\
\hline $10 \mathrm{~kW}$ & 465 & 1182 & 39 \\
\hline $15 \mathrm{~kW}$ & 1138 & 2124 & 54 \\
\hline $30 \mathrm{~kW}$ & 1329 & 3006 & 44 \\
\hline $60 \mathrm{~kW}$ & 1479 & 4063 & 36 \\
\hline
\end{tabular}


Density of aluminum is $0.1 \mathrm{lb} / \mathrm{in}^{3}{ }^{3}$, while that of steel is $0.28 \mathrm{lb} / \mathrm{in} .^{3}$ Although the generator, engine, and accessory weight only increased from 717 to $986 \mathrm{lb}$, the frame and housing weight increased from 465 to $1138 \mathrm{lb}$. For this reason, redesign and incorporation of lightweight materials has the most potential for weight reduction of $15-\mathrm{kW}$ and larger units.

The existing housing design consists of small sheet metal panels attached with many mechanical fasteners and welds. This approach was probably taken to allow limited access to the internal components without opening large portions of the enclosure.

\subsection{CURRENT SYSTEM PERFORMANCE}

Military mobile electric generators are required to provide reliable, lightweight, and cost-effective power under an extreme range of mission requirements and operating conditions. These diverse requirements affect design philosophy and present a significant design challenge. The operating temperature can range from -50 to $140^{\circ} \mathrm{F}$, and the altitude ranges from sea-level to $10,000 \mathrm{ft}$. The design is also challenged to extract good performance from the gen-set under the diverse requirements of both wartime and peacetime compared in Table 5.2. The average peacetime and projected wartime DOD mobile generator use profiles are shown in Table 5.3 and Fig. 5.1.

Table 5.2. Average demand power and operating time for the DOD mobile electric generators

\begin{tabular}{|c|c|c|c|}
\hline Mission & Peacetime $^{2}$ & $\begin{array}{c}\text { Wartime } \\
\text { 15-d mission }\end{array}$ & $\begin{array}{c}\text { Wartime } \\
\text { 30-d mission }\end{array}$ \\
\hline $\begin{array}{c}\text { Generator rated } \\
\text { power }\end{array}$ & $5-60 \mathrm{~kW}$ & $60 \mathrm{~kW}$ and under & Over 60 kW \\
\hline $\begin{array}{c}\text { Average demand } \\
\text { power, \% of rated }\end{array}$ & 27.8 & 58.1 & 69.9 \\
\hline $\begin{array}{c}\text { Average operating } \\
\text { time, \% of months }\end{array}$ & 3.2 & 47.2 & 95.3 \\
\hline $\begin{array}{c}\text { Average operating } \\
\text { time, h/month }\end{array}$ & 23.2 & 340 & 686 \\
\hline
\end{tabular}

Note: Based on a 30-d month or $720 \mathrm{~h}$.

Table 5.3. DOD gen-set percent of operating time at percent rated load capacity for average peacetime and projected wartime missions

\begin{tabular}{|c|c|c|c|c|}
\hline \multicolumn{2}{|c|}{ Peacetime mission } & \multicolumn{3}{|c|}{ Wartime mission } \\
\hline \multirow{2}{*}{$\begin{array}{l}\text { Demand } \\
\text { power } \\
\text { range } \\
\text { (\% of rated) }\end{array}$} & \multirow{2}{*}{$\begin{array}{c}\text { Average } \\
\text { operating time } \\
\text { (\%) for } \\
5-60 \mathrm{~kW}\end{array}$} & \multirow{2}{*}{$\begin{array}{l}\text { Demand } \\
\text { power } \\
\text { range } \\
\text { (\% of rated) }\end{array}$} & \multicolumn{2}{|c|}{ Projected operating time (\%) } \\
\hline & & & $\begin{array}{l}60 \mathrm{~kW} \text { and } \\
\text { under for } 15 \mathrm{~d}\end{array}$ & $\begin{array}{l}\text { Over } 60 \mathrm{~kW} \\
\quad \text { for } 30 \mathrm{~d}\end{array}$ \\
\hline $0-20$ & 45.7 & NA & NA & NA \\
\hline $20-40$ & 32.4 & $0-40$ & 19.4 & 7.0 \\
\hline $40-60$ & 11.8 & $40-60$ & 30.6 & 16.9 \\
\hline $60-80$ & 7.2 & $60-80$ & 30.6 & 42.3 \\
\hline $80-100$ & 2.9 & $80-100$ & 19.4 & 33.8 \\
\hline
\end{tabular}




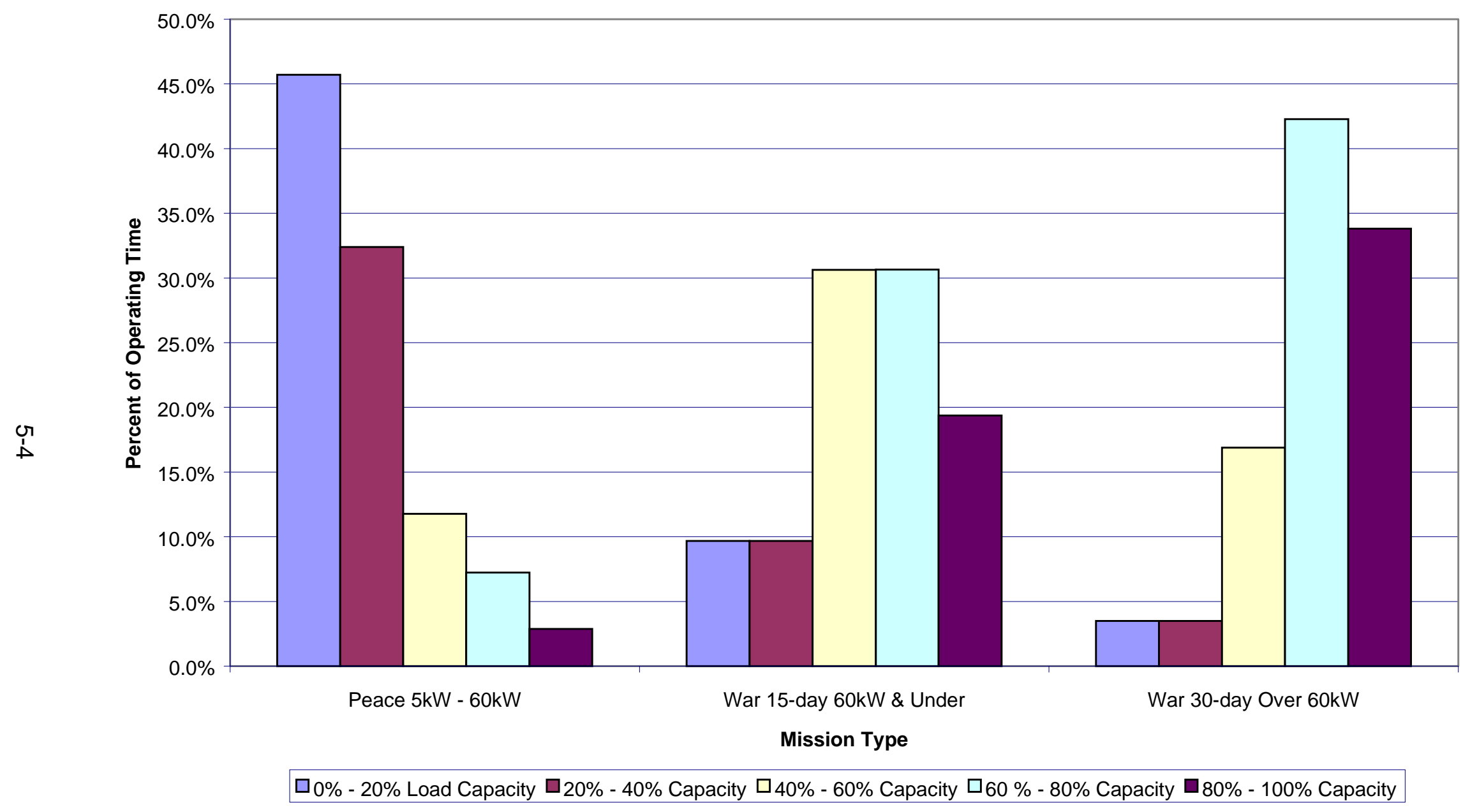

Fig. 5.1. Gen-set percent operating time at percent load capacity for average peacetime and projected wartime missions. 
In general, the gen-sets work longer and have higher loads during wartime scenarios than during peacetime. The projected demand power level during war utilization is 2 to 3 times the average power demand during peacetime exercises.

Further, the monthly gen-set projected operating time during war is 15 to 30 times longer than the average peacetime monthly usage depending on gen-set family size. The wartime electric energy produced, which is the product of demand power and duration, can be from 30 to 70 times greater than the peacetime gen-set output energy. A distribution of demand energy vs power level generated from the DOD inventory of 3- to 100-kW gen-sets for projected wartime and average peacetime missions is shown in Fig. 5.2. Figure 5.2 illustrates the dramatic difference between war and peacetime energy generated with DOD gen-sets. The peacetime energy distribution is shown with an expanded scale in Fig. 5.3.

In peacetime, more than two-thirds of operations occur at less than $40 \%$ load (Table 5.3), and more than one-half of all generators are used less than $10 \mathrm{~h} /$ month, with the average usage about $23 \mathrm{~h} /$ month (Ref. 3). The same data show that increasing usage greatly improves reliability [increases mean time between unscheduled events (MTBUSE)].

Based on MTBUSE data, ${ }^{3}$ the likelihood of an unscheduled event occurring during a typical wartime mission is quite high, between $40 \%$ and $99 \%$. Fortunately, an unscheduled event does not always mean mission failure, but rather that some anomaly occurred and a repair is eventually needed. The more important mission performance parameter is the operational readiness rating averaging about $95 \%$.

At least four consequences of equipment underutilization are apparent.

- Reduced gen-set reliability and availability. Data 3 clearly indicate that reliability improves with both increased load and operating time.

- Greater maintenance cost. Wetstacking, a significant maintenance problem, is directly related to the engine running too cool, which takes place when the engine is underutilized.

- Decreased fuel efficiency. Fixed-speed engines are forced to run outside their optimum fuel consumption envelope when they are operated well below their rated load.

- Greater weight and logistics burden. Using gen-sets larger than necessary imposes a much greater logistics burden getting the gen-sets to their required destinations.

In peacetime, the motivation to reduce operating costs, specifically fuel costs, means reduced gen-set deployment, power demand, and operating time. The motivation to reduce fuel costs tends to increase maintenance cost. ${ }^{3}$ One approach to minimize peacetime operating costs is to try to run the gen-sets long enough and hot enough to minimize the sum of maintenance and fuel costs.

Mobile generators must satisfy the heavy energy demands of war missions yet operate well under relatively light peacetime energy demands during most of their lives. The new gen-set design philosophy must accommodate the dichotomy of war and peace utilization scenarios. Much of the new philosophy in this report is an attempt to decrease the negative consequences of underutilization and yet to assure satisfactory performance under extreme military conditions of war. The new gen-set designs must be flexible to perform well at extreme environmental conditions under a wide range of mission loads and durations. 


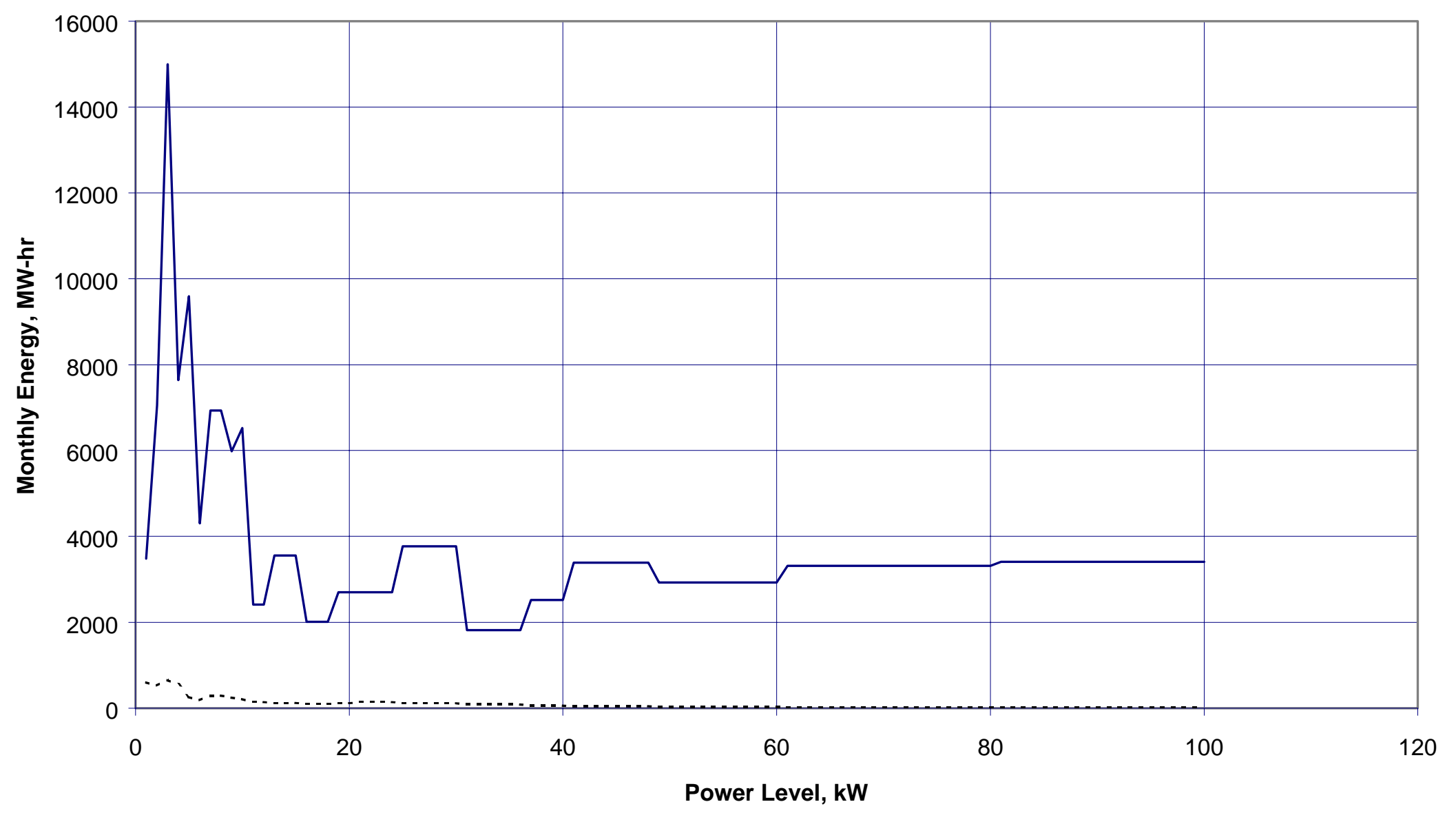

War-time $\cdots \cdot$... Peace-time

Fig. 5.2. Monthly energy produced by the DOD 2- to $100-\mathrm{kW}$ inventory of mobile electric generators during wartime and peacetime missions. 


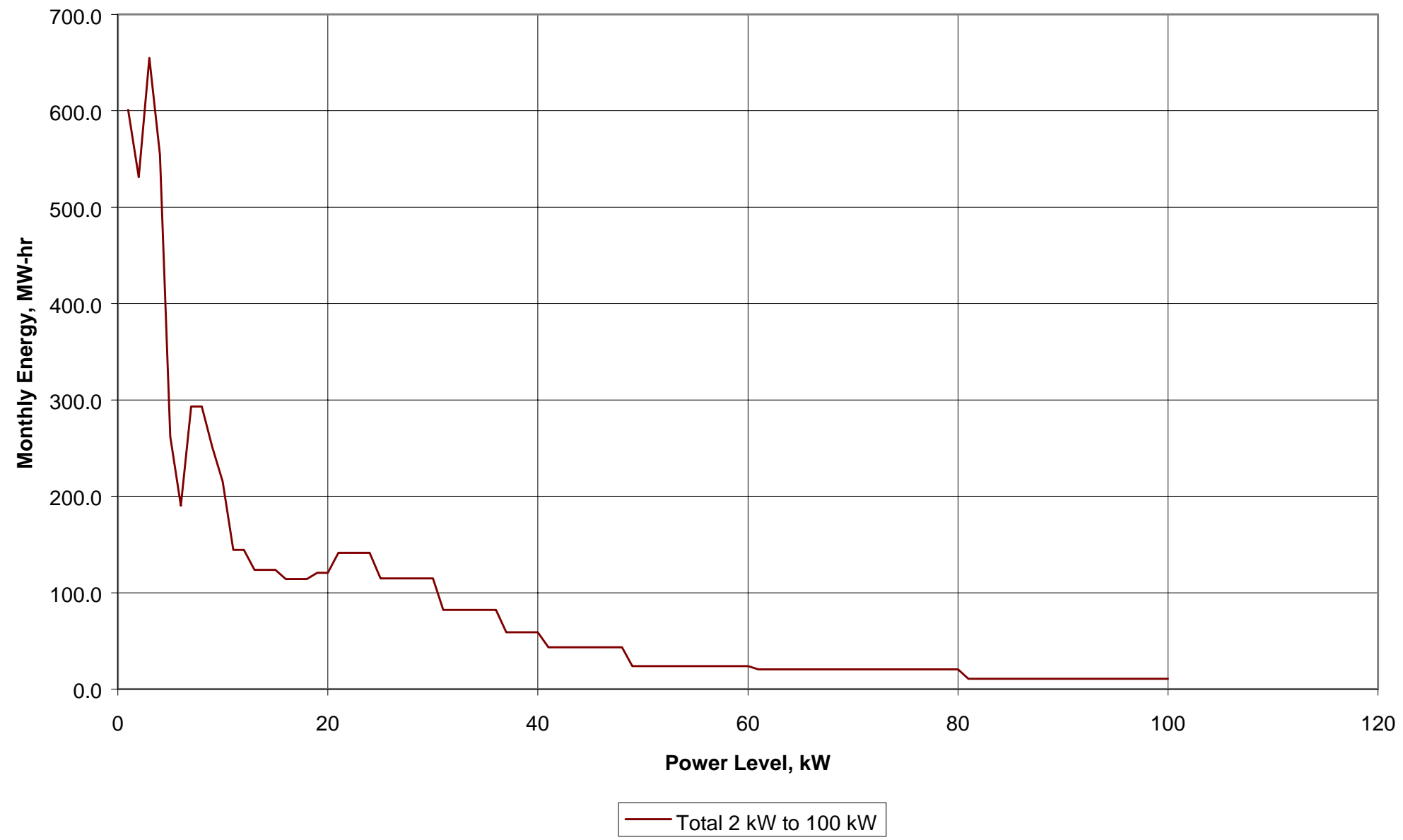

Fig. 5.3. Peacetime monthly energy produced by the DOD 2- to 100-kW inventory of mobil electric generators. 


\subsection{DATA ANALYSIS}

Data related to the energy demand, mission weight, and cost of the existing inventory of gensets was analyzed to better understand their current performance. The analysis, summarized here, is described in more detail in Appendixes 5-A and 5-B. Analysis of existing gen-sets is useful in determining if the existing families of gen-sets of $5,10,15,30$, and $60 \mathrm{~kW}$ can be effectively replaced in the future with fewer family sizes.

Part of the approach for selecting generator family sizes, described in Chap. 6, is based on examining energy demand, mission weight, and cost. The data used in the analysis are the best available to the authors at the time of this report preparation. The analysis here is subject to the validity of the underlying assumptions described in Appendixes 5-A and 5-B.

The energy demand, mission weight, and cost of the existing inventory of gen-sets yielded the following conclusions:

1. The historical energy demand distribution has two dominant peaks in the 2- to 10-kW range. From 10 to $100 \mathrm{~kW}$, the wartime and peacetime energy demand is less than $25 \%$ of their respective maximum $2-\mathrm{kW}$ peaks.

2. In general, the most weight-efficient strategy is to use generators with rated power equal to the demand power level.

3. There is a mission weight penalty for choosing off-optimum generator size combinations.

4. The use of lightweight materials in the generators can provide a large weight reduction especially when paralleling multiple units.

5. The difference in fuel consumption (fuel weight) does not significantly affect the optimum family size selection.

6. In peacetime operations, generator capital and maintenance costs are the most significant.

7. In average monthly peacetime operations ( $24 \mathrm{~h} /$ month), fuel costs are less than $10 \%$ of the total cost, assuming the power demand is $28 \%$ of rated power. If the power demand is assumed to be $100 \%$ of rated power, the fuel cost is $30 \%$ of the total cost.

8. In projected wartime missions (long duration and high power demand), the fuel costs dominate the total cost of ownership of the gen-set accounting for $60 \%-90 \%$ of the total cost depending on gen-set size, fuel costs, and capitalization costs.

9. The monthly capital-plus-maintenance cost per rated power ranges from $\$ 29.27 / \mathrm{kW}$-month to $\$ 2.28 / \mathrm{kW}$-month depending on generator size and capitalization life. The energy cost (capital + maintenance + fuel) ranges from $\$ 1.15 / \mathrm{kWh}$ to $\$ 0.22 / \mathrm{kWh}$ depending on generator size and capitalization life. Both of these costs decrease with rated power.

\subsection{REFERENCES}

1. Wartime profile data taken from Appendix A, "Operational Mode Summary/Mission Profile for Tactical Electric Power (TEP)."

2. Data taken from a 2-year generator utilization survey at Ft. Bragg and Ft. Hood, supported by DATA Inc. (Decisions and Technology Associates), October 1995 through June 1997.

3. Power utilization data from CECOM, PM-MEP web page, http://www.pmmep.org/utiliz.htm. 


\section{Appendix 5-A. UTILIZATION AND DEMAND ENERGY ANALYSIS OF EXISTING GEN-SET DATA}

Various analyses were performed using existing data from DOD mobile electric generators to aid in developing design philosophy for state-of-the-art generators of the 21 st century. These analyses include utilization, energy/power demand, mission weight, volume, and cost. This appendix deals primarily with utilization and energy/power demand of the DOD gen-sets.

Utilization involves typical mission scenarios of demand power level and mission duration.

The energy demand in kilowatt hours is a fundamental design parameter because it combines the power level $(\mathrm{kW})$, duration $(\mathrm{h})$, and generator inventory requirements for typical operations.

The data used in the analysis are the best available to the authors at the time of this report preparation.

\section{Utilization and Energy/Power Analysis}

\section{Generator Inventory}

The mobile electric generator energy demand is estimated from the combination of several sources of data. One assumption is that the current population of DOD generators reflects the overall mobile electric needs of the military. Figure 5-A.1 shows the inventory by capacity of DOD auxiliary power units (APUs) and Mil-Standard (Mil-Std) and TQGs as of January 1999.

\section{Generator Utilization}

The war and peace mission utilization ${ }^{1,2}$ is compared in Table 5.2. The average peacetime and projected wartime DOD mobile generator utilization profiles are shown in Table 5.3 and Fig. 5.1.

For peacetime operations, the average power draw is $28 \%$ of rated power for $23 \mathrm{~h} / \mathrm{month}$. In projected wartime use of gen-sets up to $60 \mathrm{~kW}$, the average power draw is $58 \%$ of rated power for $340 \mathrm{~h} /$ month operating time. For gen-sets over $60 \mathrm{~kW}$, the projected wartime power draw is $70 \%$ of rated power for $686 \mathrm{~h} / \mathrm{month}$.

Two-thirds of peacetime operations occur at less than $40 \%$ of rated power. More than $80 \%$ of wartime operations occur at greater than $40 \%$ of rated power.

The profile of peacetime power demand and operating time for each of the 5- to 60-kW mobile generators is shown in Fig. 5-A.2. The peacetime data originate from a generator survey taken at Ft. Bragg and Ft. Hood during peacetime field exercises spanning October 1995 through June 1997.

\section{Energy Demand}

The distributions of monthly energy (MWh) generated by the current DOD population of 3-kW through 100-kW power levels for projected wartime and average peacetime missions are shown in Figs. 5.2 and 5.3. These figures show the monthly energy (MWh) produced as a function of power level at which it was generated in the field. These curves are the cumulative product of the power and time utilization profile and the 3-kW through 100-kW generator inventory (generator inventory, utilization, and monthly operation described above). 


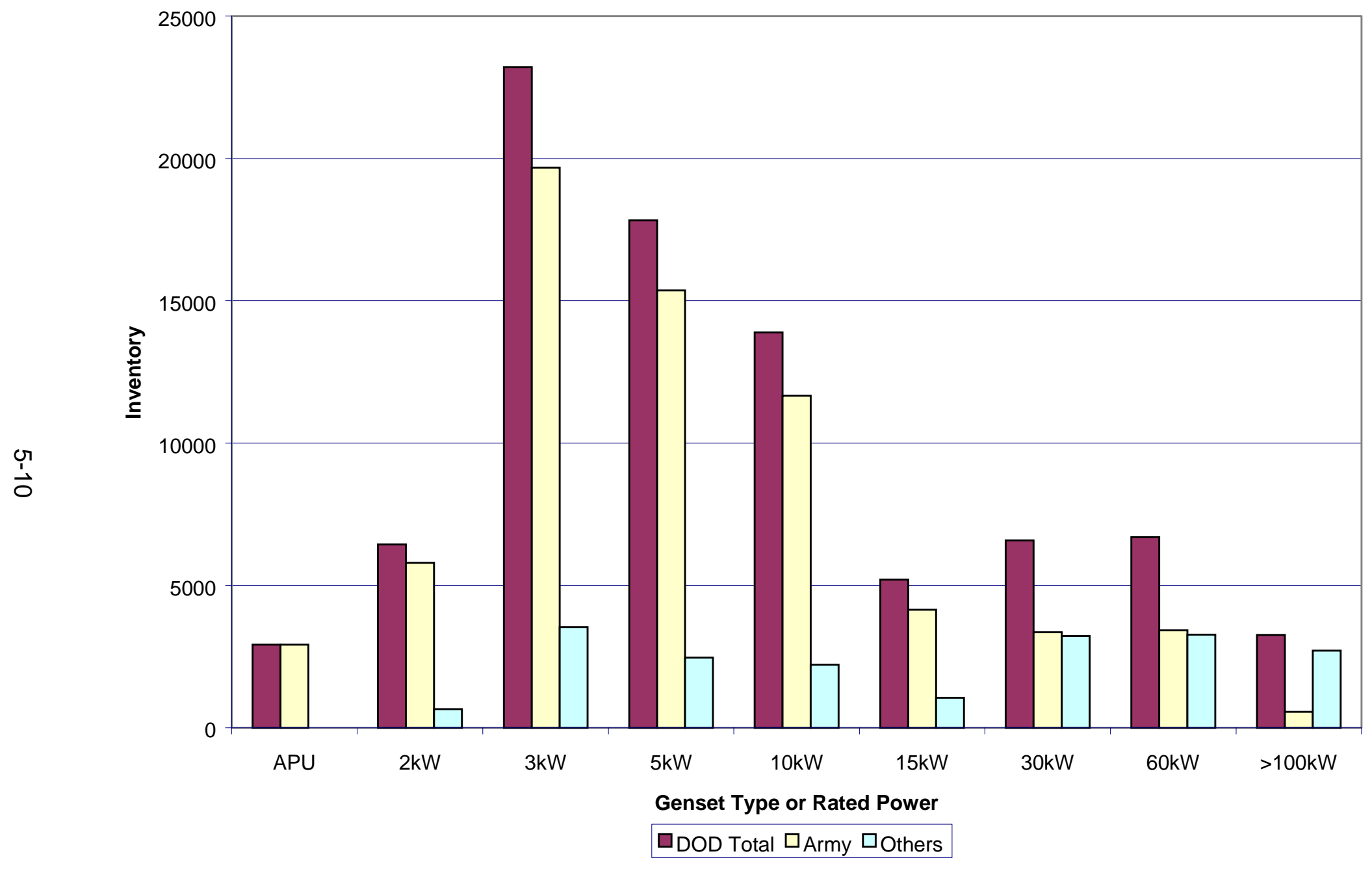

DOD Inventory Total $=86,013$ Gen-sets \& APUs

Fig. 5-A.1. DOD gen-set inventory by rated load capacity. 


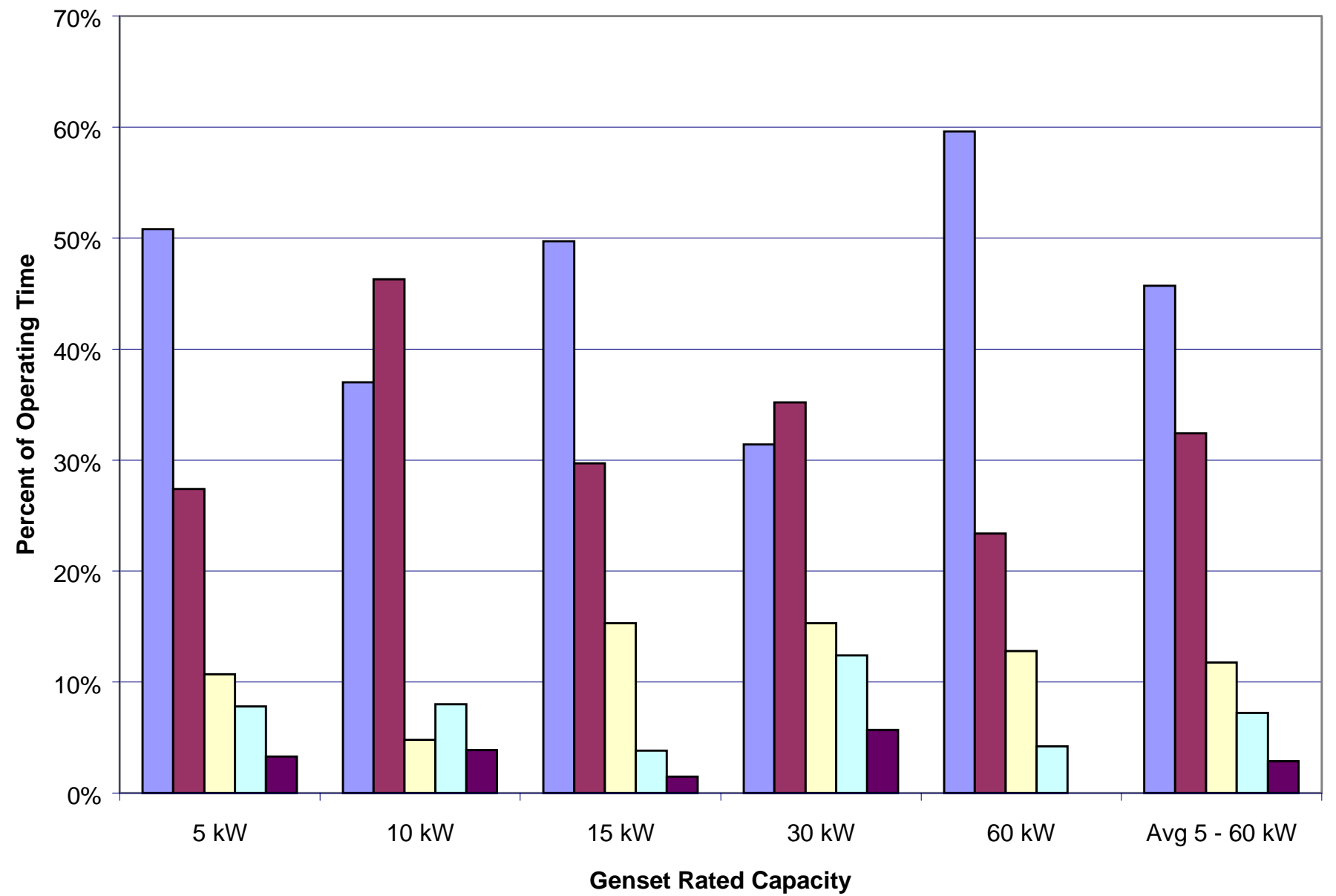

$\square 0 \%-20 \%$ Capacity $\square 21 \%$ - 40\% Capacity $\square 41 \%$ - 60\% Capacity $\square 61 \%$ - 80\% Capacity $\square 81 \%$ - 100\% Capacity

Over all, two-thirds of operations occur at $<40 \%$ load.

Fig. 5-A.2. Peacetime utilization for 5-, 10-, 15-, 30-, and 60-kW DOD gen-sets with percent of operating time at percent load capacity. 


\section{Summary of Family Size Selection Trade-Off}

The energy demand analysis (Fig. 5.2) favors the generator selection of at least one family member at the low end of the 5- to $60-\mathrm{kW}$ power range, namely a unit between 5 and $10 \mathrm{~kW}$. The optimum mission weight analysis indicates that optimum weight is achieved by selecting gen-sets no larger than capacity needed. So if a lot of missions require small gen-sets, then at least one small gen-set family member is needed. The normalized weight $(\mathrm{lb} / \mathrm{kW})$, normalized fuel consumption $(\mathrm{g} / \mathrm{kWh})$ described in Appendix 5-B, and normalized energy total cost $(\$ / \mathrm{kWh})$, all favor selecting family sizes at the high end of $5-$ to $60-\mathrm{kW}$ generator range. Therefore, a compromise mix in gen-set family member capacity selection is necessary. 


\section{Appendix 5-B. MISSION WEIGHT ANALYSIS OF EXISTING GEN-SET DATA}

Various analyses were performed using existing data from DOD mobile electric generators to aid in developing a design philosophy for state-of-the-art generators of the 21st century. These analyses include utilization, energy/power demand, mission weight, volume, and cost. This appendix deals primarily with mission weight of the DOD gen-sets.

Mission weight in this analysis includes the fixed generator weight (which depends on maximum expected demand power) and the consumable fuel weight (which depends upon both actual demand power and mission duration). The equipment weight to transport the generator and fuel to the field were not included in this analysis.

The data used in the analysis are the best available to the authors at the time of this report preparation.

\section{Mission Weight Analysis}

\section{Mobile Electric Generator Weight Considerations}

The weight required to provide mobile electric power is analyzed to assess the influence that generator and fuel weight have on generator design philosophy. This analysis excludes the weight associated with transporting the generators and fuel into the training areas or battlefields. The objective is to minimize weight in the field. Another objective is to try to select gen-set family sizes that can be transported by or towed within the 4000-lb tow capability of a high-mobility multipurpose wheeled vehicle (HMMWV). It is assumed that the towable $4000-\mathrm{lb}$ limit includes the tow trailer and its payload.

\section{Generator Weight}

The weights of the current 5- to 60-kW generators are shown in Fig. 5-B.1. The weight per unit rated power is shown in Fig. 5-B.2. As expected, weight increases with rated power. In general, the decrease in weight per unit power (power density) with increased rated power indicates that larger generators are more weight efficient. Power density alone would tend to favor selection of larger generator family sizes. A mission-dependent trade-off compromise is necessary. The dip in weight per unit rated power of the $10-\mathrm{kW}$ unit is suspected to be the result of aluminum used in the skid and housing of the 5- and 10-kW sets. The 15-, 30-, and 60-kW generators have steel skids and housings and therefore have normalized weights that are greater than if aluminum was used.

\section{Fuel Consumption/Weight}

Fuel consumption rates for the 5- to $60-\mathrm{kW}$ generators are shown in Fig. 5-B.3. The fuel consumption generally decreases with rated power ranging from 360 to $238 \mathrm{~g} / \mathrm{kWh}$ for the 5 - to $60-\mathrm{kW}(60-\mathrm{Hz})$ generators, respectively, based on first article test data. The average is about $293 \mathrm{~g} / \mathrm{kWh}$ and $317 \mathrm{~g} / \mathrm{kWh}$ for the 60- and 400-Hz family groups, respectively. The corresponding thermal efficiencies, shown in Fig. 5-B.4, range from about $23 \%$ to $36 \%$ with an average of $29.7 \%$ and $27.3 \%$ for the $60-$ and $400-\mathrm{Hz}$ family groups, respectively. The average fuel consumption for both the $60-$ and $400-\mathrm{Hz}$ generators is approximately $305 \mathrm{~g} / \mathrm{kWh}$.

\section{Mobile Electric Power Weight}

The total weight to generate electric power in the field is assumed to be generator plus consumed fuel. In this analysis, the weight to transport the equipment and fuel is ignored. An evaluation of combined generator and fuel weight is presented in Figs. 5-B.5 through 5-B.9. The 


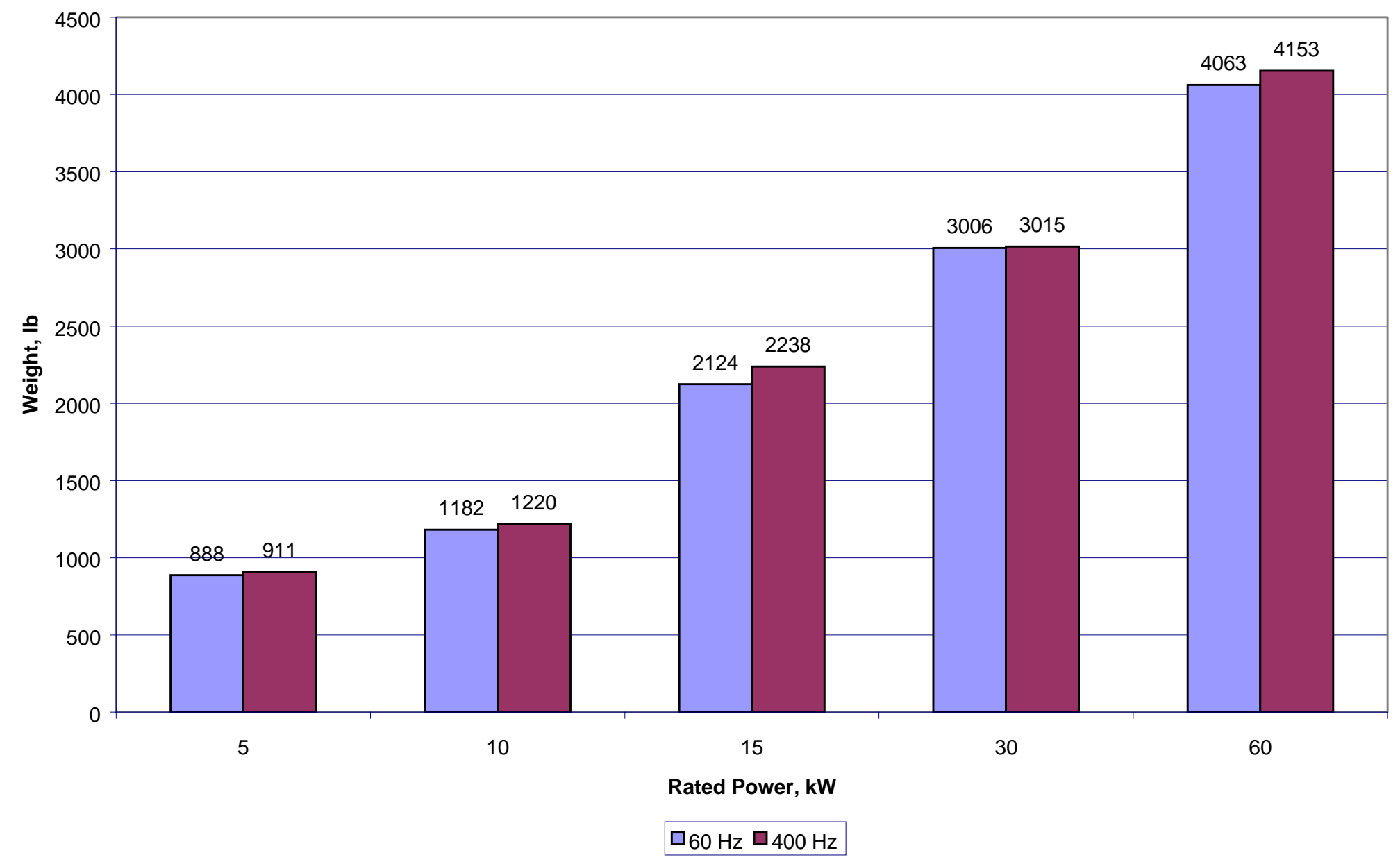

Fig. 5-B.1. Weight for DOD TQD mobile electric generators, 5 to $60 \mathrm{~kW}$. 


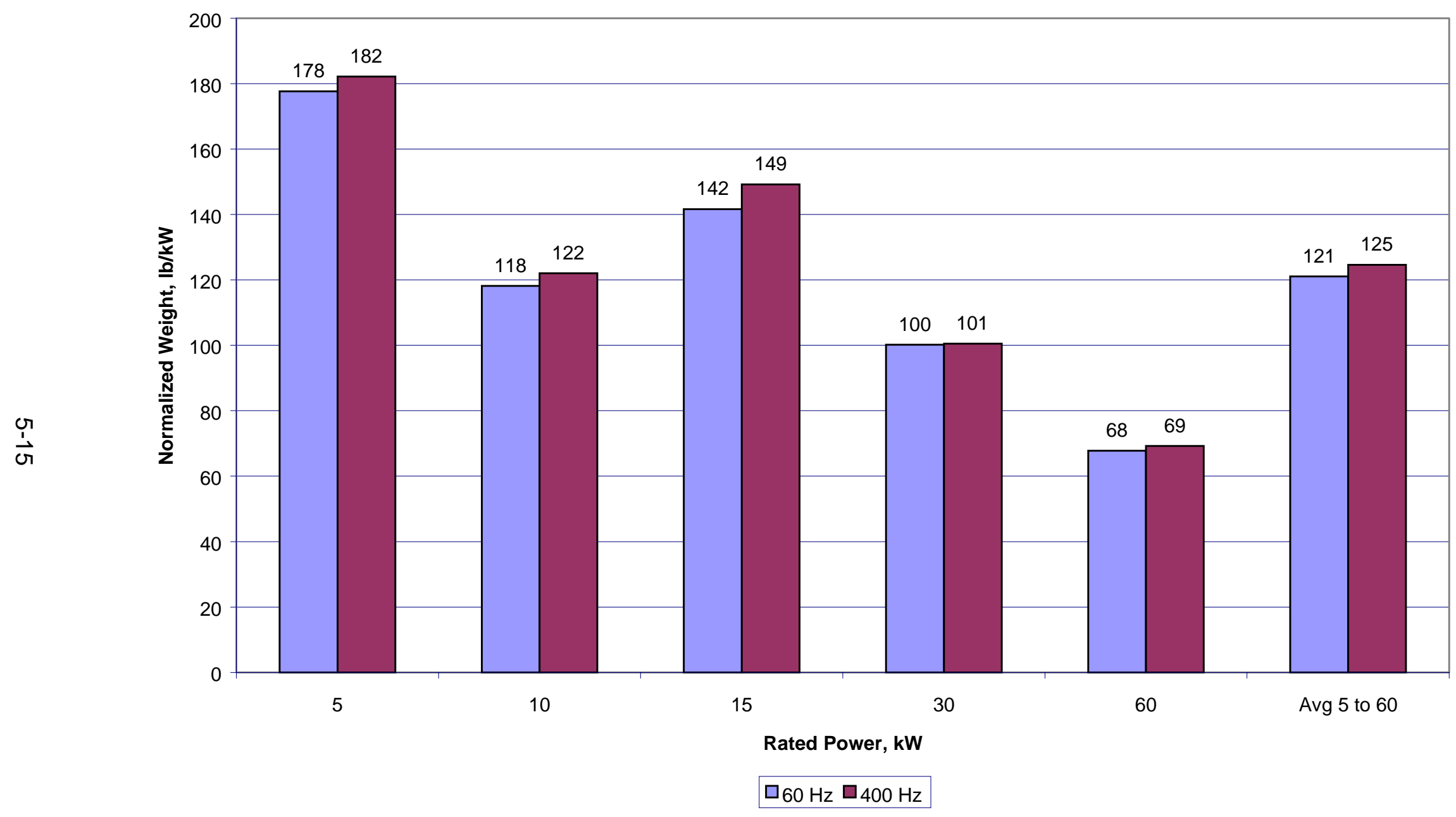

Fig. 5-B.2. Normalized weight for DOD TQG mobile electric generators, 5 to $60 \mathrm{~kW}$. 


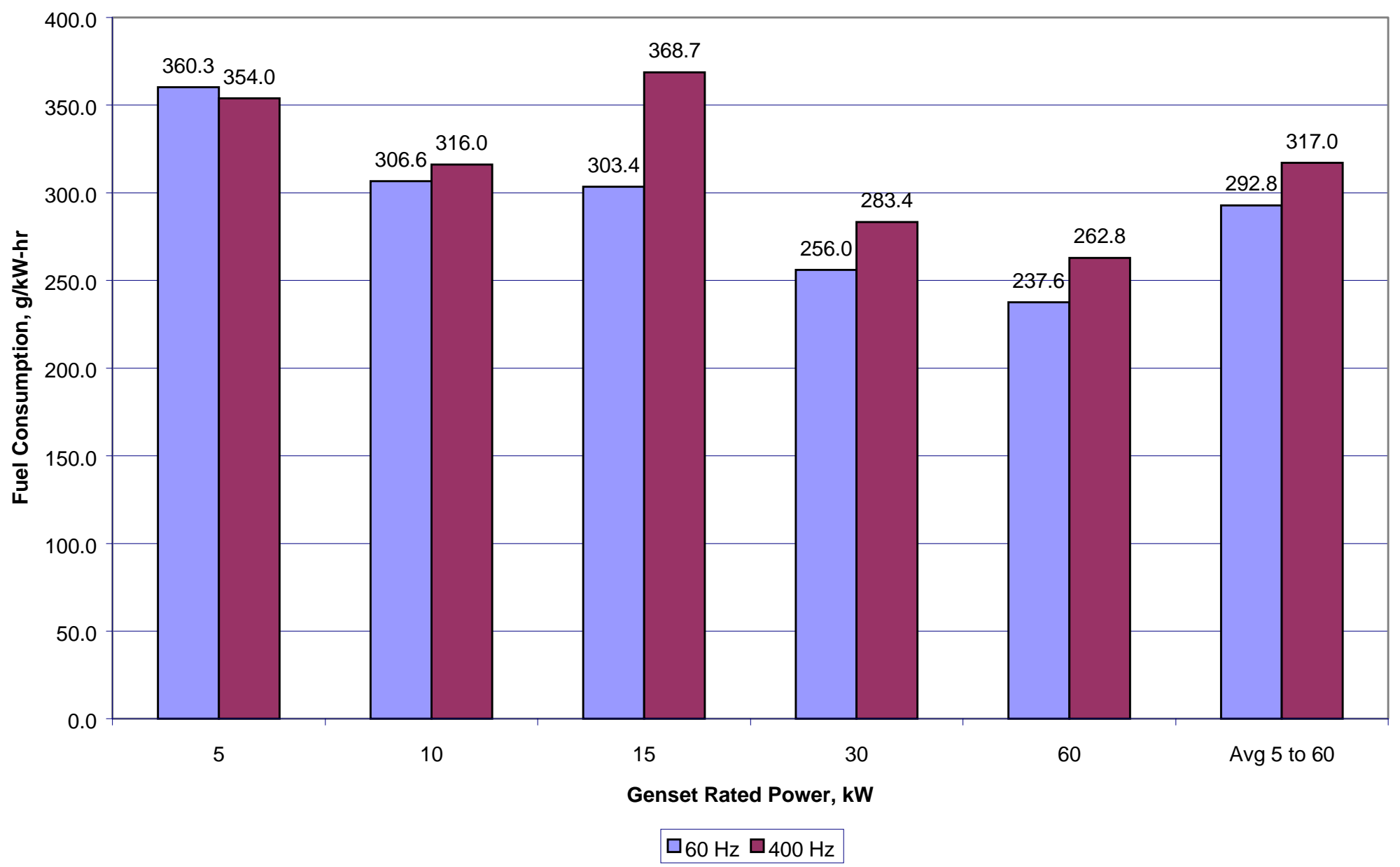

Fig. 5-B.3. Fuel consumption rate for DOD TQG mobile electric generators, 5 to $60 \mathrm{~kW}$. 


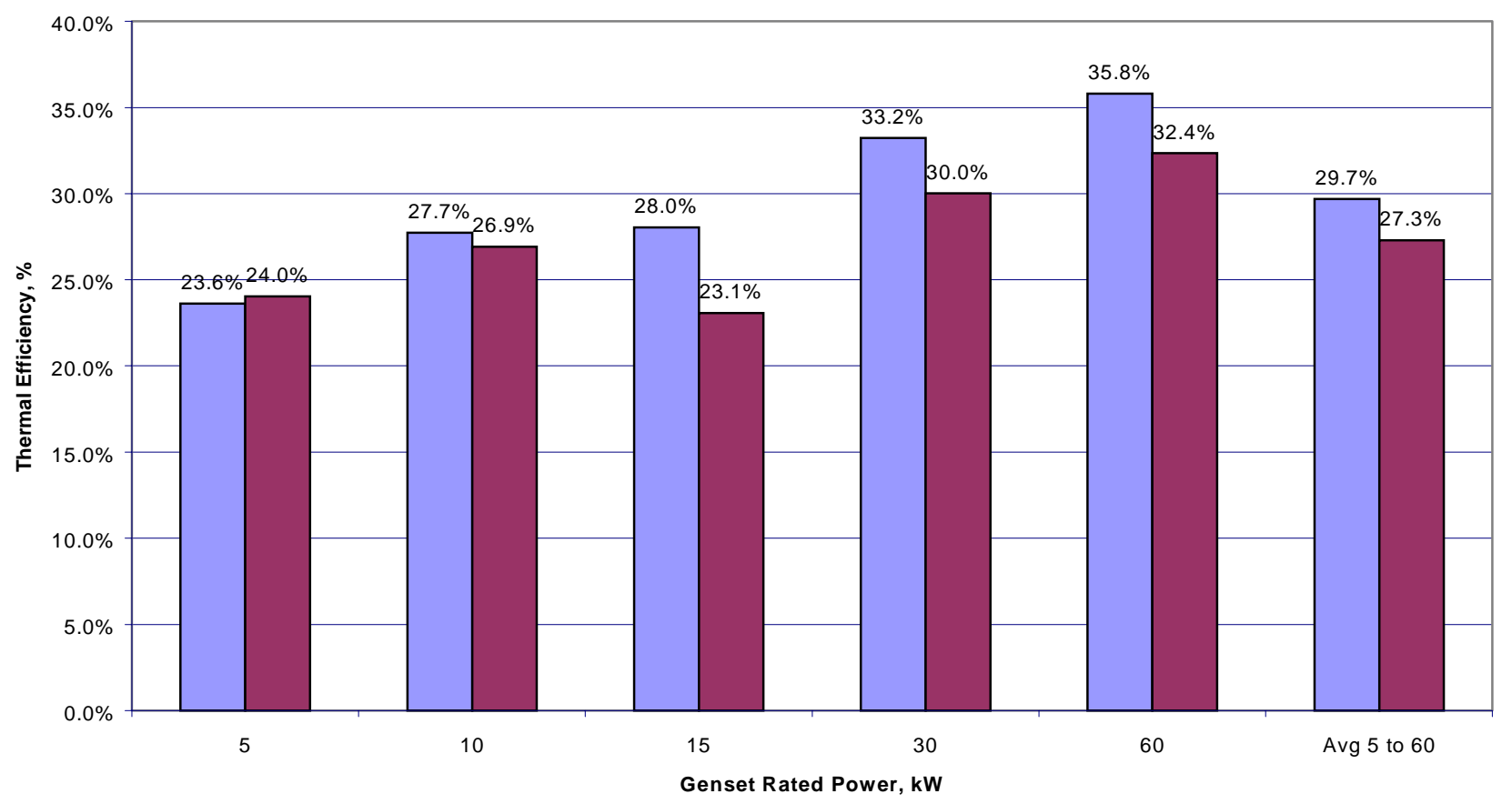

$\square 60 \mathrm{~Hz} \square 400 \mathrm{~Hz}$

Fig. 5-B.4. Thermal efficiency of DOD mobile electric generators, 5 to $60 \mathrm{~kW}$. 


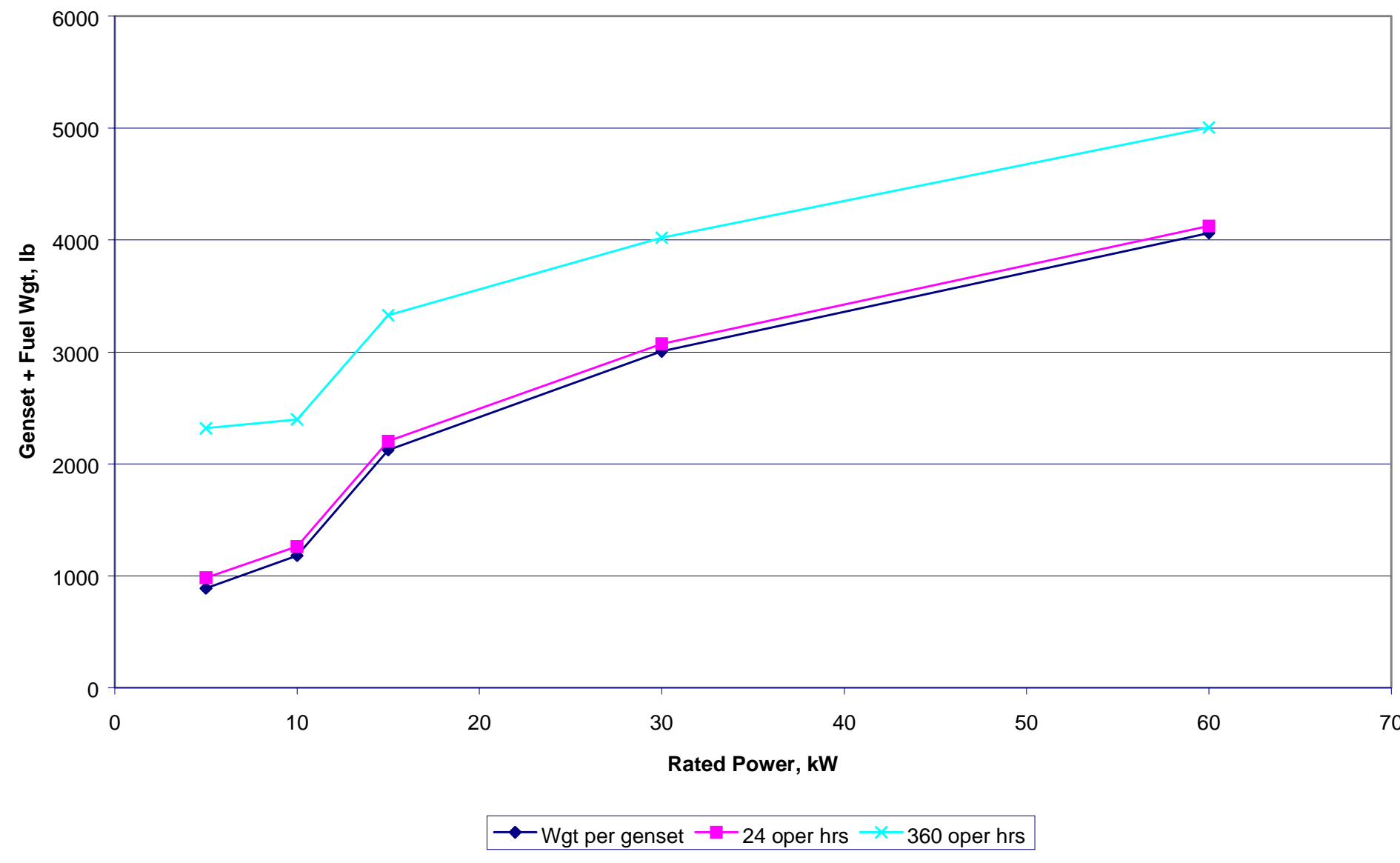

Fig. 5-B.5. Mission weight for DOD mobile electric generators for 5-kW power demand and different mission durations. 


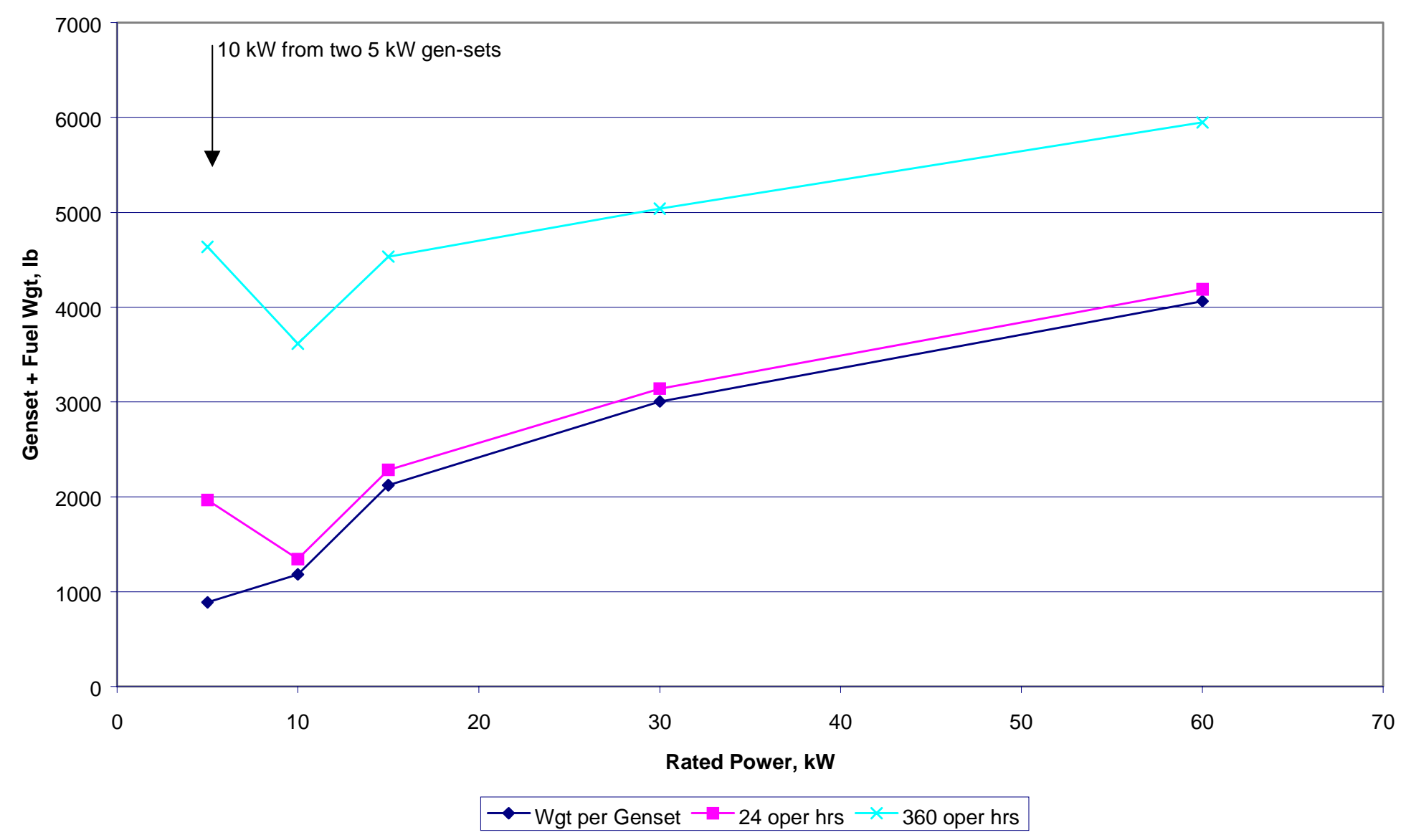

Fig. 5-B.6. Mission weight for DOD mobile electric generators for 10-kW power demand and different mission durations. 


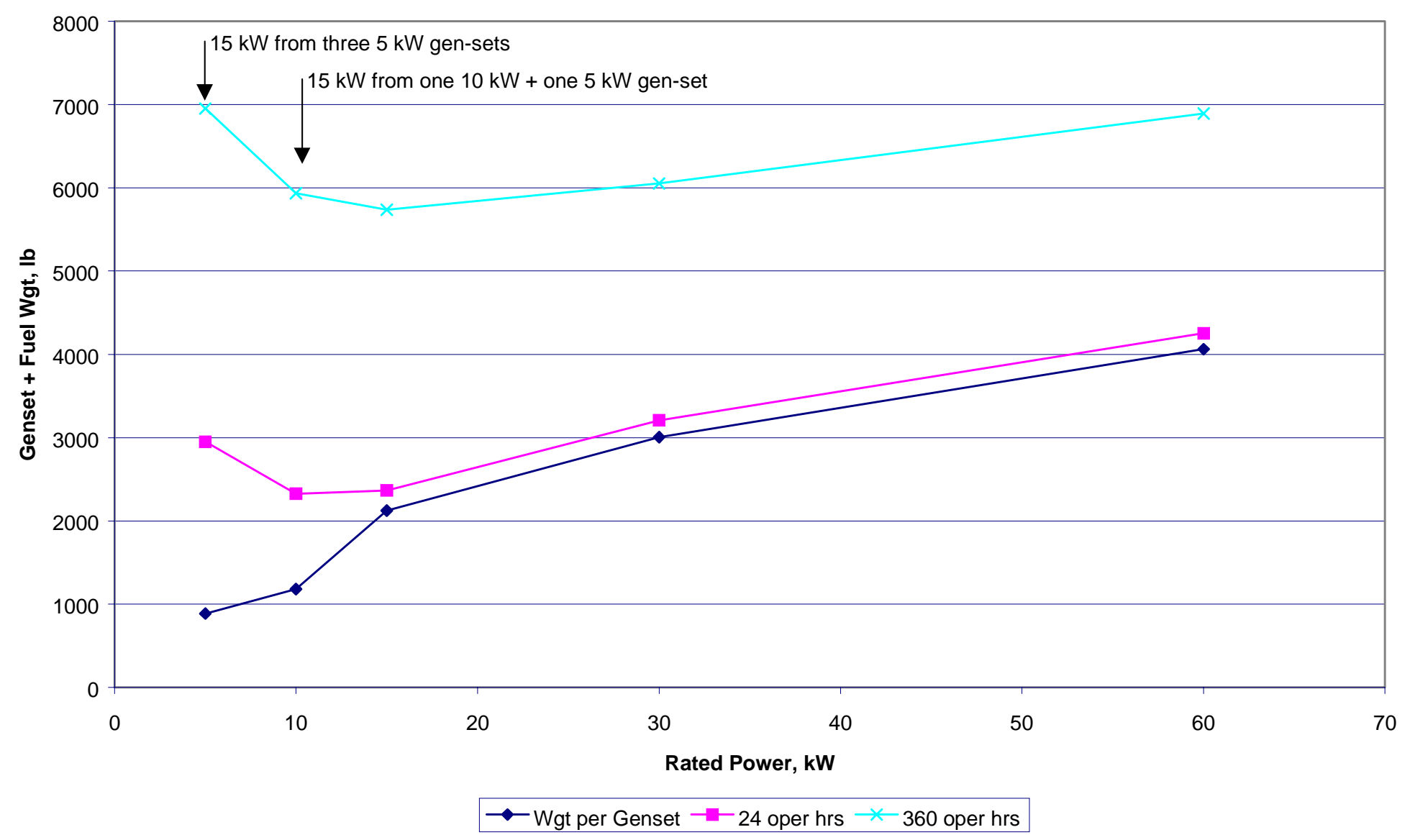

Fig. 5-B.7. Mission weight for DOD mobile electric generators for 15-kW power demand and different mission durations. 


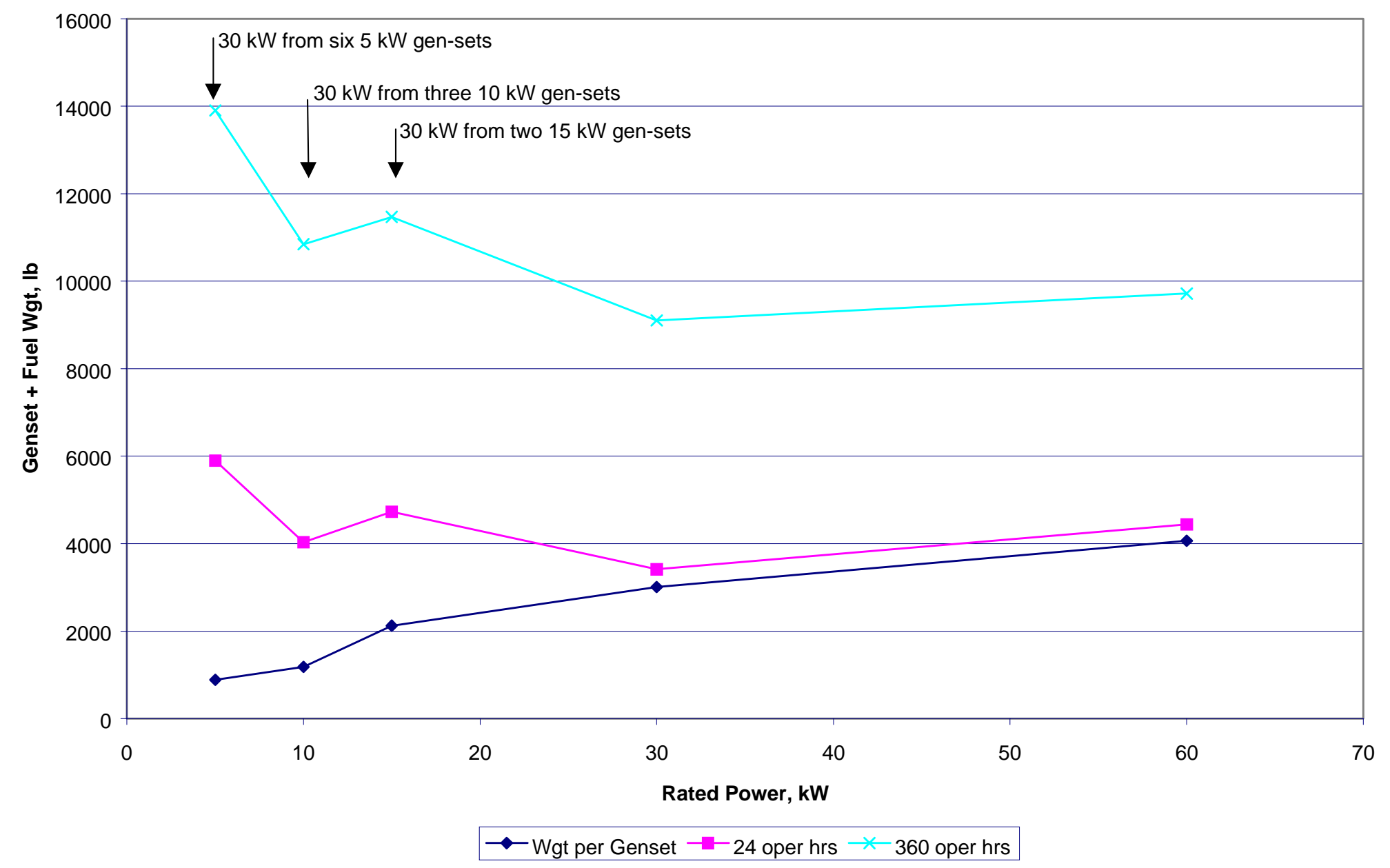

Fig. 5-B.8. Mission weight for DOD mobile electric generators for 30-kW power demand and different mission durations. 


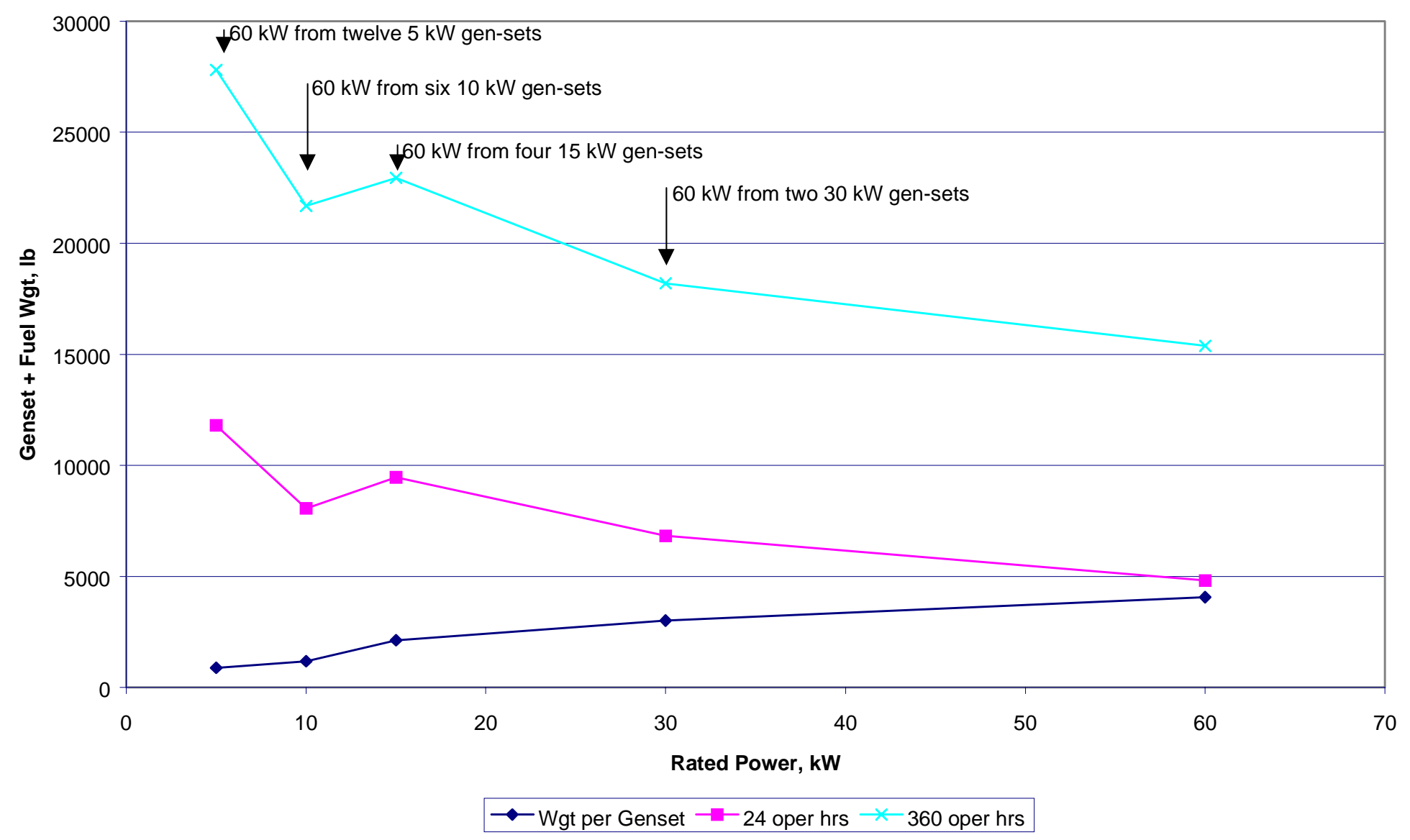

Fig. 5-B.9. Mission weight for DOD mobile electric generators for $60-\mathrm{kW}$ power demand and different mission durations. 
analysis shows total weight for two mission operating times, 24 and $360 \mathrm{~h} \mathrm{(1}$ and $15 \mathrm{~d}$ ) for different demand power levels using different rated generators that operate separately or in various parallel combinations to produce the demand power. The 24- and 360-h operating times are approximately equivalent to average monthly peacetime use $(23 \mathrm{~h} / \mathrm{month})$ and wartime mission duration (340-h/15-d mission) for $60 \mathrm{~kW}$ and under gen-sets.

This set of curves shows the following:

1. In general, the most weight-efficient strategy is to use generators with rated power equal to the demand power level.

2. These curves also show the weight penalty for choosing off-optimum parallel generator combinations for the sample 24- and 360-h missions. Some examples are examined and discussed below.

3. The use of lightweight materials in the generators can be a strong weight improvement, especially when paralleling multiple units.

4. The difference in fuel efficiency (difference in fuel consumption weight) does not significantly affect the optimum family size selection unless the mission duration is very long (hundreds of hours).

Figure 5-B.5 shows the total mission weight for a 5-kW demand power level using each rated generator size $5,10,15,30$, and $60 \mathrm{~kW}$ (on the horizontal axis). Regardless of mission duration, Fig. 5-B.5 shows the minimum fielded weight for $5-\mathrm{kW}$ power is achieved with a $5-\mathrm{kW}$ generator. Using greater capacity generators to generate only $5 \mathrm{~kW}$ results in carrying greater weight into the field even though the greater capacity generators are more fuel efficient per Fig. 5-B.4. Even the 360-h mission duration is not long enough to take full advantage of the more fuel-efficient larger generators to reduce total mission weight. Figure 5-B.5 illustrates the weight penalty for fielding generators of greater capacity than is needed.

Likewise, Fig. 5-B.6 shows the total mission weight for a 10-kW demand power level. Two 5-kW generators are combined to generate $10 \mathrm{~kW}$. Figure 5-B.6 shows that the minimum total mission weight for $10-\mathrm{kW}$ demand is with the $10-\mathrm{kW}$ unit. The weight penalty for producing $10 \mathrm{~kW}$ with other rated generators is also shown. Interestingly, Fig. 5-B.6 shows that producing $10 \mathrm{~kW}$ with two 5-kW generators requires less mission weight than one 15-kW unit for the 24-h mission. The suspected cause is that the 5- and $10-\mathrm{kW}$ generators employ lightweight aluminum in the skid and housing where the $15 \mathrm{~kW}$ and other generator family members have heavier steel skids and housings. It takes the 360-h mission duration for the heavier but more fuel-efficient $15-\mathrm{kW}$ unit to have about the same mission weight as the lighter, less fuel-efficient pair of 5-kW units.

Continuing on for power demands of 15,30 , and 60 kW, Figs. 5-B.7-5-B.9, respectively, show that in general, the minimum fielded weight is achieved by using generators that are rated similar to the power demand level. An interesting result is shown in Fig. 5-B.7 for the 15-kW demand power level. For short 24-h mission duration, the total mission weight for $15-\mathrm{kW}$ demand is satisfied equally well with a $5-\mathrm{kW}$ plus a $10-\mathrm{kW}$ combination, or a $15-\mathrm{kW}$ unit. Again, this result is probably due to the fact that the 5- and $10-\mathrm{kW}$ generators employ lightweight aluminum in the skid and housing where the $15 \mathrm{~kW}$ and other generator family members have heavier steel skids and housings. For the longer duration (360-h) mission, the lightweight aluminum skid and 
housing advantage in the $5-\mathrm{kW}$ plus $10-\mathrm{kW}$ generator combination is deteriorated by the greater fuel consumption of the 5- and 10-kW (60-Hz) generators shown in Fig. 5-B.3.

\section{Generic Weight Analysis}

A generic weight trade-off analysis comparing fixed generator weight and consumable fuel weight for various mission parameters is shown in Figs. 5-B.10 and 5-B.11. The ratio of fuel weight to generator weight is plotted vs mission duration for various ratios of demand power to rated power. The curves in Figs. 5-B.10 and 5-B.11 permit the user to determine the mission duration time for selectable normalized generator weight $(\mathrm{lb} / \mathrm{kW})$ and selectable fuel to gen-set weight ratio.

Figure 5-B.10 shows the fuel to generator weight ratio for an average generator with normalized fixed weight of $125 \mathrm{lb} / \mathrm{kW}$ (Fig. 5-B.2) and an average fuel consumption rate of $305 \mathrm{~g} / \mathrm{kWh}$ (Fig. 5-B.3). It takes about $185 \mathrm{~h}$ of operation time at full power (demand to rated power ratio of 1 ) for the fuel weight to equal the generator weight. At $25 \%$ load ( 0.25 demand to rated power ratio, similar to historical average utilization), the operating time is about $744 \mathrm{~h}$ (31-d full-time operation) for the fuel weight to equal the generator weight.

Figure 5-B.11 shows a similar curve of fuel to generator weight ratio vs operating time for a typical light-specific-weight generator weighing $70 \mathrm{lb} / \mathrm{kW}$ and with low fuel consumption of $240 \mathrm{~g} / \mathrm{kWh}$ (similar to the $60-\mathrm{kW}$ generator). The fuel weight would equal the generator weight in about $133 \mathrm{~h}$ (>5-d full-time operation) under full load and about $530 \mathrm{~h}$ (22-d full-time) under 25\% load.

\section{HMMWV Tow Requirement}

The advantage of limiting generator weight to permit towing the unit with a HMMWV tends to drive the family size selection toward the smaller power rating generator and toward the use of light-weight materials and design practice. This does not impact the smaller generators (15 kW or smaller), because they already satisfy the HMMWV 4000-lb tow limit as is. Any 15- to $30-\mathrm{kW}$ selected generator size would be a good candidate for a weight minimization effort to meet the towability requirement. Any proposed new generator would have to weigh about $2000 \mathrm{lb}$ or less to satisfy both the HMMWV tow limit and the 1-1/2 ton trailer load capacity. The generators greater than $30 \mathrm{~kW}$ will require a significant weight (1000- to 2000-lb) reduction to satisfy the HMMWV tow requirement.

The HMMWV towability for mobile electric generators is summarized in Table 5-B.1. The 5-kW through $60-\mathrm{kW}$ generators are mounted on three types of military trailers.

The 3/4-ton trailer weighs about $1200 \mathrm{lb}$ and is listed as carrying a 5-kW (888-lb), a 10-kW (1182-lb), or a 15-kW (2124-lb) generator that in all cases would fall within the 4000-lb HMMWV tow limit. Note that the $15-\mathrm{kW}$ generator mounted on the 3/4-ton (1500-lb capacity) trailer exceeds the trailer nominal capacity by $624 \mathrm{lb}$. But, the 3/4-ton trailer M116A3 is listed as modified, which may permit it to carry the small excess weight.

The 1-1/2 ton trailer M103A4 weighing about $2000 \mathrm{lb}$ is listed as carrying two 10-kW generators each weighing $1182 \mathrm{lb}$. This power unit can supply $20 \mathrm{~kW}$ and is only $364 \mathrm{lb}$ over the 4000-lb HMMWV tow limit. Weight reduction on a new variable-speed generator design would most likely bring this combination within the HMMWV tow limit. The 1-1/2 ton trailer could carry the $30-\mathrm{kW}(3006-\mathrm{lb})$ generator, but the total would be about $1000 \mathrm{lb}$ over the HMMWV tow limit. Thus, it is desirable to reduce the weight of any new generator (i.e., 25-kW) design to $2000 \mathrm{lb}$ or less to satisfy both the trailer load and the HMMWV tow limits. 


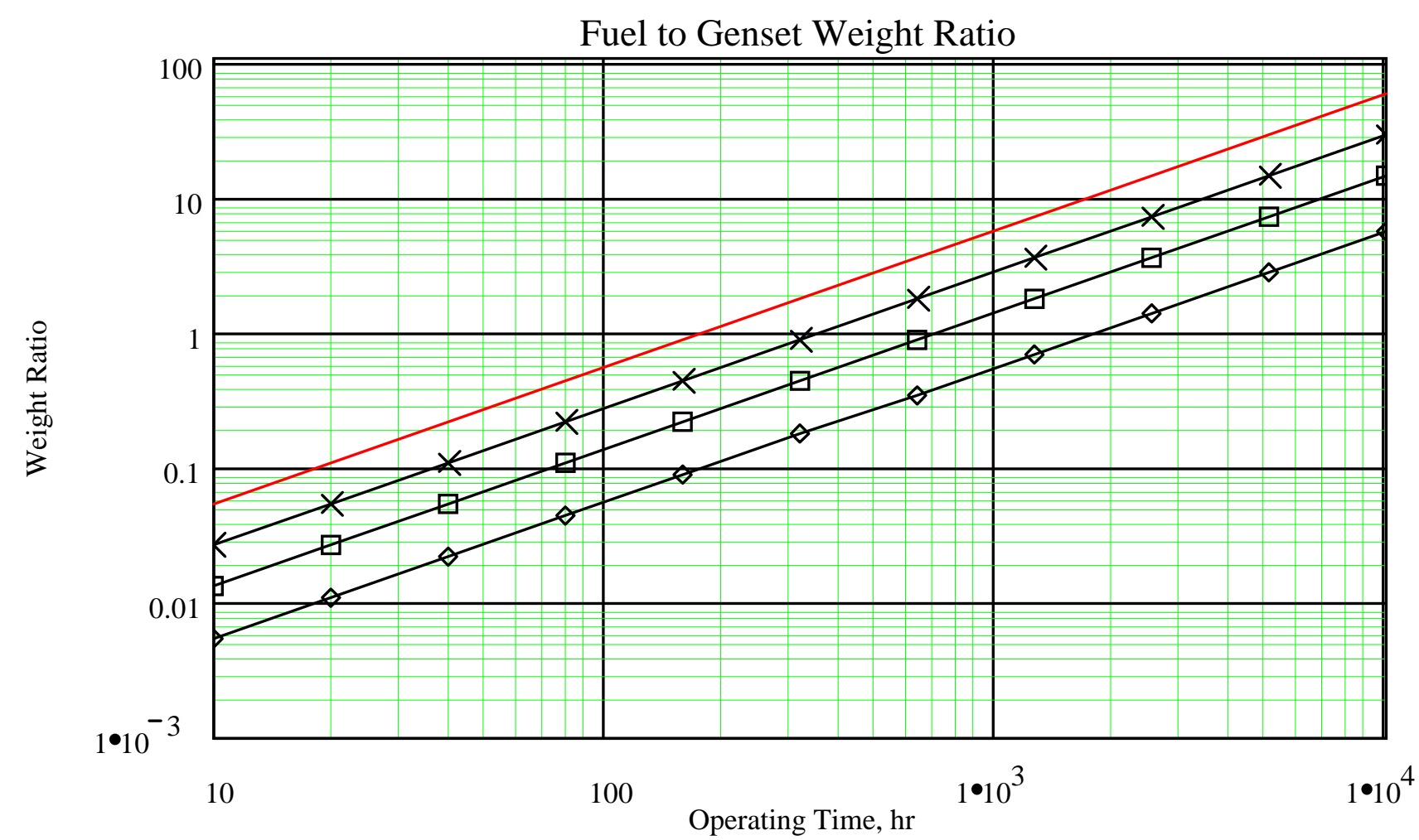

- demand $/$ rated power ratio $=1$

$* x * 0.5$

घ曰口 0.25

$\multimap 0.1$

Fuel to generator weight ratio (fwogw) vs operating time (tt) for an average gen-set, weighing $125 \mathrm{lb} / \mathrm{kW}$ and consuming $305 \mathrm{~g} / \mathrm{kWh}$ fuel.

Fig. 5-B.10. Fuel to gen-set weight ratio for an average TQG. 


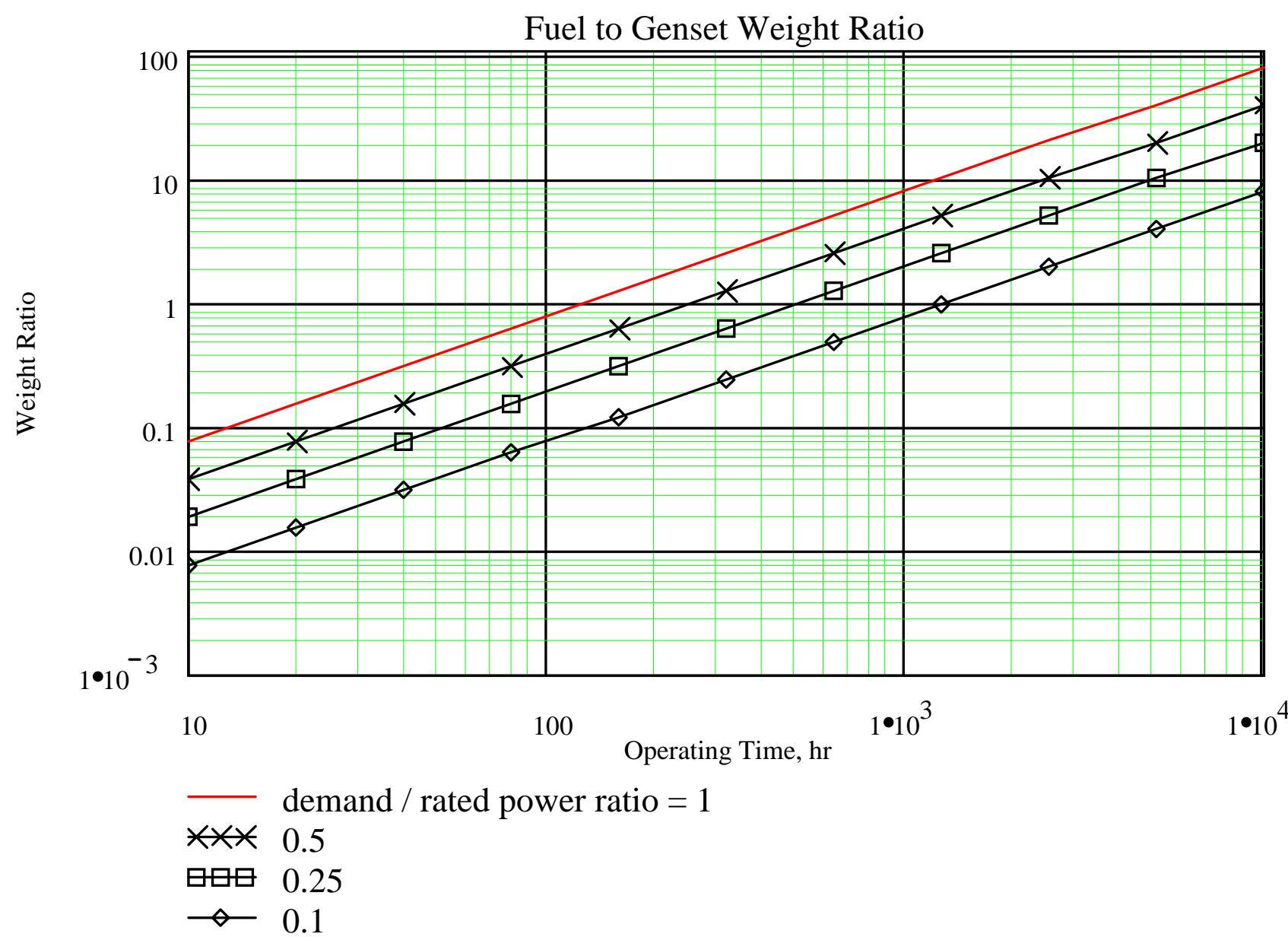

Fuel to generator weight ratio (fwogw) vs operating time (tt) for a light specific weight gen-set, weighing $70 \mathrm{lb} / \mathrm{kW}$ and consuming $240 \mathrm{~g} / \mathrm{kWh}$ fuel (i.e., typical of 60-kW gen-set).

Fig. 5-B.11. Fuel to gen-set weight ratio for a light specific weight generator. 
Table 5-B.1. Towability for mobile electric generators

\begin{tabular}{|c|c|c|c|c|c|c|c|c|c|c|c|c|}
\hline \multirow[b]{2}{*}{$\begin{array}{l}\text { Trailer } \\
\text { model }\end{array}$} & \multirow[b]{2}{*}{$\begin{array}{c}\text { Trailer payload } \\
\text { capacity } \\
\text { [ton (lb)] }\end{array}$} & \multirow[b]{2}{*}{$\begin{array}{l}\text { Trailer } \\
\text { weight } \\
\text { (lb) }\end{array}$} & \multirow[b]{2}{*}{\begin{tabular}{|} 
Maximum \\
payload + \\
trailer weight \\
(lb)
\end{tabular}} & \multirow[b]{2}{*}{$\begin{array}{l}\text { Gen-set } \\
\text { rating } \\
(\mathrm{kW})\end{array}$} & \multirow[b]{2}{*}{$\begin{array}{l}\text { Number of } \\
\text { gen-sets } \\
\text { on trailer }\end{array}$} & \multirow[b]{2}{*}{$\begin{array}{l}\text { Weight of } \\
\text { each } \\
\text { gen-set } \\
\text { (lb) }\end{array}$} & \multirow[b]{2}{*}{$\begin{array}{l}\text { Total gen- } \\
\text { set weight } \\
\text { (lb) }\end{array}$} & \multirow[b]{2}{*}{$\begin{array}{c}\text { Tow } \\
\text { weight } \\
\text { gen-set + } \\
\text { trailer } \\
\text { (lb) }\end{array}$} & \multicolumn{2}{|c|}{$\begin{array}{c}\text { Satisfies weight } \\
\text { capacity limit }\end{array}$} & \multirow[b]{2}{*}{$\begin{array}{l}\text { Exceeds } \\
\text { trailer } \\
\text { capacity } \\
\text { (lb) }\end{array}$} & \multirow[b]{2}{*}{$\begin{array}{l}\text { Exceeds } \\
\text { HMMWV } \\
\text { capacity } \\
\text { (Ib) }\end{array}$} \\
\hline & & & & & & & & & Trailer & HMMWV & & \\
\hline M116A3 & $3 / 4(1500)$ & 1200 & 2700 & 5 & 1 & 888 & 888 & 2088 & Yes & Yes & --- & --- \\
\hline & & & & 10 & 1 & 1182 & 1182 & 2382 & Yes & Yes & --- & --- \\
\hline & & & & 15 & 1 & 2124 & 2124 & 3324 & No & Yes & 624 & --- \\
\hline \multirow[t]{2}{*}{ M103A4 } & $1-1 / 2(3000)$ & 2000 & 5000 & 10 & 2 & 1182 & 2364 & 4364 & Yes & No & --- & 364 \\
\hline & & & & 30 & 1 & 3006 & 3006 & 5006 & Yes & No & Negligible & 1006 \\
\hline \multirow[t]{3}{*}{ M200A1 } & $2-1 / 2(5000)$ & 2700 & 7700 & 15 & 1 & 2124 & 2124 & 4824 & Yes & No & --- & 824 \\
\hline & & & & 30 & 1 & 3006 & 3006 & 5706 & Yes & No & --- & 1706 \\
\hline & & & & 60 & 1 & 4063 & 4063 & 6763 & Yes & No & $\begin{array}{l}-- \\
\end{array}$ & 2763 \\
\hline
\end{tabular}


The 2-1/2 ton trailer M200A1, weighing about $2700 \mathrm{lb}$, is listed as carrying a 15-kW (2124-lb), a $30-\mathrm{kW}(3006-\mathrm{lb})$ or a $60-\mathrm{kW}(4063-\mathrm{lb})$ generator. Each of these are within the trailer capacity, but are beyond the HMMWV tow limit. The 2-1/2 ton trailer $(2700 \mathrm{lb})$ can be towed by a HMMWV if the payload is restricted to about $1300 \mathrm{lb}$. Therefore; any generator mounted on the $2-1 / 2$ ton trailer must be within the $1300-\mathrm{lb}$ limit. It is unlikely that the current $30-$ or $60-\mathrm{kW}$ generators can be reduced enough in weight to be towable on a 2-1/2 ton trailer within the HMMWV tow limit. The 2-1/2 ton trailer weighs too much to be useful behind a HMMWV tow vehicle because of the HMMWV tow limit. The 3/4- and 1-1/2 ton trailers are more weight payload compatible for service behind the HMMWV.

\section{Summary of Weight Analysis}

The analysis of total field weight (generator and fuel) in Figs. 5-B.5 through 5-B.9 indicates that the best minimum weight strategy is to field a generator with rated power equal to the demand power. This result influences the decision toward having to select a large number of generator families to match a broad range of power demand. But, the effort to economize by standardizing a smaller number of family members contradicts this minimum field weight finding. Again, a compromise is necessary. The energy demand curve and the economics of standardization lean the compromise in favor of selecting a small number of family members on the low end of the capacity range ( 7 and $25 \mathrm{~kW}$ ) that has the flexibility of operation over a wider load range like that permitted by variable-speed control.

Another result is that reduction in the initial generator weight is more advantageous than reducing fuel consumption unless mission duration is considerably longer than normal peacetime field operations or even longer than 15-d wartime missions. It is difficult for lower fuel consumption to compensate for excess initial generator weight for short-duration field operations.

The advantage of limiting generator weight to permit towing the unit with a HMMWV tends to drive the family size selection toward the smaller power rating generator and toward the use of lightweight materials and design practice. This does not impact the smaller generators (15 kW or smaller) because they already satisfy the HMMWV $4000-\mathrm{lb}$ tow limit as is. Any 15- to $30-\mathrm{kW}$ selected generator size would be a good candidate for a weight minimization effort to meet the towability requirement. Any proposed generator would have to weigh less than $2000 \mathrm{lb}$ to satisfy both the HMMWV tow limit and the 1-1/2 ton trailer load capacity. The generators greater than $30 \mathrm{~kW}$ will require a significant weight (1000- to 2000-lb) reduction to satisfy the HMMWV tow requirement. 


\section{SYSTEM AND COMPONENT CONSIDERATIONS}

The purpose of this chapter is to present the advantages and disadvantages of various options available for the primary mechanical components of the gen-set and the overall system integration of those components into a functional system.

\subsection{PRIME MOVER DESIGN PHILOSOPHY}

As discussed in Chap. 2, only the gas turbine appears able to compete with the well-proven reciprocating diesel engine as the prime mover of choice in future gen-sets. The rotary and/or Stirling engines are simply not available at this time, and both performance and durability of these engines for this application are unproven.

The primary advantages of gas turbines over diesel engines are

- lightweight,

- lower noise and emissions, and

- longevity and decreased maintenance.

Gas turbines have several disadvantages compared with diesel engines:

- lower efficiency,

- increased cost,

- poorer performance at partial loads,

- not available below $25 \mathrm{~kW}$, and

- unproven durability for military gen-set applications.

The cost of gas turbines in this size range is expected to decrease as the technology and market matures. It is expected that gas turbines will become even more competitive and advantageous for MEP in the future (especially at higher load levels). The primary trade-off is between efficiency and weight, which is discussed in the following section.

\subsubsection{Diesel vs Gas Turbine Weight Comparison (Weight vs Efficiency)}

A comparison of field mission weight is made between a hypothetical, relatively heavy, fuel efficient diesel generator and a lighter, lower fuel efficient micro-turbine generator. Consider that the total mission weight of interest is the generator weight plus the consumed fuel weight. The consumed fuel weight depends on the generator efficiency (fuel consumption), the demand power level, and the mission duration. It is desirable to determine the mission duration time when the total diesel generator weight (including consumed fuel) equals the total turbine generator weight. This will be referred to as the break-even time.

\section{Comparison of TQG and Micro-Turbine}

This hypothetical comparison is fashioned after the 30-kW TQG diesel generator and the Capstone 28-kW micro-turbine (see Sect. 2.3). To simplify the analysis, both are assumed to be rated at $30 \mathrm{~kW}$. The diesel generator weighs $3006 \mathrm{lb}$ and is estimated to have a $35 \%$ overall thermal efficiency $(243 \mathrm{~g} / \mathrm{kWh})$. The micro-turbine generator weighs $1213 \mathrm{lb}$ and is estimated to have a $25 \%$ overall thermal efficiency $(340 \mathrm{~g} / \mathrm{kWh})$. The initial equipment weight includes an $8-\mathrm{h}$ fuel supply. The difference in normalized weight between the diesel and gas turbine gen-sets is 
about $60 \mathrm{lb} / \mathrm{kW}$. The difference in fuel consumption between these two prime movers is $97 \mathrm{~g} / \mathrm{kWh}$.

The total generator plus fuel weight vs mission duration for the diesel and the micro-turbine are shown in Figs. 6.1 and 6.2 for typical peacetime and wartime power demands.

\section{Peacetime Mission Weight}

For an average peacetime demand of $28 \%$ of rated power, the micro-turbine total mission weight is less than the reciprocating diesel gen-set total mission weight for approximately $1006 \mathrm{~h} \mathrm{(42} \mathrm{d)} \mathrm{of} \mathrm{full-time} \mathrm{operation.} \mathrm{The} \mathrm{average} \mathrm{monthly} \mathrm{gen-set} \mathrm{peacetime} \mathrm{use} \mathrm{is} \mathrm{about} 23 \mathrm{~h}$, which is much less than the break-even time. For the low peacetime power demand, the lightweight micro-turbine gen-set in this example yields a lower mission weight than the diesel genset.

Wartime Mission Weight

For gen-sets up to $60 \mathrm{~kW}$, the projected average wartime demand is approximately $58 \%$ of rated power, and the break-even time is about $481 \mathrm{~h}(20 \mathrm{~d})$ of full-time operation. The projected wartime mission operating time of $340 \mathrm{~h}$ for gen-sets up to $60 \mathrm{~kW}$ is less than the mission weight break-even time. Thus, for wartime situations for gen-sets up to $60 \mathrm{~kW}$, the lightweight micro-turbine gen-set would yield a lower mission weight than the diesel engine.

The wartime mission loads are greater and longer duration for gen-sets larger than $60 \mathrm{~kW}$ than for gen-sets $60 \mathrm{~kW}$ or less. For gen-sets larger that $60 \mathrm{~kW}$, the projected average load demand is about $70 \%$ of rated power, and operating time is $686 \mathrm{~h}(29 \mathrm{~d})$. If these load criteria are applied to the $30-\mathrm{kW}$ reciprocating diesel and the micro-turbine gen-sets described above, then the mission weight break-even time is $400 \mathrm{~h}(17 \mathrm{~d})$. Thus, after $17 \mathrm{~d}$ of operation in the more demanding wartime mission, the heavier, higher efficiency reciprocating diesel yields a lower mission weight than the lightweight, lower efficiency micro-turbine gen-set.

These results show that it takes a long mission duration with high power demand for the total mission weight of a heavy, more efficient (diesel) generator to be less than total mission weight of a light, less efficient (micro-turbine) generator. A discussion of a hypothetical new lighter diesel vs a heavier rugged turbine is compared next.

Note: The Capstone set includes $625 \mathrm{lb}$ for housing/frame and a 200-lb battery, which could be reduced. Thus, it may be conservative to assume, in the following discussion, that weight would have to be added to this example micro-turbine to make it "military rugged," where in fact there may be opportunity to reduce the micro-turbine weight or at least offset weight increases due to ruggedization.

\section{Universal Mission Weight Comparison Tool}

A universal mission weight comparison analysis tool was developed that applies to any kind of mobile generator design trade-off, not just diesel reciprocating vs micro-turbines. We wish to examine, in generic parameters, the mission duration break-even time for the total mission weight of a heavyweight, more efficient generator design to equal the total mission weight of a lightweight, less efficient generator design. The break-even time depends on the difference in power density $(\mathrm{lb} / \mathrm{kW})$ between the two generators, the fuel consumption difference $(\mathrm{g} / \mathrm{kWh})$, and the ratio of average demand-to-rated power. A brief description of the universal mission weight comparison tool is given in Appendix 6-A. 
Lightweight gen-sets (i.e. micro-turbine) can reduce the total (gen-set + fuel) mission weight despite having higher specific fuel consumption (lower thermal efficiency) depending on mission duration. Mission weight break-even time is at curve intersection.

\section{Peace-time average power demand fraction, avp $=0.278 \quad$ of rated power, $\mathrm{pwr}=30 \quad \mathrm{~kW}$}

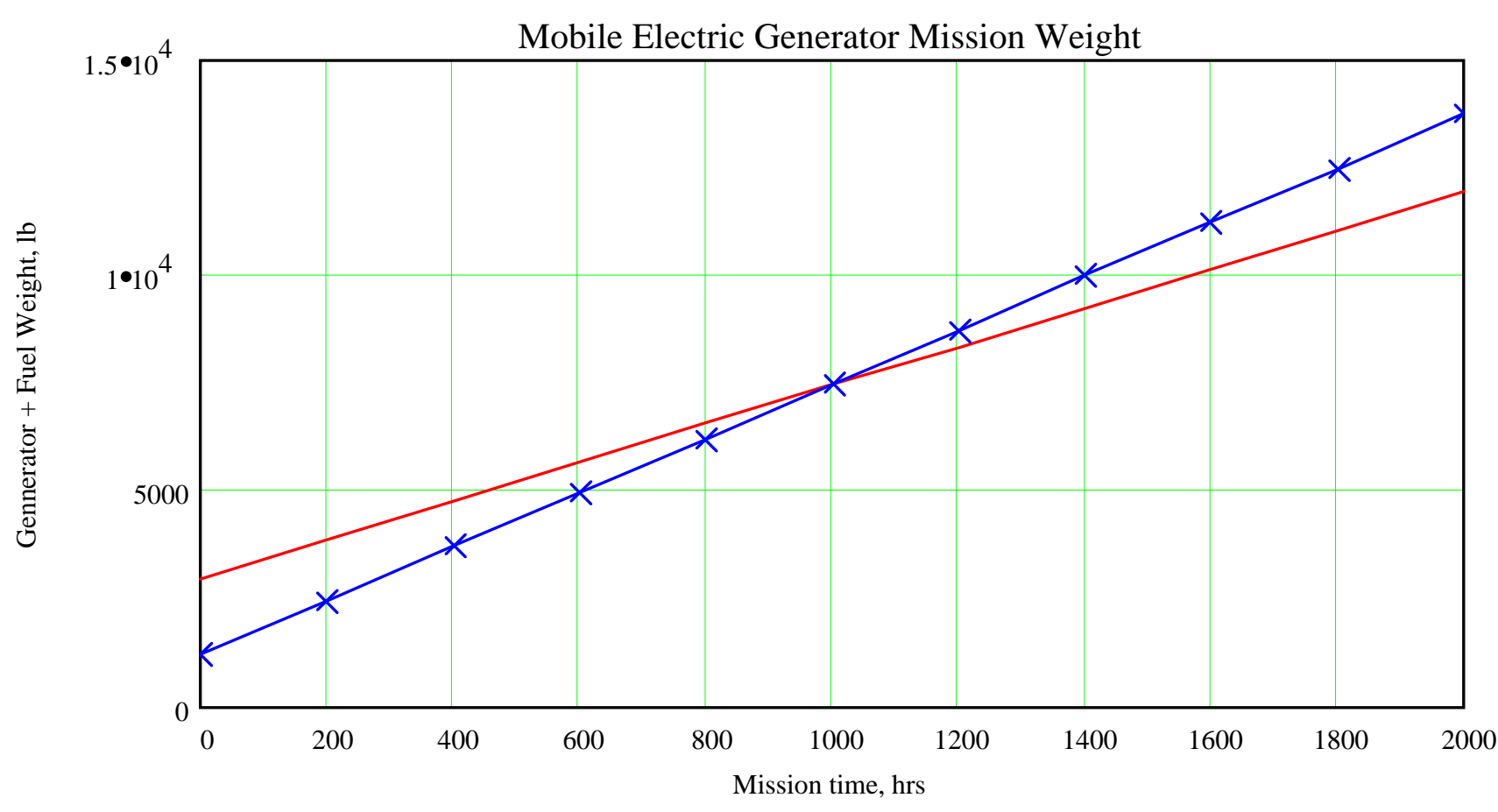

diesel engine

*** micro-turbine

Initial diesel generator weight, $w d g f(e d, a v p, 0)=3006 \mathrm{lb}$ including hfi $=8 \mathrm{~h}$ fuel at full load.

Initial micro-turbine generator weight, wtgf(et,avp,0 $)=1232 \mathrm{lb}$ including hfi $=8 \mathrm{~h}$ fuel at full load.

Diesel generator thermal efficiency, ed $=0.35$.

Micro-turbine generator thermal efficiency, et $=0.25$.

Fig. 6.1. Mobile electric generator average peacetime mission weight. 
Lightweight gen-sets (i.e. micro-turbine) can reduce the total (gen-set + fuel) mission weight despite having higher specific fuel consumption (lower thermal efficiency) depending on mission duration. Mission weight break-even time is at curve intersection.

Projected war-time average power demand fraction, avp $=0.58$ of rated power $\mathrm{pwr}=30 \quad \mathrm{~kW}$

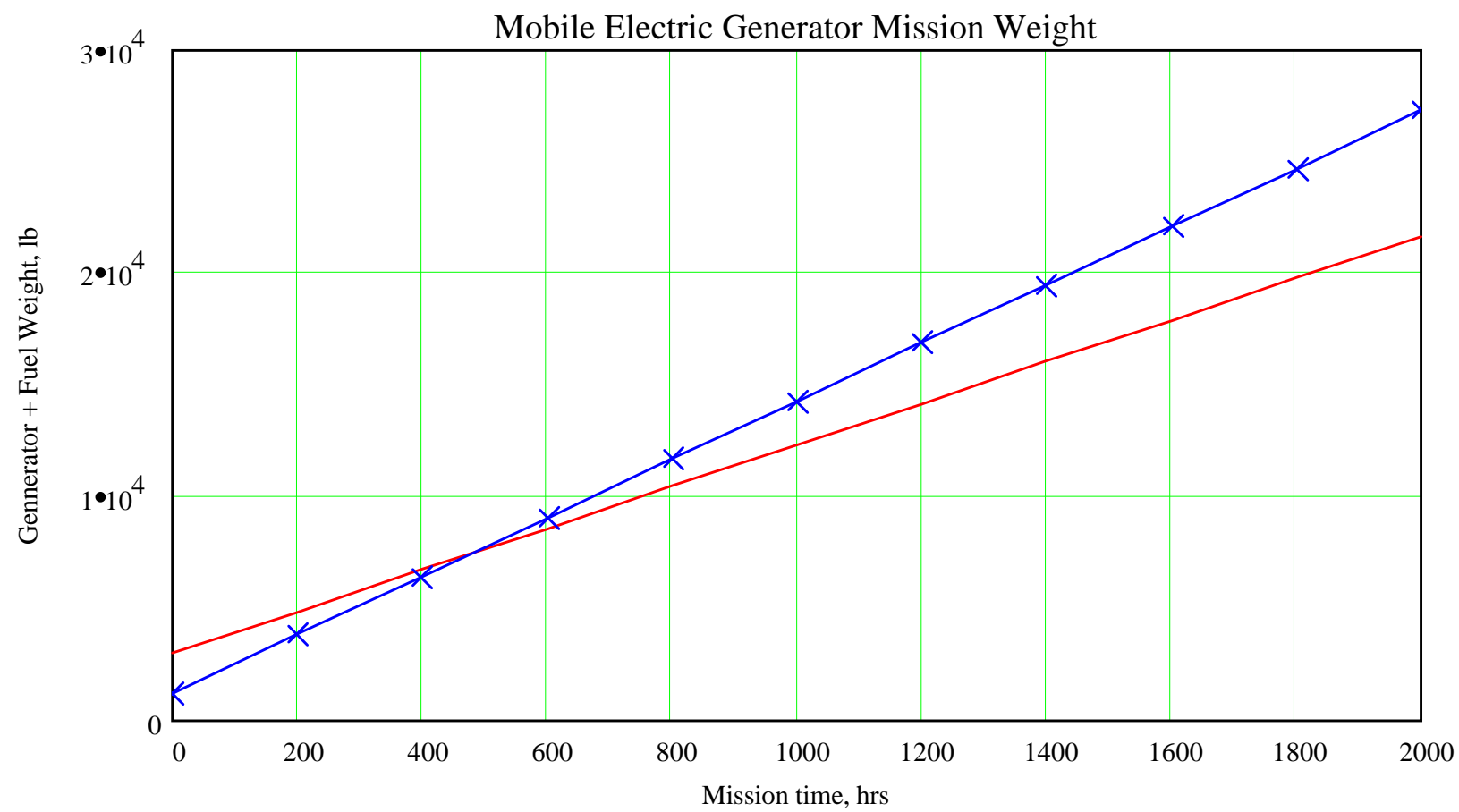

- diesel engine

$\star * X *$ micro-turbine

Initial diesel generator weight, $w d g f(e d, a v p, 0)=3006 \mathrm{lb}$ including $\mathrm{hfi}=8 \mathrm{~h}$ fuel at full load.

Initial micro-turbine generator weight, wtgf(et,avp,0 $=1232 \mathrm{lb}$ including $\mathrm{hfi}=8 \mathrm{~h}$ fuel at full load.

Diesel generator thermal efficiency, ed $=0.35$

Micro-turbine generator thermal efficiency, et $=0.25$.

\section{Fig. 6.2. Mobile electric generator projected wartime mission weight.}


Reduced-Weight Diesel Compared to Ruggedized Turbine

Suppose $10 \%$ or $121 \mathrm{lb}$ is added to the turbine to improve ruggedness, bringing the total turbine generator to $1334 \mathrm{lb}$. Further, the new 30-kW diesel generator weight is estimated at $1765 \mathrm{lb}$; $1341 \mathrm{lb}$ lighter than the current generator. This reduces the normalized weight difference between the new diesel and ruggedized turbine from $60 \mathrm{lb} / \mathrm{kW}$ to about $15 \mathrm{lb} / \mathrm{kW}$. The efficiencies for the reciprocating diesel and the micro-turbine remain the same at $35 \%$ and $25 \%$, respectively, retaining a $97-\mathrm{g} / \mathrm{kWh}$ difference in fuel consumption. These gen-set weight and fuel consumption parameters are used in the weight comparison tool to evaluate weight performance for peacetime and wartime missions.

Peacetime Mission Weight Comparison for Reduced-Weight Diesels and Ruggedized Turbines At the average peacetime power demand of $28 \%$ rated power, the 252-h (11-d) weight breakeven time significantly exceeds the average monthly peacetime utilization time of about $23 \mathrm{~h}$ (1 d). Thus, the ruggedized micro-turbine gen-set has less mission weight than the reducedweight reciprocating diesel gen-set in this hypothetical example.

Wartime Mission Weight Comparison for Reduced-weight Diesels and Ruggedized Turbines At the projected wartime power demands of $58 \%$ of rated power (for gen-sets rated up to $60 \mathrm{~kW}$ ), and $70 \%$ of rated power (for gen-sets rated over $60 \mathrm{~kW}$ ), the break-even times are $121 \mathrm{~h}(5 \mathrm{~d})$ and $100 \mathrm{~h}(4 \mathrm{~d})$, respectively. These break-even times are less than the projected wartime mission durations of 340 operating hours (14 d) and 686 operating hours $(29 \mathrm{~d})$ for gensets rated up to $60 \mathrm{~kW}$ and over $60 \mathrm{~kW}$, respectively. Thus, the reduced-weight-reciprocating diesel gen-set has less wartime mission weight than the ruggedized micro-turbine gen-set in this hypothetical example.

\section{Weight Comparison Summary}

Peacetime missions, on average, have too low a power demand and too short an operating time for excessive gen-set weight to be compensated by reasonable fuel efficiency advantages. In peacetime short-duration missions, the lightest gen-set is likely to give the lowest total mission weight independent of any reasonable fuel efficiency.

Wartime missions have larger power demands and long enough operating times to allow reasonable fuel efficiency advantages to compensate for gen-set overweight design as long as the excess weight is small enough.

These mission weight examples show that it takes a worst-case wartime mission duration greater than $17 \mathrm{~d}$ for a gen-set with a 10 percentage-point fuel efficiency advantage to overcome $60 \mathrm{lb} /$ rated kilowatt excess weight. But it only takes about 4 or $5 \mathrm{~d}$ of wartime mission operation time for a gen-set with a 10 percentage-point fuel efficiency advantage to overcome 15-lb/rated kilowatt excess weight. The projected wartime mission operating times are about $14 \mathrm{~d}$ for gen-sets up to $60 \mathrm{~kW}$ and $29 \mathrm{~d}$ for gen-sets larger than $60 \mathrm{~kW}$. Therefore, in terms of total mission weight, it is feasible in wartime utilization, for a sufficiently efficient gen-set to overcome $15 \mathrm{lb} /$ rated kilowatt excess weight but not $60 \mathrm{lb} /$ rated kilowatt. The exception in this example would be for wartime missions for gen-sets larger than $60 \mathrm{~kW}$ with operating time longer than $17 \mathrm{~d}$. For peacetime or wartime missions, which are $15 \mathrm{~d}$ or less, it is necessary to design reciprocating diesel gen-sets with significant weight reduction to have lower mission weight than ruggedized micro-turbine gen-sets.

It is desirable for heavier, more efficient gen-sets (like the reciprocating diesel generator) to minimize total mission weight in both peacetime as well as wartime missions. This can be accomplished by emphasizing the use of lightweight materials and design for all parts and 
components of the generator. It is especially important to reduce the weight from reciprocating diesel gen-sets sizes up to $60 \mathrm{~kW}$ because their wartime missions have relatively lower power demands and shorter operating times during which to benefit from their better fuel efficiency.

The lightweight design philosophy will greatly enhance the mission weight performance of the reciprocating diesel generator (allowing it to compete better with micro-turbines) in low usage peacetime missions, while retaining its efficiency advantage for the long-duration ( $>15-d)$ wartime missions.

\section{Conclusions on Mission Weight Comparison}

1. It takes relatively long durations and high power loads typical of wartime missions for the benefits of fuel efficiency to compensate for excess hardware weight in the generator.

2. For peacetime missions, the lightweight, less efficient generators can outperform the heavy, more efficient generators in terms of total mission (generator + fuel) weight.

3. For wartime missions, heavy, more efficient generators can outperform the lightweight, less efficient generators in terms of total mission weight only if demand power is high enough, mission duration is long enough, and gen-set overweight is not too great.

4. A high priority should be placed on reducing weight of any generator. The use of lightweight materials, such as aluminum and composites, throughout the generator design is very important, especially for generators of $60 \mathrm{~kW}$ or less

5. Improving generator efficiency is most advantageous for long missions requiring loads near the maximum gen-set capacity.

\subsubsection{Recommendations for Prime Mover}

A summary of major diesel engine technology advances is given in Table 6.1, including drawbacks and benefits. This summary is based on the information and discussions presented in the diesel engine market survey (Sect. 2.3). From the many benefits cited in Table 6.1, it is seen that advanced turbo-charged, charge-cooled, diesel engines designed for automotive use have a large power-to-weight advantage over the standard industrial diesel engines (including those now used in military generators). The new engines cost more but not prohibitively so. The advantages of the advanced automotive diesel engine clearly justify its use as the prime mover in most new gen-sets.

Advanced automotive diesel engines are not available in smaller sizes that could power 3- to $15-\mathrm{kW}$ gen-sets. However, there are a few relatively lightweight, naturally aspirated industrial diesel engines that have recently become available in this power range. Such an engine will likely have an aluminum crankcase (such as the Ruggerini MD 191 or the Yanmar, twin V78), an innovation only seen recently.

- Turbo-charged, charge-cooled, automotive diesels featuring advanced high-pressure, electronically controlled fuel injection systems (common rail or unit injection) and lightweight construction are the recommended prime movers for gen-sets in the 15 to $60+\mathrm{kW}$ range. 
Table 6.1. Benefits and drawbacks of industrial diesel engine technology advancements

\begin{tabular}{|c|c|c|c|}
\hline Device, innovation, application & Benefits & Drawbacks & Use \\
\hline Basic diesel engine & $\begin{array}{l}\text { Good fuel economy, reliability, and low } \\
\text { cost }\end{array}$ & & \\
\hline Aluminum alloy head & Reduces weight by roughly $5 \%$ & Costs slightly more & $\begin{array}{l}\text { Relatively common for certain } \\
\text { industrial engines }\end{array}$ \\
\hline Aluminum alloy crankcase & Reduces weight by about $10 \%$ & $\begin{array}{l}\text { Increased cost. Requires additional } \\
\text { engine design considerations to } \\
\text { handle stresses for good engine life }\end{array}$ & $\begin{array}{l}\text { Only a few engines are currently } \\
\text { available. It is likely a few more will } \\
\text { be introduced in the next several } \\
\text { years. }\end{array}$ \\
\hline Turbocharging & $\begin{array}{l}\text { Generally a } 20 \text { to } 35 \% \text { gain in engine } \\
\text { power output; may improve engine } \\
\text { efficiency slightly }\end{array}$ & $\begin{array}{l}\text { Adds } 2-6 \% \text { to weight of the engine } \\
\text { system depending on system } \\
\text { configuration. Adds cost and } \\
\text { complexity. }\end{array}$ & $\begin{array}{l}\text { Currently used only for engines with } \\
3 \text { or more cylinders, and } 1.2-\mathrm{L} \text { or } \\
\text { greater displacement. }\end{array}$ \\
\hline $\begin{array}{l}\text { Wastegate or variable geometry } \\
\text { turbocharger }\end{array}$ & $\begin{array}{l}\text { Can obtain maximum turbocharging } \\
\text { efficiency and benefits at intermediate } \\
\text { speeds and loads }\end{array}$ & Added cost and complexity & $\begin{array}{l}\text { Seldom used in industrial diesels in } \\
\text { the size range of interest. }\end{array}$ \\
\hline $\begin{array}{l}\text { Intercooling (charge cooling) with } \\
\text { turbocharging system. Cooling fluid can } \\
\text { be ambient air or liquid engine coolant. }\end{array}$ & $\begin{array}{l}\text { Generally a } 5-15 \% \text { additional gain in } \\
\text { engine power due to intercooling; can } \\
\text { reduce } \mathrm{NO}_{\mathrm{x}} \text { emissions. }\end{array}$ & $\begin{array}{l}\text { Adds } \sim 1-2 \% \text { to weight of the engine } \\
\text { system. Adds cost and complexity. }\end{array}$ & $\begin{array}{l}\text { Generally only used on larger } \\
\text { industrial engines ( }>90 \mathrm{hp}) \text { and } \\
\text { automotive engines. }\end{array}$ \\
\hline DI replacing IDI & $\begin{array}{l}\text { Modestly improved power, torque, and } \\
\text { fuel economy. Fuel economy can be } \\
\text { improved } 10 \% \text { over IDI. DI is rapidly } \\
\text { displacing IDI. }\end{array}$ & Slightly more costly & $\begin{array}{l}\text { DI is currently used on many families } \\
\text { of industrial diesel engines and in } \\
\text { all sizes of interest. }\end{array}$ \\
\hline $\begin{array}{l}\text { High-pressure direct fuel injection: } \\
\text { common-rail or unit injection type, in } \\
\text { combination with advanced electronic } \\
\text { control }\end{array}$ & $\begin{array}{l}\text { Finer fuel spray improves combustion } \\
\text { and heat release. Improvement in } \\
\text { torque and power rating and reduced } \\
\text { PM emissions. Noise and vibration } \\
\text { reduction. Fuel economy is } \\
5-10 \% \text { better than standard DI. }\end{array}$ & $\begin{array}{l}\text { Increased cost, complexity, and } \\
\text { high-pressure components, require } \\
\text { a sophisticated electronic control } \\
\text { unit. Only available in the latest } \\
\text { automotive engines. }\end{array}$ & $\begin{array}{l}\text { Not known to be available for } \\
\text { industrial engines in the size range } \\
\text { of interest at this time. Will be } \\
\text { introduced for a few industrial } \\
\text { engines in the next several years. }\end{array}$ \\
\hline $\begin{array}{l}\text { High-speed automotive operation (low } \\
\text { weight, }>=4000 \mathrm{rpm} \text { ) }\end{array}$ & $\begin{array}{l}\text { Generally, power-to-weight ratio is } \\
\text { much greater than typical industrial } \\
\text { engines. Engines are designed for } \\
\text { low weight. }\end{array}$ & $\begin{array}{l}\text { Increased cost and complexity. Few } \\
\text { engine choices available for gen- } \\
\text { set application. Noise level rises } \\
\text { with rotational speed. Fuel } \\
\text { economy drops significantly as } \\
\text { rated speed is approached. }\end{array}$ & $\begin{array}{l}\text { Few automotive diesels can be } \\
\text { obtained for industrial use. } \\
\text { Selection should improve in the } \\
\text { next several years. Engines are } \\
>60 \mathrm{hp} \text {. }\end{array}$ \\
\hline
\end{tabular}


- For a smaller gen-set, with a peak rating below $15 \mathrm{~kW}$, it is recommended that naturally aspirated industrial diesel engines with a relatively high power-to-weight ratio (for that size range of engine) be utilized until the technology in the automotive diesels migrates to the smaller industrial diesel lines.

- Gas turbines should be evaluated more closely and warrant consideration in niche areas where the need for lighter weight is substantially more important than fuel efficiency (e.g., short mission durations). For most applications, however, the diesel engine is still advantageous.

\subsection{VARIABLE-SPEED DIESEL ENGINE OPERATION}

Current generators are constant speed (usually $1800 \mathrm{rpm}$ ), governor-controlled, reciprocating diesel engine generators designed to deliver the desired electrical power frequency (60 or $400 \mathrm{~Hz}$ depending on the unit). Virtually all diesel engines of interest (especially the lightweight automotive engines) are designed for sustained operation at rotational speeds much higher than $1800 \mathrm{rpm}$ and can produce much more power if allowed to operate at higher speeds. Limiting operation to 1800 rpm does not make use of an engine's power output capabilities and effectively derates the engine. Furthermore, under constant speed control, the engine is generally not operated at the most fuel-efficient conditions on its performance map. This may increase fuel consumption and the tendency for wetstacking under low load conditions. Wetstacking also increases maintenance cost.

A viable alternative is a variable-speed, digitally controlled diesel engine generator delivering power to a dc bus where digital power electronics convert the dc voltage to the desired electrical frequency. The numerous advantages of variable speed are listed later in this section, but the primary benefit is that for a given size and weight, a gen-set can be designed to meet a significantly greater electrical load. Furthermore, the engine can be operated at its most efficient speed and torque over an extended power range. This is expected to reduce fuel consumption and maintenance cost.

\subsubsection{Variable-Speed Fuel Consumption Analysis}

An analysis was performed to compare variable-speed with fixed-speed operation of a dieselpowered generator. The Advanced Generator Evaluation Tool (AGET) computer model dated February 1999 and developed by Dr. Pedro Otaduy at ORNL was used. This computer model calculates the fuel consumption difference between operating the diesel generator under variable speed vs fixed speed for a selectable baseline fixed speed and selectable load-time profile. The model has two selectable diesel engine performance curves, which are scalable to a selectable rated power output at a selectable speed. One engine is a 57-kW VM Motori (VMM Detroit Diesel) Model HR $392 \mathrm{SHI}$, and the other is a 70-kW Volkswagen 1.9-L TDI. A torque vs speed performance map for the Volkswagen engine is shown in Fig. 6.3. The map shows constant lines of power and contours of constant fuel consumption (efficiency). The minimum fuel consumption (maximum efficiency) variable speed/load path on the map is a diagonal line increasing with speed through the minimum fuel consumption valley (or maximum efficiency ridge).

The model determines maximum efficiency under variable-speed control for each demand power level and compares it to the efficiency as if the same engine were controlled at the selected constant speed. 


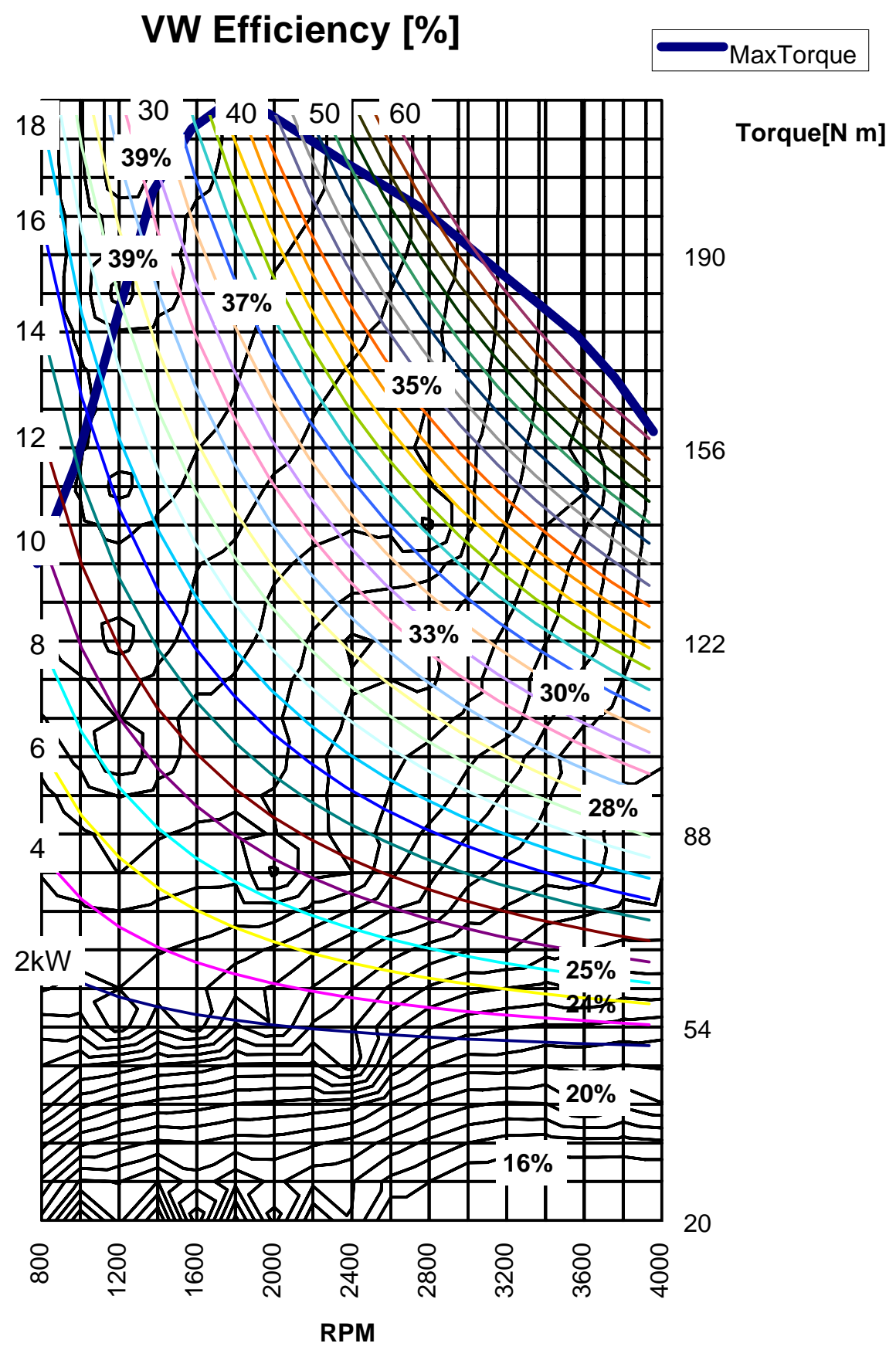

Fig. 6.3. Diesel engine performance map. 
The power demand utilization profiles input to the model are shown in Tables 5.2 and 5.3 and Fig. 5.1. For peacetime operations, the average power draw is $28 \%$ of rated power for $23 \mathrm{~h} /$ month. In projected wartime use of gen-sets up to $60 \mathrm{~kW}$, the average power draw is $58 \%$ of rated power for $340 \mathrm{~h} /$ month operating time. For gen-sets over $60 \mathrm{~kW}$, the average projected wartime power draw is $70 \%$ of rated power for $686 \mathrm{~h} /$ months. Two-thirds of peacetime operations occur at less than $40 \%$ of rated capacity, while $80 \%$ of wartime operations exceed $40 \%$ of rated capacity.

Only the efficiency of the prime mover diesel engine is included in the analysis. Efficiency of the electrical components is assumed to be $100 \%$ in the analysis. The assumed $100 \%$ electrical efficiency does not affect the analysis results because only the difference in engine fuel consumption (efficiency) is reported for the two different engine speed operating conditions.

The percent fuel saved by variable-speed control as a function of fixed control speed is shown in Figs. 6.4 and 6.5 for the peacetime and wartime utilization profiles, respectively. The results are summarized in Table 6.2.

For the profiles utilized in the analyses, the variable-speed control always saves fuel compared to fixed-speed control. The trend for increased fuel savings with increased selected fixed-speed is a result of the engine performance characteristics. Under lower power demand and high fixed-speed control, the engine operates much further away from its high-efficiency region. Operation under variable-speed control places the engine at a region of optimum efficiency under low power demand, thus reducing fuel consumption. Another trend is the reduction in fuel savings with increases in load demand. When operating close to rated load most of the time, fuel savings under variable-speed control is reduced because the fixed-speed controlled engine, if operated near its rated capacity, is likely to be near its optimum efficiency point. Thus, an important benefit and justification for variable-speed control is rooted in improving performance when generators are underutilized relative to their rated capacity. Variable-speed operation is also expected to reduce wetstacking, maintenance costs, and fuel consumption. Variable-speed control is expected to provide a greater percentage fuel savings under peacetime operations than under wartime operation.

The engine performance maps used in this analysis are typical in shape to many IC piston engines. Therefore, the effects of variable-speed vs fixed-speed control shown by these results are indicative of trends expected for the typical diesel engine. The numerical values are expected to differ for different engines and utilization profiles.

\subsubsection{Variable-Speed Advantages}

There are many advantages of variable-speed diesel engine operation:

1. Variable-speed design can reduce engine and generator (fixed) weight for the equivalent power capacity because higher speed engines, which are lighter, are used.

2. When compared to 1800-rpm fixed-speed operation, variable-speed operation can reduce fuel consumption an estimated 12 to $36 \%$ during peacetime and 1 to $3 \%$ during projected wartime missions. Compared to 3600-rpm fixed-speed operation, variable-speed control reduces the fuel consumption between 15 and $19 \%$ in wartime scenarios.

3 Fuel savings is greatest when gen-sets are under utilized, which is quite common in peacetime use.

4. Variable-speed operation is more efficient and therefore would contribute to a lower thermal signature. 


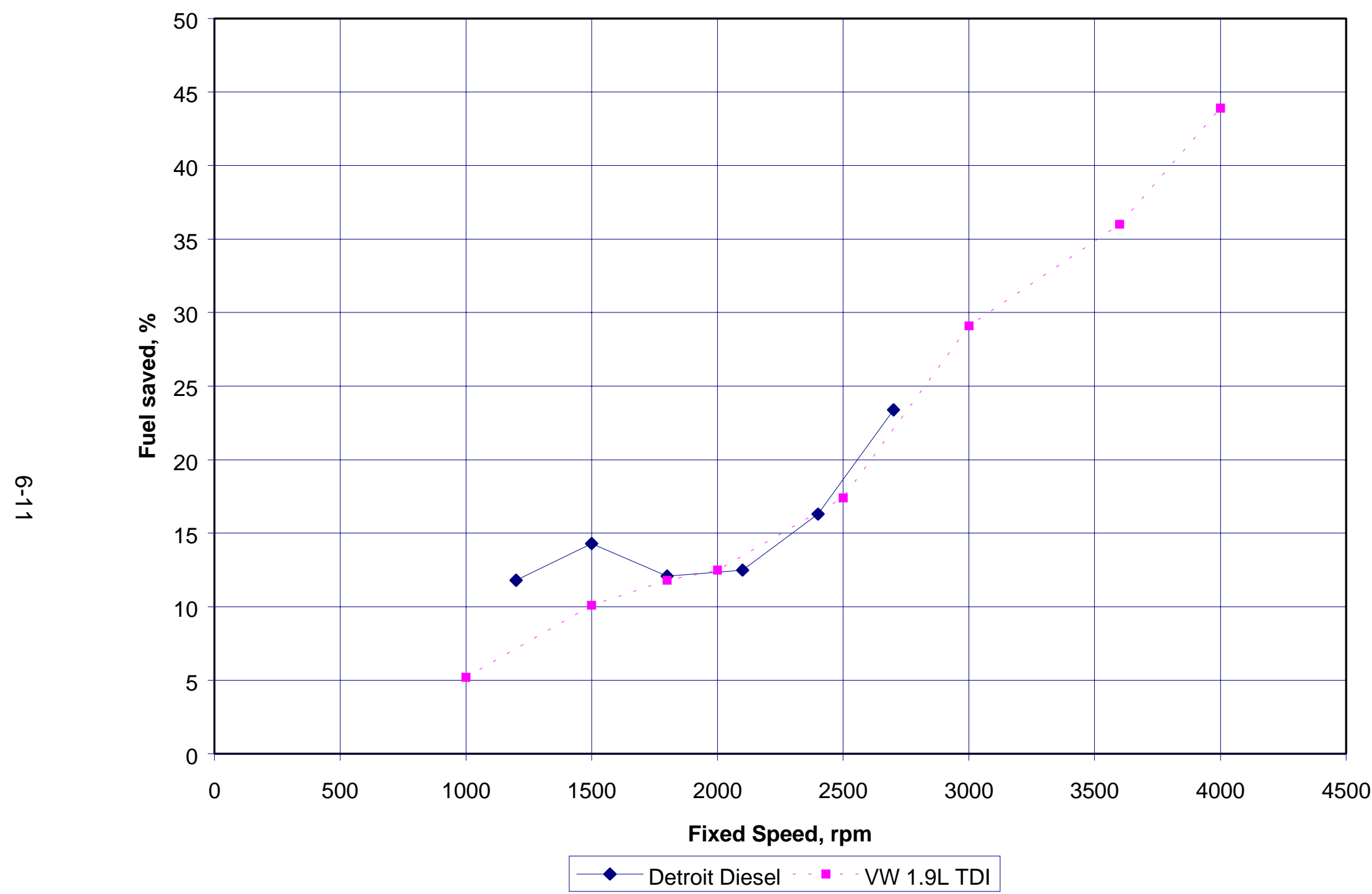

Fig. 6.4. Fuel saved by variable-speed control as function of fixed-speed for peacetime average use profile (5- to 60-kW gen-sets). 


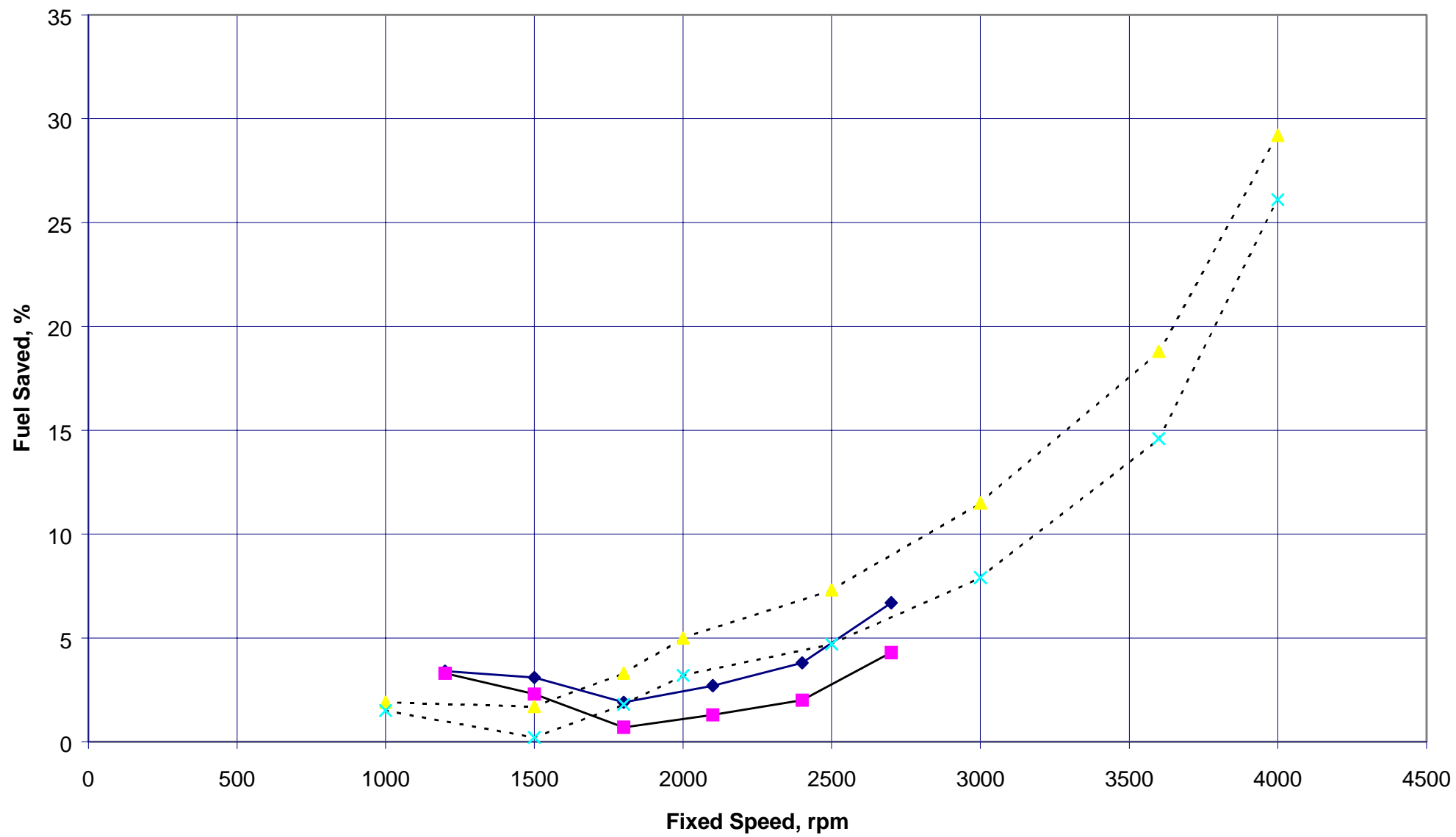

Detroit Diesel, $<=60 \mathrm{~kW}$ Use ——Detroit Diesel, $>60 \mathrm{~kW}$ Use $\cdots \cdots \cdot$ VW 1.9L TDI, $<=60 \mathrm{~kW}$ Use $\cdots \cdots \cdots$ VW $1.9 \mathrm{~L}$ TDI, $>60 \mathrm{~kW}$ Use

Fig. 6.5. Fuel saved by variable-speed control as function of fixed-speed for projected wartime use profile. 
Table 6.2. Fuel saved due to variable-speed control relative to fixed-speed control

\begin{tabular}{|c|c|c|c|}
\hline Utilization profile & $\begin{array}{c}\text { Wartime } \\
\text { 30-d mission }\end{array}$ & $\begin{array}{c}\text { Wartime } \\
\text { 15-d mission }\end{array}$ & Peacetime \\
\hline $\begin{array}{c}\text { Generator rated } \\
\text { power }\end{array}$ & Over 60 kW & $60 \mathrm{~kW}$ and under & $5 \mathrm{~kW}$ through $60 \mathrm{~kW}$ \\
\hline $\begin{array}{c}\text { Average demand } \\
\text { power, \% of rated }\end{array}$ & 69.9 & 58.1 & 27.8 \\
\hline $\begin{array}{c}\text { Average operating } \\
\text { time, h/month }\end{array}$ & 686 & 340 & 23.2 \\
\hline $\begin{array}{c}\text { Fixed operating } \\
\text { speed } \\
\text { (rpm) }\end{array}$ & \multicolumn{3}{|c|}{$\begin{array}{c}\text { Fuel savings } \\
(\%)\end{array}$} \\
\hline 1800 & 1.3 & 2.6 & 12.0 \\
\hline 3000 & 7.3 & 10.5 & 29.6 \\
\hline 3600 & 14.6 & 18.8 & 36 \\
\hline
\end{tabular}

5. Variable speed is expected to allow a wider range of power operation with minimal wetstacking, thereby lowering maintenance cost.

6. Variable-speed operation is a more flexible design option that is better suited for dealing with extremes of wartime and peacetime operation.

Simply stated, variable-speed engine operation allows the diesel engine to be more effectively utilized over its entire range of operation.

\subsubsection{Variable-Speed Disadvantages}

\section{Transient Loads}

A disadvantage of variable-speed diesel engine operation is a reduced ability to meet transient load requirements during low-speed operation. It is expected that variable-speed generators of a given capacity will have lower rotational mass. Under low power demand conditions, the generator speed is expected to be low to conserve fuel. At low speed, the momentum or stored rotational kinetic energy will be low. Thus, response to a sudden transient load increase could be sluggish.

A possible solution to sluggish transient response is to provide a minimum speed setting switch on the controller. This minimum speed setting would prevent the engine from operating below a predetermined speed, which would maintain sufficient rotational momentum to satisfy transient load recovery requirements. The price for this option is increased fuel consumption at low demand loads because the engine would be prevented from operating at optimum low-load efficiency. Another option is to allow the user to disengage the minimum speed limit during noncritical operation to conserve fuel.

Another possible solution is to draw transient power from the starter battery. This would require a dc to dc converter to increase battery voltage to the normal dc bus voltage where the inverter can supply the required fill-in transient power. This is judged to be easy to do for fill-in transients up to $15 \mathrm{~kW}$. Higher fill-in transients are judged to be more difficult and need further investigation. The dc to dc converter would add some nominal amount of weight to the system. 


\section{High-Speed Acoustics}

Although the variable-speed engine is expected to be quieter when operating at low speed, the engines are likely to be noisier when operated at high speed. This noise increase is estimated at $6 \mathrm{~dB} / 1000 \mathrm{rpm}$, but test verification is needed. It is expected that improved acoustic suppression and new engine technology will be needed to offset the higher noise source at high speed. When engines are tested, the variation of engine acoustics with speed will be measured to quantify and characterize the potential problem.

\section{Use of Power Electronics}

Variable-speed engine operations will require the use of power electronics to convert the varying frequency ac from the generator into dc, which will then be synthesized into the required frequency ac. As discussed in Chap. 3, the technology exists to do this, but the electronics are more complex for variable-speed operation than for fixed speeds of 1800 or $3600 \mathrm{rpm}$. As outlined in the following sections, however, there are numerous additional advantages to using power electronics in this manner.

Harsh environmental and physical conditions such as extremely cold temperatures, high humidity, shock, or vibration can be overcome with use of hermetically sealed packages. In addition, design of the gen-set and its controls should be such that the unit can still meet existing tolerances, such as allowable voltage drops during load addition, by considering such factors as having enough stored energy in the dc link, running the engine at a high enough speed, and perhaps using energy from the batteries for fill-in during the short load addition intervals.

It is our belief that the above advantages are compelling and that the disadvantages can be mitigated.

\subsubsection{Recommendation for Fixed- vs Variable-Speed Engine Operation}

\section{- Gen-set design should be based on variable-speed operation, and speeds of $3000 \mathrm{rpm}$ and above should be an initial design goal.}

Determination of maximum allowable speeds, both for normal operation and operation in battleshort mode, will be based on engine testing and prototype development. Maximum speed capabilities will be based on many factors including vibration, sound, heat removal and thermal limitations, and the capabilities of the engine, alternator, and other components.

\subsection{POTENTIAL FOR ENGINE WEIGHT AND VOLUME REDUCTION}

It is clear from the assessment of diesel engines and from gen-set system design considerations that a significant weight reduction for the prime mover is achievable. A brief power output and engine weight analysis is now presented to quantify the potential weight reduction that is possible for the diesel engine used in the military gen-sets. Table 6.3 contains data for engines used in the current TQGs, and Table 6.4 contains data for a carefully selected set of lightweight engines. The lightweight engines selected include five automotive engines (Volkswagen, Peugeot-Citroen, and Detroit Diesel engines) that are considered state of the art. Only one of these automotive engines is known to be currently available in the United States, but it is projected that this type of engine will have greater availability in the near future. The two smaller engines in Table 6.4 should not be considered true automotive engines, but have the best power-to-weight ratios among the smaller output engines. The Ruggerini MD191 engine is 
Table 6.3. Weight and 1800-rpm power ratings for diesel engines used in TQGs

\begin{tabular}{|c|c|c|c|c|c|}
\hline $\begin{array}{c}\text { TQG engine } \\
\text { model }\end{array}$ & $\begin{array}{c}\text { TQG } \\
\text { rating } \\
(\mathrm{kW})\end{array}$ & $\begin{array}{c}\text { Aspiration } \\
\text { method }\end{array}$ & $\begin{array}{c}\text { Continuous } \\
\text { power at } \\
1800 \mathrm{rpm} \\
(\mathrm{hp})\end{array}$ & $\begin{array}{c}\text { Reported } \\
\text { dry weight } \\
(\mathrm{lb})\end{array}$ & $\begin{array}{c}\text { Ratio of dry } \\
\text { weight to } \\
\text { power at } \\
1800 \mathrm{rpm} \\
(\mathrm{lb} / \mathrm{hp})\end{array}$ \\
\hline $\begin{array}{c}\text { Lister-Petter } \\
\text { LPW2 }\end{array}$ & 5 & Natural & 11 & 247 & 22.5 \\
\hline $\begin{array}{c}\text { Lister-Petter } \\
\text { LPW4 }\end{array}$ & 10 & Natural & 22 & 396 & 18.0 \\
\hline $\begin{array}{c}\text { Isuzu C240 } \\
\text { John Deere } \\
\text { 4045T }\end{array}$ & 30 & Turbo & 90 & 872 & 14.7 \\
\hline $\begin{array}{c}\text { John Deere } \\
6068 T\end{array}$ & 60 & Turbo & 135 & 1212 & 9.7 \\
\hline
\end{tabular}

Table 6.4. Weight and power ratings at 1800 and $3000 \mathrm{rpm}$ for selected lightweight diesel engines

\begin{tabular}{|c|c|c|c|c|c|c|}
\hline \multirow{2}{*}{$\begin{array}{l}\text { Engine } \\
\text { model }\end{array}$} & \multirow{2}{*}{$\begin{array}{l}\text { Aspiration } \\
\text { method }\end{array}$} & \multirow{2}{*}{$\begin{array}{c}\text { Continuous } \\
\text { power at } \\
1800 \text { rpm } \\
\text { (hp) }\end{array}$} & \multirow{2}{*}{$\begin{array}{c}\text { Estimated } \\
\text { continuous } \\
\text { power at } \\
3000 \mathrm{rpm} \\
\text { (hp) }\end{array}$} & \multirow{2}{*}{$\begin{array}{l}\text { Reported } \\
\text { dry weight } \\
\text { (lb) }\end{array}$} & \multicolumn{2}{|c|}{$\begin{array}{c}\text { Ratio of dry weight to } \\
\text { power }\end{array}$} \\
\hline & & & & & $\begin{array}{c}1800 \mathrm{rpm} \\
(\mathrm{lb} / \mathrm{hp})\end{array}$ & $\begin{array}{c}3000 \mathrm{rpm} \\
(\mathrm{lb} / \mathrm{hp})\end{array}$ \\
\hline $\begin{array}{l}\text { Ruggerini } \\
\text { MD191 }\end{array}$ & Natural & 8.3 & 14.4 & 117 & 14.1 & 8.1 \\
\hline $\begin{array}{l}\text { Lombardini } \\
\text { 1204T }\end{array}$ & Turbo & 20.5 & 33.3 & 223 & 10.9 & 6.7 \\
\hline $\begin{array}{l}\text { Volkswagen } \\
\text { R3 }\end{array}$ & $\begin{array}{l}\text { Cooled } \\
\text { turbo }\end{array}$ & 33 & 54 & 251 & 7.4 & 4.6 \\
\hline $\begin{array}{l}\text { Peugeot } \\
\text { DW10 ATED }\end{array}$ & $\begin{array}{l}\text { Cooled } \\
\text { turbo }\end{array}$ & 55 & 84 & 331 & 6.0 & 3.9 \\
\hline $\begin{array}{l}\text { Volkswagen } \\
\text { R4 or AJM }\end{array}$ & $\begin{array}{l}\text { Cooled } \\
\text { turbo }\end{array}$ & 61 & 92 & 310 & 5.1 & 3.4 \\
\hline $\begin{array}{l}\text { Peugeot } \\
\text { DW12 TED4 }\end{array}$ & $\begin{array}{l}\text { Cooled } \\
\text { turbo }\end{array}$ & 73 & 107 & 401 & 5.4 & 3.7 \\
\hline $\begin{array}{l}\text { Detroit Diesel } \\
\text { Delta }\end{array}$ & $\begin{array}{l}\text { Cooled } \\
\text { turbo }\end{array}$ & 107 & 174 & 640 & 5.9 & 3.7 \\
\hline
\end{tabular}


a 2-cylinder, aluminum crankcase engine, and it is very lightweight for such a small displacement engine. The Lombardini 1204T engine was chosen because it was the smallest (in terms of engine displacement) and lightest turbo-charged engine known to be currently available.

The key engine information listed in Tables 6.3 and 6.4 includes the continuous power ratings and dry weights. Description of these engine parameters follows:

\section{Engine Dry Weight}

Engine dry weight generally includes the engine "fan to flywheel," including a starter motor, an alternator, and the turbocharger. Usually excluded are all fluids, the radiator and hoses, fuel tank, air cleaner and air ducting, any clutch mechanism, muffler, mounting brackets or feet, battery, control panel, flywheel housing and certain pulleys. Note that the inconsistencies in reported engine dry weight will introduce some error when comparing engines.

\section{Continuous Power Rating}

The continuous power rating is the net engine output at a given rotational speed that is sustainable for continuous operation (many hours), allowing for a $10 \%$ power margin. This means for fixed-speed operation, the engine is capable of operation at a power load level at least $10 \%$ above the continuous rating. Any further increase in load above the $10 \%$ margin may decelerate the engine (overload condition) and lower power output capability: the engine will stop if load is not decreased. Power ratings are usually given without altitude or air temperature and humidity derating. Generally, they are reported for altitudes of sea level or $100 \mathrm{~m}$, air temperature at 68 or $77^{\circ} \mathrm{F}$, and no humidity derating. Note that manufacturer's reported power ratings for various engines are not necessarily consistent, which can lead to small errors being introduced while making direct comparisons between engines.

\subsubsection{Potential Weight Reduction}

To illustrate the potential for using lighter engines, reported engine dry weight is plotted against the estimated continuous engine power rating in Fig. 6.6. The automotive engine output power ratings are not reported in terms of industrial continuous-duty power rating but rather for automotive duty. The continuous power rating was estimated to be roughly $86 \%$ of the given automotive rating (based on information from engines that reported both the automotive and the industrial continuous power rating). The upper curve represents the TQG engines operated at $1800 \mathrm{rpm}$ (the fixed speed for the current gen-sets). The middle curve plots the data for the selected lightweight engines operated at $1800 \mathrm{rpm}$. Assuming the data are reasonably accurate and similar engines are available and appropriate for future gen-sets, engine dry weight could be decreased roughly $40-50 \%$ by using such carefully selected engines.

Because it is recommended that variable-speed operation be employed in future gen-sets, data points for the light engines operating at $3000 \mathrm{rpm}$ are also plotted in the lower curve in Fig. 6.6. With the combination of $3000 \mathrm{rpm}$ and light engines, engine (dry) weight could drop by roughly 50-65\%. Note that the analysis presented here is not looking at engine peripherals and fluids such as the radiator, muffler, battery, oil, fuel and coolant, most of which will likely scale with power output. This seems reasonable, especially for this level of analysis. Also ignored are other issues associated with higher-speed/variable-speed operation, such as the need for better sound insulation, less dependence on rotating mass (flywheel) to limit electrical distortion, and change in weight and dimension of other components.

In summary, a significant weight improvement could be experienced by choosing lightweight engines for use in military gen-sets, and further weight reduction could be realized by allowing 


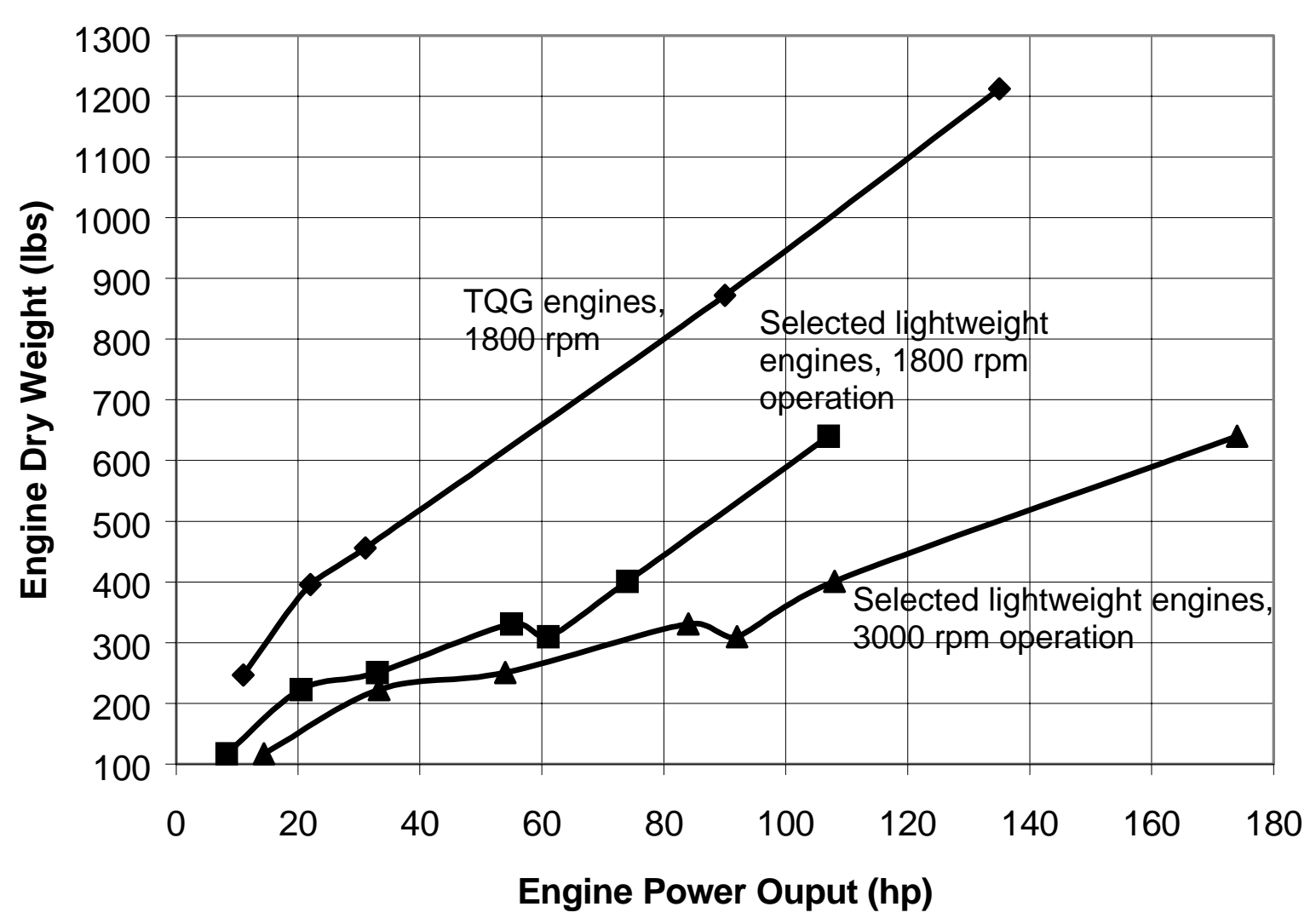

Fig. 6.6. Engine dry weight as a function of rated continuous power output for the TQG engines at 1800-rpm operation and selected lightweight diesel engines at 1800 and $3000 \mathrm{rpm}$.

higher engine rotational speeds to be employed (such as $3000 \mathrm{rpm}$ used in this discussion). This would enable the engine dry weight contribution to the overall gen-set weight to be reduced by roughly $40-60 \%$ when the TQGs are used as the standard for comparison.

\subsubsection{Potential Engine Volume Reduction}

Another benefit of higher power-to-weight ratio engines, such as advanced automotive diesel engines, is that they take up less space for a given power level. Many of the engines listed in Table 6.4 were designed to be compact for incorporation into vehicles. Information on engine dimensions shows that, in general, the automotive diesels would only occupy about one-half to two-thirds of the space required for comparable engines used in the TQGs, even assuming 1800-rpm operation. Higher speed operation would produce an even greater volume reduction. The engine space savings should allow gen-sets to be designed that are significantly smaller than the current TQGs.

\subsection{ALTERNATOR DESIGN}

Using either a three-phase PM generator or an induction machine as the generator will enable the use of standard power electronics including full-bridge (six-pack) IPMs for the active rectifier and inverter portion of the main power circuit. Use of a SR generator would require several dual modules to drive the multiple phases (four, six, or eight) of the stator. This power electronics 
configuration would be more complex and slightly more expensive. If rare earth PM generators can be mass-produced (in the thousands) at a cost-effective rate, then these should be the alternator of choice because their high power density would enable approximately a threefold reduction in mass and volume from existing induction machine technology. A 30-kW unit costs approximately $\$ 6000$ when produced in volumes of less than 10 . If the cost can be reduced to less than $\$ 2000 /$ unit, then this would be a viable option.

\subsubsection{Reduction of Weight}

The change from a synchronous machine to a high-flux PM machine is expected to reduce the weight of the generator by approximately $65 \%$. Replacing the analog dials for voltage, current, and other measurements and much of the wiring will also result in weight savings. Weight penalties for the units will come from the power electronics and heat sink, but these weights are more than offset by the reduction in weight of the electric generator. Weight savings in the electrical portion of the generator (which includes electrical generator, power electronics and heat sink, and control electronics) will be from $10 \%$ on the smaller units up to $50 \%$ on the largest unit.

Some weight could be saved by charging the battery directly from the dc bus via a buck-boost converter (power electronics) that would eliminate the need for a separate battery-charging alternator. The reliability of the buck-boost converter would be comparable to the reliability of a separate battery-charging alternator.

The electric alternator directly coupled to the prime mover (engine) also could be used as an engine starter with the required energy coupled to the main dc link via the buck-boost converter from the battery. The active rectifier in this mode would act as an inverter to drive the alternator until the engine started. Again, the reliability of the buck-boost converter would be comparable to that of an engine starter.

\subsubsection{Reduction of Volume}

The change to a high-flux PM machine will reduce the volume required by the alternator by approximately $50 \%$. When compared to traditional gen-sets, some of this volume will instead be occupied by power electronics components and heat sink. The volume reductions possible will have to be determined during the prototyping phase but will not be significant compared to those of the engine.

\subsubsection{Summary of Alternator Recommendations}

- A three-phase alternator is recommended (either a PM alternator or a more conventional inductance alternator) so that integrated power electronics modules can be used to reduce the complexity, size, and cost of the power electronics system.

- A high-flux PM alternator is the preferred alternator. The market survey indicates that mass production costs are not prohibitive.

- During the design and prototyping phase, the main alternator should be evaluated for use as the engine starter by using a two-way buck-boost converter to charge the batteries and drive the starter. Justification for this would be the weight and volume savings from eliminating the starter and alternator charger. 


\subsection{POWER ELECTRONICS}

To operate gen-sets in a mode where the IC engine runs at variable speed, an active threephase bridge rectifier will be needed to convert the variable voltage and variable frequency produced by the engine-driven generator to a controlled dc link voltage. A three-phase full-bridge inverter is then required to convert the dc link voltage to a selectable voltage (120/208 V or $240 / 416 \mathrm{~V})$ and selectable frequency $(50,60$, or $400 \mathrm{~Hz})$. The main power electronics circuit to achieve these two conversions is shown in Fig. 6.7.

Frequency and voltage regulation with power electronics should be more precise than with the present gen-sets. Waveform quality using power electronics and pulse width modulation (PWM) control will require the use of output filters to meet the voltage harmonic limits.

The advantages of this power electronics circuit are that the output frequency is completely selectable and a separate class of $400-\mathrm{Hz}$ generators can be eliminated. A small weight/cost penalty would be associated with enabling the inverter to run at $400 \mathrm{~Hz}$ in addition to the 50 and $60 \mathrm{~Hz}$. Because the cutoff frequency of the low-pass filtering required for a $400-\mathrm{Hz}$ output would be different than that for a $50-$ to $60-\mathrm{Hz}$ output, the frequency selector switch would also have to switch in/out some capacitance and/or inductance to adjust the filtering cutoff frequency.

The IPM of choice should have all of the monitoring functions (e.g., overtemperature, overcurrent, undervoltage) directly available to the control module instead of a single "fault" output. This will allow the control module to also perform D\&P to warn of an impending failure before one occurs instead of waiting until a "fault" output is latched.

\subsubsection{EMI Issues}

The introduction of power electronics into a gen-set unit to control the frequency and voltage generated by the gen-set will introduce EMI issues. Design of the power electronics section

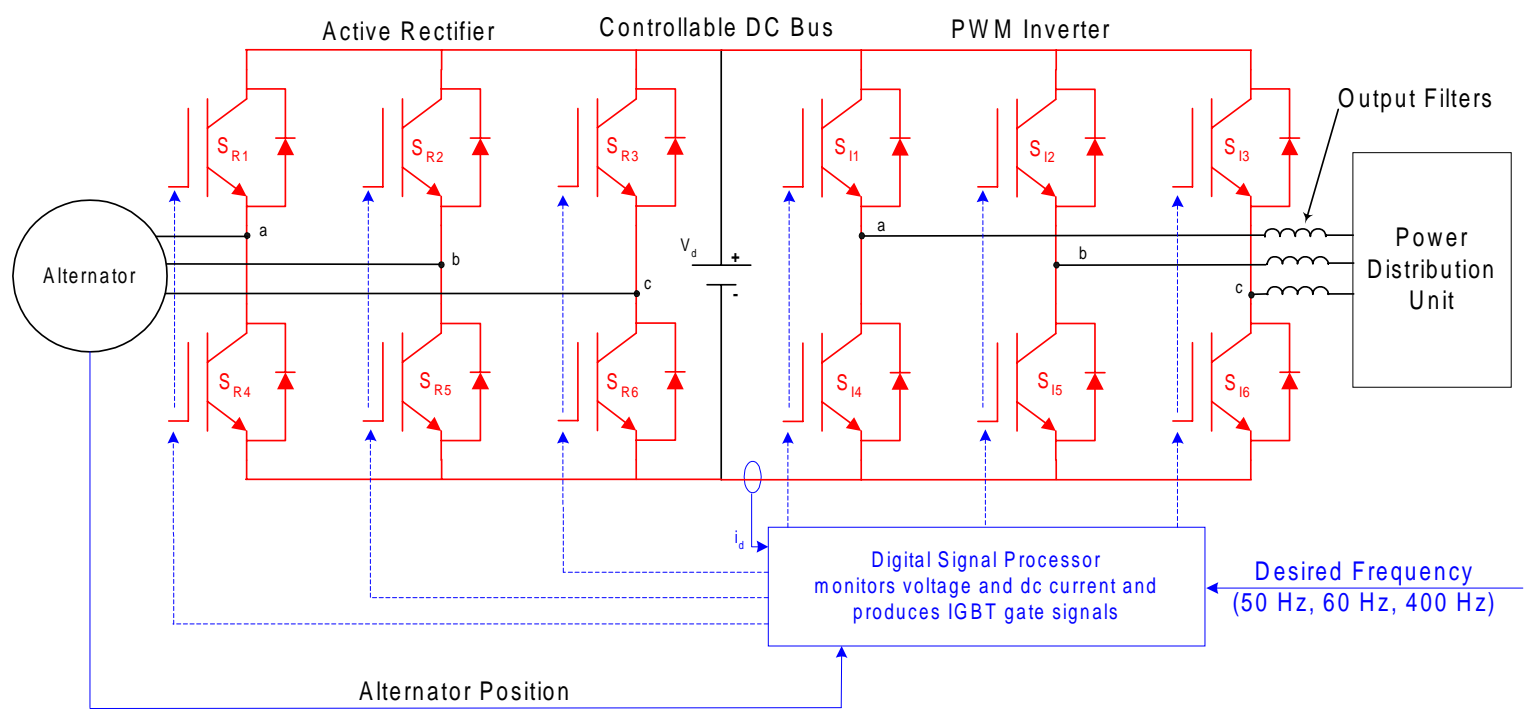

Fig. 6.7. Power electronics circuit for active rectifier and inverter for variablespeed gen-set unit. 
(active rectifier and inverter) will require knowledge of the allowable levels that connected equipment can withstand. Mitigation techniques include stacking power planes where possible, using twisted shielded cables, and filtering the output of the inverter. The EMI issues are well recognized and can be mitigated.

\subsubsection{Efficiency}

The efficiency of IGBT modules depends on several factors:

1. switching frequency,

2. load current,

3. operating voltage,

4. operating temperature, and

5. manufacturer.

The losses in an inverter are the sum of the conducting loss and switching loss. The switching loss is directly proportional to switching frequency. The load current affects both the switching loss and conducting loss in close to a linear fashion (i.e., higher load current, or load factor, will cause more loss in the IGBT module). At low load factors, the switching loss dominates the losses in an IGBT module, and it is much less efficient than at high load factors. Figure 6.8 shows the efficiency for a specific $5-\mathrm{kW}$ inverter for load factors from no load (0.0 load factor) up to full load (1.0 load factor). The inverter is greater than $90 \%$ efficient for load factors greater

\section{5-kW Inverter Switching at $10 \mathrm{kHz}$}

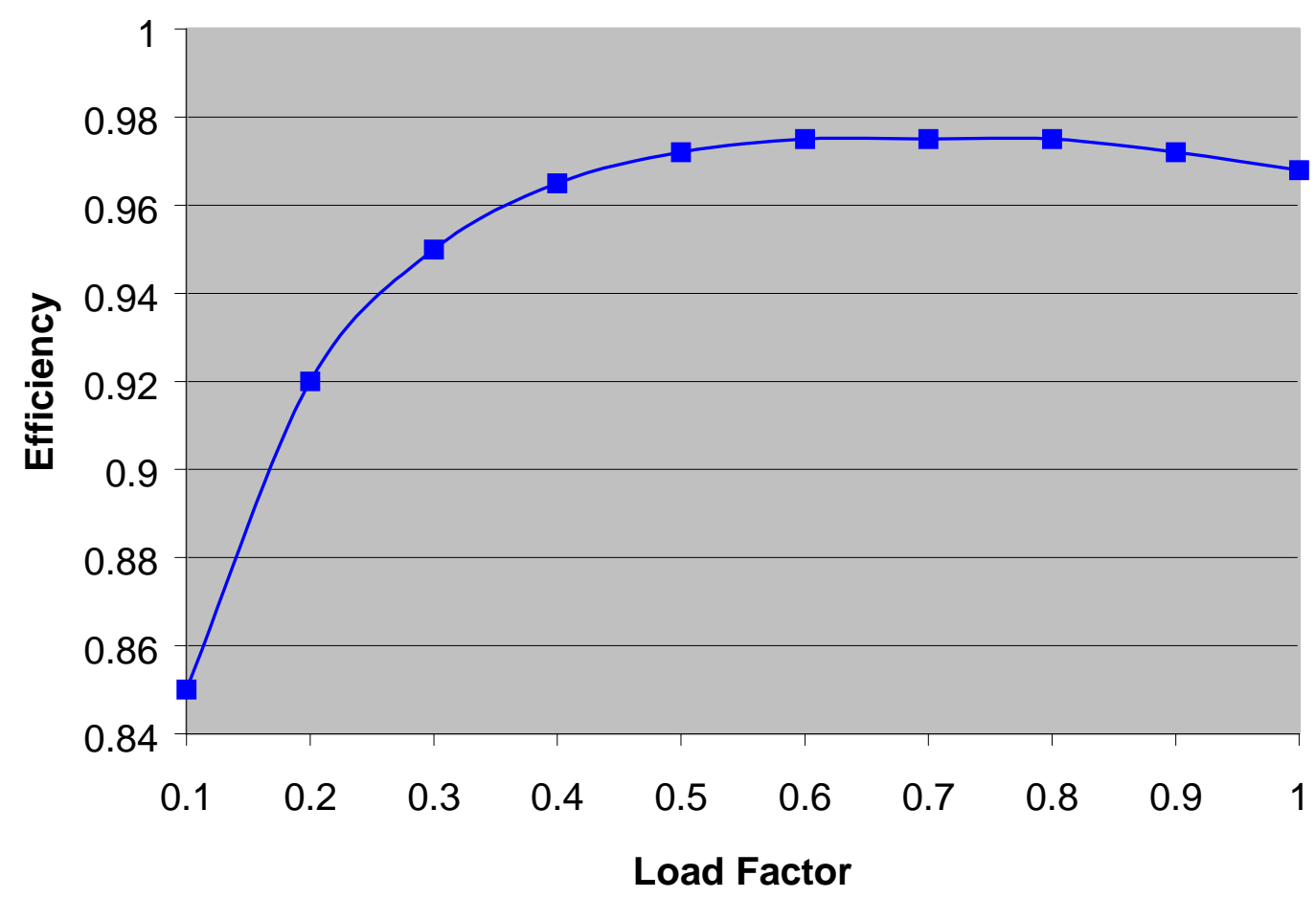

Fig. 6.8. 5-kW inverter efficiency for various load factors. 
than 0.25 and greater than $95 \%$ efficient at load factors greater than 0.5 for a switching frequency of $10 \mathrm{kHz}$. The high efficiency over a wide operating range means that these devices are very well suited for use with engines operated at variable speeds.

Likely, the initial gen-sets should have hard-switching inverters to take advantage of present and near-term mass production quantities to keep the initial costs low. However, the controller interface should be designed with soft-switching inverters in mind so that it has enough I/O to send gate drive signals and monitor additional auxiliary switches should soft-switching inverters be used on future gen-sets.

\subsubsection{Cooling of the Power Electronics}

The power electronics can either be force air cooled or liquid cooled. The liquid-cooled package would allow a smaller and lighter (probably aluminum) heat sink to be used and can dissipate more heat than an air-cooled heat sink. The liquid-cooled heat sink, however, requires a radiator, water, and pump. A loss of liquid or a pump failure would quickly lead to overheating of the devices and shutdown or failure of the power electronics. The radiator could be a separate one from the diesel engine radiator but because of size and weight restrictions would likely need to be integrated with the combustion engine radiator. If the power electronics are cooled in series with the engine, the water from the radiator should first pass through the power electronics heat sink prior to going to the engine block, because the electronics need the cooler water. The series-cooling configuration does not require an additional water pump. A serious question with the series cooling would be whether the liquid would be cold enough for the electronics. A parallel configuration would have two cooling loops and two pumps: one for the power electronics heat sink and one for the combustion engine block. Two loops would likely enable the liquid to be cold enough for the power electronics.

A forced air-cooled heat sink requires a large finned (probably aluminum) heat sink and an auxiliary fan, which could run off the dc link voltage or battery voltage. Design of the heat-sink should be such that failure of the fan would still enable the electronics to run at a reducedcapacity (probably 10-20\%) full load by taking advantage of convective heat transfer and maybe the "chimney effect" by allowing air to pass vertically through the heat sink.

\subsubsection{Summary of Power Electronics Recommendations}

- Using a variable-speed prime mover (engine) will require a system to convert the voltage generated to a selectable voltage and frequency. Power electronics are recommended to achieve this conversion because of their compact size and controllability. A single unit able to generate power at 50,60 , and $400 \mathrm{~Hz}$ would be possible.

- Use IPMs for the inverter and rectifier sections of the power electronics system to maximize integration of the electronics, increase reliability, and improve maintainability.

- Use common components as much as possible in the power electronics systems for the different sizes of gen-sets to minimize the burden of parts logistics.

\subsection{SIZING OF GEN-SET (MINIMUM AND MAXIMUM POWER RATINGS)}

Variable-speed engine operation will significantly increase the effective operating power range of future gen-sets. Therefore, it appears appropriate to size future gen-sets with both a 
maximum and minimum rated power capacity. The maximum rated power would be determined through testing similar to testing for current gen-sets. The minimum power rating, also determined through testing, would be the lower bound of effective and reliable gen-set operation. The lower power level would assure reasonable fuel consumption and would be selected to minimize the likelihood of wetstacking, or other related low utilization situations, and reduce the impact of transient load performance. The lower power level would be determined primarily from the engine map and qualification testing.

If future gen-sets were rated with both an upper and lower power rating, the family sizes could be selected to cover the entire range of interest (in this case, 5-60 kW) with sufficient overlap that parallel operation would not be required. The power management in the field should improve, fuel consumption of the overall system would decrease while being more predictable, and maintenance problems due to wetstacking would decrease dramatically.

Currently, the maximum power ratings are predetermined (5, 10, 15, 30, and $60 \mathrm{~kW})$, and the components of the gen-set are sized to meet that rating. The resulting gen-set then undergoes qualification testing to determine if it is capable of meeting the power level. If the gen-set fails to meet any of the power requirements during testing, the gen-set is redesigned with larger components (often the engine, the largest component). This process tends to result in gen-sets that may be overdesigned for their power rating.

An alternative approach would be to design a gen-set with the best components available to meet a general power range, then test the gen-set to determine the power level at which the gen-set is "qualified." Instead of preselecting gen-set ratings that would best fill the military requirements, the best engine is selected that satisfies the military power range requirements. The increased power range flexibility of variable-speed control allows sufficient overlap of adjacent gen-set sizes. The remainder of the gen-set components (i.e., alternator, etc.) are then designed to match the engine capacity. The gen-set final rating is assigned to the unit after the system passes all of the specified tests. For example, if the gen-set passes most of the qualification tests for $30 \mathrm{~kW}$ but passes all of the required tests at $28 \mathrm{~kW}$, the maximum power rating would be $28 \mathrm{~kW}$ rather than $30 \mathrm{~kW}$.

In summary, there are numerous advantages that could be realized once the effective range of gen-set operation has been determined and no substantial disadvantages.

- We recommend that gen-sets in the future be sized with both a maximum and minimum power rating. The minimum rating would be determined during future testing but would be the lower bound of effective and reliable gen-set operation. The maximum power rating would be determined using the same qualification tests used today but at the highest power level for which the gen-set fully qualifies rather than at a predetermined arbitrary level.

\subsection{SELECTION OF FAMILY SIZES}

The determination of family sizes assumes that future gen-sets will be rated with both a maximum and minimum rating as described in the preceding section. Family size selection is then accomplished with a concurrent look at the generated energy vs power profile for military gensets (shown in Figs. 5.2 and 5.3) and an understanding of the market of components recommended for future gen-sets. The generated energy/power profile identifies the power ranges for which an inventory of gen-sets is required. The market surveys identify the commercially available components that can best cover the required military power ranges. In this case, the 
engine should be selected first with all other components matched to complement that size. Market data indicated that PM alternators and power electronics have broad operating ranges such that the gen-set size is typically governed by the engine size.

This approach is expected to result in gen-set family sizes that are near optimum design of all subsystems and that complement each other in filling the entire intermediate power range without excessive capacity overlap or the need for parallel operations.

Because power electronics components and heat sinks are available in a variety of sizes, components with large enough current carrying capacity can be selected such that the electrical components are not expected to limit the power output capabilities of the gen-set.

As an example of family size selection using this approach, the engines presented in Table 6.4 have been reconsidered in Table 6.5, with the addition of the Cummins 5.9-L ISB engine. The maximum continuous power ratings of each engine at 1800 and $3000 \mathrm{rpm}$ are presented. The maximum gen-set rating (in column labeled resultant gen-set rating range) is based on the maximum continuous rating value at $3000 \mathrm{rpm}$; the minimum gen-set power rating is based on engine operation at $40 \%$ of the maximum continuous power level at $1800 \mathrm{rpm}$. (Recall this is an illustration only, final ratings would be determined through testing as described above.) This lower engine power level is thought to still be a high enough power level to avoid wetstacking. Also included in the table is the assumed overall conversion factor (or derate factor) that was used to estimate gen-set electrical output (in $\mathrm{kW}$ ) from net engine shaft output (in $\mathrm{hp}$ ). These factors are based on the current TQGs.

A plot of the estimated gen-set size ranges (minimum and maximum) as a function of engine weight is shown in Fig. 6.9. This figure, although a demonstration, is useful in selecting the family sizes. The family sizes should be selected with sufficient overlap in the ranges so that if the end points vary somewhat, the family sizes can cover the entire range of interest.

Based upon this approach, three families can be seen from Fig. 6.9 that together supply power over a 3- to $60-\mathrm{kW}$ range without depending on parallel gen-set operation. The power rating for the three family sizes that appear optimum are approximately $2-7 \mathrm{~kW}, 6-25 \mathrm{~kW}$, and 20-80 kW, and are highlighted as the dashed lines in Fig. 5.9. The chosen engines (i.e., Ruggerini MD191, VW R3, and DDC Advanced Delta) can adequately cover the power range of about 2 to $80 \mathrm{~kW}$ because of the flexibility of variable-speed control. The $25-\mathrm{kW}$ gen-set could cover the $6-$ to $25-\mathrm{kW}$ range. The $80-\mathrm{kW}$ gen-set is required to supply the $20-$ to $60-\mathrm{kW}$ range, but it is capable of covering the entire 20 - to $80-\mathrm{kW}$ range. As more advanced prime movers become available, more options will also be available (e.g., a lighter engine from 20 to $60 \mathrm{~kW}$ ), but the general approach is advantageous.

It is emphasized that these family size selections are not hard and fast values but represent approximate ranges. The actual new design ratings may vary somewhat to allow for detail design options such as available engine capacities when the final decision is made, other component design considerations, or limits established by test results.

- Based on the engines available in the market survey, the number of future gen-set families recommended to cover the $5-$ to $60-\mathrm{kW}$ range is three.

- Based on projected market availability, the gen-set families should be sized at approximately 2-7 kW; 6-25 kW; and 20-80 kW. Final size ratings will be determined at the conclusion of the qualification testing. 
Table 6.5. Weight and power ratings for selected lightweight diesel engines and estimated gen-set electrical output rating for gen-set application

\begin{tabular}{|c|c|c|c|c|c|c|}
\hline Engine model and description & $\begin{array}{l}\text { Continuous } \\
\text { power rating at } \\
1800 \text { rpm (hp) }\end{array}$ & $\begin{array}{l}\text { Continuous } \\
\text { power rating } \\
\text { at } 3000 \mathrm{rpm} \\
\text { (hp) }\end{array}$ & $\begin{array}{l}\text { Resultant } \\
\text { gen-set } \\
\text { rating } \\
\text { range } a(\mathrm{~kW})\end{array}$ & $\begin{array}{c}\text { Maximum gen-set } \\
\text { output rating for rated } \\
\text { engine speed [battle- } \\
\text { short mode] } \\
\text { (kW @ rpm) }\end{array}$ & $\begin{array}{l}\text { Engine } \\
\text { dry } \\
\text { weight } \\
\text { (lb) }\end{array}$ & $\begin{array}{l}\text { Assumed } \\
\text { derate factor } \\
\text { [engine } \\
\text { (hp)/gen-set } \\
\text { electrical } \\
\text { (kW) output] }\end{array}$ \\
\hline $\begin{array}{l}\text { Deutz-Ruggerini, } \quad \text { MD } \quad 191, \\
\text { 2-cylinder aluminum crankcase } \\
\text { industrial engine }\end{array}$ & 8.3 & 14.4 & $1.5-6.5$ & $8.3 @ 3600$ & 117 & 2.2 \\
\hline $\begin{array}{ccc}\text { Lombardini } & 1204 / T & \text { FOCS, } \\
\text { 4-cylinder turbo industrial engine }\end{array}$ & 20.5 & 33.3 & $3.7-15.1$ & $17.3 @ 3600$ & 223 & 2.2 \\
\hline $\begin{array}{l}\text { Volkswagen R3, 3-cylinder, cooled- } \\
\text { turbo, unit-injector fueled, automo- } \\
\text { tive engine }\end{array}$ & 33 & 54 & $6.3-25.7$ & $33 @ 4000$ & 251 & 2.1 \\
\hline $\begin{array}{l}\text { Peugeot-Citroen DW10 TED, } \\
\text { 4-cylinder, cooled-turbo, common- } \\
\text { rail fueled, automotive engine }\end{array}$ & 55 & 84 & $10.5-40$ & $48 @ 4000$ & 331 & 2.1 \\
\hline $\begin{array}{l}\text { Volkswagen R4, 4-cylinder, cooled- } \\
\text { turbo, unit-injector fueled, automo- } \\
\text { tive engine }\end{array}$ & 61 & 92 & $11.6-44$ & $51 @ 4000$ & 310 & 2.1 \\
\hline $\begin{array}{l}\text { Peugeot-Citroen DW12 TED4, } \\
\text { 4-cylinder, } 4 \text { valve/cylinder, vari- } \\
\text { able geometry cooled-turbo, } \\
\text { common-rail fueled, automotive } \\
\text { engine }\end{array}$ & 73 & 107 & $14-51$ & $60 @ 4000$ & 401 & 2.1 \\
\hline $\begin{array}{l}\text { Detroit Diesel Advanced } \\
4 \text { valta, } \\
4 \text { valinder, cooled turbo, } \\
\text { common-rail fueled, light truck } \\
\text { engine }\end{array}$ & 106 & 172 & $20-82$ & $95 @ 4000$ & 640 & 2.1 \\
\hline $\begin{array}{l}\text { Cummins } 5.9 \text { L ISB, 6-cylinder, } \\
4 \quad \text { valve/cylinder, cooled-turbo, } \\
\text { medium duty truck engine }\end{array}$ & 134 & 200 & $25.5-95$ & $105 @ 2700$ & 900 & 2.1 \\
\hline
\end{tabular}

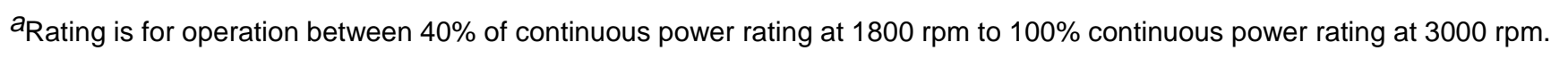




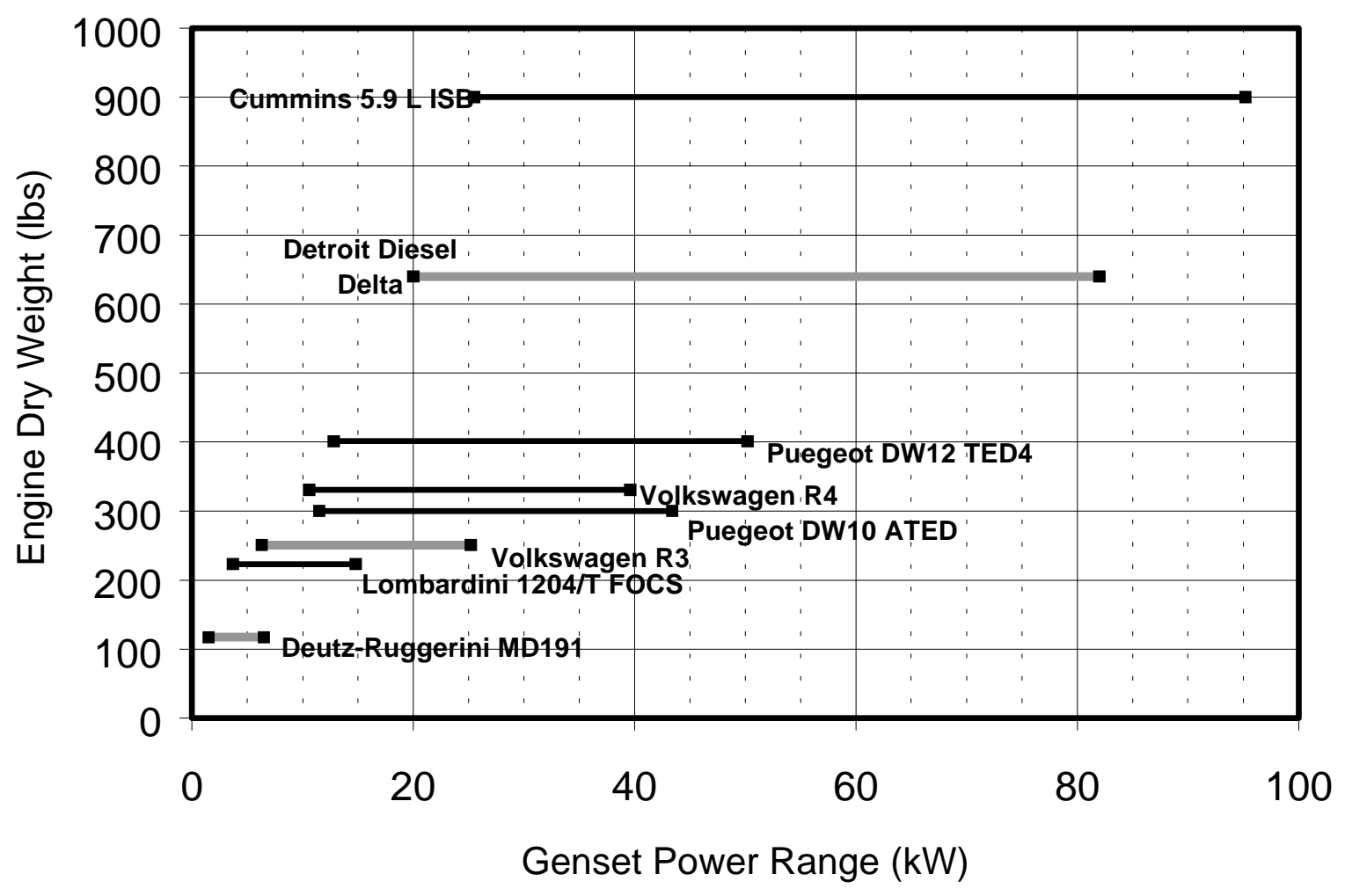

Fig. 6.9. Estimated gen-set size ranges (minimum and maximum) as a function of engine dry weight for selected lightweight diesel engines. 
6-26 


\section{Appendix 6-A. UNIVERSAL MISSION WEIGHT COMPARISON TOOL}

The mission weight comparison analysis applies to any kind of mobile electric generator design trade-off. The analysis examines the mission duration break-even time when the total mission (gen-set + fuel) weight of a heavier, more efficient generator design equals the total mission weight of a lighter, less efficient generator design. The break-even time depends on generic design parameters, including the difference in power density $(\mathrm{lb} / \mathrm{kW})$ between the two generators, the fuel consumption difference $(\mathrm{g} / \mathrm{kWh})$, and the ratio of average demand-to-rated power. The two gen-set designs being compared are assumed to be of equal rated power capacity.

Total mission weight is the weight of the gen-set plus the weight of the consumed fuel for specified power demand and mission duration.

Break-even time interpretation: If the break-even time exceeds the mission duration time, then the lightweight, less efficient gen-set has lower total mission weight than the heavier, more efficient gen-set because there is insufficient time to take advantage of the lower fuel consumption. If the break-even time is less than the mission time, then the lightweight, less efficient gen-set has greater total mission weight than the heavier, more efficient gen-set. In the latter case, there is sufficient mission operating time to take advantage of the lower fuel consumption of the more efficient gen-set to compensate for the it's initial excess weight.

The mission duration break-even time (for equal mission weight) for two generator designs is presented in Figs. 6-A.1, 6-A.2, and 6-A.3 for one peacetime and two wartime power demand scenarios of approximately 28,58 , and $70 \%$ of rated power. The demand powers of 28,58 , and $70 \%$ of rated power, respectively, correspond to the peacetime average demand (Chap. 5, Ref. 2), the projected average wartime demand for gen-sets up to $60 \mathrm{~kW}$ and for gen-sets over 60 kW (Chap. 5, Ref. 1).

The break-even time is plotted vs fuel consumption difference for various normalized generator weight differences. The generator normalized weight difference ranges from 10 to $80 \mathrm{lb} / \mathrm{rated} \mathrm{kW}$. The fuel consumption difference is arbitrarily allowed to range from 1 to $200 \mathrm{~g} / \mathrm{kWh}$. Figure 6-A.4 is an aid to graphically estimate the fuel consumption difference from the two known efficiencies of the competing designs. 
Peace-time average power demand fraction avp $=.278$ of rated power for gen-sets $60 \mathrm{~kW}$ or less.

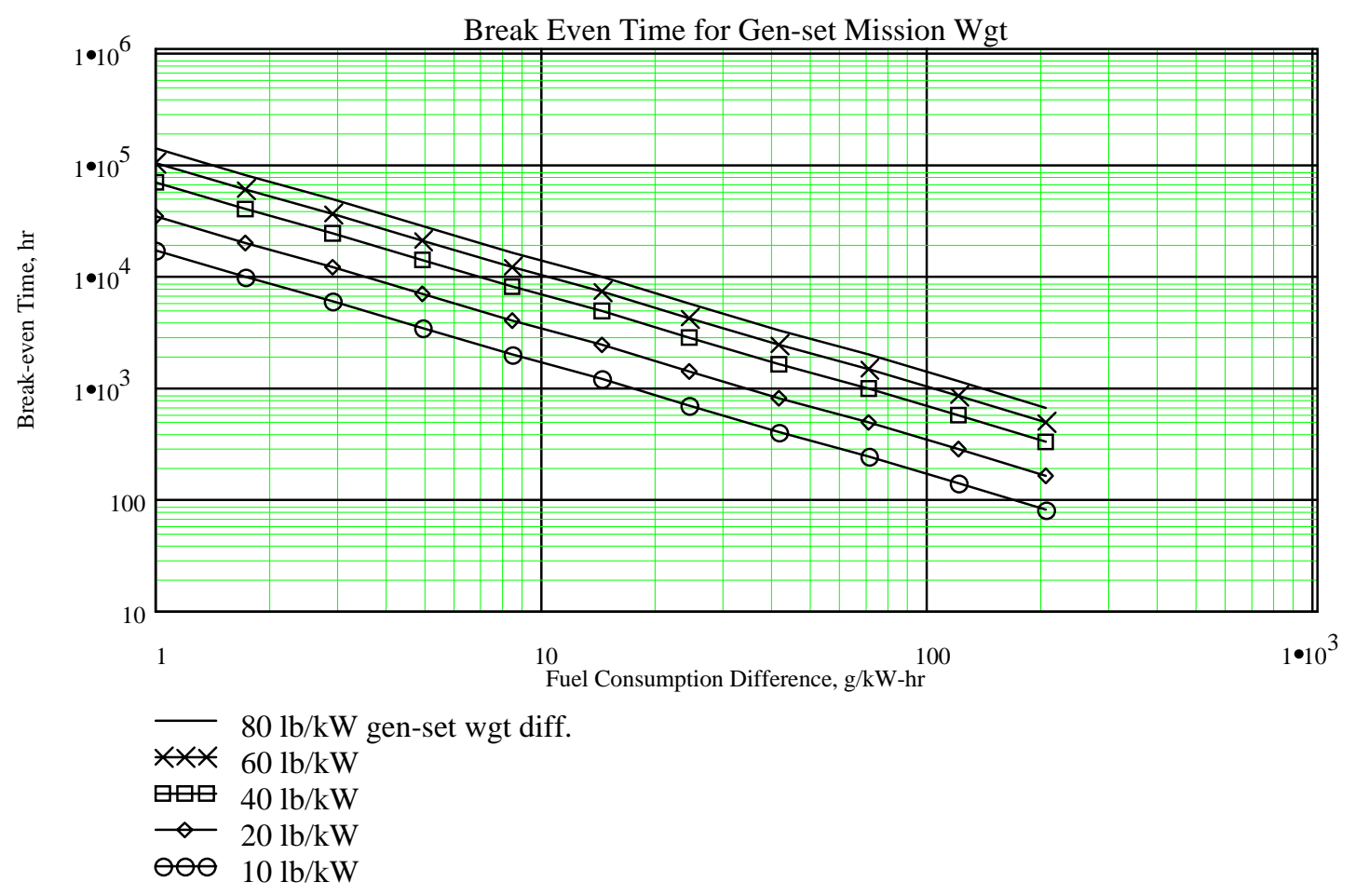

Fig. 6-A.1. Mission weight break-even time comparing two gen-set designs for average peacetime mission.

Note:

The break-even time is the mission duration when the total (gen-set + fuel) weight for the lighter, lower efficiency gen-set equals the total weight of the heavier, higher efficiency gen-set.

For break-even time > mission duration, the light, less efficient gen-set has lower total mission weight than the heavier, more efficient gen-set.

For break-even time < mission duration, then the light, less efficient gen-set has higher total mission weight than the heavier, more efficient gen-set. 
Projected war-time average power demand fraction avp $=.58$ of rated power for gen-sets $60 \mathrm{~kW}$ or less.

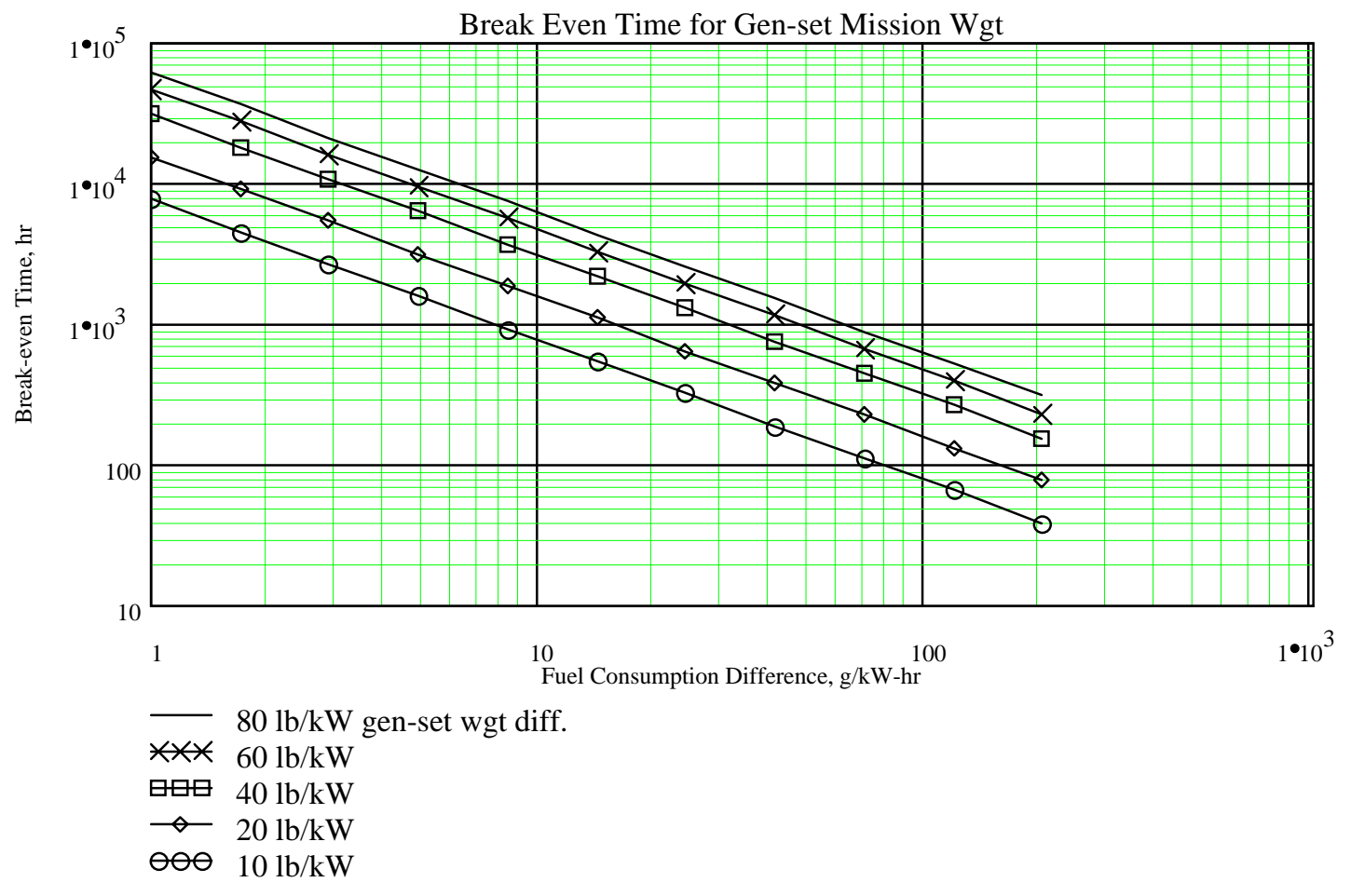

Fig. 6-A.2. Mission weight break-even time comparing two gen-set designs for projected wartime mission for gen-sets $60 \mathrm{~kW}$ or less.

Note:

The break-even time is the mission duration when the total (gen-set + fuel) weight for the lighter, lower efficiency gen-set equals the total weight of the heavier, higher efficiency gen-set.

For break-even time > mission duration, the light, less efficient gen-set has lower total mission weight than the heavier, more efficient gen-set.

For break-even time < mission duration, then the light, less efficient gen-set has higher total mission weight than the heavier, more efficient gen-set. 
Projected war-time average power demand fraction avp $=0.7$ of rated power for gen-sets over $60 \mathrm{~kW}$.

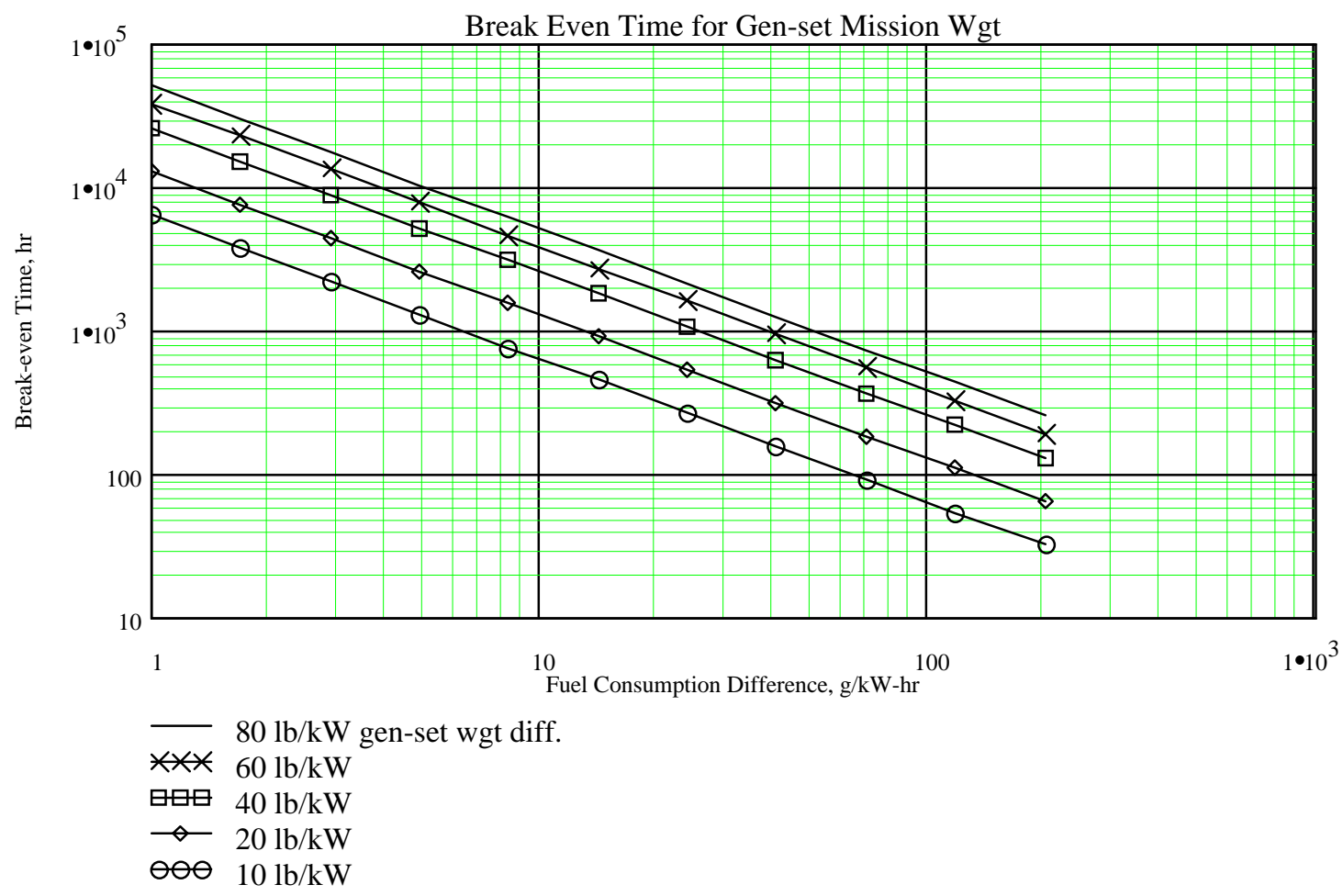

Fig. 6-A.3. Mission weight break-even time comparing two gen-set designs for projected wartime mission for gen-sets over $60 \mathrm{~kW}$.

Note:

The break-even time is the mission duration when the total (gen-set + fuel) weight for the lighter, lower efficiency gen-set equals the total weight of the heavier, higher efficiency gen-set.

For break-even time > mission duration, the light, less efficient gen-set has lower total mission weight than the heavier, more efficient gen-set.

For break-even time < mission duration, then the light, less efficient gen-set has higher total mission weight than the heavier, more efficient gen-set. 


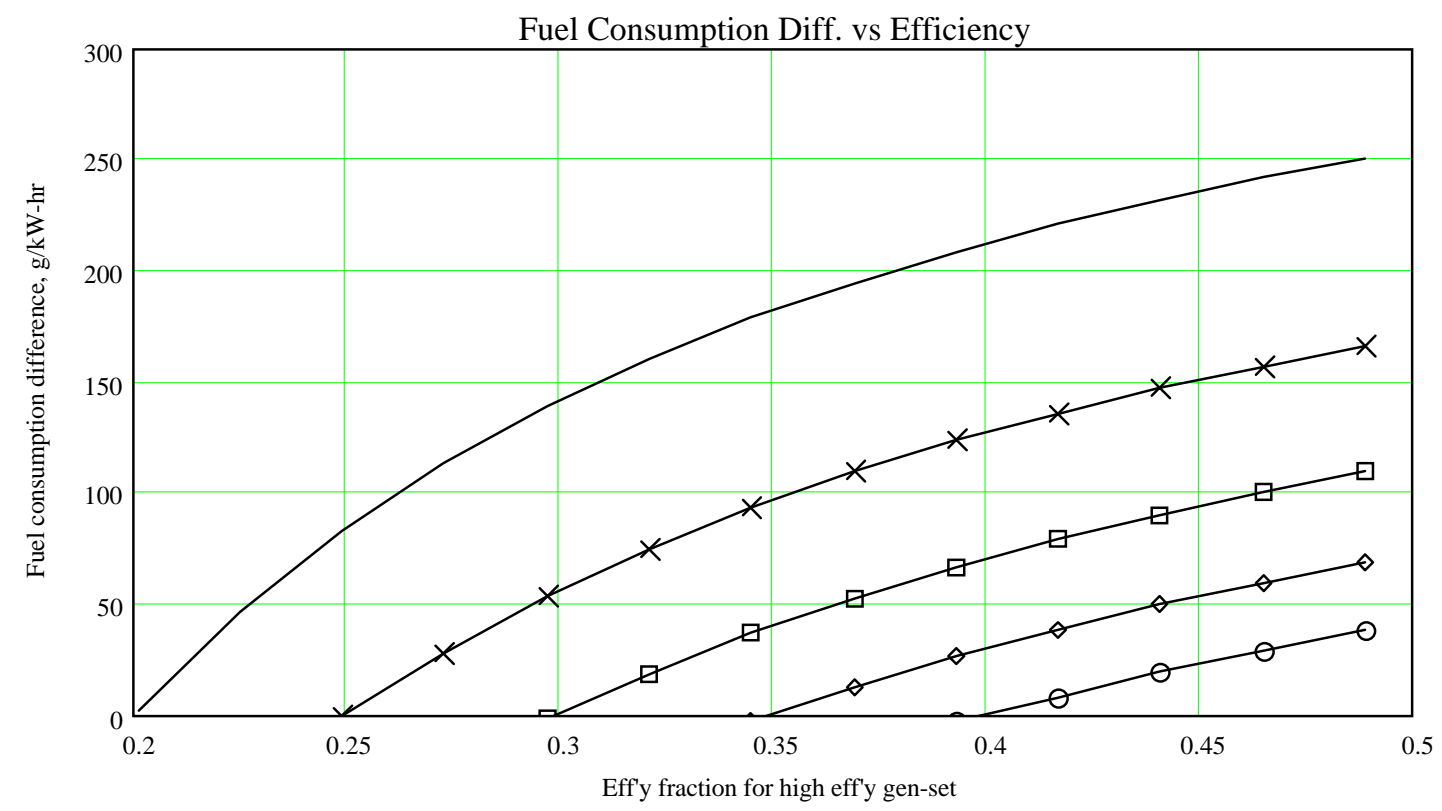

- .2 effy. fraction for low effy. gen-set

$* x * .25$

घ曰口 3

$\diamond .35$

๑๐ 4

Fig. 6-A.4. Curves to estimate the difference in fuel consumption from two different gen-set efficiencies. 
6-32 


\section{DIGITAL CONTROL SYSTEM}

The purpose of this chapter is to describe and recommend the control systems for incorporation in future gen-sets. The control system will include operation of the generator during normal and battle-short modes as well as the D\&P system. The D\&P system is described in Chap. 8.

\subsection{PURCHASE VS DEVELOPMENT OF CONTROL SYSTEM}

While at first glance it would seem appropriate to purchase an off-the-shelf controller, this is not really a viable option. Each controller is designed to handle a specific gen-set. A generic controller would add too much expense and design time for options that are not required for a particular gen-set. If a vendor sold the control system separately, it would still have to provide all intellectual property details of the control system for the controller to be useful. In other words, a control system is an integral portion of the gen-set and is not a "plug-and-play" component that can be taken from one unit and used on a different unit. Moreover, no existing control system was located that included all the features that are desirable for the next generation of gen-sets (such as prognostics or variable-speed control).

The most desirable controller for a variable-speed gen-set would be developed to be upgradable and applicable for each of the gen-set family sizes. This modularity will reduce the number of replacement parts because a single unit will be useable for all gen-sets. As new developments occur, the controller can expand to handle these with a software modification and perhaps an additional module to condition the signal. One will be able to update the software via a maintenance computer link in the same fashion that a PC's BIOS is updated today.

If the system is developed specifically for the new gen-sets, then a potential vendor would simply obtain a license and build the units with the new control system. The architecture would be open and easily updated with the latest development. The technologies and components on which the gen-set control system would be based are well established and have been implemented previously. It will be necessary to integrate the control of these components in a digital control system specifically for this application. A customized control system would be designed for use on all family sizes.

- Based on the survey of the market, it appears highly unlikely that a control system can be purchased separately from the gen-set. Therefore, we recommend that the control system be developed specifically to operate the future gen-sets.

\subsection{GEN-SET MODULAR CONSTRUCTION BLOCKS}

A schematic of the control system is shown in Fig. 7.1. The following sections address the control necessary to operate each of the modules.

\subsubsection{Engine}

The IC engine that has a digital or analog control input for speed or power converts fuel to mechanical power that turns the generator. Desired outputs include a tachometer reading and diagnostic sensor readings such as oil pressure and other pertinent operating information. 


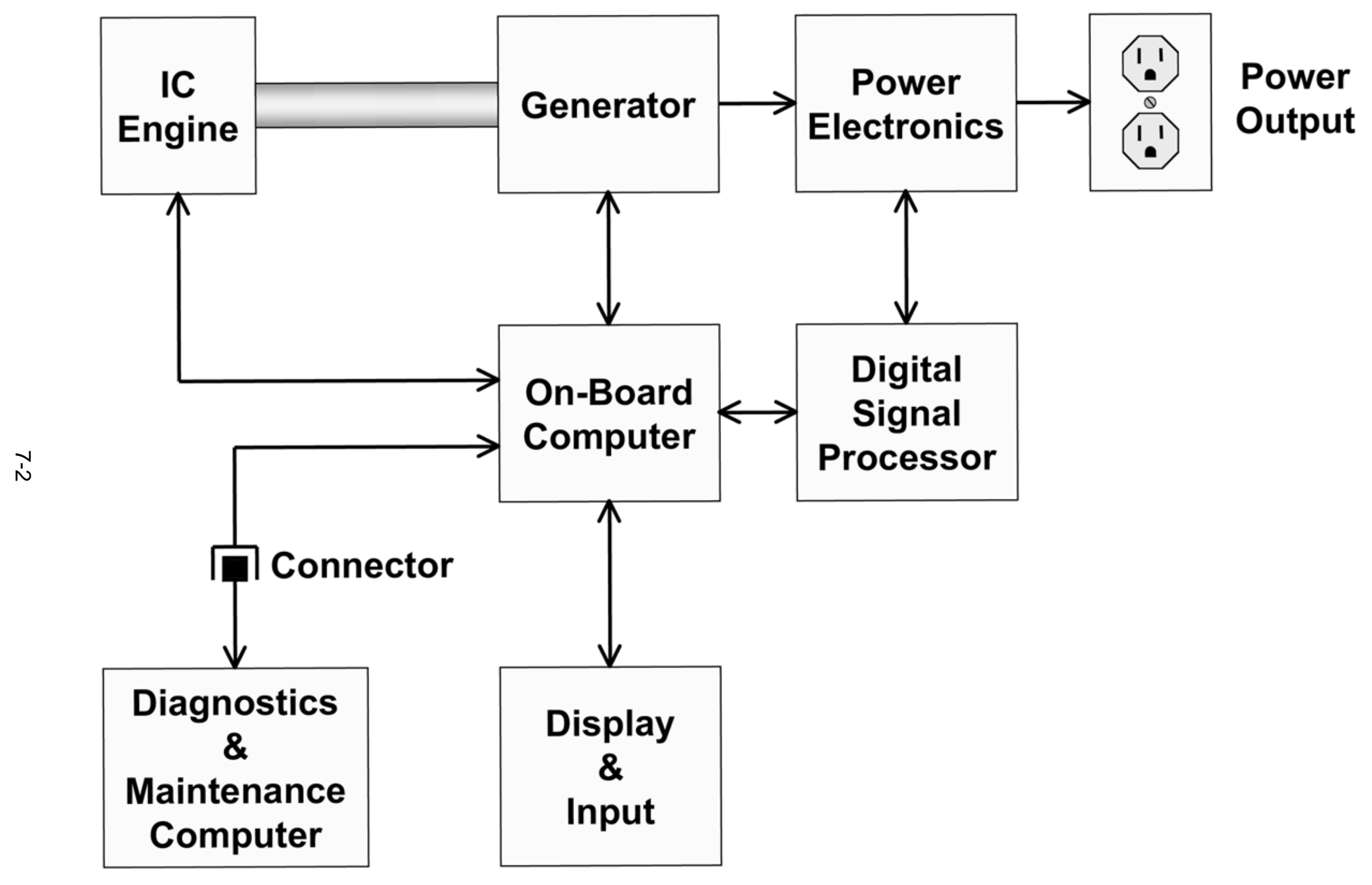

Fig. 7.1. Schematic of the control system. 


\subsubsection{Alternator}

As far as the control system is concerned, the alternator can be any type of electrical generator. The control of the generator may require an excitation current control and/or output a shaft position or tachometer. If a PM motor/generator is used, then no excitation current is required.

\subsubsection{Power Electronics}

This will be the unit that converts the variable frequency and voltage of the generator output due to the variable-speed shaft input and generates the desired electrical output voltage and frequency. It will consist primarily of the switching power transistors and the control circuitry necessary to operate them.

\subsubsection{Onboard Computer (Global Controller)}

This computer would perform a variety of computations that are necessary for global operation or the macro-commands to the various subcomponents, which will orchestrate the overall smooth operation and coordination between the subcomponents. This system supports those components that need millisecond (ms) and longer time response.

The scale of this unit remains to be determined by the diagnostics capability chosen to be incorporated into the gen-set. It may consist of anything from a simple 8-bit microcomputer $(\mu \mathrm{C})$ up to a sophisticated Pentium class (or equivalent) machine. The operating system may range from a simple prom monitor to a more complex Windows CE operating system. The determination of the operating system will depend on the diagnostic computation(s) required and the display that needs to be driven. Once requirements for diagnostics and the display are identified, then the selection of this component will be straightforward. Software factors to consider beyond those discussed so far are the robustness of the operating system, the familiarity of the operators with it, the speed of boot (operational readiness), the ease of programming and updating, and both the development and the purchase cost. Other hardware factors to consider are ease of system updates, cost, weight, robustness, heat dissipation requirements, and ease of maintenance and modification.

The software development effort will depend primarily upon the diagnostic requirements, which could range from a few hundred to many thousand lines of code. How much of the diagnostics will be incorporated directly into the gen-set and how much might be relegated to a separate portable diagnostic and maintenance computer (DMC) remains to be determined.

In this application the control system would be an integral part of the inverter package, which itself would be a modular unit in all of these new gen-sets. It appears that due to the nature of the gen-set requirements for power, some interchangeability in the electronics package may be possible between units. This control system would control not only the inverter DSP, but also the generator and the engine for a unified control approach. It could also interface to other gensets to parallel the power outputs for additional power capability and reliability. The control to the engine, the generator, and any other gen-set subcomponent would be a generic control such as more or less power to be delivered by the engine. It is felt that the engine manufacturer would best know how to control all the internals to the engine that it designed far better than any external vendor. Therefore, only generic controls would be required by the control system. In the case of the engine, a prerecorded map of the engine efficiency would tell the controller where to set the engine speed for the requested power. In battle-short mode it would probably set the engine to run at an optimum speed to be able to pick up large electrical loads more quickly without concern for fuel efficiency. 
Paralleling units together would allow smaller lighter weight units to be combined into larger units as needed. An intelligent controller would also allow units to come on line automatically as needed for the power demand and to pick up the load if another gen-set in the system fails or needs to be shut down for maintenance (see Sect. 7.4.3).

In the design of the controller, the overall cost would be reduced by use of field programmable logic arrays (FPLAs) and other programmable logic to reduce parts count, cost, and physical complexity. When possible, standard components would be used over more exotic and less obtainable ones.

Advantages of $\mu \mathrm{C}$ for global controller:

- elegant

- very simple to operate

- few failure modes

- cheaper to produce

- less weight

- more robust

Disadvantages of $\mu C$ for global controller:

- display must be simple ASCII (text) or additional programming needed

- may lack power to do all that is necessary

- not easily expandable for more computational speed

- need external computer (DMC) to get at internals of operation

- a more complex operating system with a sophisticated graphical user interface (GUI) is not available

Advantages of PC-based global controller:

- $\quad$ plenty of power and expansion capability

- better debugging tools

- more programmers familiar with system

- can be operated with a greatly simplified operating system

- can utilize a more sophisticated display

Disadvantages of PC-based global controller:

- more expensive

- slightly heavier

- larger size

- GUI operating system more complex (Windows CE)

- more to fail

- not as robust

- difficulty obtaining robust GUI displays

- $\quad$ higher power requirements and therefore more cooling required

\section{Recommendation}

- The advantages tend to favor a PC-based global controller to run the control system. The final decision will be made during the prototyping phase of this program. The selection of the operating system will have to be made at a later date based on the other system requirements chosen by the military. 


\subsubsection{DSP}

The DSP will be the workhorse on the micro-level command, which operates the switching of the power transistors to achieve the instantaneous power and voltage output to the load. It will operate on the microsecond $(\mu \mathrm{s})$ timing level and will most likely cycle through its entire program in $20 \mu \mathrm{s}$ or less. Therefore, the code for this processor is typically on the order of a hundred lines. It will need to be compact and highly efficient to be able perform the necessary calculations in the required time frames. It will most likely communicate to the onboard computer through shared memory and will have its own sensor input to instantaneous output voltage and current and generator state.

In the case of an induction generator, the excitation current to it will have to be controlled by this DSP. If a standard alternator is used, then a dc excitation current will be controlled by this process. In the case of PM generator, no control is necessary here at this level.

During development of the first prototype, a PC-based DSP board that has floating point capability will be used, because it will be much easier to develop code and program changes in algorithms, without the worry of overflow and underflow that has to be considered with an integer DSP. Once the algorithm is fully developed and verified, then the algorithm will be converted to run on a stand-alone integer DSP development board. While this will take additional work, the cost savings of an integer DSP will more than offset the expense of the conversion. On the third-generation prototype, the integer DSP chip will be incorporated directly into the controller board itself. Several companies (Motorola and Texas Instruments) make a DSP specifically designed to control inverters such as this and will sell in quantities at prices as low as $\$ 15$ each.

The alternative to a DSP control is discreet logic. This means designing a fixed circuit to control the inverter switches. It is not a software-based (programmable) system and can get very complex to implement all of the functions desired.

\section{Advantages of DSP:}

- very versatile-easy to change program

- inexpensive in production unit

- reduced parts count and weight

- easy design (hardware moved to software)

Disadvantage of DSP:

- requires software development system and corresponding learning curve

Advantage of discreet circuitry:

- very fast-virtually instantaneous control

Disadvantages of discreet circuitry:

- very complex design

- difficult to alter circuit design

- requires large board layout

- many discreet components

- uses more power requiring greater heat dissipation

- expensive to develop and reproduce 


\section{Recommendation}

- We recommend the use of DSPs in the control system to govern the final current and voltage output.

\subsubsection{Display and Input}

The display can range from a few mechanical buttons and gages to a full-color active matrix with touch screen input. Again, the final selection will depend on the desired end result.

If an active matrix is chosen, then it may be the weak link in the entire system due to the rugged environment that it will be required to operate in. It will be a more easily damaged component in the system, and consideration will have to be given to the possibility of continuing to function if this unit is damaged or rendered inoperable due to moisture or extreme temperatures. In this module will be included any operator input device whether it is a touch screen or a mechanical switch.

The mechanical approach would mimic the present-day operation of the TQGs with their mechanical switches and meters.

A third option is available, which may be a compromise between these two extremes. There are liquid crystal displays in the form of a dot matrix, which allows a viewing area of up to 8 lines by 40 characters. These are fairly robust and have been used in outdoor applications such as weighing systems. This type of display would allow some simple graphics and be easy to program. It would not require the sophistication of a Windows or GUI operating system. It would not allow complex graphics or color to be displayed, and it would be limited to brief descriptions of operator messages due to its compact size. But, the cost is very reasonable compared to an active matrix.

This component will require the military to determine its requirements and desires for what and how it wants to display information to the operator in order to make the final selection.

Advantages of simple mechanical display:

- most rugged

- simple to use

- inexpensive

- familiar to personnel

Disadvantages of mechanical display:

- not as informative to user as desired/required

- requires separate PC (DMC) to interrogate system

- could end up weighing more

Advantages of a liquid crystal display:

- robust

- simple to use

- relatively inexpensive 
Disadvantages of a liquid crystal display:

- limited display area

- coarse resolution

- messages need to be cryptic

Advantages of GUI:

- display picture information

- achieve many levels of complexity

- be completely self-contained

Disadvantages of GUI:

- more easily damaged (fragile)

- more expensive

\section{Recommendation}

- The final recommendation for the display will depend on further input from the military about what is needed in the field. Once it is determined what is required on the display, then selection of that display will be relatively simple.

\subsubsection{DMC}

External to the gen-set one can use a standard computer (notebook or other ruggedized system) with a standard RS-232 serial port to connect to the gen-set. With this connection one can obtain all the information available on the gen-set's state of health as well as control internal parameters for testing or other specific operations. This could be used for D\&P, service, and maintenance applications not available onboard the gen-set.

The DMC would have all of the figures and diagrams and troubleshooting information on a CDROM. This CDROM could be updated easily and inexpensively whenever a new development became available just as operating systems to PCs are updated frequently in this manner. In addition, a network connection may allow automatic updates from Web addresses in a timely fashion.

This system would mimic the diagnostic capability of an automobile service department. It would interrogate the gen-set as to detailed stored information and perhaps lead maintenance personnel through step-by-step resolution of any detected problems. This may include anything from changing the oil to replacing a fundamental component. It may be possible to house a CDROM disk with each gen-set, which contains all the information on that gen-set so it will always be available for use on any PC.

Advantages of a separate DMC:

- can put full schematics, diagnostic, mechanical diagrams, and repair information onboard

- one unit that can service many gen-sets (also a disadvantage if not used properly)

- saves weight and cost of each gen-set

- easy to update with a CDROM

- can make it easy to upgrade gen-set programs

- can be a standard rugged PC, which can have other uses 


\section{Disadvantage:}

- requires an additional unit to be maintained with gen-sets

The final maintenance computer can be any rugged computer with a serial port on it and a CDROM drive. Other options such as network links are highly desirable.

\section{Recommendation}

- A separate maintenance computer should be included to provide additional useful functions, which are not deemed appropriate to be included onboard the gen-set itself.

\subsection{BACKUP PLAN FOR CONTROL SYSTEM}

The likelihood that the control system just described and recommended can be built is very high. Time and resource constraints will determine the sophistication of the controller. Computer and DSP controllers of this type have been built many times before. The initial prototype may very well include a DSP control board that has been designed at ORNL and is currently operational in an electric bus. Only the software for it would need to be modified.

It is not a matter of designing one to do all that is required of it, but of compromises between cost, weight, robustness, durability, capability, and user friendliness. Contingency plans for the development effort of the controller are more a matter of updating the decisions for these tradeoffs. In other words, we are confident that a control system can be built that would operate the gen-sets within these recommendations. However, it is possible that some of the features that have been discussed in this chapter might not be practical in the initial control system because of cost and development time constraints.

As with any development there is always a risk that an unforeseeable event will delay or render a design inoperable. If for some reason the power electronics module (consisting of the power electronics and the computer control) were to fall into this category, then it would be a relatively simple matter to scale down the degree of sophistication to a system that would work. This would allow the simpler and more dependable design to be used until the more sophisticated unit could become operational.

\subsection{ADDITIONAL FEATURES}

Given that a digital control system will be used in the manner previously described, several features could be built into the control system that might be beneficial. These options can be incorporated with little additional cost and risk.

\subsubsection{Fail Safe Options}

In the event of a component failure in the power electronics, it would be possible with some generators to design the system such that it could be field rewired to run power directly off the generator, thus bypassing the power electronics. In this case the engine would be controlled to operate in the standard fixed-speed mode to achieve the desired ac frequency and voltage on output. This would not be practical for $400-\mathrm{Hz}$ operation, but would be possible for 50 - or $60-\mathrm{Hz}$ operation. This type of operation would preclude any paralleling or fuel optimization. 


\subsubsection{Long Electrical Power Delivery Cables}

When a gen-set is placed a long distance from the load and/or the power cables are not of sufficient gauge, then there can be a significant voltage drop in the cable by the time the power reaches the load. Through use of an intelligent controller this can easily be corrected. The operator could simply tell the controller about how long and what gauge wire is being used to deliver the electrical power, and the inverter would be adjusted to provide the correct voltage at the load. In cases where very precise voltage regulation is required, a sensor line can be run to the load, but this should not be necessary in any foreseeable application.

\subsubsection{Parallel Operation of Gen-Sets}

One of the advantages of using a power electronics inverter for generating power is the additional control capacity, which when coupled with the proper communication, allows the paralleling of the power outputs together for greater total power delivery. The system envisioned could feature automatic phase matching of power output among multiple units, either the same or different sizes. The only addition to software and communication between gen-sets is the increased size of the power delivery connectors to handle the total load.

In addition to being able to automatically phase match the power outputs, the control system would be designed to operate in either a "master" or "slave" role. The control system would then be able to tell by the connections which role it should assume. This would prevent problems by an operator assigning more than one master among several sets operating in parallel. Should one unit in the set fail, the control system could be designed to reassess the power demands and continue operation.

\section{Communication}

The most fault-tolerant form of communication between paralleled gen-sets would be to put the communication signal between gen-sets over the power lines themselves. That way if the gensets were paralleled, they would automatically have the communication link established.

The difficulty here would be ensuring a reliable communication method to "ride on top" of the delivered power. Because the inverters typically produce high-frequency switching noise, it may be difficult to keep this noise from interfering with the control communication link. However, if this can be accomplished reliably, then this would be the preferred mode of operation for paralleling gen-sets.

The use of wireless communication between gen-sets seems problematic at this time. The costs of wireless links, which would be nondetectable, is high. In addition, the communication itself would need to take place very rapidly, which would be a very difficult task via wireless communication.

\section{Reliability for Parallel Operation}

Parallel operation of multiple gen-sets can either improve or reduce reliability of generating electricity depending on how it is implemented. In general, reliability is inversely related to the demand load. If the demand load is close to the total capacity of the sum of the multiple gensets, then the reliability of the parallel system is less than the reliability of a single gen-set. If the demand load is a fraction of total capacity of the sum of the multiple gen-sets, then the reliability of the parallel system is greater than the reliability of a single gen-set. 
An example is illustrated in Table 7.1. In the example, generators having an assumed reliability of 0.9 are operated as one, two, three, or four units in parallel with an assumed maximum capacity of $60 \mathrm{~kW}$. The example system reliability ranges from 0.656 to 0.9999 , depending on the ratio of demand power to total power capacity and on the number of generators in parallel.

The table shows that when operating near maximum (i.e., 100\%) system capacity, the system reliability decreases with increased number of gen-sets operating in parallel. This is because there is greater opportunity for failure when every unit is required to generate the demand power. As demand power decreases, system reliability increases with increased number of generators. This is because not all of the paralleled generators are required to deliver the necessary fraction (i.e., $<75 \%$ ) of the system capacity.

In general, the military prefers to avoid parallel operation where possible to minimize the amount of equipment transported to the field and to maximize reliability with minimum fielded equipment. When necessary, parallel operation is used for critical missions where high reliability and redundancy is essential.

\section{Advantages of paralleling:}

- smaller units easier to transport

- fewer sizes of units needed (fewer different replacement parts needed)

- much higher reliability for partial power delivery

- can scale to power demand much easier

- can turn off individual gen-sets when full power not needed, saving fuel

Disadvantages of paralleling:

- full power reliability reduced

- smaller units tend to have lower fuel efficiency

- more complexity in control system

- increased logistics burden

The details of including automatic parallel operation in the control system will need to be explored in the design phase of the prototyping based on additional input from the military. If the new digital control system cannot operate multiple units automatically, the units can be combined using the same techniques that are used today.

Table 7.1. Reliability for example parallel operation of gen-sets ${ }^{a}$

\begin{tabular}{|c|c|c|c|c|c|c|}
\hline \multirow{2}{*}{$\begin{array}{l}\text { Number of } \\
\text { generators }\end{array}$} & \multirow{2}{*}{$\begin{array}{c}\text { One } \\
\text { generator } \\
\text { capacity } \\
(\mathrm{kW})\end{array}$} & \multirow{2}{*}{$\begin{array}{c}\text { Total } \\
\text { capacity } \\
(\mathrm{kW})\end{array}$} & \multicolumn{4}{|c|}{$\begin{array}{l}\text { Reliability at load demand } \\
\text { (\% total load capacity) }\end{array}$} \\
\hline & & & $\begin{array}{l}15 \mathrm{~kW} \\
(25 \%)\end{array}$ & $\begin{array}{l}30 \mathrm{~kW} \\
(50 \%)\end{array}$ & $\begin{array}{l}45 \mathrm{~kW} \\
(75 \%)\end{array}$ & $\begin{array}{l}60 \mathrm{~kW} \\
(100 \%)\end{array}$ \\
\hline 1 & 60 & 60 & 0.90 & 0.90 & 0.90 & 0.90 \\
\hline 2 & 30 & 60 & 0.990 & 0.990 & 0.81 & 0.81 \\
\hline 3 & 20 & 60 & 0.999 & 0.972 & 0.729 & 0.729 \\
\hline 4 & 15 & 60 & 0.9999 & 0.9963 & 0.948 & 0.656 \\
\hline
\end{tabular}

${ }^{a_{\text {Assumes }}}$ the reliability of one generator $=0.90$ for illustration. 


\section{D\&P RECOMMENDATIONS}

This chapter provides a description of how a D\&P system would be used and incorporated into future gen-set design. The diagnostics system would aid in both reducing maintenance costs and, more importantly, minimizing unexpected failures in the field. The prognostics system could eventually help predict the remaining life of selected gen-set components under a variety of operating conditions. When considering D\&P, several sources were studied. These are included as Refs. $1-10$.

\subsection{BACKGROUND}

A background section is included in Appendix 8-A. The examples provided illustrate the type of information that is obtainable by doing D\&P testing. These examples focus on showing the versatility and strong capabilities of electrical signature analysis (ESA) as a D\&P technology. In addition to ESA, many other technologies are available for application to gen-sets. It is important to realize, however, that the application of even a proven technology to a new application requires an initial development effort to establish the relationships between the measured parameters (e.g., signatures) and the true condition of the monitored device. Fortunately, the time for development of this knowledge does not have to be long, if defect implantation and accelerated wear tests are done.

The development of a reliable prognostic system, however, is not an easy task. Because machine wear items can degrade at different rates according to their initial condition, their service environment, and their maintenance history, predicting the time of their failure requires up-to-date trends of key parameters known to be directly related with component condition and life-span. The algorithms used for these predictions should be refined (updated) as necessary based on experience with the prognostic system. Thus, it is expected that the prediction accuracy of these algorithms will improve as they are used more and more.

\subsection{D\&P CAPABILITIES IN THE PURCHASE DESCRIPTION FOR 100- TO 200-kW TQGs}

The recently prepared purchase description (PD) for 100- to 200-kW gen-sets (PD-6115-0115) contains specifications for many monitoring systems (sensors and display instruments) for ensuring that the condition of these gen-sets is known and maintained. Included in these specifications are requirements for monitoring and displaying several key parameters known to be related to safe and reliable operation. Also included in this document are requirements for D\&P. These requirements confirm the relevance and acceptance of condition monitoring elements onboard these gen-sets.

The D\&P capabilities specified by PD-6115-0115 were reviewed and considered for possible application to new gen-sets in the 5- to 60-kW range. Key sections from PD-6115-0115 that are relevant to D\&P are summarized in the following two sections.

\subsubsection{Required Parameters}

According to PD-6115-0115, the following indicating instruments are required on the 100- to 200-kW units:

- lube oil pressure indicator (3.28.1.1.1)

- $\quad$ engine temperature indicator (3.28.1.1.2)

- fuel-level indicator (3.28.1.1.3) 
- battery charging indicator (3.28.1.1.4)

- running-time meter (3.28.1.1.5)

- voltmeter (3.28.1.1.6)

- ammeter (3.28.1.1.7)

- kilowatt meter (3.28.1.1.8)

- frequency meter (3.28.1.1.9)

In addition, the following engine-shutdown protection devices are specified:

- engine overspeed (3.28.1.3.1.1)

- engine high temperature (3.28.1.3.1.2)

- low oil pressure (3.28.1.3.1.3)

- low fuel level (3.28.1.3.1.4)

The following devices are also specified to provide electrical interruption by tripping the output circuit interrupter:

- undervoltage (3.28.1.3.2.1)

- overvoltage (3.28.1.3.2.2)

- $\quad$ short circuit (high current) (3.28.1.3.2.3)

- overload (high current) (3.28.1.3.2.4)

- reverse power (3.28.1.3.2.5)

- ground fault (ground fault leakage current) (3.28.1.3.2.6)

It should be noted that most of these protection devices are triggered by undesirable amplitude deviations in the same parameters used by the indicating instruments listed above.

\subsubsection{D\&P}

Section 3.28.1.4.1 of PD-6115-0115 requires that "The generator control system shall incorporate a diagnostic capability, which will diagnose gen-set failures to the operator to the Line Replaceable Unit (LRU) as defined by the maintenance concept." PD-6115-0115 further states that the status of all protective systems (e.g., engine-shutdown devices and electrical interruption devices) be clearly displayed so that if the gen-set is shut down by the trip of a protection device, the particular device responsible for the shutdown is clearly identified and remains identified until manually reset. While this approach provides the gen-set operator with information that can be useful in pinpointing the cause of an unexpected failure, the cause of a problem is only identified after the problem has occurred. The protective systems by themselves cannot provide information about the problem before it occurs. An early warning about an impending shutdown can allow the operator to alert all users of the gen-set problem so that they can power down their electrical equipment in an orderly manner, rather than suffer from a sudden power loss. Therefore, a gen-set using a diagnostics system that monitors and reports degradation level in addition to failure is likely to be less disruptive when a problem does develop.

In addition, the required onboard instruments can provide an indication of the present condition of certain gen-set systems, but they must be manually read by the operator at different points in time if any trends are to be discovered. For example, one-time readings of engine temperature and fuel level may show both to be within acceptable limits. Multiple readings are required to determine if these values are changing over time, and the quantity of rates of change. By discovering undesirable trends in the measured parameters, problems can often be identified at an early stage of development and fixed before they threaten the operability of the equipment. 
Unfortunately, multiple readings made manually by the gen-set operator may interrupt other duties. If these readings are made automatically, the trends of many parameters can be established and displayed on command, or automatically displayed. A fully automated diagnostic system could include means of alerting the gen-set operator of an unusual trend that is indicative of a serious problem. Means of alerting the operator could include lights, sounds, or could even include a remote paging system that "calls" the operator whenever the diagnostic system discovers a problem.

Section 3.28.1.4.3 of PD-6115-0115 requires that "The generator control system shall incorporate a predictive maintenance capability, which will prognosticate gen-set failures to the operator to the LRU as defined by the maintenance concept." It further specifies that both D\&P systems shall interface with the Interactive Electronic Technical Manual (IETM). A main function of the prognostic system is to estimate and display the remaining life of wear items such as

- oil

- air filter

- fuel filter

- belt

- injector

- oil filter

Each of these capabilities was considered for possible application to 5- to 60-kW gen-sets and is discussed below.

Oil life remaining

It is important to monitor the condition of all fluids used by the gen-set. The Army Oil Analysis Program (AOAP) has been developed to determine when oil and hydraulic fluids should be changed and to recommend when equipment maintenance should be done to prevent major equipment failure. Note that this preventive maintenance initiative emphasizes the importance of having participants submit accurate records (serial numbers, odometer readings, etc.) with their oil samples. Thus, it is thought that this program is sufficient to track the condition of oil used by the gen-sets, and it is probably unnecessary to incorporate an onboard D\&P capability specifically for this purpose.

Air filter life remaining

The condition of the air filter (air cleaner) can be visually determined by a quick and simple maintenance procedure. An air restriction indicator is also provided on the air cleaner assembly housing and displays red when the air cleaner element should be serviced. It is thought that the restriction indicator provides sufficient diagnostics and, because the replacement of the air cleaner is relatively simple, an onboard prognostic method is unnecessary.

Fuel filter life remaining

The condition of a fuel filter is vital to the correct functioning of the engine. A significant number of fuel system problems have been documented; therefore, reasonable attention should be directed at improving the level of monitoring of this important system. The development and/or application of a technique for fuel filter condition and remaining life assessment can likely minimize unexpected fuel filter problems and may be useful in estimating the remaining life of the filter.

Figure 8.1 is a block diagram of the fuel system for a 10-kW TQG. Two fuel filters plus a fuel filter/water separator are employed to ensure that clean fuel reaches the injection pumps and 
injectors. Fuel is moved by an auxiliary fuel pump, a transfer pump, and then by the injector pumps.

One method for estimating the level of fuel filter plugging would be to monitor the pressure drop across the filter for a known fuel flow rate through the filter. The pressure drop may be measured directly by pressure sensors on both sides (upstream and downstream) of the filter, while the flow rate can be measured directly with a flow sensor on one side of the filter. The flow rate may also be indirectly determined from the rate of change in the fuel tank level measurement. The magnitude of fuel filter plugging can then be estimated by a mathematical equation based on the relationship between the three variables (percent plugging, pressure drop, and flow rate). This relationship must be predetermined through testing (e.g., in a lab) on similar fuel filters having known levels of plugging.

The degradation rate (rate of plugging) can then be determined by making multiple plugging measurements as described above and determining the change in plugging per unit time. It is important to detect any changes in degradation rate that may occur during operation, especially if the degradation rate suddenly increases (e.g., due to dirty fuel).

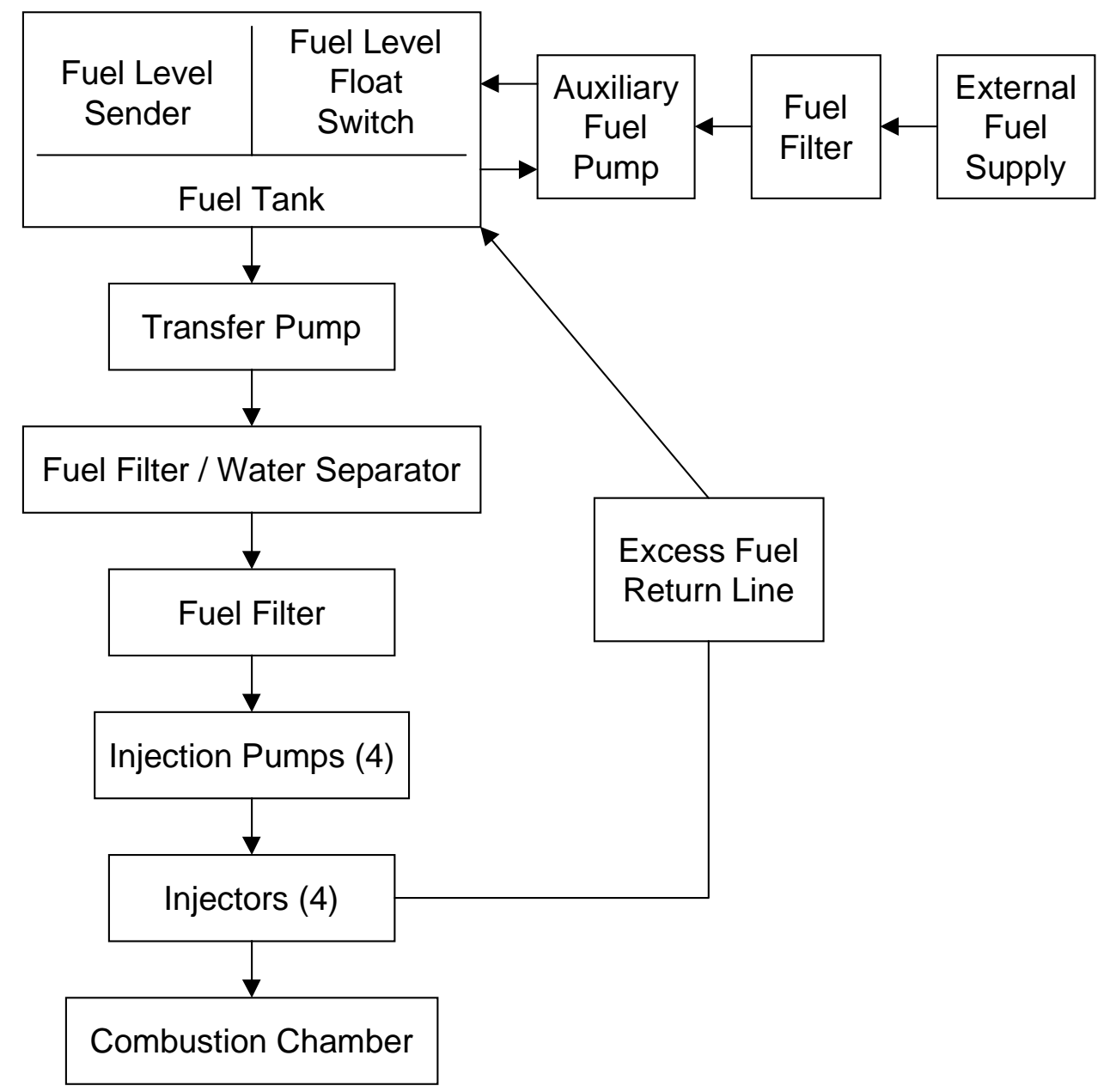

Fig. 8.1. Block diagram of the fuel system for a 10-kW TQG set. Source: Redrawn from Army TM 9-6115- 642-10. 
The remaining life of the filter can then be estimated by an additional mathematical equation that considers three variables: the present level of plugging, the degradation rate (plugging rate), and the failure point (plugging level for a failed filter). It is important to realize that the remaining life calculation is only an estimate, and its accuracy is largely determined by the accuracy of the variables that are used in the equation.

Finally, for fuel systems employing electric fuel pumps, it is likely that fuel filter plugging information can be detected in the fuel pump electrical signatures. Related testing by ORNL has shown that dirty air filters can be detected by monitoring fan running load and motor speedboth of which can be determined from the fan motor current signatures. Thus, an ESA-based method might be applicable for diagnosing problems in both fuel pumps and fuel filters.

\section{Belt life remaining}

Another important component in a TQG is the fan belt. The fan belt drives the fan, water pump, and battery-charging alternator. A broken fan belt halts the operation of these components. The condition and remaining life of the fan belt is thus an important issue, and its condition should be at least periodically checked. Obvious belt problems can include worn or frayed appearance and excessive looseness. While it seems that belt condition could be determined relatively easily through a visual inspection, criteria should be followed for deciding whether the belt is too worn or too loose. A measurement of belt condition, using a sensor to determine looseness and wear, can provide a quantified measurement that can be used to determine when the belt should be replaced.

The placement of an accelerometer on a sheave bearing housing can be beneficial for several reasons. The information obtained from a single accelerometer at this location can include belt condition information and likely will also include information related to engine health. Data from the accelerometer could be automatically analyzed and then displayed on the gen-set control panel.

\section{Injector life remaining}

Fuel spraying through the injector may produce acoustic or ultrasonic signals that might be detected, analyzed, and used to detect injector plugging. This diagnostic method would require considerable development and would likely be difficult to apply due to the high vibration environment where measurements would be made. A predominant fuel injector problem is physical damage to the injector rubber boot, and no monitoring system is presently suggested to detect this specific problem. Thus, at least for now, fuel injector condition may be best determined via periodic inspection rather than by an onboard system. If electronic fuel injectors are used; however, ESA techniques should be explored. ESA investigations at ORNL on automotive electrically activated fuel injectors have produced encouraging results.

\section{Oil filter life remaining}

The oil filter, like the air filter, is subject to plugging due to the accumulation of dirt and/or other impurities. While the air filter (air cleaner) is relatively easy to inspect, the oil filter is more difficult to inspect for accumulated debris. In a similar manner to the fuel filter, the oil filter could also be monitored using pressure sensors installed on both sides of the filter. It appears that this would probably be unnecessary as long as the oil filter was replaced according to an established periodic schedule. 


\subsection{ANALYSIS OF GEN-SET MAINTENANCE RECORDS}

Gen-sets are complex devices. For example, a 10-kW TQG is comprised of more than 400 replaceable parts. They operate in harsh environments and are subject to mechanical shock while being loaded, unloaded, and transported to and from their deployed sites. Thus, it is not surprising that over time, they experience failures from a large variety of causes. To better understand the magnitude and variety of these failures, a quick review was made of a database consisting of 10,358 gen-set maintenance events at Fort Hood and Fort Bragg. The database included descriptions of scheduled (preventative) maintenance and unscheduled (corrective) maintenance activities. While a comprehensive review of this database is beyond the scope of this project, the limited review was useful in identifying a large list of specific reasons why maintenance was performed on these units. Those reasons are listed in Appendix 8-B.

Gen-set maintenance actions were broken into three categories representing three major drivers. Figure 8.2 shows the distribution of maintenance actions in the three driver categories that are further described below.

Scheduled Maintenance (30\%)-Scheduled maintenance is preventative maintenance performed at regular intervals (e.g., annual, semiannual, etc.) It also includes scheduled tests such as those performed as part of the AOAP.

Compliance with Safety Bulletins (15\%)-These maintenance activities are performed in response to an issued bulletin such as a Safety of Use Message (SOUM). Four SOUMs have been issued pertaining to TQGs:

- Grounding Connection on 15-, 30-, 60-kW Power Unit/Power Plants

- Leaking Fuel Lines on 5- and 10-kW TQGs

- Frayed Wires on 5- and 10-kW TQGs

- Overload of Convenience Outlet Receptacles (all TQGs)

Unscheduled Maintenance (55\%)-Most maintenance activities are repairs or replacements of loose, missing, damaged, or failed parts. The effective application of onboard D\&P can minimize

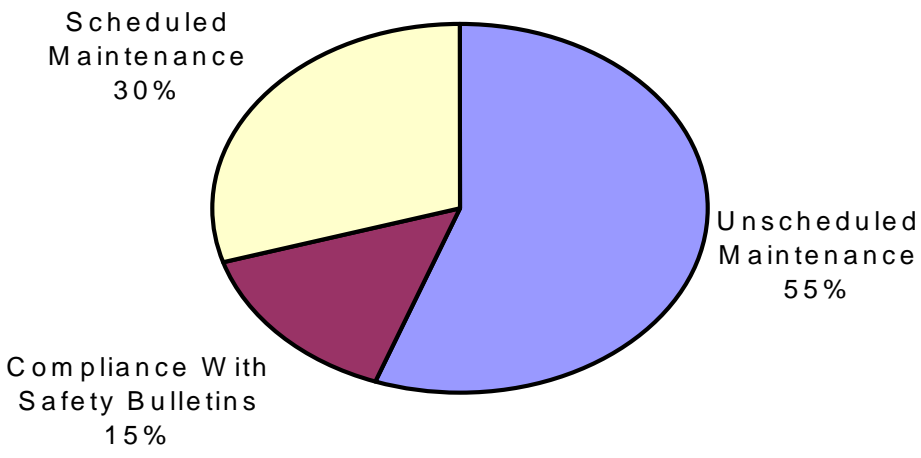

Fig. 8.2. Distribution of maintenance drivers for 10,358 gen-set maintenance activities at Fort Bragg and Fort Hood. Most maintenance is unscheduled. 
many of these problems and thus lower the number of unscheduled maintenance activities. Many problems are not suitable for D\&P and are better left up to periodic inspections. Table 8.1 shows examples of several specific problems noted in the database and whether each problem was judged to be a candidate for D\&P, a design improvement, or neither.

\subsection{WETSTACKING}

According to the PM-MEP Internet site, the majority of TQG maintenance problems (60 to $70 \%$ ) are a result of a problem called "wetstacking." Wetstacking is defined as "...the buildup of unburned diesel fuel and carbon residues in the engine and exhaust system of diesel engines..." The primary cause of wetstacking is running the gen-set in an underloaded condition. When underloaded (relative to its rated output), the diesel engine runs cooler, rougher, and with increased vibration. PM-MEP recommends that a gen-set be operated above $50 \%$, preferably $70 \%$ or higher of its rated output. This will reduce the wetstacking problem and improve the

Table 8.1. Examples of specific gen-set problems and whether they are candidates for D\&P or design improvements

\begin{tabular}{|c|c|c|c|}
\hline $\begin{array}{c}\text { Example of } \\
\text { specific problem }\end{array}$ & $\begin{array}{l}\text { Candidate } \\
\text { for D\&P } \\
\text { methods? }\end{array}$ & $\begin{array}{l}\text { Candidate } \\
\text { for } \\
\text { improved } \\
\text { design? }\end{array}$ & Comments \\
\hline Broken fan belt & Yes & Maybe & $\begin{array}{l}\text { D\&P could be used to detect belt } \\
\text { degradation and estimate } \\
\text { remaining life. }\end{array}$ \\
\hline Dead battery & Yes & Maybe & $\begin{array}{l}\text { Onboard battery tester may } \\
\text { detect weak batteries and } \\
\text { minimize unexpected battery } \\
\text { failures. }\end{array}$ \\
\hline $\begin{array}{l}\text { Deteriorated resilient mounts } \\
\text { (engine, alternator, generator) }\end{array}$ & No & Yes & $\begin{array}{l}\text { New designs may increase } \\
\text { useful life and minimize } \\
\text { required maintenance. }\end{array}$ \\
\hline $\begin{array}{l}\text { Loose or broken bolts and } \\
\text { screws }\end{array}$ & No & No & $\begin{array}{l}\text { Minimizing vibration or use of } \\
\text { thread-locking glues may mini- } \\
\text { mize loose fasteners. }\end{array}$ \\
\hline $\begin{array}{l}\text { Fuel pump runs intermittently or } \\
\text { fails unexpectedly }\end{array}$ & Yes & Maybe & $\begin{array}{l}\text { D\&P could be used to detect fuel } \\
\text { pump degradation and estimate } \\
\text { remaining life. }\end{array}$ \\
\hline $\begin{array}{l}\text { Failure of low oil pressure } \\
\text { switch due to broken wires }\end{array}$ & No & Yes & $\begin{array}{l}\text { Broken wires may result from } \\
\text { repeated bending due to vibra- } \\
\text { tion or from rubbing against } \\
\text { adjacent surfaces. }\end{array}$ \\
\hline $\begin{array}{l}\text { Worn dipstick seal (allowing oil } \\
\text { leakage) }\end{array}$ & No & Yes & $\begin{array}{l}\text { Improved seal materials should } \\
\text { lengthen life span and minimize } \\
\text { oil leakage. }\end{array}$ \\
\hline $\begin{array}{l}\text { Faulty readings from meters } \\
\text { and gages }\end{array}$ & Yes & Yes & $\begin{array}{l}\text { Improved meters and gages may } \\
\text { be needed that are self- } \\
\text { calibrating and self-diagnosing. }\end{array}$ \\
\hline
\end{tabular}


reliability of the gen-sets. Earlier recommendations (see Chap. 6) include rating gen-sets with a minimum power level at which wetstacking is not likely to occur.

One additional approach to minimizing the frequent occurrences of wetstacking would be to develop a wetstacking monitor and warning system that would alert the user to conditions that can lead to this problem. Several indicators are already available on the gen-set to monitor key parameters such as engine (coolant) temperature, current (or percent rated current), and percent rated power. Signals already sent to these meters could be further processed by the D\&P system and used to calculate a "wetstacking factor." The wetstacking factor could be continually displayed by a "wetstacking indicator" or, when a preset threshold is exceeded, to illuminate a "wetstacking conditions present" light on the control panel. This warning could also be transmitted to someone remotely via the paging method previously described. For the purpose of determining whether gen-sets are being used efficiently, the wetstacking factor could be stored and trended over time for later analysis.

\subsection{MAINTENANCE COSTS}

Annual maintenance costs for Army TQGs in the 5-kW through $60-\mathrm{kW}$ range were obtained, adjusted to 1999 dollars using the consumer price index, and shown in Table 8.2, together with the total number of units in each power level. The table shows that over $\$ 6 \mathrm{M}$ is spent annually maintaining Army TQGs.

These numbers obviously do not include intangible costs such as those incurred when a mission cannot be fully accomplished due to a lack of electrical power resulting from an unexpected gen-set failure in the field.

Table 8.2. Approximate maintenance costs for Army TQGs (5-60 kW)

\begin{tabular}{|c|c|c|c|}
\hline $\begin{array}{c}\text { Gen-set size } \\
(\mathrm{kW})\end{array}$ & $\begin{array}{c}\text { Annual maintenance } \\
\text { cost per unit } \\
(\$)\end{array}$ & $\begin{array}{c}\text { Number of } \\
\text { Army TQGs }\end{array}$ & $\begin{array}{c}\text { Total annual cost for this } \\
\text { size class } \\
(\$ \mathrm{M})\end{array}$ \\
\hline 5 & 504.31 & 4556 & 2.3 \\
\hline 10 & 484.62 & 3916 & 1.9 \\
\hline 15 & 591.13 & 1311 & 0.8 \\
\hline 30 & 534.29 & 1285 & 0.7 \\
\hline 60 & 638.45 & 898 & 0.6 \\
\hline Total & & & 6.2 \\
\hline
\end{tabular}

\subsection{RECOMMENDATIONS FOR NEW GEN-SET D\&P}

Due to the unavailability of a commercial D\&P system that meets the needs of new gen-sets, a D\&P system should be developed. Based on reviews of technical documents and available failure records, there are many opportunities for cost-effective application of D\&P methods and technologies on gen-sets in the medium power range. A D\&P system can be incorporated on a new gen-set at one of three levels:

1. Minimal incorporation-Data acquisition and display functions are onboard the gen-set. Data analysis and D\&P functions are provided by a portable (e.g., laptop) computer system that is 
separate from the gen-set. The portable computer is periodically brought to the location of the gen-set to extract the raw data and to analyze, diagnose, and display the condition and remaining life of all critical gen-set components.

2. Moderate incorporation-Data acquisition and display functions are onboard the gen-set. A minimal number of data analysis and diagnostics functions are also provided onboard and are linked to simple displays (e.g., indicator lamps) that identify the general condition of a few selected critical components. The majority of the data analysis and diagnostics is still performed by a portable computer. All prognostics functions are performed by the portable computer.

3. Total incorporation-All data acquisition and D\&P functions are performed onboard the genset. A rugged flat-panel display is provided on the gen-set for display of signal levels, component condition and remaining life, alphanumeric messages, and other gen-set related information (e.g., maintenance instructions).

A comparison chart showing the pros and cons of these three levels of D\&P incorporation is provided in Table 8.3.

While the relatively low cost of the minimal D\&P incorporation level is attractive, this approach to gen-set D\&P is not recommended because of the high probability that many component degradations and incipient failures will not be discovered on a timely basis, due to the dependence on a person to periodically extract gen-set data and perform all D\&P analyses. The overall effectiveness of the minimal and moderate D\&P integration levels will be determined in part by how quickly a given component failure mode develops from the point of initial detection to the actual failure. For example, if a particular failure mode evolves quickly, and the D\&P analyses are performed infrequently, the failure is more likely to occur by this approach than if an onboard D\&P system were used (as is utilized in the total incorporation level).

When effectively implemented, a gen-set D\&P system is expected to provide several significant benefits, including

- extended overhaul intervals

- minimized or eliminated unexpected breakdowns

- improved maintenance efficiency

- improved equipment reliability and availability

- reduced maintenance costs

- reduced total costs of ownership (over the life-span of the equipment)

- accurate estimations of needed spare parts and maintenance personnel

The main detriment associated with a D\&P system is its initial development cost. In addition, the added complexity of an onboard D\&P system means there is "more to go wrong," although the D\&P system can be designed to be rugged, weather resistant, etc., to minimize these problems. Finally, there is always the potential for developing a high confidence in the D\&P system, much as we develop a confidence in electric power, transportation equipment, etc. With this confidence may also come an exaggerated sense of security and dependency that can magnify the inconvenience and disruption when (not if) the D\&P system fails to detect a problem or identifies a problem that is not present. Most D\&P systems are based on imperfect relationships between monitored parameters and actual mechanical and electrical events and therefore cannot be $100 \%$ reliable. 
Table 8.3. Comparison of three levels of incorporation of D\&P technologies in new gen-sets

\begin{tabular}{|c|c|c|}
\hline $\begin{array}{c}\text { D\&P } \\
\text { incorporation } \\
\text { level }\end{array}$ & Advantages (pros) & Disadvantages (cons) \\
\hline Minimal & $\begin{array}{l}\text { 1. The minimal incorporation level } \\
\text { requires the least onboard computing } \\
\text { and display capabilities, and is thus } \\
\text { the least complex and least } \\
\text { expensive (cost per gen-set) option. }\end{array}$ & $\begin{array}{l}\text { 1. The condition and remaining life of } \\
\text { many gen-set components will be known } \\
\text { only at irregular intervals that are based } \\
\text { on the availability of the gen-set D\&P } \\
\text { portable computer and the person oper- } \\
\text { ating it. Thus, this level offers the least } \\
\text { capability to avoid unexpected failures } \\
\text { and unscheduled maintenance. This } \\
\text { level also requires the most interaction } \\
\text { time between the human and the gen- } \\
\text { set. } \\
\text { 2. By sharing one D\&P computer } \\
\text { between many gen-sets, the possibility } \\
\text { exists for confusion between gen-set } \\
\text { data sets. As a result, gen-set problems } \\
\text { may be misdiagnosed or undetected. }\end{array}$ \\
\hline Moderate & $\begin{array}{l}\text { 1. The moderate incorporation level } \\
\text { is a compromise (in complexity and } \\
\text { cost) between the minimal and total } \\
\text { incorporation levels. When compared } \\
\text { to the minimal level, a greater level of } \\
\text { gen-set condition information is avail- } \\
\text { able onboard. }\end{array}$ & $\begin{array}{l}\text { 1. While the condition and remaining life } \\
\text { of a few gen-set components will be } \\
\text { known on a timely basis (from onboard } \\
\text { displays), the condition and remaining } \\
\text { life of many components will still be } \\
\text { unknown until the gen-set D\&P portable } \\
\text { computer is utilized. This level requires } \\
\text { less interaction time between the human } \\
\text { and the gen-set than the minimal level, } \\
\text { but still requires considerably more } \\
\text { interaction time than the total incorpora- } \\
\text { tion level. } \\
\text { 2. By sharing one D\&P computer } \\
\text { between many gen-sets, the possibility } \\
\text { still exists for confusion between gen-set } \\
\text { data sets. As a result, gen-set problems } \\
\text { may be misdiagnosed or undetected. }\end{array}$ \\
\hline Total & $\begin{array}{l}\text { 1. The total incorporation level pro- } \\
\text { vides the onboard means to detect } \\
\text { major gen-set degradations and } \\
\text { incipient failures on a timely basis, } \\
\text { thus offering the greatest capability to } \\
\text { avoid unexpected failures, and } \\
\text { unscheduled maintenance. All D\&P } \\
\text { functions are automated and dis- } \\
\text { played efficiently using a flat-panel } \\
\text { computer display. This level requires } \\
\text { the least interaction time between the } \\
\text { human and the gen-set. }\end{array}$ & $\begin{array}{l}\text { 1. The total incorporation level requires } \\
\text { the most onboard computing and display } \\
\text { capabilities and is thus the most com- } \\
\text { plex and most expensive (cost per gen- } \\
\text { set) option; however, these costs are } \\
\text { expected to be at least partially offset by } \\
\text { the timeliness of the D\&P information } \\
\text { and the prevention of additional unex- } \\
\text { pected failures. }\end{array}$ \\
\hline
\end{tabular}


- It is recommended that the D\&P system be designed to include moderate to total incorporation. The "best" approach will be decided after the costs of these two approaches are determined through further testing, development, and application of D\&P methods and technologies.

Due to the unavailability of a commercial, ready-to-use gen-set D\&P system, such a system will need to be developed. This general sequence of efforts is necessary for the development of an effective D\&P system:

1. Gain an understanding of the failure modes and causes of the monitored equipment.

2. Identify measurable parameters relevant to selected failure modes.

3. Specify and install sensors having adequate sensitivity and dynamic range for the parameters of interest.

4. Acquire data consistently over time with sufficient speed and resolution.

5. Develop and implement data analysis methods to extract meaningful data characteristics (e.g., frequencies, amplitudes, etc.).

6. Establish relationships between data characteristics and equipment (including subcomponent) condition.

7. Determine equipment condition solely from an analysis of acquired data characteristics (diagnostics).

8. Trend data characteristics over time, and develop prediction algorithms based on degradation rates.

9. Extrapolate trends in data characteristics beyond the present to predict future behavior (prognostics).

The most important product of these efforts is the knowledge of how to relate parameter-specific "signatures" to the condition of components within the monitored equipment. Using COTS hardware (sensors, signal processors, etc.), this knowledge can be implemented by algorithms that are programmed into an easy-to-use system. With continued use of the system, the algorithms should be refined to always utilize the best relationships between the acquired data and the known condition of the monitored equipment. Any changes (in hardware or software) should be made by "qualified personnel only" to protect the integrity of the D\&P system. These changes could be made either at a maintenance depot or in the field

Many gen-set parameters can provide potentially useful diagnostic information. Most of these parameters will already be monitored as a means of ensuring that the gen-set delivers electrical power with the desired characteristics and at a level that is consistent with its capabilities and to ensure that the gen-set is being operated safely. Whether monitored manually, or via an automated system, these parameters can provide important information to the user that is relevant to the safe, reliable operation of the gen-set.

Due to the large number of measurable parameters, good judgment should be exercised in selecting the most important ones. The parameters should be selected based on two major factors:

1. the importance to establishing and verifying the desired electrical power characteristics of the gen-set and

2. the sensitivity to known degradation and failure modes of key onboard components and systems. 
For components that rarely fail, or those that can be easily replaced in the field, D\&P methods may not be a cost-effective option. Likewise, as discussed in this report, it may be more appropriate to improve the reliability of certain components through improved designs rather than through D\&P. For those components and systems where reliability is critical to the functioning of the gen-set, and where field repairs are not practical, D\&P methods can provide valuable insight into component condition and expected remaining life. Repairs of these components can then be scheduled for a time when the gen-set is not needed, and when spare parts and maintenance personnel are readily available.

- Based on knowledge of parameters that are presently monitored on existing TQGs, a review of available failure records, and discussions with CECOM, it is recommended that several but not all-available parameters be monitored for their importance in D\&P of new gen-sets. Table $\mathbf{8 . 4}$ provides an initial listing of those parameters that should be included in the D\&P system. The final list of monitored parameters will be determined during the prototyping of the new gen-sets.

Indicators should be provided as appropriate to allow for simultaneous viewing of several selected parameters such as voltage for each phase, current for each phase, etc. Warnings should be given (visual, audible) when values for these parameters fall outside the recommended range. In addition to an "emergency stop" function, the following parameters should also be used to protect the gen-set, the loads they power, and nearby people:

- engine overspeed

- low oil pressure

- undervoltage

Table 8.4. Parameters that should be Included in a gen-set D\&P system

\begin{tabular}{|l|l|}
\hline \multicolumn{1}{|c|}{ Parameter } & \multicolumn{1}{c|}{ Importance } \\
\hline Lube oil temperature and pressure & Engine protection and diagnostics \\
\hline Fuel level and rate of consumption & Remaining availability of fuel \\
\hline Engine running-time & Overall measure of gen-set service wear \\
\hline $\begin{array}{l}\text { Output voltage: all phases (line to neutral) } \\
\text { and average }\end{array}$ & Critical characteristic of delivered power \\
\hline $\begin{array}{l}\text { Output current: all phases (line to neutral) and } \\
\text { average }\end{array}$ & Magnitude and balance of connected loads \\
\hline Power factor (all phases) & Electrical efficiency, indicator of load behavior \\
\hline Real power (all phases, and total) & Electrical efficiency, indicator of load behavior \\
\hline Apparent power (all phases and total) & Electrical efficiency, indicator of load behavior \\
\hline Coolant temperature & Engine protection and diagnostics \\
\hline Coolant level & Remaining availability of coolant \\
\hline Contactor status & Verifies correct functioning of gen-set \\
\hline Voltage harmonics & Critical characteristic of delivered power \\
\hline Engine temperature & Engine protection and diagnostics \\
\hline Battery voltage and charging status & Battery condition and availability \\
\hline Percent rated power & Wetstacking indicator \\
\hline Engine speed & Engine protection and diagnostics \\
\hline Exhaust temperature & Engine protection and diagnostics \\
\hline Output frequency & Critical characteristic of delivered power \\
\hline
\end{tabular}


- short circuit (high current)

- reverse power

- high coolant temperature

- engine high temperature

- low fuel level

- overvoltage

- overload (high current)

- ground fault (ground fault leakage current)

- incorrect (high or low) output frequency

- low coolant level

The signals displayed by the indicating instruments and monitored by the protection devices should be further analyzed where applicable for additional useful diagnostic information and especially for trends that may provide early indications of impending problems. Figure 8.3 shows two examples of this approach.

Present TQGs utilize a "battle-short" switch to ensure continued gen-set operations under emergency conditions. The battle-short switch is used to override all safety (protection) devices except the short circuit devices and the emergency stop function.

- It is recommended that a similar battle-short switch be provided by the new gen-set that disables the action of the safety parameters listed above (with exception of the short circuit and emergency stop function). It is further recommended that the indication (e.g., displays showing high current, high temperature, etc.) of all parameters still be available so that the user has the ability to monitor the condition of the gen-set, even though the actions of its safety devices have been bypassed.
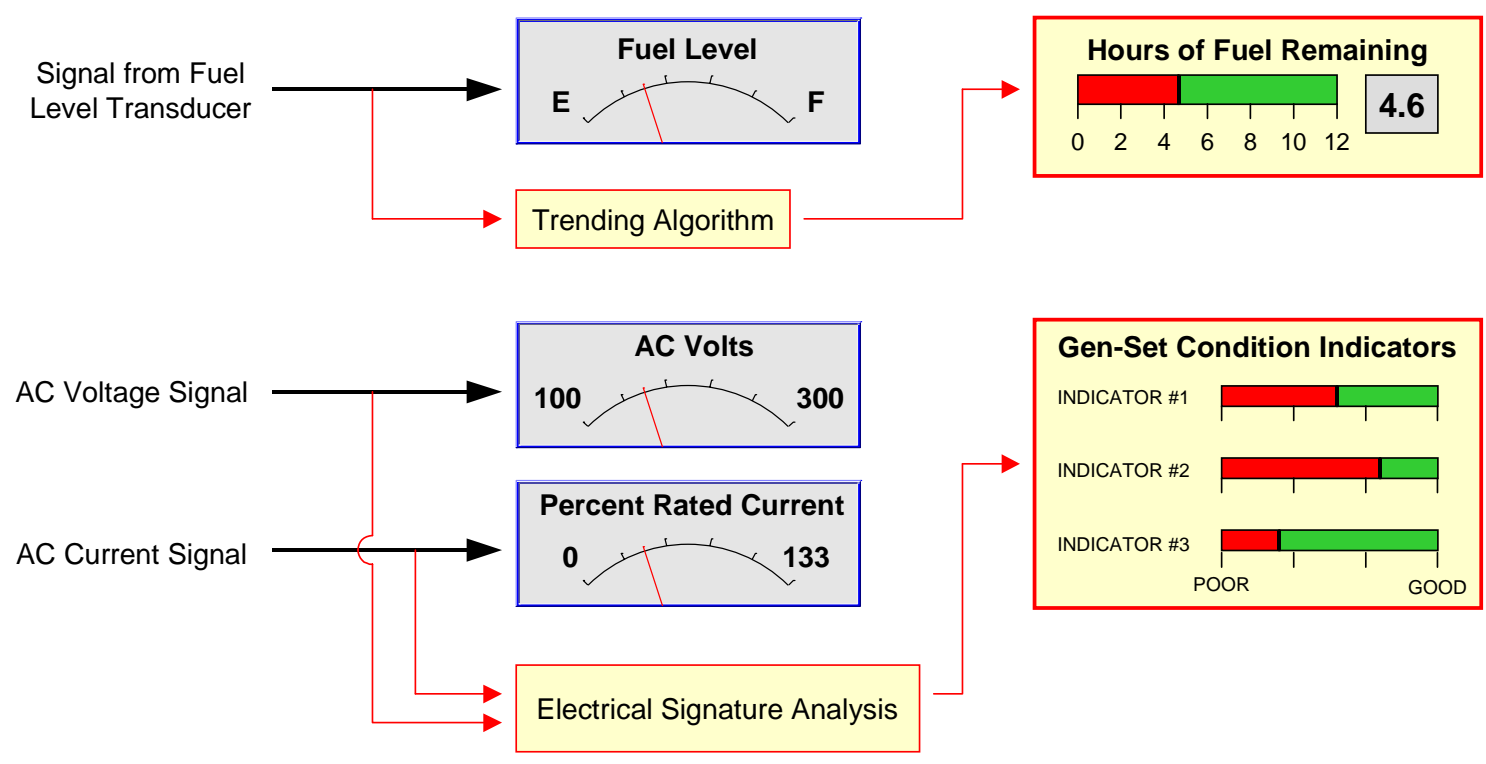

Fig. 8.3. Illustration of how existing signals can be exploited for additional information useful in performing D\&P. 
The D\&P system should always be active, regardless of operating mode. Even when running in battle-short mode, it can be very important to know that a critical component is about to fail. The D\&P system can alert the user to short-term maintenance needs that can be performed during battle-short mode operations. Even if a component failure cannot be prevented, the D\&P system can give valuable early warnings for needed spare parts and maintenance personnel.

\section{Additional D\&P Features}

- We recommend several additional items (described below) be included in the D\&P system for the prototype and evaluated for effectiveness during prototype testing. The final resolution of exactly what is in the D\&P system will depend on the effectiveness of the system and additional input from the military.

In addition to the parameters listed above, new cost-effective D\&P methods should be explored that would improve capabilities to monitor the condition of the following items:

- fuel pumps

- fan belt

- fuel, oil, and air filters

- fuel and oil condition

By detecting degradation and impending failure of these items, maintenance can be performed on a timely basis rather than in response to an unexpected failure during a period when the genset is needed the most and spare parts may not be available. When deemed to be costeffective, and especially when D\&P methods fail to work acceptably, automated monitoring should be replaced by simple maintenance alerts based on pre-established periodic maintenance intervals (e.g., measured in operational hours). These intervals should be based on failure history whenever possible. While this approach may reduce the need for D\&P methods, it is difficult to establish maintenance intervals that are optimal. Replacement of parts and components (overhauls), strictly on a periodic schedule, can often result in unnecessary maintenance.

New detectors should be identified that would detect the presence of leaking fluids, especially fuel. The detectors should provide an "alarm" or other warning when fluid leakage has been detected. Methods for detecting air in fuel lines should also be identified and evaluated. These new methods could minimize the loss of fluids, especially in unattended gen-sets, but would add a little more complexity and cost to the D\&P system.

The D\&P system should be able to sense wetstacking or at least the engine conditions that can lead to this common problem. A warning indication should be provided when wetstacking is detected or when conditions that promote wetstacking occur. The "wetstacking indicator" could provide substantial benefits, and would require very little additional D\&P system complexity or cost because the parameter signals needed for this indicator are going to be monitored anyway, for other purposes.

A system for remote notification that a generator problem or impending problem exists should be investigated. This system could be based on short-range radio frequency (RF) transmission to a small receiver "pager" that is activated by the gen-set when a problem (e.g., low fuel, overheating, etc.) is detected that needs short-term attention. This system could potentially prevent gen-set failures that are quick to develop and would also allow the gen-set to operate reliably with minimal human monitoring. 
The D\&P system should be designed to interface with the IETM. The additional complexity and cost of the D\&P system for this capability will need to be determined.

The reliability of sensors and switches (and associated wiring and quick-disconnects) that have experienced high incidences of failure-such as the fuel level switch, low oil pressure switch, and high-temperature switch-should be improved. Improvements should primarily be in the areas of shock immunity and strain relief and are not expected to add significantly to the cost of the D\&P system.

Finally, the D\&P system should provide a means of quickly verifying the calibration and correct operation of all critical indicators (meters, and gauges) to promote confidence in the instrumentation and to minimize reported "faulty readings." The additional complexity and cost of the D\&P system to provide this new capability is not clear. The costs associated with this improvement should be determined, and then a decision can be made as to its cost-effectiveness.

A strong benefit is gained by integrating the D\&P system with the digital control system due to their similar data requirements; however, the capabilities of the D\&P system would improve greatly from the use of a dedicated computer (processor). While both systems will utilize many of the same sensed parameters, the sample rates, data block size, data storage, and other characteristics of the two systems are vastly different. Due to the potential for malicious intrusion (viruses and other inappropriate programs), access to system software should be restricted to those who are "qualified." Hardware barriers (e.g., key locks) and software barriers (e.g., passwords) should be strongly considered. Hardware and software integrity checks, including anti-virus software, could be utilized if desired.

The D\&P system should be easy to use and should provide easy to interpret displays that do not require an expert to understand. Whether D\&P methods are implemented onboard the genset or by a portable computer, a recommended approach is the VI platform due to its "userfriendly" GUI, versatile display features, and powerful programming capabilities. The VI platform provides the capability to create "virtual displays" that can be viewed on-demand or displayed automatically if problems are detected. If utilized onboard the gen-set, the consolidation of the many required instrument displays into a common, centralized location will save considerable space. The major detriment to an onboard VI system is the initial cost of the computer and display. By utilizing a relatively small display, these costs can be minimized. The additional costs of an onboard D\&P system are expected to be at least partially offset by the timeliness of the D\&P information, which should result in the prevention of additional unexpected failures.

\subsection{REFERENCES}

1. "Purchase Description, Generator Sets, Diesel Fueled, Skid Mounted, Tactical, Quiet, 100/200 kW," PD-6115-0115.

2. http://www.pmmep.org, Internet Site for The Project Manager-Mobile Electric Power.

3. "Power Generation-Setup and Operation-Tactical Quiet Generator (TQG)," Training Videotape, Production 710844, ICN TVT9-312.

4. "Military Standard, Generator Sets, Engine Driven, Methods of Tests and Instructions," MIL-STD-705C. 
5. Military Handbook, Generator Sets, Electrical, Measurement and Instrumentation Methods, MIL-HDBK-705C.

6. Database of 10,358 Generator Set Maintenance Events at Fort Hood and Fort Bragg.

7. Discussions and correspondence with Communications and Electronics Command.

8. http://www.logsa.army.mil/pam700/aoap.htm, Internet Site for the Army Oil Analysis Program.

9. Operator's Manual, Generator Set, Skid Mounted, Tactical Quiet, 10 kW, 60 And $400 \mathrm{~Hz}$, Army TM 9-6115-642-10.

10. H. D. Haynes and C. W. Ayers, Non-Intrusive Monitoring of Electronic Fuel Injectors Using Electrical Signature Analysis (ESA), Lockheed Martin Energy Research Corp., Oak Ridge National Laboratory, 1998. 


\section{Appendix 8-A. BACKGROUND OF D\&P}

\section{A.1 MAINTENANCE PHILOSOPHIES}

Equipment maintenance can be performed according to two general philosophies-preventive maintenance or corrective maintenance. Preventive maintenance can be either periodic or predictive and is performed prior to failure, while corrective maintenance is performed after failure. Corrective maintenance can be very costly and inconvenient depending on the severity of the failure and the time of occurrence. Often, an unexpected failure cannot be fixed immediately due to the unavailability of spare parts and/or trained personnel. Both periodic and predictive maintenance can offer many benefits:

- extended overhaul intervals

- minimized or eliminated unexpected breakdowns

- improved maintenance efficiency

- improved equipment reliability and availability

- reduced maintenance costs

- reduced total costs of ownership (over the life span of the equipment)

- accurate estimations of needed spare parts and maintenance personnel

If a periodic maintenance program is implemented, equipment is serviced at predetermined time intervals (e.g., calendar time, operating time, number of cycles, etc.). If predictive maintenance is performed, equipment is serviced according to equipment condition, which is determined via diagnostic testing. This condition-based maintenance approach, when successful, assures that equipment maintenance is performed when it is needed to prevent unexpected failures, but without the costs incurred from unnecessary maintenance. Under certain scenarios, excessive maintenance can actually degrade equipment quicker than if the equipment was left alone.

To determine condition, detect incipient failures, and predict remaining life of equipment (including equipment subcomponents), the following general method should be followed:

1. Gain an understanding of the failure modes and causes.

2. Identify measurable parameters relevant to selected failure modes.

3. Specify and install sensors having adequate sensitivity and dynamic range for the parameters of interest.

4. Acquire data consistently over time with sufficient speed and resolution.

5. Develop and implement data analysis methods to extract meaningful data characteristics (e.g., frequencies, amplitudes, etc.).

6. Establish relationships between data characteristics and equipment (including subcomponent) condition.

7. Determine equipment condition solely from an analysis of acquired data characteristics (diagnostics).

8. Trend data characteristics over time, and develop prediction algorithms based on degradation rates.

9. Extrapolate trends in data characteristics beyond the present to predict future behavior (prognostics). 


\section{A.2 MEASURABLE PARAMETERS}

Care should be exercised in selecting measurable parameters. For example, when the functionality of a device ceases as a result of the failure of a subcomponent (e.g., a bearing failure preventing a pump from running), the condition and remaining life of the subcomponent should be monitored because it ultimately determines the remaining life of the entire device. Most machines and rotating equipment offer several potentially useful measurable parameters. These parameters can include

- mechanical vibration (e.g., proximity, velocity, acceleration);

- acoustic and ultrasonic noise;

- temperature;

- pressure;

- electrical parameters (voltage, current, power, power quality); and

- viscosity (e.g., of lubricants).

To effectively diagnose problems in monitored equipment, the signals acquired from sensors must be analyzed correctly. For example, an accelerometer is often used to monitor mechanical vibration of a pump, fan, or compressor. The signal provided by the accelerometer transduces vibration into an analog (continuous) voltage waveform. One level of diagnostics could be based on a measurement of the total RMS of the accelerometer signal. An improved diagnostic assessment could be realized by monitoring the details in the vibration signal, rather than simply the RMS magnitude.

These details can be analyzed in the time domain or more effectively in the frequency domain. The frequency spectrum of an accelerometer signal provides a revealing signature of the monitored device that can be used to identify anomalous behavior such as imbalance, damaged bearings, damaged gears, mechanical looseness, and faulty belt drive. Over the years, many relationships have been developed among these degradations and their corresponding vibration signature features.

Often a measured parameter is not fully utilized for its entire information content. A good example of this is motor current. Until about 10 years ago, only the RMS value of an ac motor current signal was typically measured. In this way, motor current was used primarily as a digital, or single value parameter, rather than for its signature. Research conducted by the ORNL has revealed that motor current signatures can be just as informative as vibration signatures. Motor Current Signature Analysis (MCSA) was thus born and continues to be developed to this day. MCSA is now a part of a larger suite of diagnostic technologies called Electrical Signature Analysis (ESA) that can be applied to a wide variety of equipment that utilize motors and generators. The following discussion is provided as an example of the level of detailed information that can be extracted from a measured parameter-in this case, an electrical parameter. The same approach can be followed when analyzing another parameter such as vibration.

\section{A.3 ELECTRICAL SIGNATURE ANALYSIS}

ESA is based on the knowledge that time-dependent load and speed variations occurring throughout an electromechanical system will induce variations in a motor's and/or generator's electrical response. These variations are observed as a change in current (for a motor) or a change in voltage (for a generator). Signal conditioning and signature analysis techniques have been developed for extracting these electrical perturbations and relating them to their source 
and have thus opened a new field for diagnostic innovations. Mission readiness can be ensured by the comprehensive D\&P provided by technologies such as ESA.

ESA techniques have been successfully demonstrated by ORNL in a wide variety of applications:

- material pulverizers

- chilled-water systems

- Army ammunition delivery system

- motor-operated valves (MOVs)

- NASA propellant control valve

- fans and blowers

- Navy fire and seawater pumps

- nylon spinning machines

- consumer hand tools and home appliances

- multiaxis machine tool

- water pumps of various designs

- electric vehicle motors and alternators

- helicopter rotor and gearbox

- aircraft integrated drive generator

- air conditioning systems

- gear boxes

- reproduction machine motors

- vacuum pumps

- centrifuges

- automotive fuel injectors

Several of these applications are now discussed to provide examples of D\&P activities that ORNL has been involved in during the last 15 years.

\section{A.4 APPLICATION OF ESA TO AIRCRAFT COMPONENTS}

The operability and health of aircraft mechanical components can be monitored nonintrusively by analyzing the voltage output from an electrical generator onboard the aircraft. For a turbinedriven rotor aircraft, available generators may include the aircraft systems' power-producing starter/generator and tachometer generators used to monitor turbine and rotor shaft speeds.

To investigate this application of ESA, ORNL acquired generator voltage signals on a Bell Jet Ranger helicopter while the helicopter was operated on the ground but "light on the skids." The voltage signal provided by the helicopter's rotor tachometer generator was analyzed and found to contain a large fundamental frequency indicative of the rotor's speed, as well as several harmonics of this fundamental component. The relative magnitude of these harmonics (e.g., harmonic distortion) was discovered to change with rotor unbalance, which was induced by installing additional mass near the end of one helicopter rotor blade. Although a detailed data analysis is beyond the scope of this document, a strong correlation was discovered between rotor unbalance and harmonic distortion of the generator signal.

In addition, the aircraft's power-producing starter generator was also seen to behave as a sensitive transducer whose signal was influenced by mechanical loads throughout the helicopter's complex gear train. The primary dc voltage provided by the generator was accompanied by a 
smaller, but inherently useful, ac signal component as well. The frequency spectrum of the ac signal content was observed to contain discrete peaks, reflecting several known gear mesh frequencies of the helicopter's transmission.

These preliminary tests demonstrate that significant diagnostic information is available from onboard aircraft generators. Their transducing abilities exceed their recognized functions (e.g., speed monitoring and battery charging) and should be exploited for diagnostic purposes when possible.

\section{A.5 USE OF ESA TO DETECT COMPRESSOR AERODYNAMIC ANOMALIES}

ORNL participated in tests in which rotating stall was induced in a large (1700-hp) axial-flow compressor at the Paducah Gaseous Diffusion Plant in Paducah, Kentucky. Plant personnel knew that this flow phenomenon occurred on several occasions, and it was known to accelerate compressor blade fatigue damage. At the time of this test, the use of motor ammeter readings and equipment-mounted accelerometers had not provided a sensitive and reliable means of detecting this damaging aerodynamic condition. The interest in purposely inducing a rotating stall in an operating process compressor was to determine if this condition could be detected with ESA. For this test, a simple clamp-on current transducer was installed on the motor's ammeter loop located in the control room.

After amplitude demodulation of the raw motor current signal, discrete frequency components were observed in the spectrum at the motor's operating speed and its slip-poles frequency (approximately $30 \mathrm{~Hz}$ and $1 \mathrm{~Hz}$, respectively). When rotating stall was induced, new peaks at 13.5 Hz (fundamental) and $27 \mathrm{~Hz}$ (harmonic) were immediately observed. These peaks remained in the demodulated motor current spectrum until the compressor was allowed to return to normal operation.

This test demonstrated that the motor was a superior transducer for detecting this damaging aerodynamic condition. As a result, several motor-current-based alarm systems were subsequently installed at the plant.

\section{A.6 DEMONSTRATION OF ESA ON A PROTOTYPE FUTURE ARMOR REARM VEHICLE}

The feasibility of using ESA-based D\&P techniques to improve the reliability of Future Armor Rearm Vehicles (FARVs) was demonstrated during a research project funded by the U.S. Army. This project included the selection of components to monitor (conveyor system) acquisition and analysis of ESA test data and the development and demonstration of an automated monitoring system. The automated monitoring system developed during this project featured a computerized VI that acquired, analyzed, displayed, and trended electrical signature information from a conveyer system's motor. The VI successfully differentiated between baseline, belt defect, and chain/sprocket defect conditions and also demonstrated a means of trending and predicting maintenance intervals based on an extrapolation of data trends.

\section{A.7 APPLICATION OF ESA TO AIRCRAFT INTEGRATED DRIVE GENERATORS}

Integrated drive generators (IDGs) on certain commercial aircraft experience complete failure, on average, at a rate of four per year; as many as ten have failed in one year. The causes are seizure and destruction of scavenge, drive pump, and axial gears on the generator's main shaft. Traditional recertification tests do not detect incipient gear failure. A gear set costs $\$ 17,000 ; a$ 
gear unit costs $\$ 250,000$. The capability to predict gear failure or incipient failure represents substantial savings for owners in replacement costs.

IDG units provide power to aircraft $(117 / 208 \mathrm{~V}$ at $400 \mathrm{~Hz})$ for passenger reading lights and galley microwave ovens. To maintain their reliability, effective measures of the onset and levels of gear wear are needed. ORNL has demonstrated both on a test stand and on a jet that ESA techniques provide signature attributes necessary to characterize good and worn gears. The strength of ESA is that current and voltage probes are easy to attach and use for monitoring, with no additional mounting required. Results show that even at extremely low generator loads, ESA provides excellent sensitivity for detecting gear-related problems.

\section{A.8 MOV MOTOR CURRENT SIGNATURES}

To further illustrate ESA, Fig. 8-A.1 provides an example of the amount of information provided by a single electrical parameter. This figure shows the time waveform and frequency spectrum of a conditioned motor current signal from a MOV. By knowing the characteristics of the MOV's internal components, the significance of each feature in the waveform and spectrum can be identified. For example, many discrete frequency peaks are evident in the spectrum that correspond to specific sub-components within the MOV, such as the motor, stem nut, valve stem, stem packing, valve gate, and various gearbox elements (drive sleeve, worm, and worm gear). Any degradation in one of these subcomponents will result in changes in the signature feature(s) associated with that degraded subcomponent.
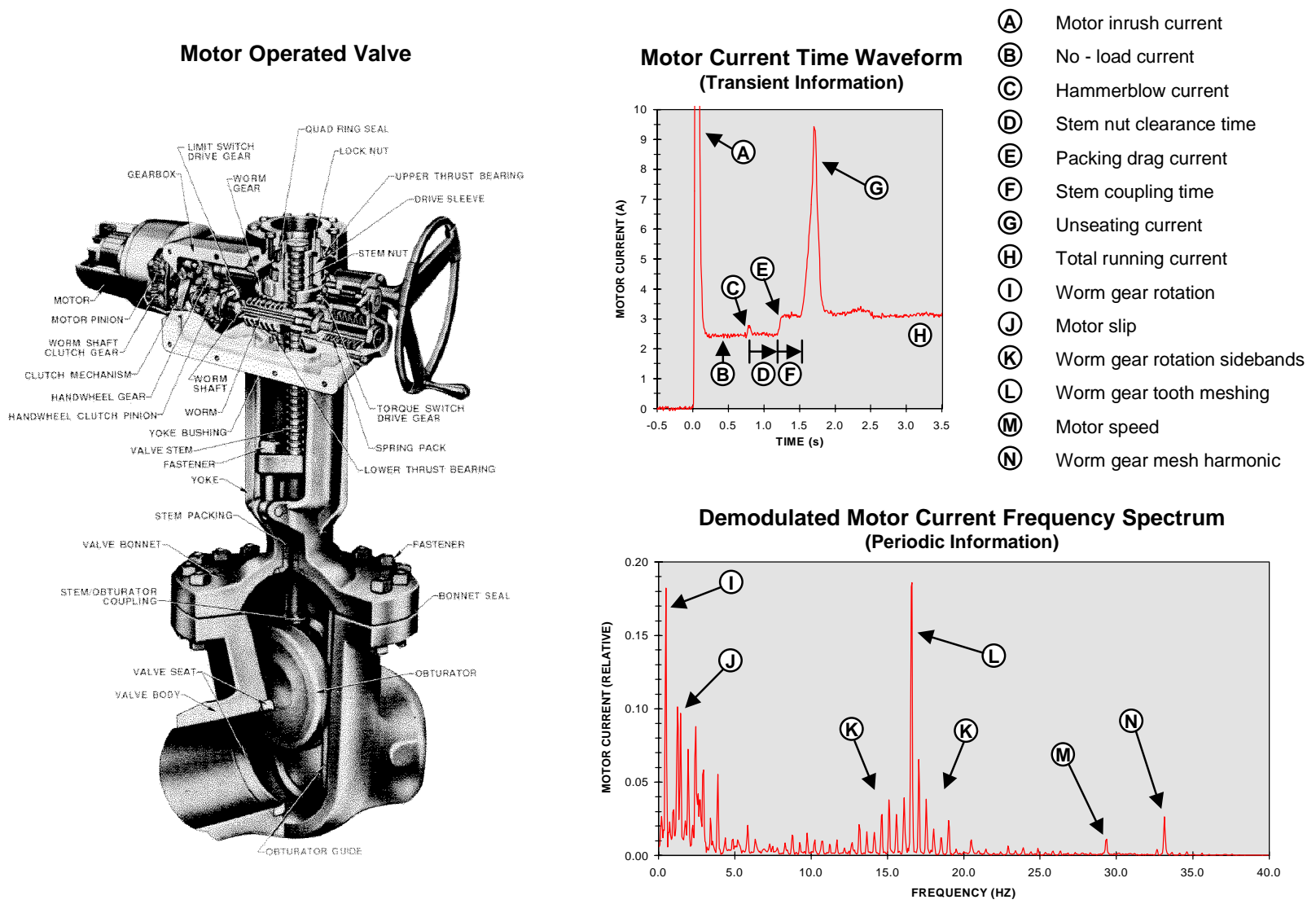

Fig. 8-A.1. Typical motor current signatures for a MOV. 


\section{A.9 COMPARISON BETWEEN VIBRATION ANALYSIS AND ESA}

The previous examples illustrate how an ac induction motor can be effectively used as a transducer for monitoring its own condition as well as the mechanical equipment that it drives. It is equally important to realize that alternators and generators produce voltage signals that also contain diagnostic information. Figure 8-A.2 illustrates a machine built by ORNL to demonstrate the similarity between mechanical vibration, motor current, and generator voltage signatures. The machine includes a small commercially available air compressor and a standard automotive dc generator that are both belt driven by a 1/2-hp ac induction motor.

Figure 8-A.3 (top plot) shows a frequency spectrum of the vibration signal acquired from an accelerometer located on the air compressor during its operation. Vibration frequencies associated with motor, compressor, and generator shaft speeds are detected and from both belt rotations as well. Demodulated motor current signals shown in Fig. 8-A.3 (middle plot) also contain similar frequency components, with the addition of the motor slip-poles frequency.

The frequency spectrum of the conditioned generator signal is shown in Fig. 8-A.3 (bottom plot) and includes many electrical and mechanical event frequencies, thus demonstrating the generator's usefulness as a transducer for equipment condition monitoring. Note that the generator output voltage was ac coupled to filter out the primary dc voltage component, and then low-pass filtered to attenuate the pole-pass frequency and higher frequency components. This process allowed the examination of low-frequency mechanical information in the generator voltage signal. Other signal conditioning methods can be used to extract the higher frequency components that are useful in diagnosing problems in the generator itself.

\section{A.10 PREDICTING FAILURE}

Figure 8-A.4 illustrates that a given piece of equipment can fail to operate due to more than one cause or mode. Furthermore, the rate of degradation can be affected by the operating environment. In Fig. 8-A.4, failure mode (A) under extreme operating conditions is used as an example to show the relative time span that might exist between the times of detection, maintenance, and failure. The time between the point of maintenance and the predicted point of failure may be viewed as a time margin or safety factor.

\section{A.11 PERISTALTIC PUMP PROGNOSTICS}

As an additional example, Fig. 8-A.5 shows a typical peristaltic pump that is similar to those used in oil, chemical, pharmaceutical, food, and wastewater treatment facilities. The pumping

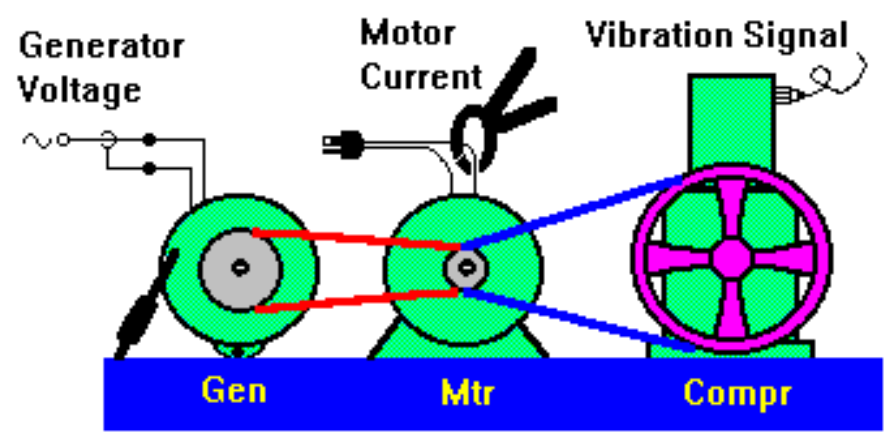

Fig. 8-A.2. Device built by ORNL to demonstrate ESA. 

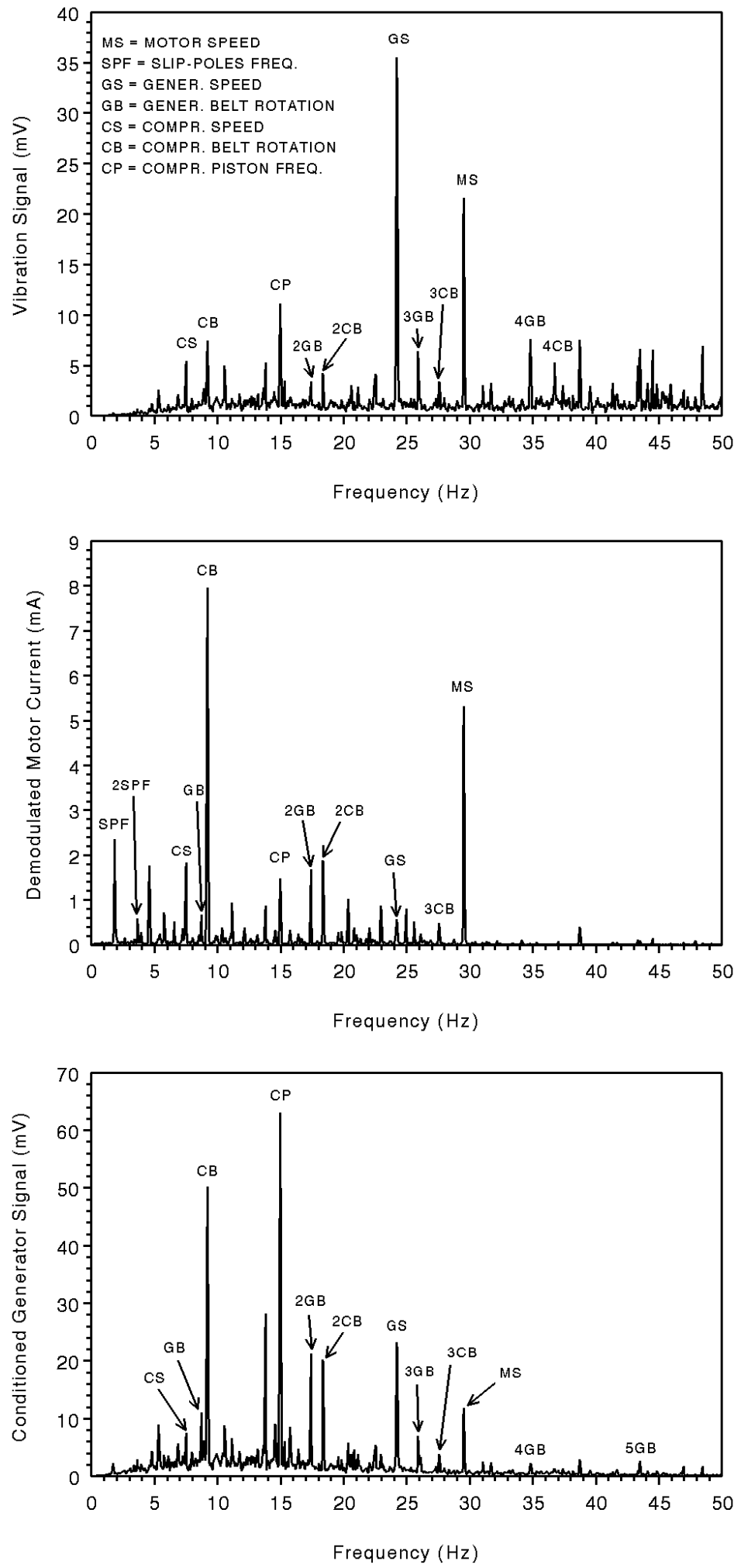

Fig. 8-A.3. Frequency spectra of vibration (top plot), motor current (middle plot), and generator voltage (bottom plot) signals from the device illustrated in Fig. 8-A.1. 


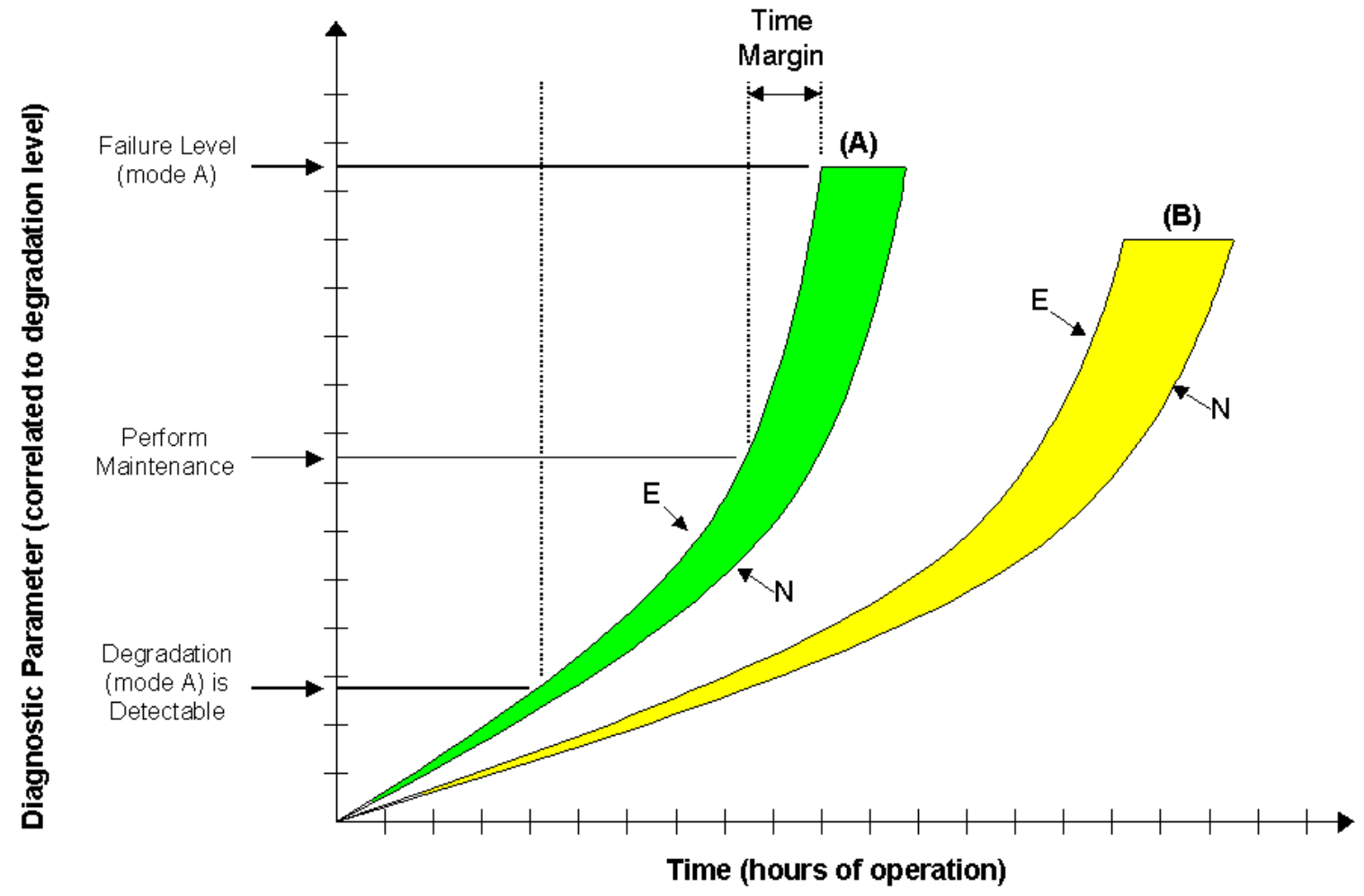

Fig. 8-A.4. Degradation curves for two failure modes, (A) and (B) for a single piece of equipment under normal $(\mathrm{N})$ and extreme $(\mathrm{E})$ operating conditions.

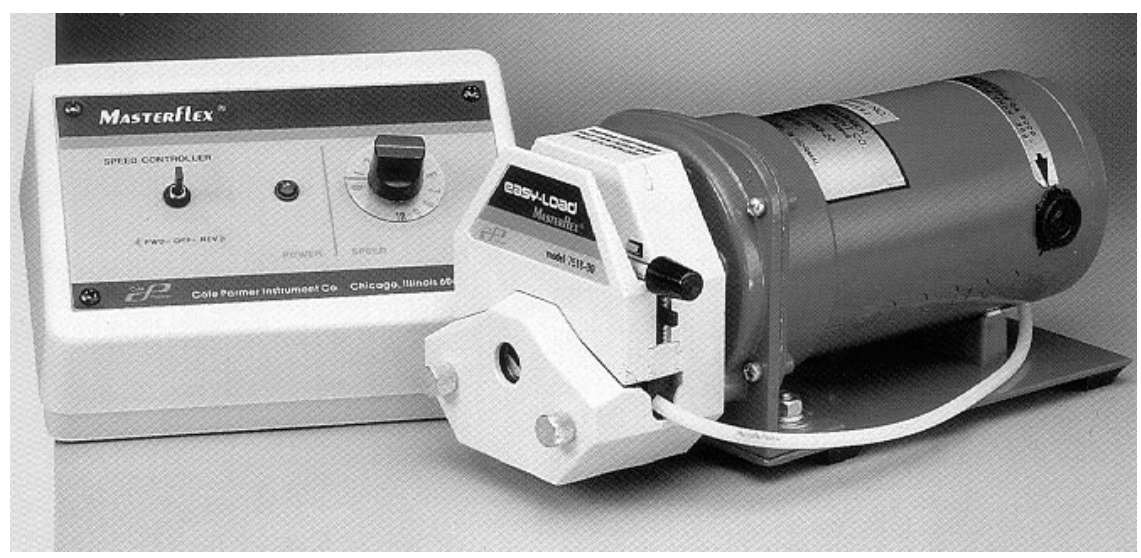

Fig. 8-A.5. Typical variable-speed peristaltic pump (shown with speed controller). 
action is provided by three rollers (for this model) that rotate with the motor shaft to squeeze "packets" of fluid in the direction of flow.

Figure 8-A.6 (upper plot) shows that the motor current spectrum of the peristaltic pump contains a discrete frequency peak at the "roller-pass frequency" (RPF), which reflects the rate at which the tubing, containing the fluid being pumped, is being compressed. The amplitude of the RPF peak reflects the energy needed by the motor to compress the tubing containing the fluid being pumped. As shown in Fig. 8-A.6 (lower plot), the RPF amplitude increases over time. This is in response to the tubing losing its resiliency as it is repeatedly compressed. Eventually, the tubing becomes so stiff that it cracks, resulting in fluid leakage and pump failure. Once the relationship between the RPF and the tubing condition is established, the RPF may now be monitored, referenced to the degradation curve for this failure mode, and used to predict the remaining life of the tubing and peristaltic pump.
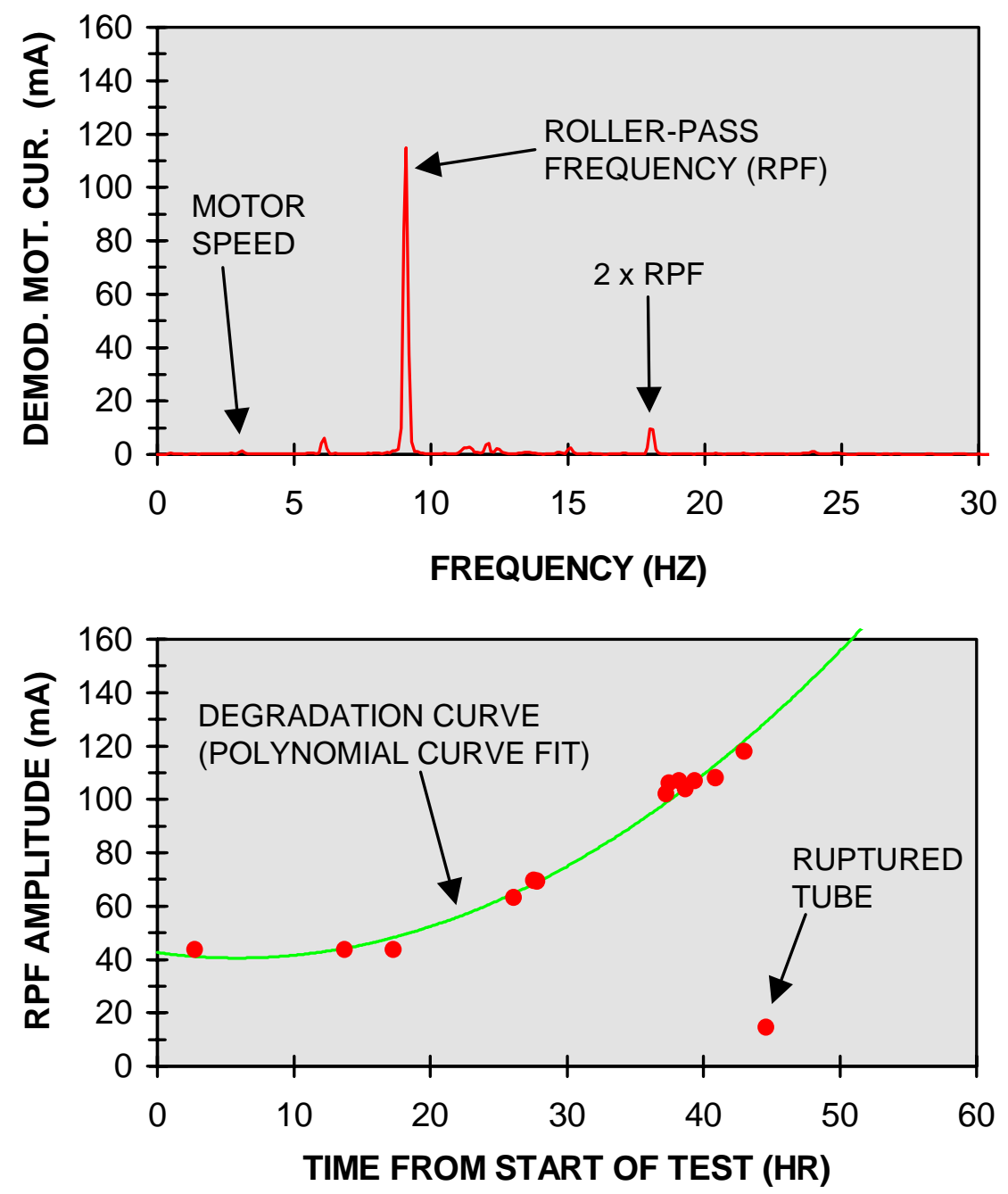

Fig. 8-A.6. Motor current spectrum (top) and RPF trend plot (bottom) of a peristaltic pump. 
8-26 


\section{Appendix 8-B. REVIEW OF MAINTENANCE EVENTS FOR TQGs}

The following are TQG maintenance events for various systems and components.

1. General Engine Problems

- engine will not start

- black smoke coming from exhaust

- engine runs with excessive vibration and/or noise

- engine cannot reach normal speed and power

- engine overheats

- wetstacking observed (classes I, II, and III)

- smoke coming from engine compartment

- excessive oil consumption

2. Fuel System

- fuel leakage from tank drain plug

- fuel leakage from tank filler neck collar (rubber)

- fuel leakage from fuel filter

- dirty fuel filter

- dirty fuel/water separator

- missing fuel filter

- water detected in fuel filter

- fuel leakage from injector

- incorrect injector spray pattern

- injector solenoid boot damage (holes, worn, torn)

- missing injector mounting bolts

- fuel leakage from return line (rubber)

- deteriorated fuel lines

- fuel leakage from fuel pump fitting

- loose fuel pump mounting bolts

- fuel pump runs intermittently or fails

3. Cooling System

- coolant leakage from radiator

- missing radiator reservoir cap

- bent radiator assembly

- coolant leakage from water pump

- coolant leakage from radiator and overflow tank hoses

- missing fan guard

- loose or missing fan guard bolts

- loose or frayed fan belt

- broken fan belt

- bent fan blade

- unusual fan noise

- contaminated coolant

4. Lubrication System

- oil leakage from drain 
- oil leakage from oil filter

- oil leakage from dipstick seal

- missing dipstick

- worn dipstick seal

- incorrect oil used

- contaminated oil

- fuel in oil

- water in oil

5. Exhaust System

- exhaust leakage from muffler

- loose or broken mounting bracket bolts

- exhaust inlet restricted with carbon

- missing exhaust manifold nuts

- missing pipe cover and/or mounting bolts

- broken pipe at mount

6. Battery/Charging

- dead battery

- missing battery

- loose or missing battery holding-brackets and bolts

- missing battery terminal covers

- corroded battery terminals

- terminal burned off

- failure of alternator to charge batteries

- alternator adjusting strap threads stripped

- broken wires

- burnt battery cable

- corroded battery cable

- missing fuse

7. Speed Control

- loose governor linkage nuts and bolts

- governor sticks

- broken throttle cable

8. Engine (other)

- missing air filter housing end cap

- broken air filter housing

- air filter dirty or soaked with oil

- chafing or fraying of heater coil wires

9. Load Terminal

- missing safety clips

- load terminal nut stripped

- chaffed wires

10. General ac Generator Problems

- cannot generate sufficient output voltage 
- excessive vibration

- looses power when load is applied

- shuts down unexpectedly due to over-voltage

- overvoltage blowing out light bulbs

- smoke coming from generator housing

- inability to control ac voltage

- inability to control output frequency

11. Housing

- loose, broken, or missing mounting bolts and screws

- bent hinges, dented doors

- broken convenience receptacle hinge or door

12. Resilient Mounts

- deteriorated or "collapsed" mounts (engine, alternator, generator)

13. General Instrumentation Problems

- sparks and smoke coming from instrument panel

14. Meters/Gages

- faulty readings or failure of ac voltmeter

- faulty readings or failure of ac ammeter

- faulty readings or failure of percent load meter

- faulty readings or failure of battery dc ammeter

- faulty readings or failure of coolant temp gage

- faulty readings or failure of hour meter

- faulty readings or failure of frequency meter

- faulty readings or failure of fuel level gage

- faulty readings or failure of oil pressure gage

15. Switches

- failure of ac circuit interrupter

- failure of fuel level switch (sticking or open circuit)

- failure of low oil pressure switch (broken wires)

- high-temperature switch missing or failure (broken wires)

- broken temperature safety switch

- ignition switch broken or frayed wires

- emergency stop switch broken or knob missing

16. Indicator Lights

- missing light lenses

- broken light bulbs

17. Wiring

- burnt wiring to frequency transducer

- burnt wiring to ground fault interrupter

- burnt main wiring harness

- burnt control box wiring

- burnt wiring to ac convenience receptacle 
8-30 


\section{MATERIALS CONSIDERATIONS}

This chapter addresses the use of lightweight materials in the new gen-sets. Since the frame and structure of the gen-set is a significant contributor to the overall weight, much attention is given to weight reduction in this chapter.

For the next generation of gen-sets, it is likely that the overall weight of the engine, generator, and accessories will be significantly reduced. Consequently, the structural requirements of the frame and the total volume of the system will be decreased. This is a significant opportunity for reducing the weight of the frame and housing. The use of lightweight materials, such as aluminum or composite materials, has the potential to reduce the weight of the overall gen-set even more.

\subsection{DESIGNING WITH COMPOSITE MATERIALS}

Composite materials encompass a wide range of material, performance, and cost characteristics. In general, a composite material consists of a fiber reinforcement combined with a matrix material. There are many different types of fiber reinforcements, resin systems, and manufacturing processes; each contributes to the specific properties of the composite material.

Polymer composites have been widely used for years in the aircraft and aerospace industries because of their high strength-to-weight and stiffness-to-weight ratios. There has been less widespread usage of composite materials in some industries, such as the automotive industry, because the composite materials have not been cost-competitive. Table 9.1 gives a comparison of several common polymer composites with steel and aluminum.

As shown in this comparison, carbon fiber composites and glass fiber composites are 4 to 5 times less dense than steel. The modulus of steel is more closely matched with carbon fiber composites, although the cost of the carbon fiber composites is more than 10 times that of steel ( $>\$ 5 / \mathrm{lb}$ vs $\$ 0.40 / \mathrm{lb}$ raw material cost). Aluminum and glass fiber composites have similar mechanical properties and are more similar in cost $(\$ 0.60 / \mathrm{lb}$ vs $\$ 0.80 / \mathrm{lb})$ for random fiber sheet molding compound (SMC).

Table 9.1. Comparison of composite material properties with steel and aluminum

\begin{tabular}{|l|c|c|c|}
\hline \multicolumn{1}{|c|}{ Material } & $\begin{array}{c}\text { Density } \\
\left(\mathrm{lb} / \mathrm{in} .{ }^{3}\right)\end{array}$ & $\begin{array}{c}\text { Strength } \\
(\mathrm{ksi})\end{array}$ & $\begin{array}{c}\text { Elastic } \\
\text { modulus } \\
(\mathrm{Msi})\end{array}$ \\
\hline Steel & 0.284 & $55-80$ & $28-30$ \\
\hline Aluminum & 0.098 & $45-70$ & 10 \\
\hline E-glass/epoxy unidirectional & 0.067 & 140 & 5.7 \\
\hline Kevlar 49/epoxy unidirectional & 0.05 & 200 & 11 \\
\hline $\begin{array}{l}\text { High-strength carbon fiber/epoxy } \\
\text { unidirectional }\end{array}$ & 0.056 & 225 & 20 \\
\hline $\begin{array}{l}\text { High-modulus carbon fiber/epoxy } \\
\text { unidirectional }\end{array}$ & 0.059 & 180 & 31.2 \\
\hline Carbon fiber/epoxy, woven fabric & 0.056 & 116 & 28 \\
\hline Glass fiber/polyester, SMC-R25 & 0.066 & 33 & 2.15 \\
\hline
\end{tabular}


The benefits of using composite materials include the following:

- lightweight (high strength-to-weight and stiffness-to-weight ratios),

- tailorable properties and design flexibility,

- corrosion resistance,

- damage tolerance and fatigue resistance,

- potential for part integration leading to reduced production costs and reduced weight,

- potential for molded-in color, and

- potential for noise reduction.

The drawbacks of using composite materials include the following:

- Cost of raw materials and manufacturing process can be much higher than for metal counterparts.

- Typically less design experience and material databases are available for composite materials whereas the properties and behavior of metals are well documented.

- Repair/nondestructive evaluation of composite materials may be more difficult.

\subsubsection{Fiber Reinforcements}

Typical fiber reinforcements used in composite materials are glass fiber and carbon fiber. Other fibers such as Kevlar, Spectra, or boron are used less often when special capabilities are required, such as ballistic protection or fire resistance. These specialty fibers are typically expensive and scarce.

Carbon or graphite fibers have the highest strength- and stiffness-to-weight ratios and are the reinforcement of choice for high-performance composite materials (applications where weight savings and mechanical properties are critical). Carbon fibers offer great weight savings potential, but high material cost has prevented significant widespread commercial usage outside the aerospace and aircraft industries. Carbon fibers cost anywhere from about $\$ 8 / \mathrm{lb}$ for pan-based fibers to $>\$ 500 / / \mathrm{lb}$ for the high stiffness, high thermal conductivity pitch-based fibers. During the last few years, the cost of carbon fibers has been going down, and the usage has increased (for instance in recreational equipment). This trend can be expected to continue. Additionally, there are a number of ongoing efforts to significantly reduce the cost of carbon fibers such as the automotive industry target of $\$ 3 / \mathrm{lb}$.

Glass fibers, the most widely used reinforcement for polymer matrix composite materials, have the lowest cost and best availability. A comparison of the properties of glass, carbon, and Kevlar fibers is given in Table 9.2. Note that these are only illustrative fiber properties and there exists

Table 9.2. Comparison of typical fiber properties

\begin{tabular}{|l|c|c|c|}
\hline \multicolumn{1}{|c|}{ Fiber type } & $\begin{array}{c}\text { Density } \\
\left(\mathrm{lb} / \mathrm{in} \text {. }^{3}\right)\end{array}$ & $\begin{array}{c}\text { Strength } \\
(\mathrm{ksi})\end{array}$ & $\begin{array}{c}\text { Elastic modulus } \\
(\mathrm{Msi})\end{array}$ \\
\hline E-glass & 0.092 & 500 & 10.5 \\
\hline S-glass & 0.090 & 700 & 12.5 \\
\hline Kevlar 29 & 0.052 & 400 & 9 \\
\hline Kevlar 149 & 0.053 & 500 & 25 \\
\hline T-300 carbon (pan-based) & 0.065 & 529 & 33.5 \\
\hline P-120 carbon (pitch-based) & 0.065 & 348 & 120 \\
\hline
\end{tabular}


a range of values for strength and stiffness. Table 9.3 includes many of the advantages and disadvantages of these fibers.

The fiber style must also be considered for the reinforcement of composite materials. Fibers are available in unidirectional tows, chopped form, a wide variety of fabric styles (unidirectional, woven), and random short fiber mats. The lower cost fiber forms, chopped fiber and random mats, also result in lower mechanical performance in the finished composite.

\subsubsection{Polymer Matrix Materials}

Polymer matrix materials can either be thermosetting or thermoplastic. Thermosetting materials are normally liquid at room temperature and crosslink with heat and pressure to harden or cure the matrix material. Thermoplastic materials melt at temperature and refreeze to form the composite material. Thermoplastics have the advantage of being reformable and may have higher temperature capability, but are typically more expensive.

Thermoset materials include polyester, vinylester, epoxy, phenolic and urethane. Polyester and vinylesters are the least expensive polymer resin systems and are often used in fiberglass composites. Epoxy resin has a higher strength but is more expensive. These resins are available with additives and modifiers to improve certain properties such as resin viscosity, composite toughness, heat-resistance and chemical resistance.

\subsubsection{Manufacturing Process}

There are a variety of manufacturing processes for composite materials including molding (open mold, closed mold, injection molding), prepreg lay-up, filament winding, and pultrusion (structural shapes such as I-beams, angles). It is important to choose a manufacturing method that will minimize the cost and weight of the composite structure. For example, pultrusion is probably the lowest cost process, but molding may allow for more part consolidation, fewer fasteners, less finishing work, and reduced weight.

Sandwich construction of composite materials offers several advantages. It allows for increased stiffness with a low weight. Sandwich panels are layered composites with strong facesheets such as carbon or glass composite, aluminum, or polymer bonded to a lightweight core material made of foam, aluminum, or polymer honeycomb. Selection of adhesive is also important to ensure transfer of load and prevent debonding. Acoustical panels designed for reducing noise are often manufactured in sandwich construction.

Table 9.3. Advantages and disadvantages of typical fiber reinforcements

\begin{tabular}{|l|l|l|}
\hline \multicolumn{1}{|c|}{ Fiber type } & \multicolumn{1}{c|}{ Advantages } & \multicolumn{1}{c|}{ Disadvantages } \\
\hline E, S-glass & $\begin{array}{l}\text { Low cost } \\
\text { High strength }\end{array}$ & $\begin{array}{l}\text { Low stiffness } \\
\text { Temperature sensitivity }\end{array}$ \\
\hline Kevlar & $\begin{array}{l}\text { High tensile strength } \\
\text { Low density }\end{array}$ & $\begin{array}{l}\text { Low compressive strength } \\
\text { High moisture absorption }\end{array}$ \\
\hline Pitch-based carbon & Very high stiffness & $\begin{array}{l}\text { Low strength } \\
\text { High cost }\end{array}$ \\
\hline Pan-based carbon & $\begin{array}{l}\text { High strength } \\
\text { Moderate stiffness }\end{array}$ & Moderate cost \\
\hline
\end{tabular}




\subsubsection{Adhesive Bonding and Mechanical Fastening}

Although some polymer composites are weldable, many polymer composites cannot be welded, and these require other joining techniques. In principle, adhesive joints are structurally more efficient than mechanical joints. Stress concentrations can be minimized, weight can often be reduced, and the fatigue properties can be improved. In many cases, however, mechanical fasteners can not be entirely eliminated because of the need to disassemble or to gain access to the internal structure. This issue is currently being addressed by the development of reversible bonding utilizing thermoplastic adhesives. Assurance of bond quality is also an important issue. It is difficult to ensure quality of bonded joints, and this should be considered for joints where bond failure can induce gen-set failure.

\subsubsection{Summary}

The flexibility of choosing the components and manufacturing process makes composite materials designer-friendly but can make them more difficult to specify than alloys. To maximize the cost/benefit of a composite material, the component materials and manufacturing process must be considered together and tailored for best results. The overall competitiveness of composite materials with steel and especially with aluminum will depend heavily on the cost vs weight trade-off. Also, replacing metal structures with composites should take advantage of the unique capabilities of composite materials. However, the composite design must be considered from the beginning. If metal components are merely replaced with composites, ignoring shape and structural design, many of the advantages will be compromised.

A redesign of the gen-set that takes advantage of part consolidation, or integrated structures, has the potential to minimize weight, eliminate fasteners, and reduce production costs. The use of composite materials could potentially allow for alternative joint designs such as fabric, plastic hinges, or repairable bonds. Additionally, this type of redesign could be tailored to allow for a modular approach to gen-set assembly and to reduce noise.

\subsection{MATERIALS FOR THERMAL MANAGEMENT}

To reduce the thermal signature and improve performance of the gen-sets, thermal management materials can be used to distribute excess heat from hot spots, cool the power electronics, and potentially remove heat from the exhaust stream. Two materials that have been developed at ORNL have the potential to help reduce thermal signature without significantly increasing overall weight and cost.

The first material is a thermal management fabric that could be used to drape over the gen-set and reduce thermal signature. The fabric consists of several layers that work together to distribute heat more evenly and alter the rate of thermal emissions. This material may not make the gen-set undetectable, but it might alter the thermal signature and make it harder to recognize.

A second material, a high-thermal-conductivity carbon foam, has the potential to be used in several locations in the gen-set. This material has an isotropic thermal conductivity of greater than $150 \mathrm{~W} / \mathrm{mK}$ with a specific gravity of 0.54 . The specific conductivity, which is the thermal conductivity/specific gravity, of the foam is $275 \mathrm{~W} / \mathrm{mK}$ compared to 54 for aluminum and 45 for copper. The foam, which should be commercially available in the next 2 years, is currently being investigated for incorporation into heat exchangers to cool power electronics. The foam-based heat exchangers should be smaller, lighter, and cheaper than conventional aluminum-based 
systems. The foam could also be used to cool the exhaust gases and other hot spots to help reduce the thermal signature.

\subsection{PREVIOUS ORNL WORK TO INCORPORATE COMPOSITE MATERIALS INTO GEN-SETS}

In the early 1990s, ORNL worked with the Army Belvoir RD\&E Center to identify opportunities to improve diesel engine/generator prototypes. Both a 15-kW unit and a 10-kW unit were prototyped with incorporation of composite materials to reduce weight and improve performance. Additional information can be found in Refs. 1-3, which can be obtained upon request.

\subsubsection{The 15-kW Unit}

The first prototype that ORNL worked on was a 15-kW unit. For this prototype, the feasibility of reducing size and weight of the gen-set was investigated. Redesign of parts, components, assemblies, and subassemblies were considered along with the use of alternate lightweight materials.

Efforts were concentrated on changes that would reduce production costs or result in the largest weight and/or size savings per unit of increased production cost. The prototype design incorporated composite materials but was very conservative. A main advantage of using composite materials is the ability to design the material form and properties. However, for this unit the weight reduction was determined from essentially a component replacement for the existing steel structure. Also, for this unit, only commercially available pultruded composite materials were used, resulting in some additional components, fasteners, and reinforcements that could be minimized in a full redesign.

Fabrication of the skid base, lift frame, housing, and intake and exhaust boxes utilizing composite materials resulted in a 50\% weight savings of more than $600 \mathrm{lb}$ as shown in Table 9.4.

Table 9.4. Weight savings using composite materials in previous gen-sets

\begin{tabular}{|c|c|c|}
\hline Component & $\begin{array}{c}\text { Original weight of } \\
\text { steel structure } \\
(\mathrm{lb})\end{array}$ & $\begin{array}{c}\text { Weight of composite } \\
\text { structure } \\
(\mathrm{lb})\end{array}$ \\
\hline Skid base/lift frame & 655 & 275 \\
\hline Housing & 400 & 225 \\
\hline Intake/exhaust boxes & 140 & 55 \\
\hline Total & 1195 & 555 \\
\hline
\end{tabular}

\subsubsection{The 10-kW Unit}

The objective of prototyping the 10-kW unit was to improve performance to meet Army procurement specifications. The goals were to improve noise suppression through structural damping, high-temperature performance, and maintainability, while minimizing weight and fabrication costs. 
For the demonstration prototype, structural sandwich composite panels, with fiberglassreinforced polypropylene sheets bonded to a polyurethane foam core were selected. The composite sandwich panels replaced the 0.062-in. aluminum panels. The polypropylene was selected for the resin material in part because of how easily it can be welded using a hot air gun and thermoplastic welding rod. The sandwich structure had several advantages over the aluminum; however, its area density is $1.2 \mathrm{lb} / \mathrm{ft}^{2}$, which is more than the $0.9 \mathrm{lb} / \mathrm{ft}^{2}$ of aluminum.

The demonstration prototype utilized an aluminum lifting frame and some aluminum framing supports for the composite housing. The skid base design was not changed. The combined weight of the original skid base and housing structures were approximately $260 \mathrm{lb}$ of the total gen-set weight of $1075 \mathrm{lb}$. The prototype structure weighed approximately $50 \mathrm{lb}$ more. Several reasons for the weight increase include additional structure for high lift and tie-down points, a larger muffler, and slightly larger overall volume of housing.

The prototype accomplished the major objectives of increased noise suppression, improved high-temperature capability, and increased accessibility. The baseline noise was 70 to $74 \mathrm{dbA}$ at $7 \mathrm{~m}$, which exceeded the requirement of $70 \mathrm{dbA}$. Although the exact design and fabrication processes for the prototype were not optimized for production, the prototype unit successfully met the requirement of $70 \mathrm{dbA}$ at $7 \mathrm{~m}$.

\section{Hump Testing}

ORNL fabricated a test skid base to gather background data for a design to withstand the rigorous requirements of hump testing and end drop testing. ${ }^{3}$ This test piece was not a verification article for the composite prototypes for the 10- and 15-kW units. Instead a less conservative design approach and was used as the skid base at a sacrificial 30-kW engine/gen-set to identify potential failure mechanisms.

The test plan with a more thorough discussion of the design and testing objectives is included in Ref. 3.

\subsubsection{Summary}

This early prototype development and analysis work gives a head start for incorporating lightweight materials in the current gen-sets. The drastic reduction in weight for the 15-kW unit illustrates the potential for incorporating both aluminum and composite lightweight materials to reduce the weight of the frame and housing for the steel frame gen-sets. The prototype of the $10-\mathrm{kW}$ unit indicates that it will be more challenging to take weight out of the aluminum frames and housings, but it shows that the use of composite materials can have benefits beyond weight savings. The experience gained from these prototype efforts should be leveraged whenever possible.

\subsection{COMPOSITE TECHNOLOGY DEVELOPMENTS}

Currently a number of efforts are under way, including PNGV, to increase the fuel efficiency and decrease the harmful emissions of automobiles. One promising way to accomplish these goals is to reduce the weight of the automobile by incorporating lighter weight materials. Many potential alternative materials are being considered for reducing weight without sacrificing size, performance, cost and safety; they include aluminum, aluminum alloys, polymer composites, magnesium alloys, intermetallics, and ceramics. Additionally, suppliers are exploring the potential for weight reduction of steel structures as part of the UltraLight Steel Auto Body Program. 
ORNL is involved with several efforts, including the PNGV program, to overcome some of the obstacles to widespread use of the lightweight materials: high raw material costs, high production costs, and difficulty of attachment of polymer matrix composites. Many of the concerns of the automotive industry focus on cost vs performance benefit, and the progress made in these research efforts should be leveraged in the gen-set designs. Several promising research projects may impact the gen-set designs:

- Low-cost carbon fiber manufacturing-Reduce capital and operating cost for processing carbon fibers by using microwave energy for graphitization.

- P4 process (Programmable Powder Preform Process)-Develop and demonstrate costeffective technologies for high-volume production of large, complex composite components.

- Adhesive bonding-Overcome the hurdles in adhesive bonding of current and future automotive materials.

- Durability-Develop durability-driven design guidelines for composite structures to demonstrate the applicability of composite automotive structures.

- Reversible bonding-Use of microwave energy to process adhesives and then soften the adhesive while maintaining the integrity of the adherent, which will be critical for structural repair.

ORNL has extensive experience with designing and prototyping composite structures to achieve specific functionality or properties that cannot be achieved with traditional homogeneous materials such as metals. The Advanced Surgical Suite for Trauma Casualties (ASSTC), or "Hospital-in-a-Box" project is a good example. The design requirements for ASSTC presented a number of unique challenges in terms of providing a compact, sound structure that was durable, lightweight, and easy to transport to and from medical emergencies around the globe. The ORNL team concluded that providing all of these capabilities required more advanced materials than the structural steels and aluminums typically employed in military structures. The completed structure for the ASSTC prototype consisted of a hybrid design incorporating aluminum, carbon composites, and both carbon and glass sandwich panels with a nonmetallic Nomex honeycomb core.

\subsection{POTENTIAL WEIGHT REDUCTIONS}

Although it is difficult to quantify the weight reduction for the frame and housing until all components are selected and the unit is fairly well defined, some assumptions can be made to give a representation of the benefits of using lightweight materials. Two cases can be considered including the most cost-competitive redesign, which reduces weight, and less cost-competitive but more aggressive approach, incorporating higher performance composite materials to get a greater weight savings. For both cases, the weight of the housing and frame will be reduced due to shrinking the overall dimensions of the gen-set, which results from a reduction in the diesel engine size.

For the most cost-competitive approach, additional weight savings will result from the use of a combination of low-cost/high-cost performance composite materials and aluminum, integration of components, and reduction of fasteners. The frame and housing weight savings for these design changes are estimated to be 10-15\% using the current 5- and 10-kW gen-set design as a baseline and 30-40\% using the current 15- to $60-\mathrm{kW}$ gen-set design as a baseline. Recall that the current 5- and 10-kW units are built with aluminum, but the larger sets are built with steel. 
The second design approach would allow for a higher weight savings but a more costly design. Use of a combination of composite materials, including high-performance composites, to achieve a maximized weight reduction is estimated to save $45-55 \%$ of the weight of the frame and housing of the current 15- to $60-\mathrm{kW}$ gen-set and $20-25 \%$ of the 5 - and $10 \mathrm{~kW}$-units as the baseline.

It may be desirable to develop both a low-cost/low-performance and a high-cost/highperformance structural frame design with identical internal components, resulting in a consistent performance for the family size with one design weighing less for the more weight-critical applications. The cost of fabricating and maintaining several frame designs for one family size will need to be assessed.

\subsection{RECOMMENDATIONS FOR ADVANCED MATERIALS}

With any redesign or incorporation of new lightweight materials into the gen-sets, several factors need to be considered which contribute to the suitability of the material for the application and the total cost of ownership.

- cost vs weight savings

- cost vs other advantages of composite materials (beyond weight)

- maintainability

- repairability

- compatibility of material system with NBC requirements and decontamination

From the ORNL work on past gen-sets, it is likely that a significant weight reduction can be achieved for the current 15-, 30-, and 60-kW units because those systems rely heavily on steel components. Use of both aluminum and composite materials can be considered to reduce the weight in a cost-effective manner. The most cost-effective solution may include a hybrid design with a combination of materials, both metal and composite, to utilize the advantages inherent in each material.

For the current 5- and 10-kW units it will be more challenging to significantly reduce the weight of the frame and housing without increasing their cost. Aluminum and low-cost composites have comparable properties and a comparable price. However, there is an opportunity for part consolidation and elimination of fasteners in these units through the use of polymer composites.

From a cost perspective, glass fibers and polyester or vinylester resins are the most likely candidates for the composite material components. However, the suitability of these materials for the gen-set environment must be verified. Molding of integrated components and use of pultruded structural members will contribute to the cost competitiveness. A team approach should be taken in the design process to include manufacturability in addition to material selection to take best advantage of the potential provided by composite components.

Structural analysis work will need to be done to ensure that possible mounting, lifting, and frame constructions can withstand the rigorous end drop and hump requirements for the gen-sets. This kind of modeling and analysis can be started once the size, location, and weight of the internal components are better defined and can build on past design experience. The results of the structural analysis will define the critical mechanical properties necessary for selection of final materials. 
For some situations, the weight reduction payoff may be high enough to allow for the use of some more expensive yet higher performing composite materials. For instance, an increase in the cost of a larger unit may be tolerated if it can be constructed with a weight low enough to be towed behind a HMMWV. Another excellent opportunity for weight reduction, although beyond the scope of this report, is a redesign of the trailer to include lightweight materials. The possibility of having multiple frames with identical internal components ("mules") remains a viable option.

The disadvantages of using composites, other than their cost, will be considered during the design and prototyping stage and are not considered prohibitive. Final design of the frame and structure, including the extent of composite material usage, will be determined during these subsequent stages based on additional input from the military.

- Recommendation: A hybrid design for the frame/enclosure using a combination of lower cost composites and aluminum appears to be a cost-effective means for reducing the gen-set weight beyond the savings due to lighter components. More costly designs can reduce the weight even further and should be considered during the design phase of the gen-set prototyping. The final frame/enclosure design will require additional input from the military and evaluation of the prototype.

\subsection{ESTIMATED WEIGHT AND VOLUME FOR NEXT GENERATION OF GEN-SETS}

A brief description of the estimated weight and volume of the proposed next generation of genset families is presented in this section. Note that all estimates are based only on conceptual design information, much of which is described in this report. The weight and volume values given here serve as preliminary design goals for producing prototype gen-sets.

Assumptions for weight and volume estimating

1. Engine dry weights are those presented in Tables 6.3-6.5 and Fig. 6.9.

2. Engine operation at $3000 \mathrm{rpm}$ is achievable for proposed gen-sets.

3. Engine peripheral weights and dimensions are estimated to be similar to those of existing TQGs (no credit for eliminating the starter and alternator).

4. The housing and frame outside dimensions $(\mathrm{L} \times \mathrm{W} \times \mathrm{H})$ of new gen-sets are estimated based on the existing TQGs with similar output ratings. "Credit" for shrinking the housing dimensions is taken for use of smaller engines.

5. Credit is taken for lower weight PM alternator and power electronics systems, which would replace the synchronous alternator systems used in TQGs. The weights are based on the estimated weight of the equipment.

6. A small credit is taken for shrinking the gen-set dimensions due to the new designs of alternator and electronics compared with the analogous system in the TQGs.

7. All frames and enclosures are a hybrid construction consisting of aluminum and lower cost composites. Some doors, handles, fasteners, and other components are eliminated by combining access doors and component integration.

8. Redesign described in assumption 7 eliminates about $15 \%$ of the housing and frame weight compared with existing TQG aluminum frame and housing design.

9. New gen-sets rated for 7,25 , and $80 \mathrm{~kW}$ are the targets used as examples.

10. The need for additional sound insulation offsets other weight-saving opportunities such as that implied in 3.

11. The digital control system to be used in the new gen-sets has negligible effect on the weight and dimensional comparison between the conceptual designs and the TQGs. 
The estimated sizes and weights for the proposed gen-sets are given in Tables 9.5 and 9.6, along with data for the $400-\mathrm{Hz}$ TQGs to allow comparison (50- to $60-\mathrm{Hz}$ units are slightly lighter, but the comparison is still valid). The gen-set weight information is plotted in Fig. 9.1. Although the electrical output rating of the TQGs and the next-generation units do not coincide, it is implied from Fig. 9.1 that weight can be reduced by a third to a half of that expected from a TQG or similar design. If the entire inventory of TQGs from 5-60 kW were replaced with these proposed gen-sets with a smaller size distribution, the total weight of the inventory would be reduced $\sim 30 \%$. Similarly it appears feasible to reduce gen-set volume by $25-50 \%$. The lower values apply to the smaller gen-sets, while larger appear feasible for units above $15 \mathrm{~kW}$.

Table 9.5. Breakdown of gen-set estimated weights for proposed gen sets

\begin{tabular}{|c|c|c|c|c|c|}
\hline $\begin{array}{c}\text { Normal gen-set } \\
\text { rating } \\
(\mathrm{kWe})\end{array}$ & $\begin{array}{c}\text { Engine and } \\
\text { accessories } \\
\text { weight } \\
(\mathrm{lb})\end{array}$ & $\begin{array}{c}\text { Alternator and } \\
\text { electronics and } \\
\text { control system } \\
(\mathrm{lb})\end{array}$ & $\begin{array}{c}\text { Enclosure } \\
\text { and frame } \\
\text { weight } \\
(\mathrm{lb})\end{array}$ & $\begin{array}{c}\text { Fluid } \\
\text { weight } \\
(\mathrm{lb})\end{array}$ & $\begin{array}{c}\text { Total } \\
\text { weight } \\
(\mathrm{lb})\end{array}$ \\
\hline 7.0 & 160 & 170 & 320 & 50 & 700 \\
\hline 25 & 340 & 240 & 470 & 150 & 1200 \\
\hline 80 & 760 & 540 & 890 & 410 & 2600 \\
\hline
\end{tabular}

Table 9.6. Size and weight estimates for proposed gen-sets compared with current $400-\mathrm{Hz}$ TQGs

\begin{tabular}{|c|c|c|c|c|c|}
\hline $\begin{array}{c}\text { Nominal } \\
\text { gen-set rating } \\
(\mathrm{kW})\end{array}$ & $\begin{array}{c}\text { Estimated } \\
\text { gen-set weight } \\
(\mathrm{lb})\end{array}$ & $\begin{array}{c}\text { Estimated } \\
\text { length } \\
\text { (in.) }\end{array}$ & $\begin{array}{c}\text { Estimated } \\
\text { width } \\
\text { (in.) }\end{array}$ & $\begin{array}{c}\text { Estimated } \\
\text { height } \\
(\mathrm{in} .)\end{array}$ & $\begin{array}{c}\text { Estimated } \\
\text { volume } \\
\left(\mathrm{ft}^{3}\right)\end{array}$ \\
\hline \multicolumn{6}{|c|}{ Proposed gen-sets based on conceptual design } \\
\hline 7 & 700 & 49 & 29 & 33 & 27 \\
\hline 25 & 1200 & 55 & 37 & 34 & 40 \\
\hline 80 & 2600 & 68 & 47 & 50 & 92 \\
\hline \multicolumn{7}{|c|}{ Existing 400-Hz TQGs } \\
\hline 5 & 911 & 50.3 & 31.8 & 36.2 & 33.5 \\
\hline 10 & 1220 & 61.7 & 31.8 & 36.2 & 41.1 \\
\hline 15 & 2238 & 69.2 & 35.3 & 54.1 & 76.5 \\
\hline 30 & 3015 & 79.2 & 35.3 & 54.1 & 87.5 \\
\hline 60 & 4153 & 87 & 35.3 & 58.2 & 103 \\
\hline
\end{tabular}




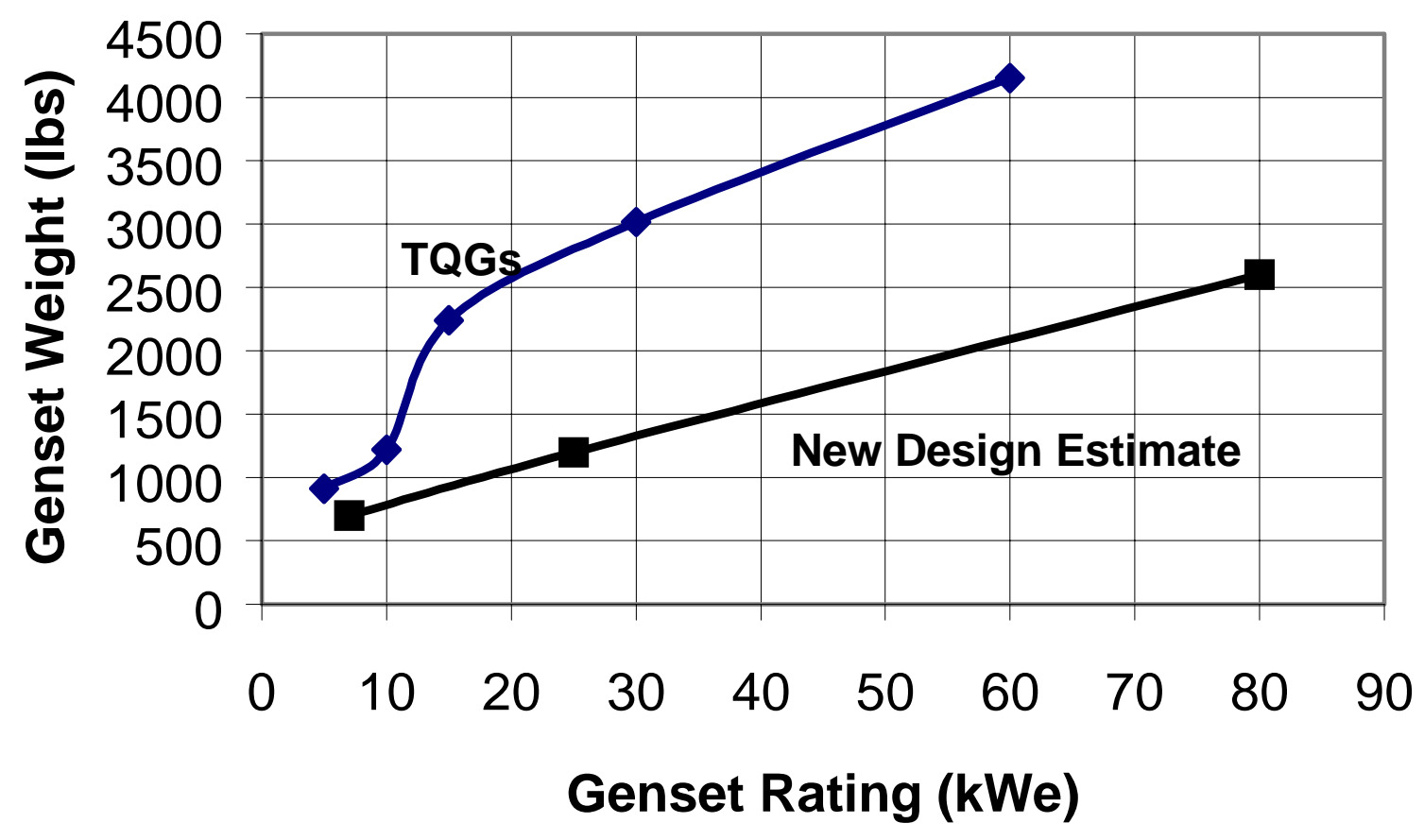

Fig. 9.1. Weight estimates for proposed gen-sets compared with current 400-Hz TQGs.

\subsection{REFERENCES}

1. Fabrication and Testing of 10-kW Engine/Generator Prototypes, ORNL Report, March 1991.

2. Fabrication of 15-kW Engine/Generator Prototype, ORNL Report.

3. Test Plans for Rail Car Impact Evaluation, ORNL correspondence, November 1989. 
9-12 


\section{RECOMMENDATIONS FOR A DESIGN PHILOSOPHY}

This chapter collects and summarizes the recommendations comprising the design philosophy for the next generation of medium-power mobile electric generators. Metrics for new gen-sets are estimated and compared against established goals. Note that these metrics are only rough estimates and will certainly change during the design process.

\subsection{Summary of Recommendations}

The following recommendations, which comprise a new design philosophy, are submitted for the next generation of medium-sized (5- to 60-kW) MEP generators. The recommendations are listed here without the supporting justification. For convenience, the section in which the recommendation was originally made is included.

\section{Component And System Recommendations}

- Turbocharged, charge-cooled, automotive diesels, featuring advanced high-pressure, electronically controlled fuel injection systems (common rail or unit injection) and lightweight construction, are the recommended prime movers for gen-sets in the 15 to $60+\mathrm{kW}$ range (Sect. 6.1.2).

- For a smaller gen-set with a peak rating below $15 \mathrm{~kW}$, it is recommended that naturally aspirated industrial diesel engines with a relatively high power-to-weight ratio (for that size range of engine) be utilized until the technology in the automotive diesels migrates to the smaller industrial diesel lines (Sect. 6.1.2).

- Gas turbines should be evaluated more closely and warrant consideration in niche areas where the need for lighter weight is substantially more important than fuel efficiency (e.g., short mission durations) (Sect. 6.1.2).

- Gen-set design should be based on variable-speed operation, and speeds of $3000 \mathrm{rpm}$ and above should be an initial design goal (Sect. 6.2.4).

- A three-phase alternator is recommended (either a PM alternator or a more conventional inductance alternator) so that integrated power electronics modules can be used which reduce the complexity, size, and cost of the power electronics system (Sect. 6.4.3).

- A high-flux PM alternator is the preferred alternator. The market survey indicates that mass production costs are not prohibitive (Sect. 6.4.3).

- During the design and prototyping phase, the main alternator should be evaluated for use as the engine starter by using a two-way buck-boost converter to charge the batteries and drive the starter. Justification for this would be the weight and volume savings from eliminating the engine starter motor and the alternator for charging the battery (Sect. 6.4.3).

- Using a variable-speed engine will require a system to convert the voltage generated to a selectable voltage and frequency. Power electronics are recommended to achieve this conversion because of their compact size and controllability. Designing a single gen-set unit able to generate power at 50,60 , and $400 \mathrm{~Hz}$ is recommended (Sect. 6.5.4). 
- Use IPMs for the inverter and rectifier sections of the power electronics system to maximize integration of the electronics, increase reliability, and improve maintainability (Sect. 6.5.4).

- Use common components as much as possible in the power electronics systems for the different sizes of gen-sets to minimize the burden of parts logistics (Sect. 6.5.4).

- We recommend that gen-sets in the future be sized with both a maximum and minimum power rating. The minimum rating would be determined during future testing but would be the lower bound of effective and reliable gen-set operation. The maximum power rating would be determined using the same qualification tests used today but at the highest power level for which the gen-set fully qualifies, rather than at a predetermined arbitrary level (Sect. 6.6).

- Based on the engines available in the market survey, the number of future gen-set families recommended to cover the 5 - to $60-\mathrm{kW}$ range is three (Sect. 6.7).

- Based on projected market availability, the gen-set families should be sized at approximately 2-7 kW; 6-25 kW; and 20-80 kW. Final size ratings will be determined at the conclusion of the qualification testing (Sect. 6.7).

\section{Digital Control System Recommendations}

- Based on the survey of the market, it appears highly unlikely that a control system can be purchased separately from the gen-set. Therefore, we recommend that the control system be developed specifically to operate the future gen-sets (Sect. 7.1).

- The advantages tend to favor a PC-based global controller to run the control system. The final decision will be made during the prototyping phase of this program. The selection of the operating system will have to be made at a later date based on other system requirements chosen by the military (Sect. 7.2.4).

- We recommend the use of DSPs in the control system to govern the final current and voltage output (Sect. 7.2.5).

- The final recommendation for the display will depend upon further input from the military about what is needed in the field. Once display requirements are defined, then selection of the display will be relatively easy (Sect. 7.2.6).

- A separate maintenance computer should be included to provide additional useful functions, which are not deemed appropriate to be included onboard the gen-set itself (Sect. 7.2.7).

\section{D\&P System Recommendations}

- It is recommended that the D\&P system be designed to include moderate to total incorporation of diagnosing and predicting impending failure. The "best" approach will be decided after the costs of these two approaches are determined through further testing, development, and application of D\&P methods and technologies (Sect. 8.6).

- Based on knowledge of parameters that are presently monitored on existing TQGs, a review of available failure records, and discussions with CECOM, it is recommended that several but not all-available parameters be monitored for their importance in D\&P of new gen-sets. An initial listing of those parameters that should be included in the D\&P system is provided. 
The final list of monitored parameters will be determined during the prototyping of the new gen-sets (Sect. 8.6).

- It is recommended that a similar battle-short switch be provided on the new gen-set that disables the action of the safety (and unit protection) parameters listed in Sect. 8.6 (with exception of the short circuit and emergency stop function). It is further recommended that the indication (e.g., displays showing high current, high temperature, etc.) of all parameters still be available so that the user has the ability to monitor the condition of the gen-set, even though the actions of its safety devices have been bypassed (Sect. 8.6).

- We recommend several additional items be included in the D\&P system for the prototype and evaluated for effectiveness during prototype testing. The final resolution of exactly what is in the D\&P system will depend on the effectiveness of the system and additional requirements of the military (Sect. 8.6).

\section{Materials Recommendations}

- A hybrid design for the frame/enclosure using a combination of lower cost composites and aluminum appears to be a cost-effective means for reducing the gen-set weight beyond the savings from lighter components. More costly designs can reduce the weight even further and should be considered during the design phase of the gen-set prototyping. The final frame/enclosure design will require additional input from the military and evaluation of the prototype (Sect. 9.5).

\subsection{COMPARISON OF NEW GENERATORS WITH GOALS}

The technical objective of the AMMPS program is to develop a new standard family of mediumsized (5- to 60-kW) mobile electric generators for Force XXI and the AAN. The resulting new standard family is expected to improve performance as follows:

- Decrease weight and size up to $55 \%$.

- Increase mission duration up to $30 \%$.

- Increase system efficiency up to $15 \%$.

- Decrease noise by $5 \mathrm{dBA}$.

The key comparison issues are weight and size; mission duration; efficiency; signature suppression; reliability, availability, and maintainability; and cost.

The performance of the recommended future design is estimated for comparison with these goals. This does not constitute a design criterion but instead is a rough estimate of anticipated performance compared with established metrics.

\subsubsection{Weight and Size}

The weight and volume of the recommended family sizes is estimated and compared with TQGs in Sect. 9.7 (see Tables 9.5 and 9.6 and Fig. 9.1). The estimated weights for the 7-, 25-, and $80-\mathrm{kW}$ units are 690, 1330, and $3070 \mathrm{lb}$, respectively. This gives a power density (maximum rating/weight) of 10,19 , and $26 \mathrm{~W} / \mathrm{lb}$, for the 7-, 25-, and $80-\mathrm{kW}$ units. The existing TQGs have a power density of $5.5,8.2,6.7,10$, and $14 \mathrm{~W} / \mathrm{lb}$ for the 5-, 10-, 15-, 30-, and 60-kW units, respectively. Comparing the power density at similar sizes ( 7 vs $5 \mathrm{~kW}, 25$ vs $30 \mathrm{~kW}$, and 80 vs $60 \mathrm{~kW}$ ) shows an 80 to $90 \%$ increase in power density, which corresponds to about a $45 \%$ reduction in weight per kilowatt. 
The estimated volume for the proposed gen-sets is also compared with the volume for the TQGs in Table 9.6. Based on the estimates, it appears that significant volume reductions (25 to $50 \%)$ are possible.

Overall, the weight and size of the proposed gen-sets are estimated to be significantly smaller than the existing TQGs. It is doubtful that a full 55\% reduction in these values can be achieved across the range of 5-60 kW, but reductions approaching $55 \%$ for the larger units are anticipated.

\subsubsection{Mission Duration}

Obviously, mission duration is increased in proportion to improved fuel efficiency, which is discussed in more detail below. As described, fuel efficiency and subsequently mission duration will increase from improvements realized from variable-speed control (1 to 12\%) and the DI fuel systems (5 to $10 \%)$.

Variable-speed control is expected to reduce wetstacking, which is expected to reduce unscheduled downtime and maintenance. This will improve generator availability to the mission.

Automated digital D\&P are expected to reduce repair and maintenance time and cost. Further reduction of unscheduled downtime and maintenance cost should eventually be achieved through the implementation of predictive maintenance practice with the mobile electric generators.

The new gen-sets should improve mission duration significantly although a quantification of the improvement is not available at this time.

\subsubsection{Efficiency}

Fuel efficiency will be improved primarily by the use of variable-speed control and by using new high-pressure DI engine technology. Some moderate efficiency improvements are possible with the use of PM alternators rather than induction alternators.

The high-pressure electronic control DI technology is emerging from the automotive industry, which is legislatively and economically motivated to improve pollution control and fuel economy. The military mobile electric generator is expected to benefit from the new DI technology as it transitions through market forces from automobile engines to the industrial engines suitably sized for electric generators. High-pressure $\mathrm{DI}$ is expected to reduce fuel consumption by $5-10 \%$ over the current generation of engines. These options are not available in the lowest engine sizes today but should become available in the future.

The percent fuel saved by variable-speed control as a function of fixed control speed was calculated for two typical medium-sized diesel engines. When compared to 1800-rpm fixed-speed operation, variable-speed control can reduce fuel consumption an estimated $12 \%$ for peacetime operations and $1-3 \%$ for projected wartime operations.

The PM alternators and power electronics have a maximum efficiency somewhat higher than their previously used counterparts, but more importantly, the high efficiency extends over a much broader range of operation. 
Based on the improvements in fuel injection and the increased system efficiency with variablespeed operation, PM alternators, and power electronics, an increased efficiency in the new gensets of $15 \%$ seems very likely.

\subsubsection{Signature Suppression}

Acoustic

The goal is to reduce the sound pressure level (SPL) $5 \mathrm{dBA}$ below the current requirement of $70 \mathrm{dBA}$ at $7 \mathrm{~m}$. Although the variable-speed engine is expected to be quieter when operating at low speed, the engines are likely to be noisier when operated at high speed. The increase in engine source noise due to increased speed is estimated to be about $6 \mathrm{~dB} / 1000 \mathrm{rpm}$. Test data are needed to quantify the noise as a function of speed.

It is expected that improved acoustic suppression and new engine technology will be needed to offset the higher noise source at high speed. Much of the noise source of the generator is the airflow noise. Attention will need to be given to acoustic baffling of the airflow inlet and outlet. Mufflers featuring good passive acoustic attenuation would help reduce exhaust noise. The addition of active noise control, currently being worked at Brookhaven National Laboratory, may further reduce the acoustic signature, especially in the low-frequency end of the noise spectrum.

Automotive diesel engine developers have had success in reducing engine noise by using the new electronically controlled DI technology, which also improves the fuel economy and pollution emissions. It is expected that use of this technology will make mobile electric generators quieter, although it is difficult to quantify the noise reductions at this time. When engines are tested, the variation of engine acoustics with speed will be measured to quantify and characterize the noise source. These data are essential to facilitate noise suppression design for the generators. Once the noise levels are known, the appropriate amount of noise suppression can be integrated into the enclosure.

\section{Thermal}

The thermal signature is expected to be reduced by the improved efficiency expected from using high-pressure electronically controlled DI and variable-speed engine control. Thermal management materials have been identified that can be used to reduce and relocate the thermal signature to make thermal detection less likely. Quantification of the thermal signature in the proposed gen-sets is not possible until the design phase has been completed, but reductions seem quite likely.

\subsubsection{Reliability, Availability, and Maintainability}

The reliability and availability of the gen-sets will improve through the use of D\&P. It is impossible to quantify these improvements now, but they should be significant. During peacetime missions, the operation of the diesel engine at variable speeds within its established range should dramatically decrease the incidence of wetstacking. Maintainability should improve as the D\&P system matures and influences the maintenance schedules. The use of a modular composite enclosure can improve the maintainability of the gen-set. The commonality of several components will assist maintenance operations.

\subsubsection{Cost}

Cost benefits from the proposed design philosophy are expected for a number of reasons. 
- Logistics, inventory, and procurement costs are expected to be reduced by reducing the number of generator family sizes. The number of generator family sizes in the 5-kW through $60-\mathrm{kW}$ range has been reduced from 5 to 3 . Original family units are $5,10,15,30$, and $60 \mathrm{~kW}$ for 60 and $400 \mathrm{~Hz}$. The new family sizes overlap each other and are approximately 2-7 kW, 6-25 kW, and 20-80 kW with each size being switch selectable for 50-, 60-, or $400-\mathrm{Hz}$ service.

- Procuring larger numbers of identical generators is expected to lower the per unit capital costs.

- More commonality of components among fewer generator sizes is expected to reduce capital and maintenance costs. Common parts should include digital controller, D\&P module, and portions of the power electronics package.

- Automatic D\&P are expected to reduce maintenance costs. Digital diagnostics is expected to further reduce maintenance cost through the implementation of predictive maintenance practice with the mobile electric generators. Addition of D\&P is likely to add to procurement cost, although the amount depends on how extensively the D\&P techniques are implemented.

- Improved engine efficiency will reduce fuel costs an estimated 5 to $10 \%$ in the new gen-sets. Variable-speed control will reduce fuel costs about $12 \%$ in peacetime operations and $1-3 \%$ during wartime operations. The use of new component technology (i.e., electronic DI fuel system) is likely to increase procurement cost, although the costs are expected to be reasonable and more than offset by the reduced fuel costs.

- The use of advanced composite materials is expected to increase procurement cost. This will be offset somewhat if the new design can use less expensive manufacturing techniques (i.e., molded parts).

- The need for greater sound suppression treatment will likely increase the procurement cost.

\subsection{CONCLUDING REMARKS}

The purpose of this report is to document the results of our study, which can be used to enhance the performance of the next generation of DOD MEP gen-sets in the medium power range (5-60 kW).

The primary finding of the market survey portion of this study is that the commercial market is in a state of flux and is currently or will soon (within 2-3 years) be capable of providing the technologies recommended here in a cost-effective manner. In most of the component areas of interest in gen-set design, new technologies are being introduced at a rapid rate. More suppliers in these new technical areas are introducing products into the market, and significant cost reductions are expected in the next few years.

The design philosophy portion of the report summarizes existing gen-set design in the $5-\mathrm{kW}$ through $60-\mathrm{kW}$ range, identifies options for reducing the number of fielded families of gen-sets, evaluates the major components used in the gen-sets, addresses system effectiveness, considers onboard D\&P, and explores the use of advanced materials. Viable options are evaluated in light of military goals and applicable technology and components. Recommendations that 
comprise a design philosophy for the next generation of gen-sets are made. These recommendations, if implemented, should result in future power generation systems being much more versatile than today's gen-sets. The number of differing units necessary (both family sizes and frequency modes) to cover the medium power range would be decreased significantly, while the weight and volume of each unit would decrease markedly, improving the transportability of the power source. Improved fuel economy and overall performance would result from more effective utilization of the prime mover in the gen-set. The units would allow for more flexibility and control with improved reliability and more effective power management in the field. The established metrics (i.e., weight reductions and efficiency improvements) are ambitious but appear to be viable design targets for the proposed gen-sets.

While much has been learned during this study and we are optimistic about meeting the established targets, additional work remains before more precise design parameters can be established. We have assumed and we strongly concur that the design and prototyping phase should proceed as soon as reasonable. This stage should have the goals of introducing the design recommendations as much as possible and determining areas in which additional trade-offs and investigation are required. 
10-8 
ORNL/TM-1999/213

\section{INTERNAL DISTRIBUTION}

$\begin{aligned} 1 . & \text { D. J. Adams } \\ 2-4 . & \text { J. B. Andriulli } \\ 5 . & \text { C. W. Ayers } \\ 6 . & \text { J. E. Cook } \\ 7 . & \text { G. Farquharson } \\ 8 . & \text { E. C. Fox } \\ 9 . & \text { R. L. Graves } \\ 10 . & \text { H. D. Haynes } \\ 11 . & \text { D. K. Irick } \\ 12 . & \text { L. B. Klett } \\ 13 . & \text { R. Lenarduzzi } \\ 14 . & \text { J. W. McKeever } \\ 15 . & \text { S. McNeany }\end{aligned}$

$\begin{aligned} 16 . & \text { G. W. Morrison } \\ 17 . & \text { R. E. Norris } \\ 18 . & \text { P. J. Otaduy } \\ 19 . & \text { R. M. Schilling } \\ 20 . & \text { M. B. Scudiere } \\ 21 . & \text { J. M. Storey } \\ 22-24 . & \text { T. J. Theiss } \\ 25 . & \text { J. F. Thomas } \\ 26 . & \text { L. M. Tolbert } \\ 27 . & \text { C. P. White } \\ 28 . & \text { Central Research Library } \\ 29 . & \text { ORNL Laboratory Records-RC } \\ 30 . & \text { ORNL Laboratory Records-OSTI }\end{aligned}$

\section{EXTERNAL DISTRIBUTION}

31. A. E. Gates, U. S. Army CECOM RD\&E Center, Power Generation Branch, AMSEL-RD-C2-AP-PG, 10108 Gridley Road, FT. Belvoir, VA 22060

32. Capt. J. T. Judkins, USN, Experiment Plans ñ Biosciences, Marine Corps. Warfighting Lab, Quantico, VA 22134

33-35. S. N. Matthews, U. S. Army CECOM RD\&E Center, Power Generation Branch, AMSEL-RD-C2-AP-PG, 10108 Gridley Road, FT. Belvoir, VA 22060

36. E. A. Nawrocki, U. S. Army CECOM RD\&E Center, Power Generation Branch, AMSEL-RD-C2-AP-PG, 10108 Gridley Road, FT. Belvoir, VA 22060

37. W. Rabon, PM-MEP, Mobile Electric Power, 10205 Burbeck Road, Suite 105, FT. Belvoir, VA 22060

38. E. Radoski, U. S. Army CECOM RD\&E Center, Power Generation Branch, AMSEL-RD-C2-AP-PG, 10108 Gridley Road, FT. Belvoir, VA 22060

39. P. Shivley, U. S. Army CECOM RD\&E Center, Power Generation Branch, AMSEL-RD-C2-AP-PG, 10108 Gridley Road, FT. Belvoir, VA 22060

40. C. A. Voltz, U. S. Army CECOM RD\&E Center, Power Generation Branch, AMSEL-RD-C2-AP-PG, 10108 Gridley Road, FT. Belvoir, VA 22060

41. COL. Wells, PM-MEP, Mobile Electric Power, 10205 Burbeck Road, Suite 105, FT. Belvoir, VA 22060

42. M. L. Yauss, U. S. Army CECOM RD\&E Center, Power Generation Branch, AMSEL-RD-C2-AP-PG, 10108 Gridley Road, FT. Belvoir, VA 22060 